\title{
Ancient lakes as hotspots of diversity: a morphological review of an endemic species flock of Tylomelania (Gastropoda: Cerithioidea: Pachychilidae) in the Malili lake system on Sulawesi, Indonesia
}

\author{
Thomas von Rintelen · Philippe Bouchet • \\ Matthias Glaubrecht
}

Received: 1 February 2007 / Revised: 30 April 2007/ Accepted: 11 May 2007/Published online: 3 August 2007 (C) Springer Science+Business Media B.V. 2007

\begin{abstract}
The viviparous freshwater gastropod Tylomelania (Caenogastropoda: Cerithioidea: Pachychilidae) endemic to the Indonesian island Sulawesi has radiated extensively in two ancient lake systems. We here present the first systematic species-level review of taxa in the five lakes of the Malili lake system, which contains the most diverse and best studied freshwater fauna on Sulawesi. Our results indicate a significantly higher diversity of Tylomelania in these lakes than previously perceived based on morphological evidence for delimiting the taxa. We describe nine new species, thus increasing the number of taxa known from the Malili lakes to 25. Tylomelania species are inhabiting all available substrates in the lakes, and the diversity of habitats is reflected in an unparalleled range of radula types in this closely related group. Several species show a high intraspecific variability in some characters, and their closer investigation will probably lead to the discovery of more cryptic species. As it is, this
\end{abstract}

Handling editor: K. Martens

T. von Rintelen $(\bowtie) \cdot$ M. Glaubrecht Museum of Natural History, Humboldt University Berlin, Invalidenstr. 43, 10115 Berlin, Germany e-mail: thomas.rintelen@rz.hu-berlin.de

P. Bouchet

Muséum National d'Histoire Naturelle, 55 rue

Buffon, 75231 Paris cedex 05, France species flock on Sulawesi is among the largest freshwater mollusc radiations known. Since the Malili lake system also contains other large endemic species flocks of e.g. crustaceans and fishes, it is a major hotspot of freshwater biodiversity in Asia to become a conservation priority.

Keywords Freshwater gastropods - Adaptive radiation · Taxonomy · Morphology · Ecology · Biodiversity

\section{Introduction}

The Indonesian island Sulawesi (Fig. 1a), the easternmost of the Greater Sunda islands, has a peculiar and highly endemic fauna very different from that of the other Sunda islands (for general reviews see e.g. van Oosterzee, 1997; Whitten et al., 2002). Especially rich in endemics are the two ancient lake systems in the central mountains of the island, the solitary Lake Poso and the five connected lakes of the Malili system (Fig. 1b). Their fauna was initially described by the Swiss naturalists Paul and Fritz Sarasin, who also were the first Europeans to visit the Malili lake system in 1896 (Sarasin \& Sarasin, 1905). Among other endemic freshwater molluscs, Sarasin \& Sarasin (1897, 1898) described from both lake systems a total of 16 species of peculiar gastropods ("Paläomelanien", today recognized as Pachychilidae, 


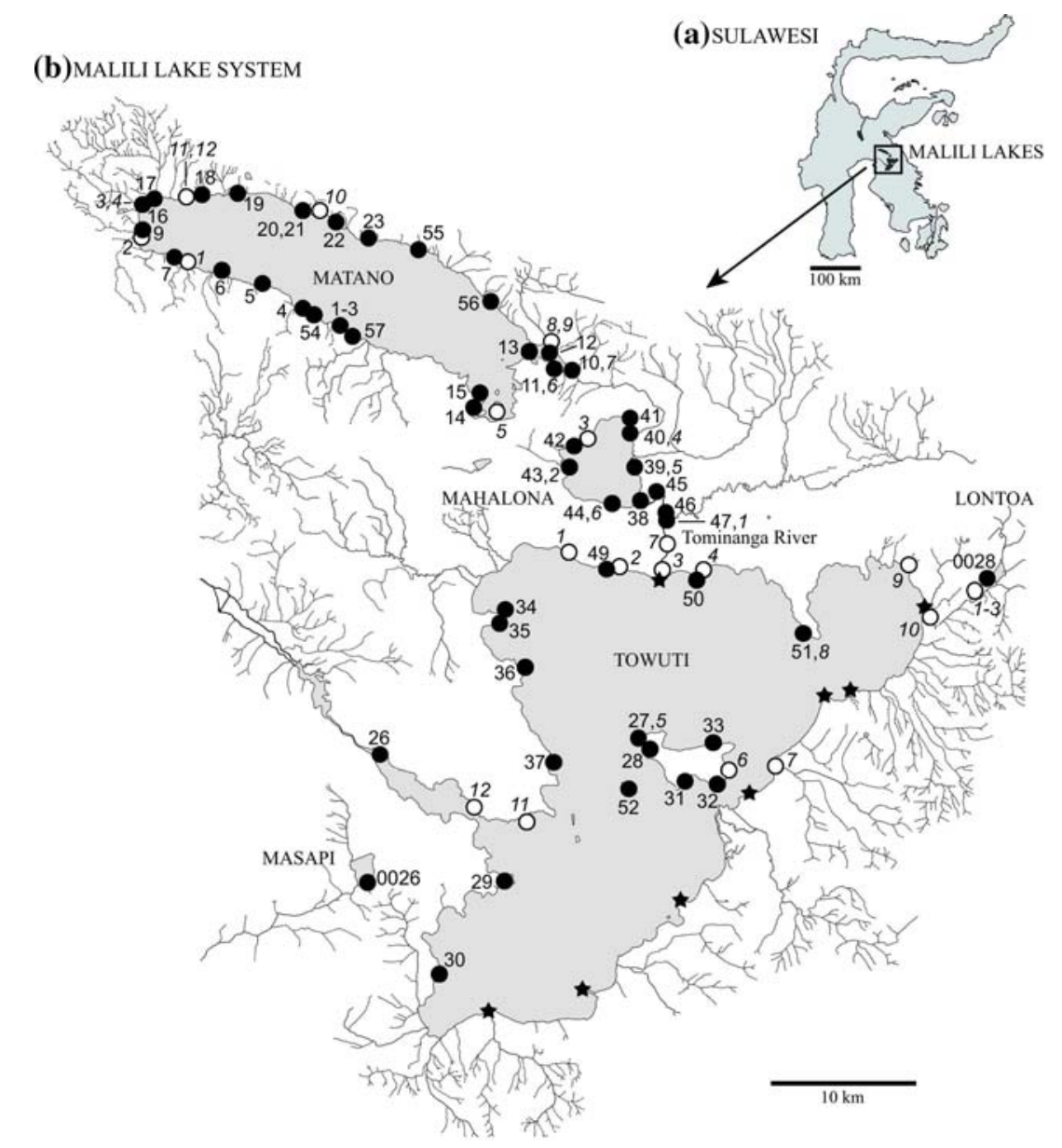

Fig. 1 Sulawesi and the Malili lake system with sample sites. a, Sulawesi; b, Malili lake system and sample sites. Filled circles: sites sampled by M.G. \& T.v.R. in 1999 and

see Glaubrecht (1996), Köhler \& Glaubrecht (2003) and Rintelen \& Glaubrecht (2005) for a detailed treatment of the taxonomy involved). Roughly fifteen years later, the Dutch geologist E.C. Abendanon visited the lakes in 1909/1910, and a subsequent description of his mollusc samples by Kruimel (1913) increased the number of endemic lake species by eight to a total of 24 . With 16 species the majority was found in the Malili lake system. Most new species were originally assigned to the invalid genus "Melania" (later considered to be Brotia H. Adams, 1866), with the exception of three species endemic to Lake Poso which were considered sufficiently distinct to justify the erection of the new genus Tylomelania Sarasin \& Sarasin, 1897 (for taxonomic details see Rintelen \& Glaubrecht, 2005).
2000, distinguished by the prefix 00 for localities sampled in 2000. Open circles and italic numbers: sites sampled by P.B. in 1991. Asterixes: no snails found

The Sarasins regarded the lake gastropods as 'ancient elements' (Sarasin \& Sarasin, 1898: 9398), and the species-flock was later occasionally cited as an example of intralacustrine (adaptive) radiation (Wesenberg-Lund, 1939; Brooks, 1950; Davis, 1982), but otherwise neglected and remained unstudied until 1991, when the second author (P.B.) collected the first new samples more then 80 years after Abendanon. Following preliminary reports (Bouchet, 1995; Marwoto, 1997), the present study was initially based on this material. However, fixation in formalin and numerous series of dry shells rendered it of limited value for molecular studies and prompted the collection of new ethanol-preserved samples by T.v.R. and M.G. (for details see Material and methods). All samples provide the basis for the 
present revision. In the course of this study it soon became evident that the lakes are more speciesrich than previously anticipated, leading to the description of two new species in the Malili lake system (Rintelen \& Glaubrecht, 2003). Further morphological and molecular studies have helped to clarify the disputed taxonomic position of the lacustrine species flock on Sulawesi and to address the question of the existence of a truly adaptive radiation (sensu Schluter, 2000). Molecular data have revealed at least four independent lake colonization events, three of those in the Malili lake system (Rintelen et al., 2004). That study could also show that each colonization event was followed by a subsequent adaptive radiation, with trophic (radula) diversification as a driving force in the evolution of lacustrine diversity, In addition they showed that coevolution (escalation) with crabs may play a role in the origin of typical lacustrine, i.e. stronger, shell morphologies. Both anatomical and molecular data have provided clear evidence for the existence of an endemic pachychilid lineage on Sulawesi with the single genus Tylomelania (see Rintelen \& Glaubrecht, 2005).

While these current studies have revealed a new model system for the study of adaptive radiation, a taxonomic treatment of the species involved, which may be considered critical for a more in-depth discussion of some of the relevant issues (Rintelen \& Glaubrecht, 2005), has still been lacking. The present species review is an attempt to close this taxonomic gap, at least for the Malili lake system. A revision of the Lake Poso species (Marwoto \& Ponder, unpubl. data) is currently being prepared by an IndonesianAustralian research cooperation focusing on that lake.

Our review of the Malili lake taxa pursues two major aims: The elimination of taxonomic confusion by critically reviewing the type specimens and original species descriptions, and an assessment of the existing morphological variation and disparity based on the comprehensive series or material collected between 1991 and 2000 (for details see Material and methods), including the description of nine new species. However, this work also exemplifies the difficulties inherent in any treatise on species recognition and delimitation (Glaubrecht, 2004). It has been attempted to apply the Biological Species Concept sensu Mayr (Mayr, 1942, 2000), which is the predominant species concept employed in evolutionary biology (for justification see e.g. Harrison, 1998; Coyne \& Orr, 2004). The feasability and pitfalls of such an approach are assessed in light of possible ecophenotypic and other morphological variation in the Discussion. The range of geographic intraspecific variation described herein is quite large for some taxa, suggesting the possible existence of more than one species in these cases. However, we have not in every such case considered the evidence sufficient to describe new species, for various reasons (e.g. when only very few specimens were available for study, or a lack of data on occurrence and substrates). Consequently, several species treated in this review are more likely to represent species complexes, which remain to be resolved elsewhere. Under taxonomic remarks we have explicitly pointed out these cases.

\section{The Malili lake system}

The five lakes in the Malili system have a unique setting. All lakes share a common drainage (Fig. 1 b). The three larger lakes are directly connected: Lake Matano (-590 m, $164.0 \mathrm{~km}^{2}$ ) flows into Lake Mahalona via the narrow and fast flowing Petea River, and Lake Mahalona $\left(-73 \mathrm{~m}, 24.4 \mathrm{~km}^{2}\right)$ in turn spills into Lake Towuti via the slightly more sluggish Tominanga River (also called Mahalona River). Lake Towuti $\left(-203 \mathrm{~m}, 561.1 \mathrm{~km}^{2}\right)$ is drained by the Larona River into the Gulf of Bone (Teluk Bone). Two smaller satellite lakes, Lake Lontoa (also known as Wawontoa, $-3 \mathrm{~m}, 1.6 \mathrm{~km}^{2}$ ) and Lake Masapi ( $\left.-4 \mathrm{~m}, 2.2 \mathrm{~km}^{2}\right)$, are much less directly connected to the system (see Fig. 1b).

Lake Matano is of tectonic origin, which accounts for the extraordinary depth. It is situated in a strike-slip fault, the Matano fault, which was formed in the final juxtaposition process of South-, Southeast- and East Sulawesi since the Pliocene (c. $4 \mathrm{Ma}$ ) to the present day (Wilson \& Moss, 1999). The age of the Malili system has been estimated at 1-2 Ma based on sedimentation data (G. Hope, pers. comm.). All other lakes in the system are merely blocked-off valleys, though 
their origin is likely linked to the same tectonic processes that gave rise to Lake Matano.

All Malili lakes are surrounded by moderately steep to steep hills rising 200-700 $\mathrm{m}$ above the level of the lakes. Bathymetrically, Lake Matano resembles a near-to-perfect example of a graben lake (Hutchinson, 1957), with very steep sides along the mid-northern and mid-southern sides reaching from an average $15^{\circ}$ to $30^{\circ}$ resulting in extensive almost vertical drop-off zones. The other two major lakes are less steep-sided, with average slopes of $2-3^{\circ}$, which in Lake Towuti may reach 6 $7^{\circ}$, though (Giesen et al., 1991). A characteristic feature of large stretches of the lake shore especially in Lake Matano are-sometimes narrowshelves of shallow water (1-6 m) with soft substrate, often bordered by rocks at the bank, and a slope or drop-off on the lake side. All major lakes in the Malili system are oligotrophic, with a very low nutrient and organic content and a high transparency of up to $22 \mathrm{~m}$ in Lake Towuti (Giesen et al., 1991; Giesen, 1994; Haffner et al., 2001). Water temperatures range from $27-31^{\circ} \mathrm{C}$ in all Malili lakes. Lake Matano and Lake Towuti have complete vertical mixing, they are isothermal and dissolved oxygen is maintained throughout the entire water column (Haffner et al., 2001). The complete mixing is a unique feature of the deep Malili lakes, while in Lake Poso a thermocline was discovered at a depth of $50 \mathrm{~m}$. According to Haffner et al. (2001), the foodweb is equally unique in consisting of only three trophic levels, viz. phytoplankton/detritus, zooplankton and forage fish. These authors propose that the lake community is largely dependent on the input of allochtonous organic carbon, as the autotrophic production is limited due to the extensive vertical mixing which continuously moves phytoplankton out of the euphotic zone.

\section{Material and methods}

\section{Material}

This study was initiated by systematic collections on Sulawesi in 1991 by the second author (P.B.) who made available both dry and wet series (fixed in formalin) which are now housed in Paris
(MNHN). The samples collected during two more recent expeditions to the Malili lake system in 1999 by M.G. \& T.v.R. and in 2000 by T.v.R. have been fixed and preserved in 70-95\% ethanol. This material is divided between Berlin (ZMB) and Bogor (MZB) as indicated in the species descriptions. The sample localities of all material studied are shown in Fig. $1 \mathrm{~b}$ and listed in the Material studied sections of the systematic part.

In addition to these new samples, the available material from previous collections at the lakes including all types was borrowed from the Natural History Museum in Basel (Sarasin \& Sarasin types) and the Zoological Museum Amsterdam (Kruimel types). Single paratypes in the Museum für Naturkunde (Berlin), the Natural History Museum (London) and the Museum of Comparative Zoology (Cambridge, Mass.) were also studied. All lots listed in the 'material examined' paragraph of the species descriptions are dry shells, unless otherwise stated. Type material is listed in the synonymy preceding every description.

Lectotypes are designated under strict consideration of the stipulations of the International Code of Zoological Nomenclature (ICZN, 4th edition, 1999), in particular to fulfil the requirements of article 74, which is to ensure the name's proper and consistent application by fixing the status of a specimen as the sole name-bearing type.

\section{Methods}

Shells were measured to $0.1 \mathrm{~mm}$ using an electronic calliper. Standard shell parameters were taken following Dillon (1984). Embryonic shells were measured to $0.1 \mathrm{~mm}$ using an ocular micrometer, parameters were taken as in adult specimens.

Anatomy was studied with a stereo microscope, and drawings were done with a drawing prisma. The sex ratio is given as the proportion of males among sexed individuals.

Radulae and embryonic shells were studied by scanning electron microscopy (SEM). The radula was cleaned enzymatically with proteinase $\mathrm{K}$ as described by Holznagel (1998), sonicated and then mounted on aluminium specimen stubs with 
adhesive pads. Embryonic shells were cleaned mechanically, sonicated, and mounted on adhesive carbon-coated pads. Both radulae and embryonic shells were coated with gold-palladium and studied on a LEO 1450VP Scanning electron microscope (software: $32 \mathrm{~V} 02.03$ ) at $10 \mathrm{kV}$. The dimensions of the initial whorl of embryonic shells were measured to $1 \mu \mathrm{m}$ by SEM using the attached software. In radulae, teeth were counted and total radula length measured to $0.1 \mathrm{~mm}$.

\section{Museum codens}

BMNH - The Natural History Museum, London MCZ - Museum of Comparative Zoology, Cambridge (Mass.)

MZB - Museum Zoologi, Bogor

MNHN - Muséum d'Histoire Naturelle, Paris

NMB - Naturhistorisches Museum, Basel

ZMA - Zoological Museum, Amsterdam

ZMB - Museum für Naturkunde, Humboldt University Berlin (formerly Zoologisches Museum Berlin)

\section{Abbreviations (material)}

These locality abbreviations are only used for samples collected by the second author (P. Bouchet). The numbers behind these codes in figure legends and material lists refer to the exact locality within the respective lake as marked by open circles and italic numbers in the map (Fig. 1b).

$$
\begin{aligned}
& \text { MHL - Lake Mahalona } \\
& \text { MT - Lake Matano } \\
& \text { PS - Lake Poso } \\
& \text { TW - Lake Towuti } \\
& \text { WWT - Lake Lontoa }
\end{aligned}
$$

\section{Results}

Species revision

Caenogastropoda

Cerithioidea

Pachychilidae
Tylomelania Sarasin \& Sarasin, 1897

Tylomelania Sarasin \& Sarasin, 1897: 317.

Type species: Tylomelania neritiformis Sarasin \& Sarasin, 1897 (subsequent designation by Thiele, 1929)

\section{Introductory remark}

The anatomy of Tylomelania has been described in detail by Rintelen \& Glaubrecht (2005). Their study revealed a high degree of similarity among species, where all taxa studied anatomically showed virtually no qualitative differences in major character complexes such as e.g. the pallial organs, in particular the gonoduct, but also the nerve system and alimentary tract. Both anatomical and molecular data have shown Tylomelania to be a monophyletic group endemic to Sulawesi (Rintelen \& Glaubrecht, 2005).

Species specific differences are found, however, in shell, embryonic shell, radula and, to a lesser degree, external anatomical characters, such as pigmentation. Differences in shell size are reflected in correlated characters like body coil number. Consequently, the species descriptions presented in this paper focus on these characters, and their value in this particular model case is evaluated (see Discussion). A molecular phylogeny by Rintelen et al. (2004), albeit based only on maternally inherited mitochondrial DNA, has revealed a considerable mismatch between morphologically discriminated species and molecular clades, indicating the presence of phenomena such as introgression or incomplete lineage sorting as frequently observed in such studies (Funk \& Omland, 2003). Consequently, all species descriptions presented are based entirely on morphological evidence.

While species are here presented in alphabetic order, they can be assigned to two groups based on the sculpture of their embryonic and adult shells (Fig. 2; Table 1).

In Tylomelania, two distinct types of embryonic shells are found (Rintelen \& Glaubrecht, 2005). The 'completely-ribbed' form has axial ribs on the whole embryonic shell, while the 'partially-ribbed' form has axial ribs on the apical whorls of the embryo only (Fig. 2). Every 

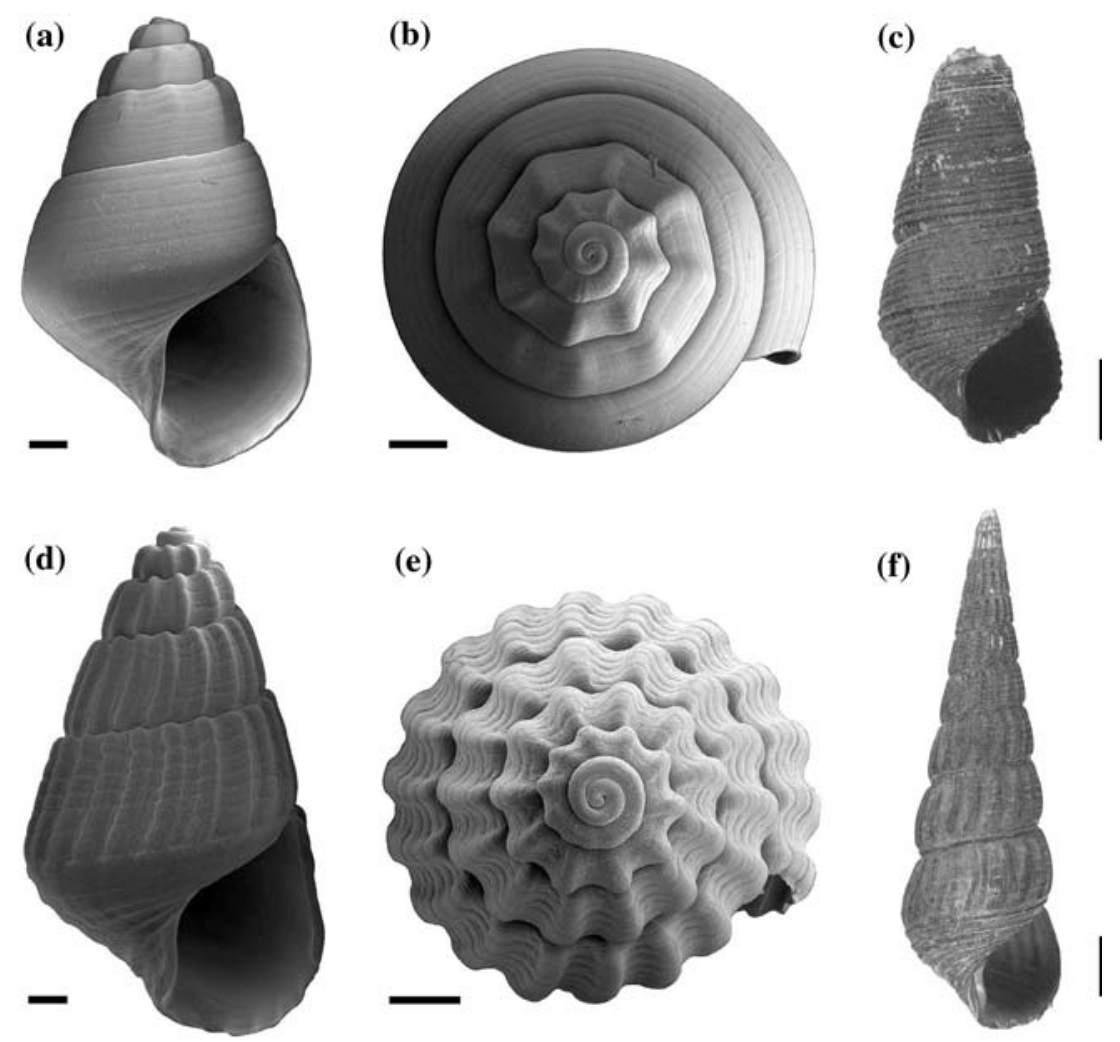

(e)

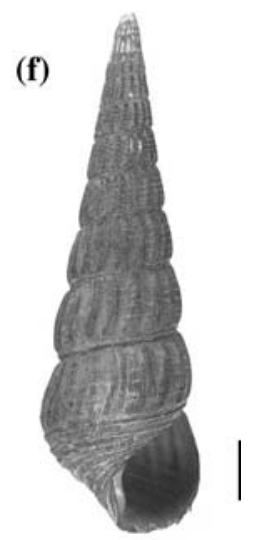

Fig. 2 Embryonic and adult shell groups of Tylomelania. a-c, 'partially-ribbed' form (T. sarasinorum, ZMB 190143, loc. 27). a, embryonic shell; b, embryonic shell, apical view; c, adult shell, d-f, 'completely-ribbed' form

species falls unequivocally into one of these two groups (Table 1), and these purely phenetic groupings are largely supported by molecular data, which show the 'completely-ribbed' form to represent the derived condition in Tylomelania (Fig. 3). Among the lacustrine species (but not among riverine taxa, see Rintelen \& Glaubrecht, 2005) this embryonicshell-based division is reflected in adult shell morphology as well, i.e. the 'completely-ribbed'group species have shells with axial ribs, which are lacking in the 'partially-ribbed'-group species (Figs. 2, 4, 5).

\section{Tylomelania abendanoni (Kruimel, 1913)}

Melania abendanoni Kruimel, 1913: 223, pl. 4 Fig. 9. (Lake Lontoa; lectotype, ZMA, present designation-Kruimel mentions 36 specimens in his description, all except the lectotype are missing
(T. patriarchalis, ZMB 190111, loc. 56). d, embryonic shell; e, embronic shell, apical view; f, adult shell. Scale bar $(\mathrm{a}, \mathrm{b}, \mathrm{d}, \mathrm{e})=0.5 \mathrm{~mm} ;(\mathrm{c}, \mathrm{f})=1 \mathrm{~cm}$

in the ZMA collection, though-Moolenbeek, pers. comm.; 3 paralectotypes, MCZ 65142).

\section{Description}

Shell (Fig. 6): Medium sized, brown to black, turriform, spire angle $11-26^{\circ}$. Top whorls in adult specimens always corroded to a varying degree, 4-8 remaining whorls, can reach up to $40.0 \mathrm{~mm}$ (Table 2). Sculpture consists of curved axial ribs and spiral ribs resulting in a reticulate pattern, sometimes only on last whorl(s). Aperture oval, pointed at top, drawn out at base.

External morphology: Headfoot black with yellowish-white dots, mantle edge very slightly serrated. Body coiled in 2.5-4 whorls.

Operculum (Fig. 7a): Almost round and multispiral, with 6-7 whorls.

Radula (Fig. 8a, b): 164-204 rows, 9.8-12.5 mm long, on average 17.0 teeth $/ \mathrm{mm}(n=3)$. Central 
Table 1 Malili lake system species of Tylomelania and their distribution, grouped by embryonic and adult shell form

\begin{tabular}{|c|c|c|c|}
\hline \multicolumn{2}{|c|}{$\begin{array}{l}\text { 'Partially-ribbed' embryonic shells } \\
\text { (smooth or spiral-ribbed adult shells) }\end{array}$} & \multicolumn{2}{|c|}{$\begin{array}{l}\text { 'Completely-ribbed' embryonic shells } \\
\text { (axial-ribbed adult shells) }\end{array}$} \\
\hline T. inconspicua & Lake Mahalona & T. abendanoni & Lake Lontoa \\
\hline T. insulaesacrae & Lake Mahalona, Towuti & T. amphiderita & Lake Towuti \\
\hline T. kruimeli & Lake Mahalona & T. bakara & Lake Mahalona \\
\hline T. lalemae & Lake Towuti & T. confusa & Lake Towuti \\
\hline T. masapensis & Lake Masapi & T. gemmifera & Lake Matano \\
\hline T. molesta & Lake Matano & T. kristinae & Lake Towuti \\
\hline T. palicolarum & Lake Matano, Mahalona, Towuti & T. mahalonensis & Lake Mahalona \\
\hline T. sarasinorum & Lake Towuti & T. marwotoae & Lake Mahalona \\
\hline T. tominangensis & Tominanga River, Lake Lontoa & T. matannensis & Lake Matano \\
\hline \multirow[t]{6}{*}{ T. wesseli } & Tominanga River & T. patriarchalis & Lake Matano \\
\hline & & T. towutensis & Lake Towuti, Tominanga River \\
\hline & & T. towutica & Lake Towuti, Tominanga River \\
\hline & & T. turriformis & Lake Matano \\
\hline & & T. wolterecki & Lake Mahalona \\
\hline & & T. zeamais & Lake Matano \\
\hline
\end{tabular}

See text for further explanation

tooth with larger, slightly blunt major denticle, accompanied by two smaller denticles at each side of it. Glabella narrow. Lateral teeth with enlarged major denticles and two smaller denticles on each side as well. Marginal teeth straight, tips curved and narrow, with three denticles each, the outermost ones are c. twice as long as the inner ones.

Reproductive biology: Sex ratio $0.36(n=11)$. Males do not differ significantly in size from females. About $85 \%$ of females $(n=6)$ carry shelled embryos in their brood pouch, which contains 1-4 embryos, their size can reach $8.5 \mathrm{~mm}$ (Table 3 ).

Embryonic shells (Fig. 8c-e): Turreted, with strong axial ribs emerging on the third whorl. Shallow, widespaced spiral ribs emerging on 2 nd to 3 rd whorl.

\section{Distribution}

South Sulawesi, Lake Lontoa (Fig. 9).

\section{Ecology and habitat}

On soft substrate and submerged wood.

\section{Taxonomic remarks}

Tylomelania abendanoni is a very distinctive species by virtue of its highly characteristic, comparatively fragile, reticulate shell. Radula and embryonic shell differences are equally sufficient to recognize the taxon among the other Tylomelania species. The only other species occuring sympatric and syntopic with $T$. abendanoni in Lake Lontoa, T. tominangensis Kruimel, 1913, has a smooth or almost smooth shell-if present the only sculpture consists of spiral striae (Fig. 52). In addition, its embryonic shells have axial ribs limited to the initial whorls. Further differences can be found in the radula (compare Fig. 8 and 53).

\section{Material examined}

Lake Lontoa: SW-shore, loc. WWT1 (MNHN, $n=15 ; n=11$, in alc.); W-shore, loc. WWT2 (MNHN, $n=19 ; n=60$, in alc.); W-shore, loc. WWT3 (MNHN, $n=24$, in alc.); W-shore, 02³9.90’ S, $121^{\circ} 43.46^{\prime} \mathrm{E}$, loc. 0028 (ZMB $190210 \mathrm{a}, n=4$, in alc.).

\section{Tylomelania amphiderita new species}

Type material: Holotype (Fig. 11a; $49.9 \mathrm{~mm} \times$ $20.4 \mathrm{~mm}$ ): Lake Towuti, $\mathrm{N}$ shore, 02 $39.36^{\prime} \mathrm{S}$, $121^{\circ} 29.80^{\prime} \mathrm{E}$, Loc. 49 (MNHN 9989, in alc.). Paratypes (Fig. 11b, c): Lake Towuti, N shore, shallow bay W of mouth of Tominanga River, TW1 


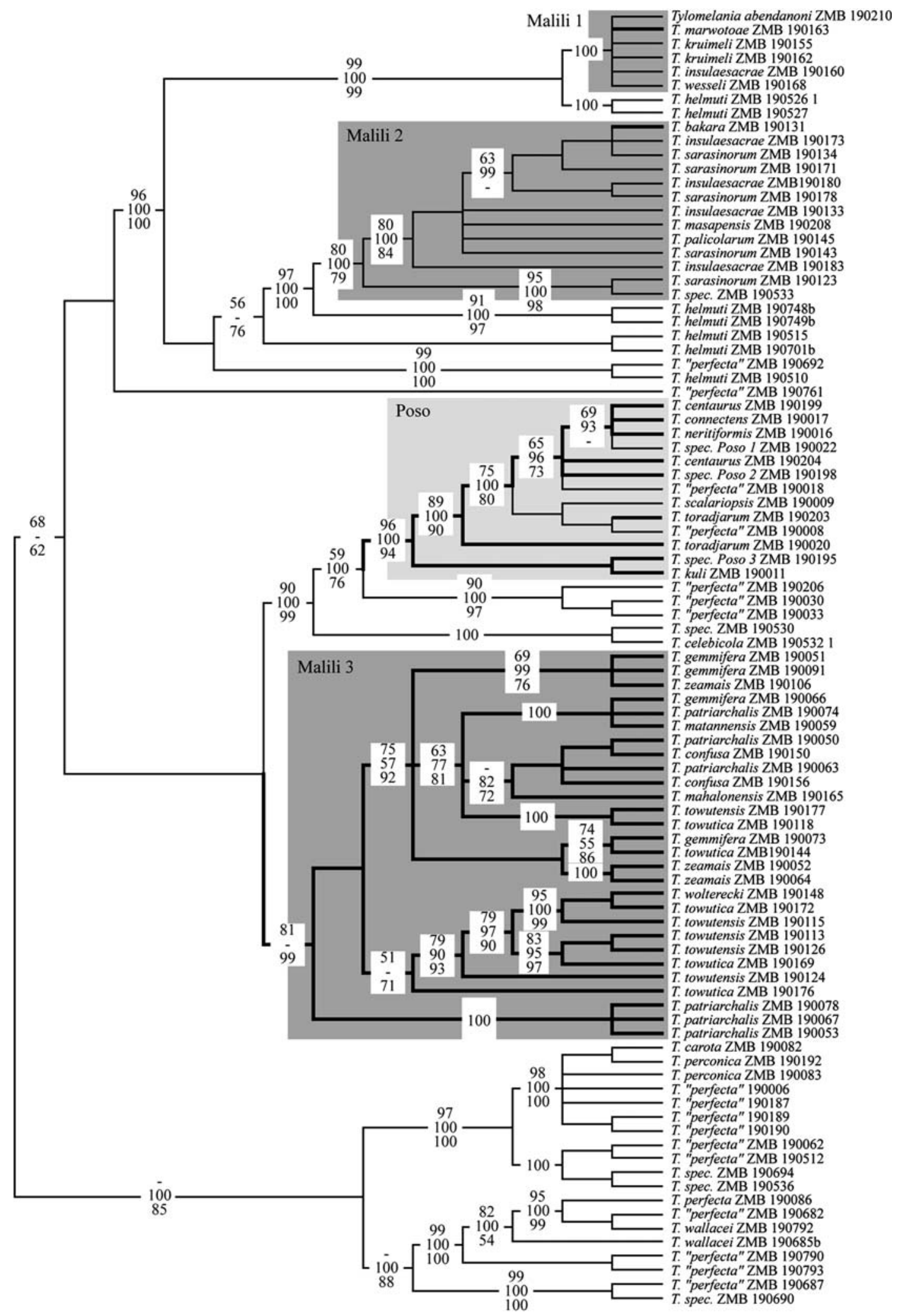


Fig. 3 Molecular phylogeny of Tylomelania and embryonic shell form. Maximum parsimony (MP) strict consensus tree based on 1498 bp of mitochondrial DNA. Tree topology from Fig. 2 in Rintelen et al. (2004), see there for technical details. Lacustrine species are marked by grey boxes (dark grey-Malili lakes, light grey-Lake Poso), bold branches indicate 'completely-ribbed' species. Numbers on branches are, from top, MP bootstrap values, Bayesian posterior probabilities, and Neighbor Joining (NJ) bootstrap values. The topologies obtained by Bayesian inference and NJ are identical to the MP topology

(MNHN 1990, $n=3$ ); N-shore, 02³9.36' S, $121^{\circ} 29.80^{\prime}$ E, Loc. 49 (MZB Gst. 12.101, $n=1$; ZMB 190170, $n=1$; all in alc.).

Etymology: As the taxonomic affinities and ecological preferences of this species are still unclear, we have named it amphiderita, a latinized form of the Greek adjective amphideritos, meaning disputed.

\section{Description}

Shell (Fig. 11): Medium sized, brown, elongately conic, spire angle $16-20^{\circ}$. Top whorls in adult specimens always corroded to a varying degree, 5-8 remaining whorls, can reach up to $58.1 \mathrm{~mm}$ (Table 2). With moderately curved strong axial ribs and weaker spiral ribs. Aperture oval, pointed at top and slightly siphonated at base. Columella and interior brownish.

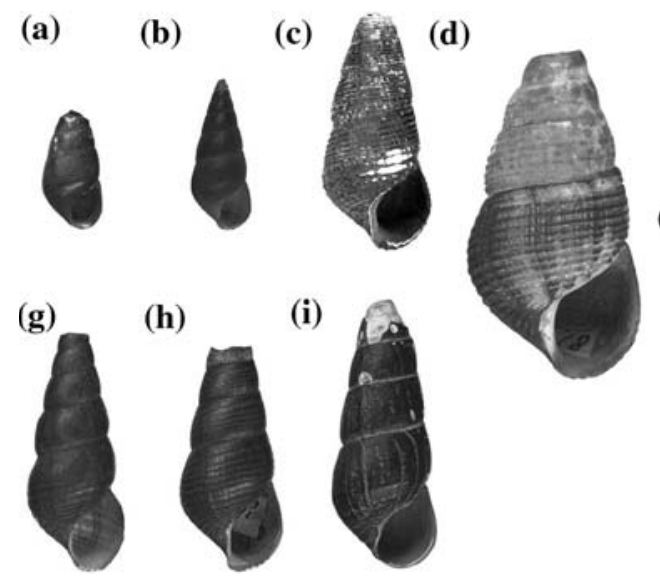

Fig. 4 Shells (types) of Malili lake Tylomelania species, 'partially-ribbed'-group (see text for explanation). a, T. insulaesacrae (LT, NMB 1342a); b, T. inconspicua (HT, MNHN); c, T. wesseli (HT, MZB Gst. 12.104); d, T. sarasinorum (LT, ZMA); e, T. kruimeli (HT, MZB Gst.
External morphology: Headfoot with few small white dots, tentacles with white stripes, mantle edge serrated to a varying degree. Body coiled in 3 whorls.

Operculum (Fig. 7b): ovate, last whorl strongly inflated, multispiral with 10 whorls.

Radula (Fig. 12a, b): 208 rows, $22.0 \mathrm{~mm}$ long, on average 9.5 teeth per $\mathrm{mm}$. Central tooth with very large and almost squarish major denticle. Glabella with straight base. Lateral teeth with very much enlarged squarish major denticles and one minor denticle on each side. Marginal teeth shovel-like, inner and outer marginals with three denticles each, the outermost ones considerably wider than the inner ones.

Reproductive biology: Brood pouch contains six embryos, their size can reach $8.7 \mathrm{~mm}$ (Table 3).

Embryonic shells (Fig. 12c-e): Ovate-conic, with strong axial ribs emerging on the 2 nd to 3rd whorl. Shallow, widespaced spiral ribs emerge on 3 rd to 4 th whorl. Diameter of first whorl about $270 \mu \mathrm{m}$ (Table 3).

\section{Distribution}

South Sulawesi, Lake Towuti (Fig. 9).

\section{Ecology and habitat}

Presumably hard substrate dweller.

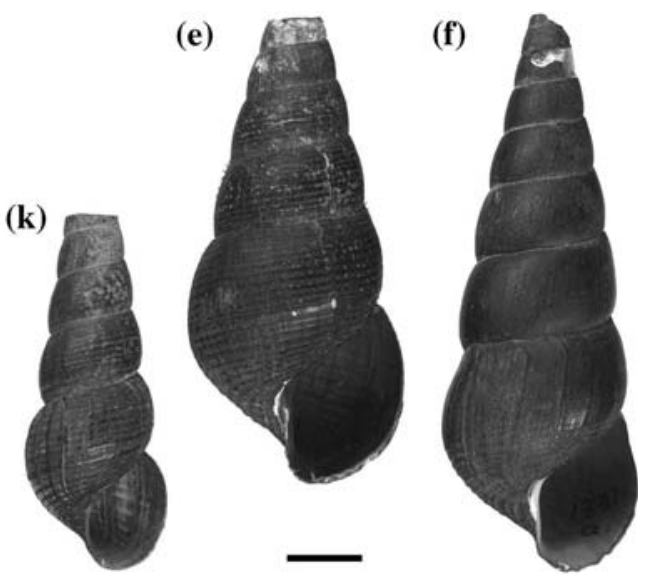

11.959); f, $T$. palicolarum (LT, NMB 1331a); g, $T$. tominangensis (LT, ZMA); h, T. lalemae (LT, ZMA); i, T. molesta (LT, NMB 1340a); k, T. masapensis (LT, ZMA). Scale bar $=1 \mathrm{~cm}$. HT-holotype, LT-lectotype 
(a)

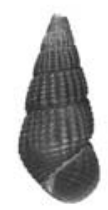

(g)

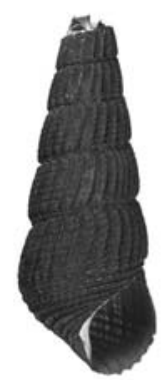

(m)

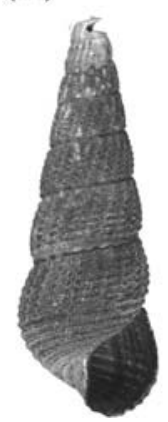

(b)

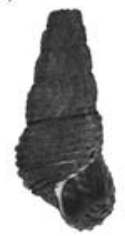

(h)

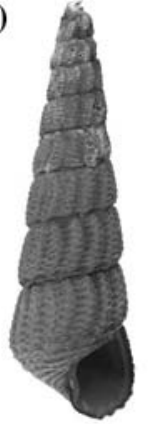

(n)

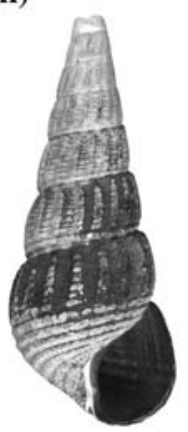

(c)

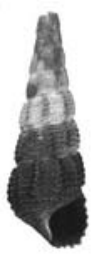

(d)

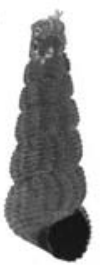

(e)

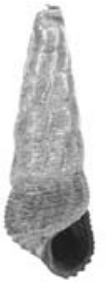

(i)

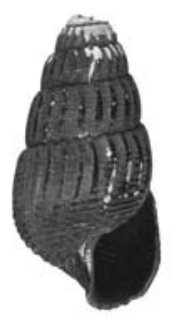

(o)

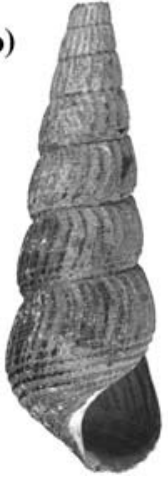

(k)

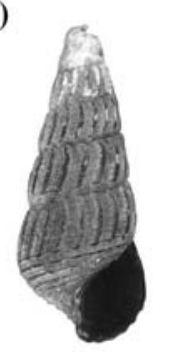

(f)

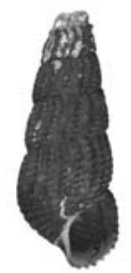

(l)

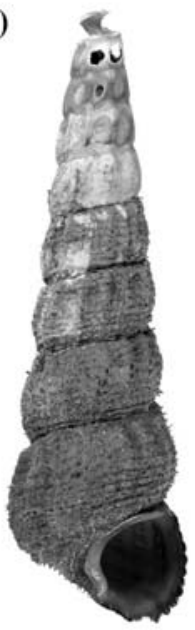

Fig. 5 Shells (types) of Malili lake Tylomelania species, 'completely-ribbed'-group (see text for explanation). a, $T$. zeamais (LT, NMB 1337a); b, T. abendanoni (LT, ZMA); c, T. gemmifera (LT, NMB 1344a); d, T. wolterecki (HT, MZB Gst. 12.281); e, T. marwotoae (HT, MZB Gst. 12.319); f, T. towutica (LT, ZMA); $\mathbf{g}, T$. towutensis (PLT, NMB 4790b); h, T. kristinae (PT, MZB Gst. 12.106); i, T.

\section{Taxonomic remarks}

The highly characteristic shell of Tylomelania amphiderita makes it hard to confuse the species with any other taxon in the Malili system. The radula is rather similar to that of $T$. bakara, though, while the general form of the shell suggests an affinity to T. towutensis. The sympatric occurrence with a 'typical' form of $T$. towutensis at both localities and the lack of intermediates is considered as indicative of bakara (HT, MZB Gst. 11.956); k, T. amphiderita (HT, MZB Gst. 12.100); I, T. turriformis (HT, MZB Gst. 12.103); m, T. confusa (HT, MZB Gst. 12.102); n, T. matannensis (HT, MZB Gst. 12.309); o, T. mahalonensis (PLT, ZMA); p, T. patriarchalis (LT, NMB 1330a). Scale bar $=1 \mathrm{~cm}$. HT—holotype, LT—lectotype, PLT—paralectotype, PT—paratype

specific status for $T$. amphiderita, however. Unfortunately there is no field record on the substrate preference of $T$. amphiderita, the similarity of the radula to that of $T$. bakara and $T$. sarasinorum suggests, through a conclusion by analogy, a preference for hard substrate as in those species.

\section{Material examined}

see type material 
(a)

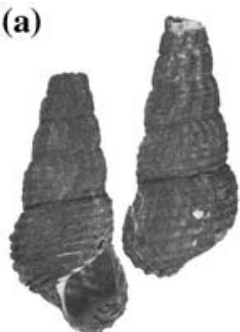

(d)

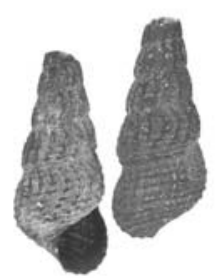

(b)
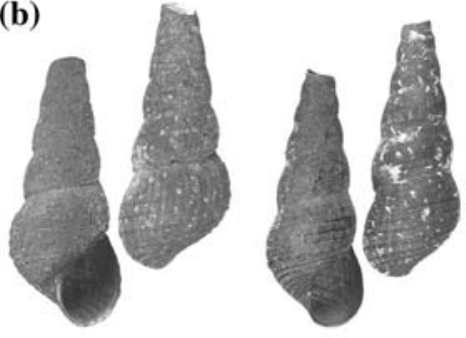

(c)
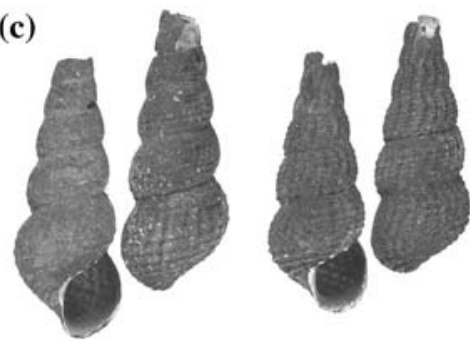

(e)
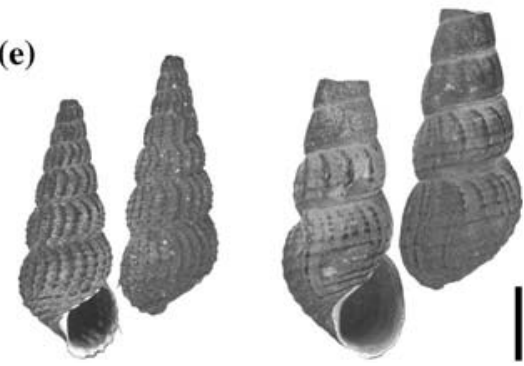

Fig. 6 T. abendanoni, shells. a, lectotype, ZMA; b, ZMB 190210 (loc. 0028); c, MNHN (loc. WWT 1); d, MNHN (loc. WWT 2); $\mathbf{e}$, MNHN (loc. WWT 3). Scale bar $=1 \mathrm{~cm}$

Table 2 Shell parameters of Malili lake system Tylomelania

\begin{tabular}{|c|c|c|c|c|c|c|c|c|}
\hline Species & $\mathrm{h}(\mathrm{mm})$ & $\mathrm{w}(\mathrm{mm})$ & aph (mm) & apw (mm) & bwl (mm) & whorls (N) & angle $\left({ }^{\circ}\right)$ & $\begin{array}{l}\text { axial ribs } \\
(\mathrm{N}, \text { on bwl) }\end{array}$ \\
\hline \multirow[t]{3}{*}{ T. abendanoni } & $15.8-40.0$ & $6.7-16.9$ & $5.5-13.7$ & $3.3-.84$ & $8.6-22.3$ & $4-8$ & $11-26$ & $14-33$ \\
\hline & $28.97 \pm 4.822$ & $11.84 \pm 1.810$ & $9.35 \pm 1.548$ & $5.75 \pm 0.918$ & $15.15 \pm 2.541$ & $5.4 \pm 0.99$ & $18.0 \pm 3.14$ & $21.8 \pm 3.92$ \\
\hline & 72 & 72 & 72 & 72 & 72 & 72 & 68 & 59 \\
\hline \multirow[t]{3}{*}{ T. amphiderita } & $19.8-63.5$ & $11.1-29.9$ & $9.8-23.3$ & $4.8-12.9$ & $13.1-34.4$ & $4-7$ & $18-48$ & - \\
\hline & $40.78 \pm 6.518$ & $21.57 \pm 3.048$ & $17.45 \pm 1.304$ & $9.54 \pm 2.062$ & $26.02 \pm 3.507$ & $5.0 \pm 0.90$ & $26.6 \pm 5.30$ & \\
\hline & 142 & 141 & 142 & 141 & 142 & 142 & 141 & \\
\hline \multirow[t]{3}{*}{ T. bakara } & $42.5-64.6$ & $16.5-26.5$ & $11.4-19.5$ & $6.7-12.2$ & $20.5-31.5$ & $4-7$ & $14-23$ & $16-32$ \\
\hline & $54.53 \pm 5.504$ & $21.67 \pm 2.101$ & $16.28 \pm 1.757$ & $9.35 \pm 1.131$ & $26.60 \pm 2.458$ & $6.3 \pm 0.80$ & $19.4 \pm 2.22$ & $26.1 \pm 4.28$ \\
\hline & 35 & 35 & 35 & 35 & 35 & 35 & 24 & 34 \\
\hline \multirow[t]{3}{*}{ T. confusa } & $48.1-58.1$ & $19.1-25.0$ & $15.1-17.0$ & $8.5-10.5$ & $23.4-28.2$ & $5-8$ & $16-20$ & $18-28$ \\
\hline & $52.237 \pm 3.358$ & $21.33 \pm 2.354$ & $16.01 \pm 0.769$ & $9.19 \pm 0.809$ & $25.53 \pm 1.641$ & $6.4 \pm 0.98$ & $18.5 \pm 1.64$ & $23.2 \pm 3.25$ \\
\hline & 7 & 6 & 7 & 7 & 7 & 7 & 6 & 6 \\
\hline \multirow[t]{3}{*}{ T. gemmifera } & $35.5-80.1$ & $11.2-23.0$ & $6.3-19.8$ & $3.9-10.6$ & $13.6-30.3$ & $5-13$ & $13-20$ & $9-23$ \\
\hline & $54.32 \pm 10.547$ & $16.43 \pm 3.090$ & $11.38 \pm 2.390$ & $7.21 \pm 1.501$ & $20.19 \pm 3.639$ & $9.7 \pm 1.68$ & $17.6 \pm 1.66$ & $14.3 \pm 2.55$ \\
\hline & 80 & 81 & 81 & 81 & 81 & 81 & 24 & 77 \\
\hline \multirow[t]{3}{*}{ T. inconspicua } & $12.1-22.0$ & $5.6-8.9$ & $4.5-7.0$ & $2.6-4.6$ & $7.0-11.9$ & $4-7$ & $14-28$ & n.a. \\
\hline & $15.40 \pm 1.988$ & $6.91 \pm 0.678$ & $5.58 \pm 0.521$ & $3.26 \pm 0.360$ & $8.87 \pm 0.960$ & $6.0 \pm 0.94$ & $20.6 \pm 3.66$ & \\
\hline & 33 & 33 & 33 & 33 & 33 & 33 & 32 & \\
\hline \multirow[t]{3}{*}{ T. insulaesacrae } & $6.1-20.6$ & $4.0-11.7$ & $3.2-8.5$ & $1.8-4.7$ & $5.8-17.1$ & $2-6$ & $19-43$ & n.a. \\
\hline & $14.68 \pm 2.675$ & $8.57 \pm 1.392$ & $5.88 \pm 0.663$ & $3.56 \pm 1.153$ & $12.57 \pm 2.832$ & $3.7 \pm$ & $29.4 \pm 6.34$ & \\
\hline & 110 & 110 & 110 & 110 & 110 & 110 & 54 & \\
\hline \multirow[t]{3}{*}{ T. kristinae } & $33.6-50.6$ & $11.7-17.4$ & $10.4-14.0$ & $6.4-8.4$ & $16.9-24.1$ & $8-9$ & $17-18$ & $12-14$ \\
\hline & $45.32 \pm 7.145$ & $14.503 \pm 2.851$ & $12.20 \pm 2.546$ & 7. $17 \pm 1.079$ & $19.93 \pm 3.027$ & $8.8 \pm 0.41$ & $17.5 \pm 0.71$ & $13.2 \pm 0.84$ \\
\hline & 5 & 3 & 2 & 3 & 4 & 6 & 2 & 5 \\
\hline \multirow[t]{3}{*}{ T. kruimeli } & $13.9-69.3$ & $7.5-29.3$ & $5.8-24.8$ & $3.3-16.6$ & $9.1-37.0$ & $4-9$ & $18-39$ & n.a. \\
\hline & $44.57 \pm 10.722$ & $20.81 \pm 4.528$ & $17.66 \pm 2.113$ & $9.90 \pm 3.553$ & $26.03 \pm 5.578$ & $6.1 \pm 1.05$ & $28.4 \pm 4.07$ & \\
\hline & 213 & 211 & 213 & 211 & 213 & 213 & 180 & \\
\hline \multirow[t]{3}{*}{ T. lalemae } & $18.3-33.0$ & 8.9-13.6 & $7.6-12.2$ & $4.4-6.5$ & $11.4-19.2$ & $3-5$ & $19-26$ & n.a. \\
\hline & $21.85 \pm 3.338$ & $10.36 \pm 1.083$ & $9.28 \pm 0.489$ & $4.99 \pm 1.109$ & $14.08 \pm 1.867$ & $3.8 \pm 0.59$ & $22.6 \pm 1.95$ & \\
\hline & 26 & 21 & 26 & 21 & 26 & 26 & 23 & \\
\hline
\end{tabular}


Table 2 continued

\begin{tabular}{|c|c|c|c|c|c|c|c|c|}
\hline Species & $\mathrm{h}(\mathrm{mm})$ & $\mathrm{w}(\mathrm{mm})$ & aph $(\mathrm{mm})$ & apw (mm) & bwl (mm) & whorls $(\mathrm{N})$ & angle $\left({ }^{\circ}\right)$ & $\begin{array}{l}\text { axial ribs } \\
(\mathrm{N}, \text { on bwl) }\end{array}$ \\
\hline \multirow[t]{3}{*}{ T. mahalonensis } & $32.4-80.7$ & $12.9-29.2$ & $9.7-22.1$ & $5.8-13.2$ & $16.6-36.2$ & $4-10$ & $14-26$ & $19-42$ \\
\hline & $51.63 \pm 9.624$ & $19.39 \pm 3.295$ & $15.16 \pm 2.676$ & 1.634 & $24.66 \pm 4.053$ & $6.8 \pm 1.17$ & $21.3 \pm 2.67$ & $27.5 \pm 5.31$ \\
\hline & 90 & 80 & 89 & 84 & 90 & 91 & 56 & 83 \\
\hline \multirow[t]{3}{*}{ T. marwotoae } & $37.9-56.3$ & $11.7-19.3$ & $7.7-13.4$ & $4.7-7.8$ & $15.3-23.0$ & $6-11$ & $10-17$ & $13-21$ \\
\hline & $48.08 \pm 4.848$ & $15.01 \pm 1.995$ & $10.77 \pm 1.531$ & $6.26 \pm 0.873$ & $19.03 \pm 2.059$ & $8.2 \pm 1.14$ & $12.9 \pm 2.00$ & $17.0 \pm 2.20$ \\
\hline & 31 & 31 & 31 & 31 & 31 & 31 & 20 & 30 \\
\hline \multirow[t]{3}{*}{ T. masapensis } & $15.0-48.0$ & $7.6-19.5$ & $6.2-15.8$ & $3.9-9.8$ & $10.3-26.1$ & $3-6$ & $12-25$ & n.a. \\
\hline & $26.59 \pm 5.183$ & $11.37 \pm 1.940$ & $9.66 \pm 1.011$ & $5.76 \pm 1.622$ & $15.72 \pm 2.689$ & $4.3 \pm 0.61$ & $17.3 \pm 2.11$ & \\
\hline & 177 & 176 & 177 & 176 & 177 & 177 & 176 & \\
\hline \multirow[t]{3}{*}{ T. matannensis } & $22.8-82.0$ & $9.6-32.4$ & $7.7-22.3$ & $4.4-12.9$ & $11.8-39.1$ & $5-10$ & $20-34$ & $15-29$ \\
\hline & $53.40 \pm 11.095$ & $21.80 \pm 3.780$ & $16.85 \pm 2.474$ & $10.00 \pm 1.486$ & $26.46 \pm 4.346$ & $7.2 \pm 0.93$ & $28.7 \pm 2.67$ & $20.8 \pm 3.01$ \\
\hline & 81 & 80 & 81 & 81 & 81 & 81 & 42 & 76 \\
\hline \multirow[t]{3}{*}{ T. molesta } & $32.5-34.8$ & $13.2-13.8$ & $10.8-10.9$ & $6.7-6.7$ & $17.9-19.0$ & 5 & $12-15$ & n.a. \\
\hline & $33.65 \pm 1.626$ & $13.50 \pm 0.424$ & $10.85 \pm 0.071$ & $6.55 \pm 0.212$ & $18.45 \pm 0.777$ & 5 & $13.5 \pm 2.12$ & \\
\hline & 2 & 2 & 2 & 2 & 2 & 2 & 2 & \\
\hline \multirow{3}{*}{ T. palicolarum } & $20.4-81.0$ & 7.1 & 6.5 & 13.0 & $11.8-54.0$ & $5-11$ & $12-26$ & n.a. \\
\hline & $42.83 \pm 12.175$ & $15.82 \pm 4.084$ & $13.37 \pm 3.385$ & $7.58 \pm 1.964$ & $21.46 \pm 5.183$ & $7.4 \pm 1.23$ & $19.2 \pm 3.13$ & \\
\hline & 107 & 102 & 104 & 102 & 105 & 106 & 72 & \\
\hline \multirow[t]{3}{*}{ T. patriarchalis } & $15.3-117.0$ & $7.0-39.4$ & $5.6-30.9$ & $2.9-18.1$ & $8.8-48.4$ & $4-13$ & $12-26$ & $10-42$ \\
\hline & 61.03 & 5.757 & $=4.308$ & \pm 2.556 & \pm 6.667 & $7.3 \pm 1.62$ & $18.4 \pm 2.80$ & $23.9 \pm 5.74$ \\
\hline & 200 & 189 & 199 & 192 & 200 & 160 & 120 & 175 \\
\hline \multirow[t]{3}{*}{ T. sarasinorum } & $9.0-58.9$ & $5.5-27.1$ & $4.6-20.4$ & $2.6-12.3$ & $6.4-33.5$ & $2-7$ & $8-41$ & n.a. \\
\hline & $34.05 \pm 9.422$ & $16.78 \pm 3.981$ & $13.64 \pm 3.129$ & $7.74 \pm 1.777$ & $20.60 \pm 5.230$ & $4.6 \pm 0.78$ & $24.9 \pm 6.04$ & \\
\hline & 561 & 559 & 559 & 560 & 560 & 561 & 500 & \\
\hline \multirow[t]{3}{*}{ T. tominangensis } & $11.4-39.1$ & $5.3-15.0$ & $4.2-12.7$ & $2.7-11.1$ & $6.8-20.0$ & $4-8$ & $15-28$ & n.a. \\
\hline & $27.43 \pm 5.074$ & $10.92 \pm 1.759$ & $9.06 \pm 1.745$ & $5.82 \pm 1.289$ & $14.79 \pm 2.459$ & $5.8 \pm$ & $20.7 \pm 2.90$ & \\
\hline & 158 & 157 & 156 & 158 & 158 & 158 & 156 & \\
\hline \multirow{3}{*}{ T. towutensis } & $24.7-86.2$ & $10.2-31.2$ & $8.4-23.4$ & $4.8-14.1$ & $12.6-37.7$ & $4-10$ & $10-24$ & $15-32$ \\
\hline & $59.40 \pm 9.931$ & $20.99 \pm 3.850$ & $16.28 \pm 1.463$ & $9.35 \pm 2.606$ & $26.78 \pm 4.323$ & $6.8 \pm 1.19$ & $15.9 \pm 3.81$ & $23.3 \pm 4.40$ \\
\hline & 162 & 156 & 157 & 161 & 162 & 163 & 100 & 81 \\
\hline \multirow[t]{3}{*}{ T. towutica } & $15.4-64.9$ & $7.1-20.4$ & $5.5-15.4$ & $3.1-9.0$ & $8.9-25.8$ & $4-9$ & $13-25$ & $13-31$ \\
\hline & $44.44 \pm 7.284$ & $16.86 \pm 2.104$ & $12.14 \pm 0.950$ & $6.97 \pm 1$ & $20.93 \pm 2$ & $6.0 \pm$ & $17.1 \pm$ & $20.1 \pm$ \\
\hline & 116 & 113 & 106 & 113 & 116 & 116 & 15 & 98 \\
\hline \multirow[t]{3}{*}{ T. turriformis } & $52.5-94.6$ & $17.8-28.2$ & $10.7-18.2$ & $7.4-12.5$ & $20.1-33.1$ & $7-10$ & $9-20$ & $14-22$ \\
\hline & $72.93 \pm 11.760$ & $21.79 \pm 3.207$ & $14.53 \pm 2.128$ & $9.28 \pm 1.366$ & $26.64 \pm 3.501$ & $8.6 \pm 0.80$ & $14.7 \pm 2.97$ & $18.5 \pm 2.60$ \\
\hline & 21 & 21 & 21 & 21 & 21 & 21 & 11 & 21 \\
\hline \multirow[t]{3}{*}{ T. wesseli } & $9.4-30.2$ & $5.3-14.6$ & $4.0-12.2$ & $2.5-6.9$ & $6.1-18.7$ & $3-7$ & $13-42$ & n.a. \\
\hline & $21.08 \pm 3.644$ & $10.47 \pm 1.484$ & $8.24 \pm 1.187$ & $4.70 \pm 0.649$ & $13.40 \pm 2.174$ & $4.7 \pm 0.60$ & $23.2 \pm 4.88$ & \\
\hline & 243 & 236 & 243 & 234 & 243 & 243 & 236 & \\
\hline \multirow[t]{3}{*}{ T. wolterecki } & $16.3-49.2$ & $7.4-18.3$ & $3.8-17.5$ & $3.3-7.6$ & $8.9-21.7$ & $3-8$ & $11-17$ & $12-36$ \\
\hline & $33.31 \pm 6.014$ & $13.15 \pm 1.975$ & $9.09 \pm 1.745$ & $5.92 \pm 0.823$ & $15.80 \pm 2.455$ & $5.1 \pm 1.22$ & $12.6 \pm 1.15$ & $22.3 \pm 5.21$ \\
\hline & 103 & 102 & 102 & 100 & & 103 & 88 & 91 \\
\hline \multirow[t]{3}{*}{ T. zeamais } & $17.9-45.3$ & $8.7-18.9$ & $6.6-15.5$ & $3.9-8.8$ & $10.0-22.9$ & $4-9$ & $15-34$ & $11-26$ \\
\hline & $31.56 \pm 6.593$ & $12.86 \pm 2.182$ & $10.12 \pm 1.768$ & $5.97 \pm 1.007$ & $16.53 \pm 2.842$ & $6.3 \pm 1.10$ & $22.0 \pm 3.66$ & $17.5 \pm 2.88$ \\
\hline & 219 & 219 & 219 & 218 & 219 & 219 & 148 & 212 \\
\hline
\end{tabular}

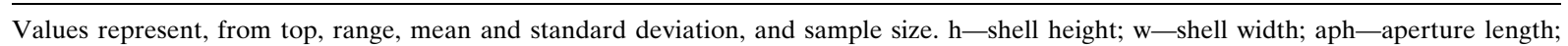
apw—aperture width; bwl—body whorl; angle—spire angle; n.a.—not applicable

Tylomelania bakara Rintelen \& Glaubrecht, 2003

Tylomelania bakara Rintelen \& Glaubrecht, 2003: 5, Figs. 2-5 (Lake Towuti, W-shore, Cape

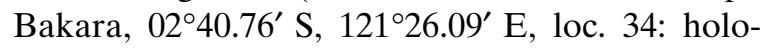
type, MZB Gst. 11.956, in alc.; 25 paratypes,
MZB Gst. 11.957; 77 paratypes, ZMB 190131; same locality, 5-40 m deep: 29 paratypes, MZB Gst. 11.958; 49 paratypes, ZMB 190184). Please note: The actual sharing of type specimens between MZB and ZMB as shown here differs from the numbers given in Rintelen \& Glaubrecht, 2003. 
(a)

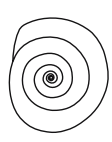

(g)

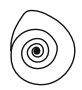

(n)
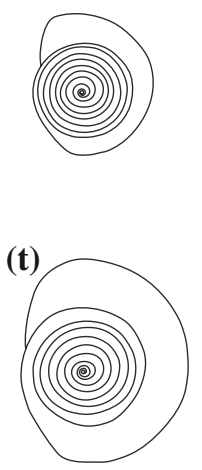

(b)

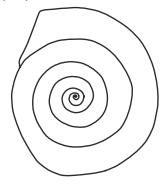

(h)

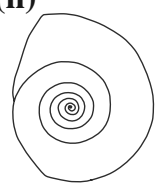

(o)

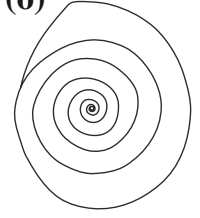

(u)

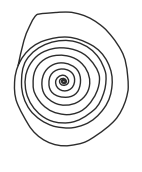

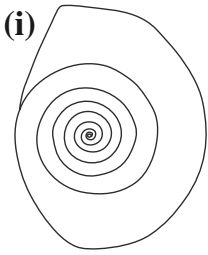

(p)

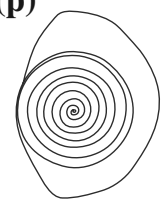

(c)

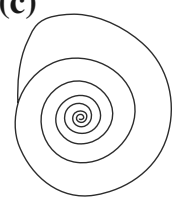

(i)

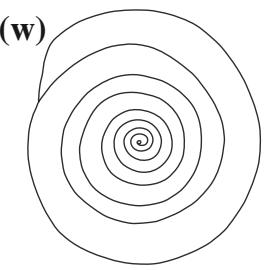

(d)

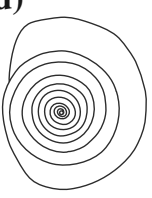

(k)
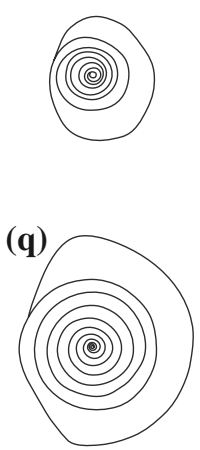

(x)

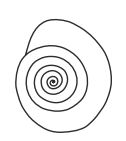

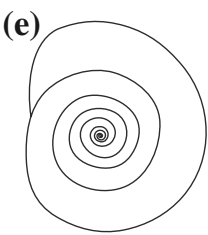

(f)

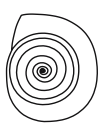

(m)

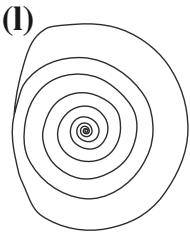

(r)

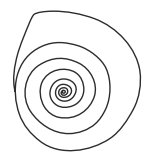

(y)
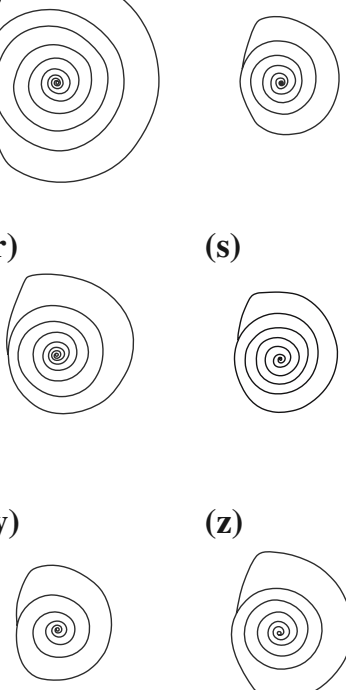

(s)

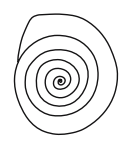

(z)

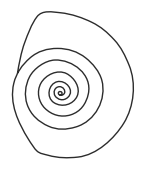

Fig. 7 Opercula of Malili lake Tylomelania. a, T. abendanoni, MNHN, (loc. WWT3); b, T. amphiderita, ZMB 190719, paratype (loc. 49); c, T. bakara, ZMB 190131, paratype (loc. 34); d, T. confusa, ZMB 190159, paratype (loc. 42); e, T. gemmifera, ZMB 190051 (loc. 1); f, T. inconspicua, MNHN, paratype (loc. MHL4); g, T. insulaesacrae, ZMB 190122 (loc. 29); h, T. kristinae, ZMB 190114 (loc. 27); i, T. kruimeli, ZMB 190155 (loc. 41); k, T. lalemae, ZMA, paralectotype (Lake Towuti); I, T. mahalonensis, ZMB 190146 (loc. 38); m, T. marwotoae, ZMB 190163 (loc. 44); n, T. masapensis, ZMB 190208 (loc.

\section{Description}

Shell (Fig. 13): Medium sized to large, brown, mostly ovate, occasionally conic to almost turriform, spire angle $18-48^{\circ}$. Top whorls in adult specimens always corroded, 4-7 remaining whorls, can reach up to $63.5 \mathrm{~mm}$ (Table 2). Sculpture consists of strong curved axial ribs and fine spiral ribs. Aperture oval, pointed posteriorly and drawn out anteriorly.

External morphology: Headfoot with fine to large white blotches, mantle edge serrated. Body coiled in 2.5-3.5 whorls.
0026); o, T. matannensis, ZMB 190103, paratype (loc. 22); p, T. palicolarum, MNHN (loc. TW2); q, T. patriarchalis, ZMB 190050 (loc. 1); r, T. sarasinorum, ZMA, paratype (Lake Towuti, Loeha Island); s, T. tominangensis, ZMB 190210 (loc. 0028); t, T. towutensis, ZMB 190113 (loc. 26); u, T. towutica, ZMB 190116 (loc. 27); w, T. turriformis, ZMB 190091, paratype (loc. 14); x, T. wesseli, ZMB 190168, paratype (loc. 47); y, T. wolterecki, ZMB 190147, paratype (loc. 38); z, T. zeamais, ZMB 190052 (loc. 1). Scale bar $=1 \mathrm{~cm}$

Operculum (Fig. 7c): almost round and multispiral with 6-7 whorls, last whorl slightly expanded.

Radula (Fig. 14a, b): 189-239 rows, 18.5$26.4 \mathrm{~mm}$ long, on average $9.6 \mathrm{teeth} / \mathrm{mm}(n=3)$. Central tooth with very large and almost perfect squarish major denticle, accompanied by two small, basal denticles at each side of it. Lateral teeth with very large and squarish major denticle and two small denticles at each side as well. Marginal teeth with three denticles each. Outer denticles large and shovel-like, in the inner marginals squarish. Two inner denticles small and pointed. 

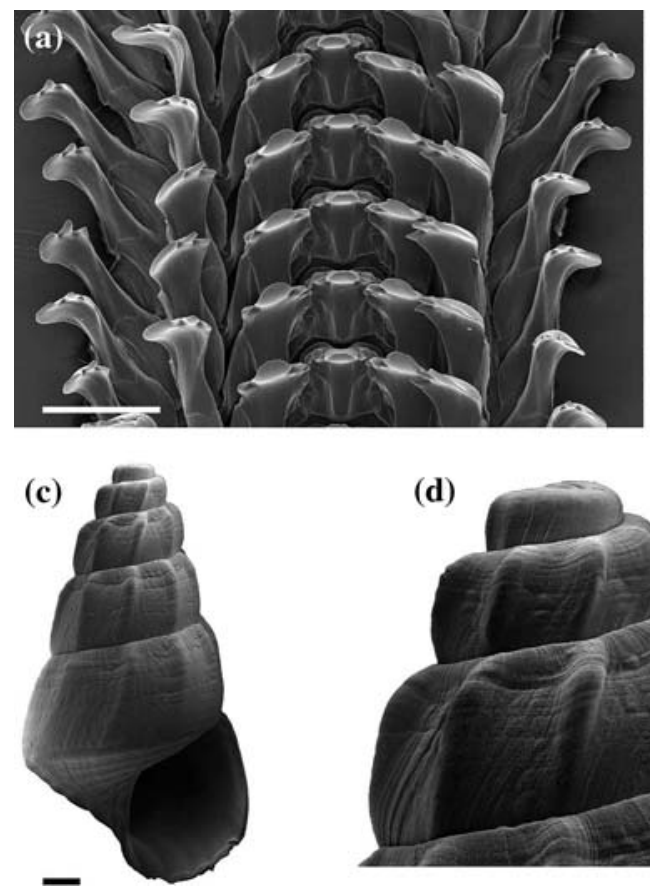

Fig. 8 T. abendanoni, radula and embryonic shells. a, b, radula. MNHN (loc. WWT 2). a, segment, frontal; b, segment, apical $\left(45^{\circ}\right)$. Scale bar $=0.1 \mathrm{~mm}$. c-e, embryonic
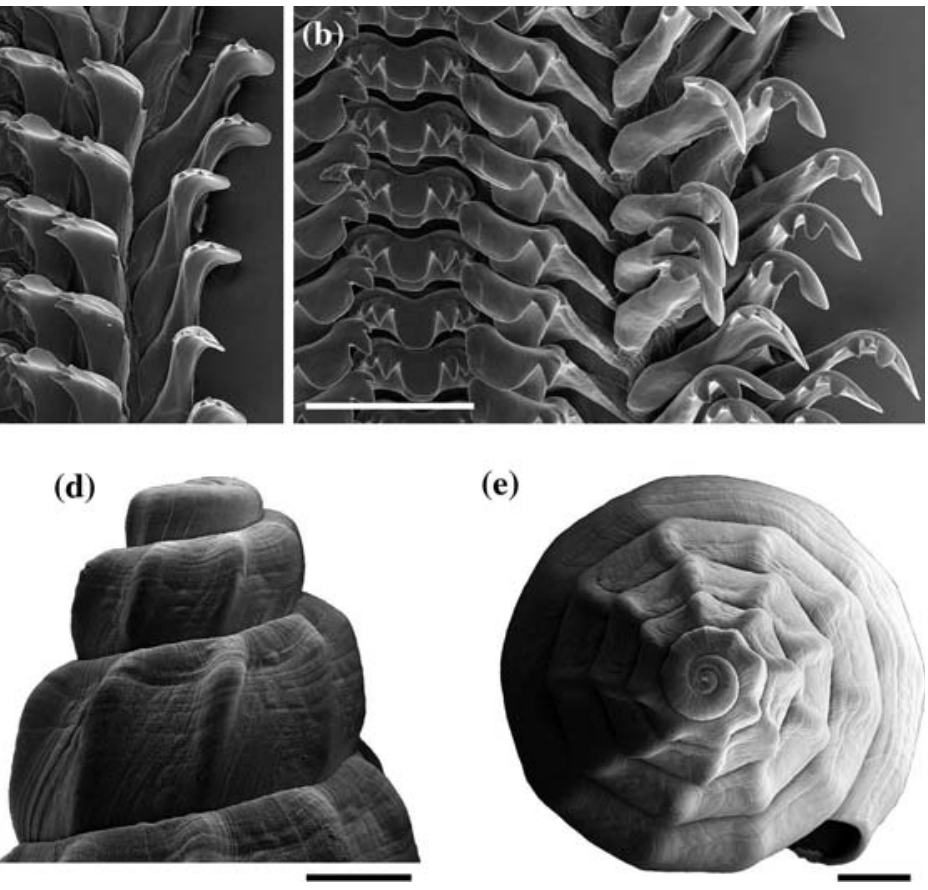

(e)

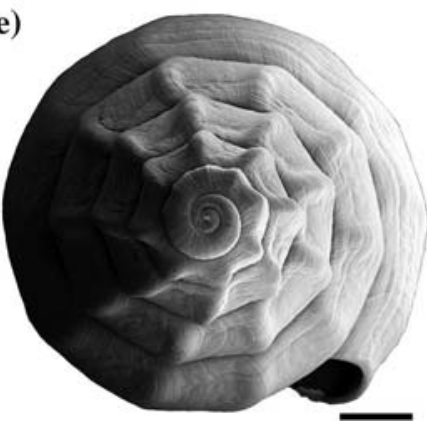

Reproductive biology: Sex ratio $0.55(n=52)$. Males are significantly smaller than females (ANOVA, last three whorls: $F=3.667$, $P=0.038)$. About $85 \%$ of females $(n=23)$ carry shelled embryos in their brood pouch, which contains 5-17 embryos, their size can reach $10.0 \mathrm{~mm}$ (Table 3).

Embryonic shells (Fig. 14c-e): Ovate, with strong axial ribs emerging on the third whorl. Ribs start to become curved on fifth whorl. Shallow spiral ribs emerge on 2nd to 3rd whorl. Diameter of first whorl between 255 and $313 \mu \mathrm{m}$ (Table 3).

\section{Distribution}

Lake Towuti, Cape Bakara (Fig. 9).

\section{Ecology and habitat}

Hard substrate dweller, on rocks. Occurs from a depth of about half a meter down to about $20 \mathrm{~m}$, where rocks are replaced by mud. Highest density at a depth of about 5-7 $\mathrm{m}$. In the first 1-5 $\mathrm{m}$ shells. MNHN (loc. WWT1). c, lateral view; d, apical whorls, lateral; e, apical view. Scale bar $=0.5 \mathrm{~mm}$

T. bakara occurs syntopic with $T$. sarasinorum (Kruimel, 1913).

\section{Taxonomic remarks}

A very distinctive species by virtue of its characteristic shell, T. bakara is hard to confuse with any other species in the Malili lake system. The only vaguely similar species is T. amphiderita (Fig. 11). The radula is characteristic for rock-dwelling species in Lake Towuti, though, and as such shared e.g. by T. amphiderita (Fig. 12a, b) and $T$. sarasinorum (Fig. 49c, d).

\section{Tylomelania confusa new species}

Etymology: The name has been given to mark the confusion caused by the mixing of two species including $T$. confusa in the type series of $T$. mahalonica, which is considered here a synonym of T. mahalonensis.

Type material: Holotype (Fig. 15a; $55.0 \mathrm{~mm} \times$ $21.7 \mathrm{~mm}$ ): Lake Mahalona, N-shore, $02^{\circ} 34.86^{\prime} \mathrm{S}$, $121^{\circ} 28.62^{\prime} \mathrm{E}$, loc. 42 (MNHN 9991, in alc); 


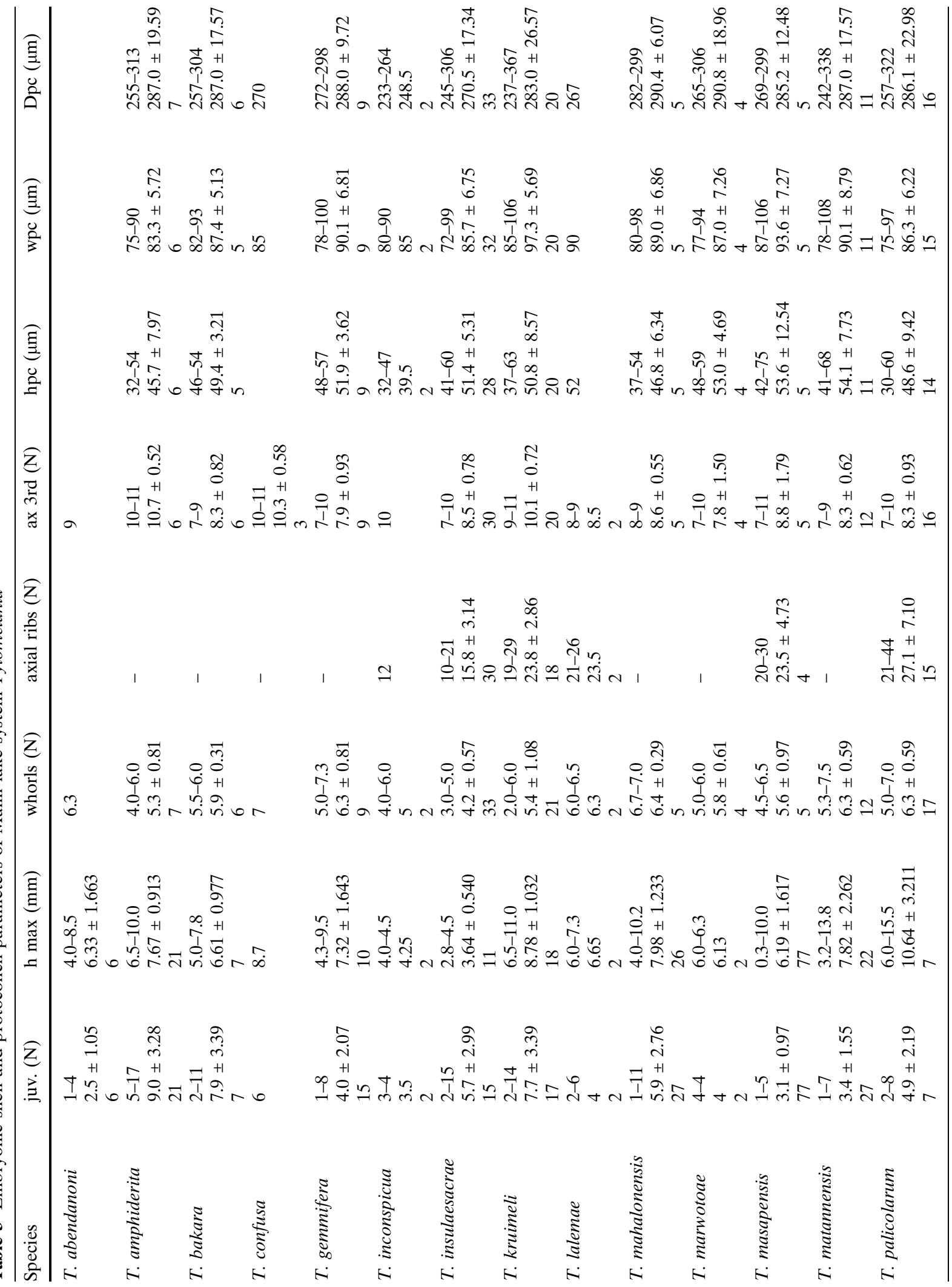




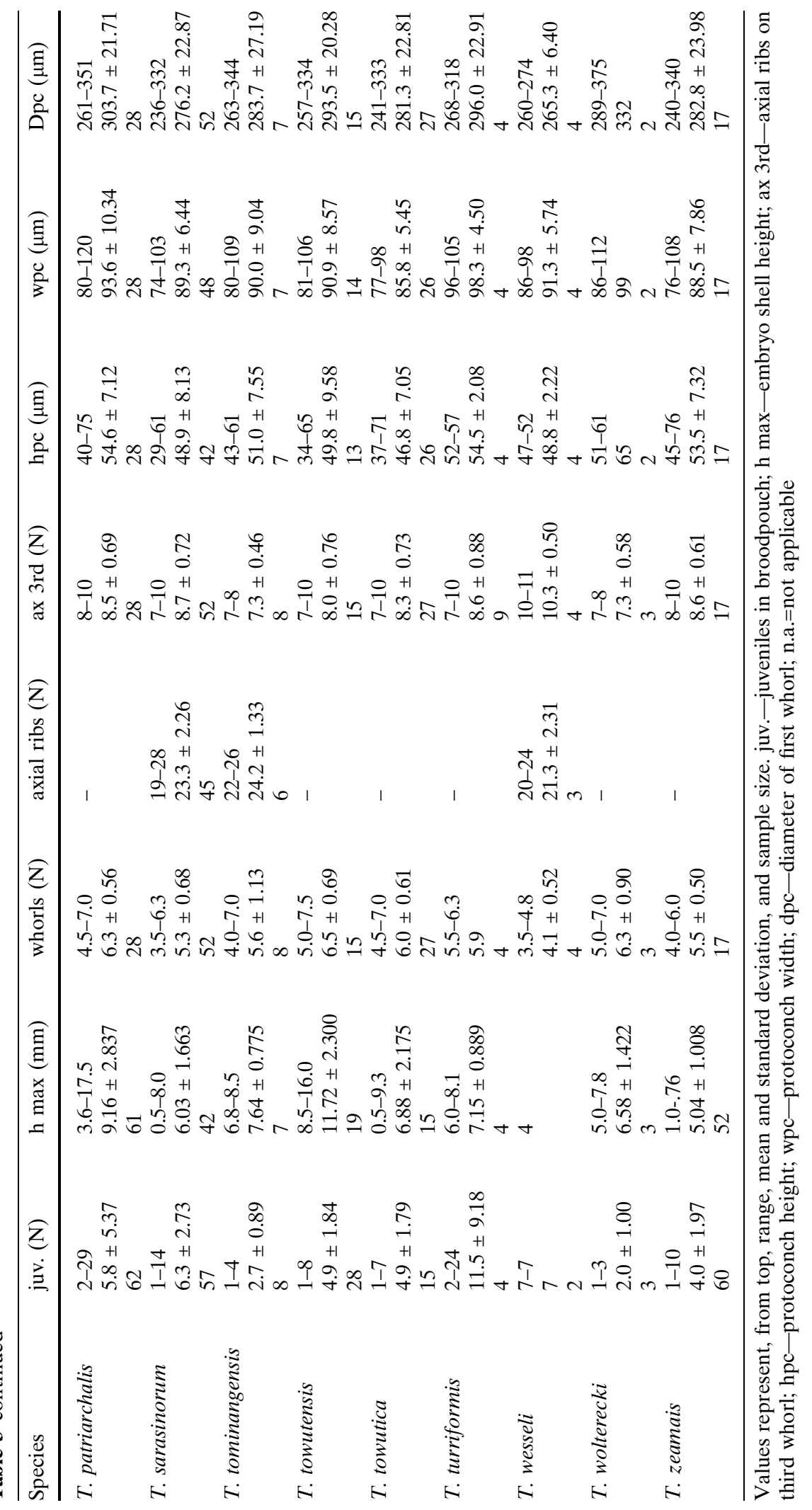



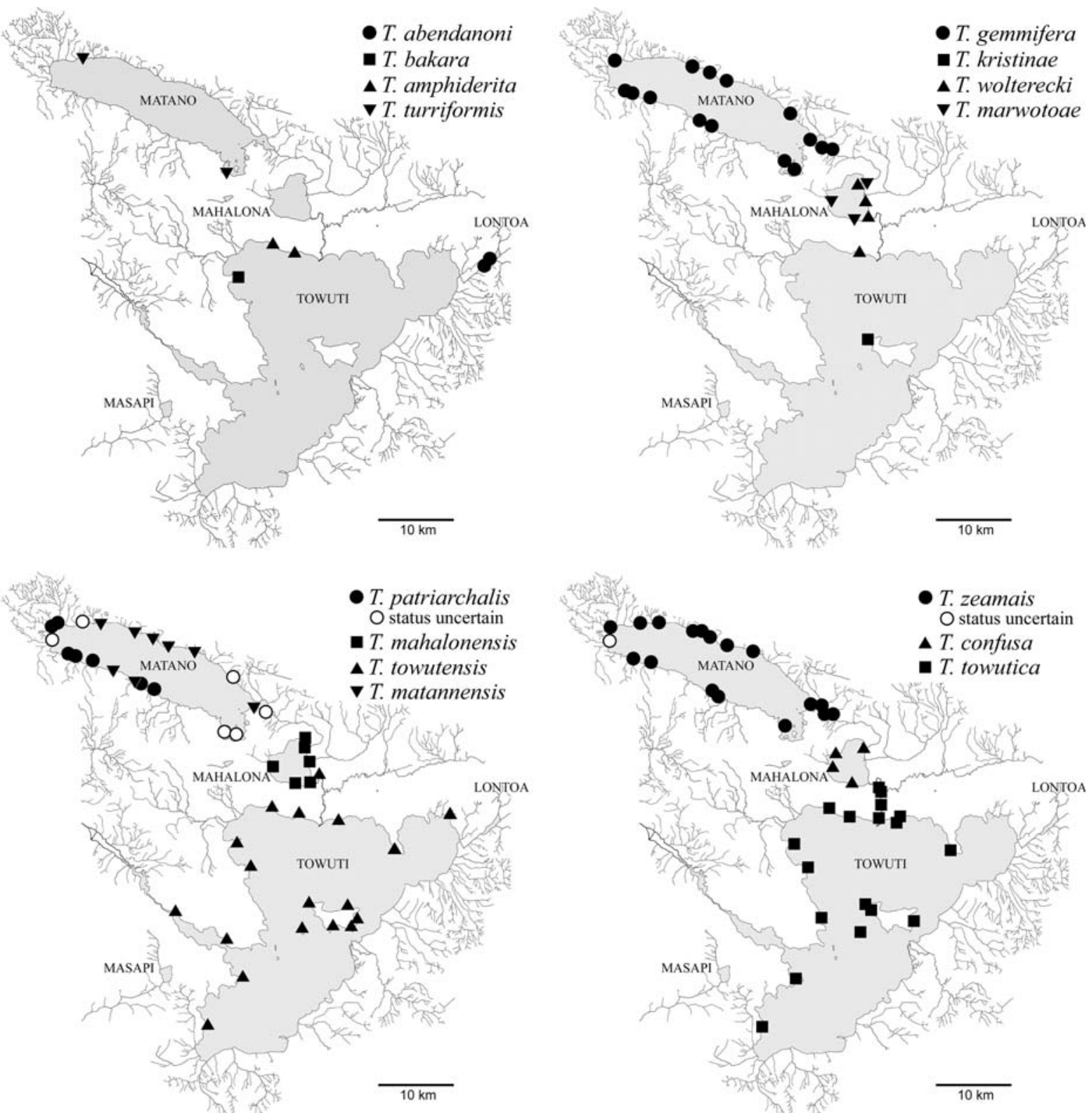

Fig. 9 Distribution of axial-ribbed Malili lake species

Paratypes (Fig. 15b-d): Lake Mahalona, W-shore, Kaloa, 02 $36^{\prime}$ S, $121^{\circ} 29.6^{\prime}$ E, loc. MHL2 (MNHN 9969, $n=212$; MNHN 9970, $n=28$, in alc.); Eshore, Timbalo, inlet of Petea River, $02^{\circ} 34.6^{\prime} \mathrm{S}$, $121^{\circ} 9^{\prime} \mathrm{E}$, loc. MHL4 (MNHN 9971, $n=4$, in alc.); N-shore, $02^{\circ} 34.86^{\prime} \mathrm{S}, 121^{\circ} 28.62^{\prime} \mathrm{E}$, loc. 42 (MZB 12.384, $n=33$; ZMB 190159, $n=56$; all in alc); $\mathrm{W}$ shore, $02^{\circ} 35.64^{\prime} \mathrm{S}, 121^{\circ} 28.52^{\prime} \mathrm{E}$, loc. 43 (ZMB 190161, $n=17$; all in alc.).

\section{Description}

Shell (Fig. 15): Medium sized, brown, turreted, top whorls in adult specimens always corroded to a varying degree, 4-7 remaining whorls, can reach up to $64.6 \mathrm{~mm}$ (Table 2). Medium sized to strong axial ribs, straight or slightly inclined, seldom slightly curved, 16-32 on body whorl. Spiral ribs shallow. 


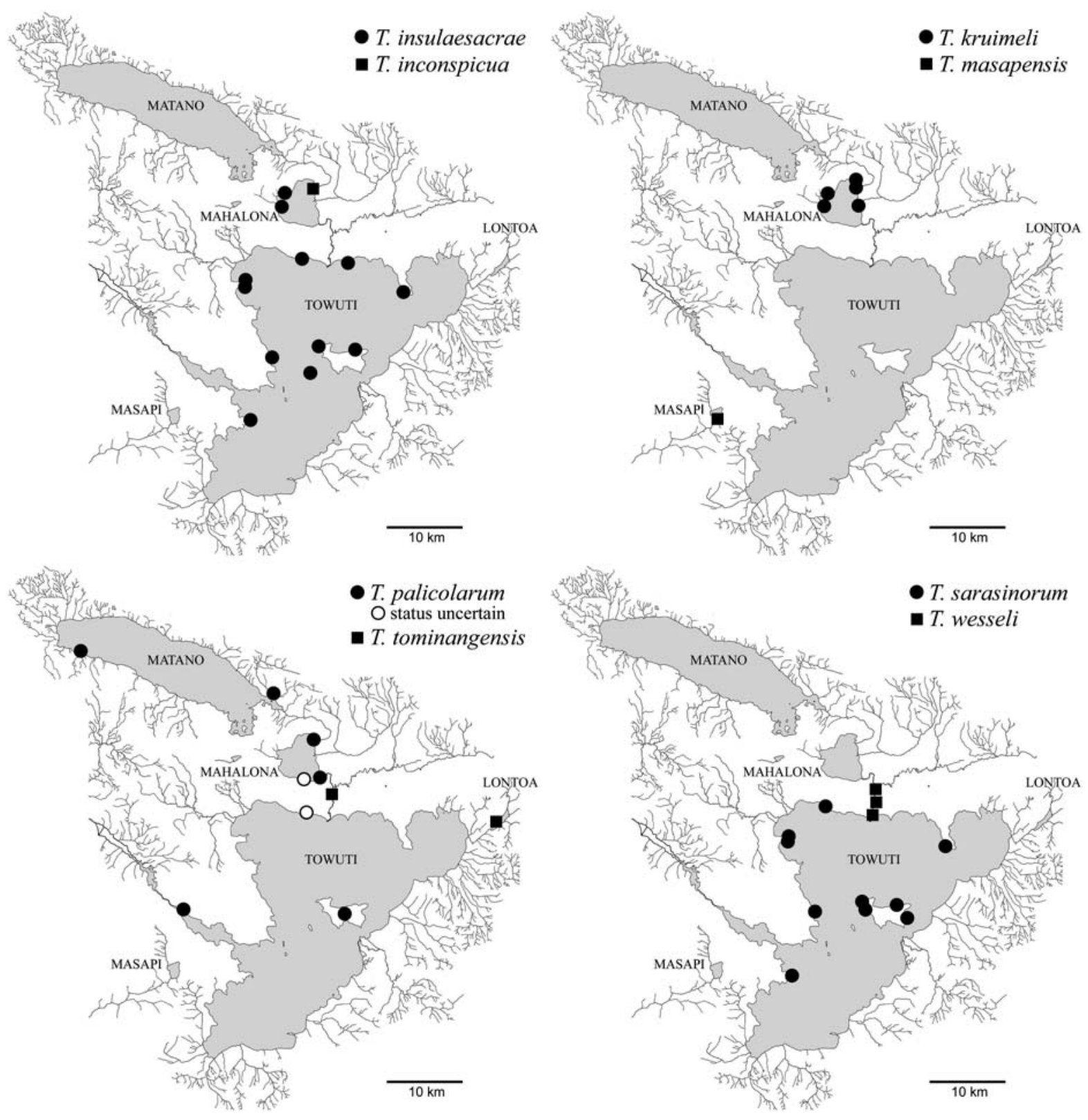

Fig. 10 Distribution of smooth or spiral-ribbed Malili lake species

Aperture oval, pointed at top and slightly siphonated at base.

External morphology: Headfoot with yellowishwhite dots or blotches, tentacles striped, mantle edge serrated. Body coiled in 2.5-3 whorls.

Operculum (Fig. 7d): almost round, last whorl expanded, multispiral, with 9-10 whorls.
Radula (Fig. 16a, b): 170-195 rows, 14.4$21.0 \mathrm{~mm}$ long, on average 10.6 teeth $/ \mathrm{mm}$ $(n=4)$. Central tooth with very large, blunt major denticle, accompanied by two smaller denticles at each side of it. Lateral teeth with greatly enlarged, blunt major denticles and two smaller denticles on each side as well. Marginal 
teeth shovel-like, with three denticles, the outermost ones 3-4 times wider than the inner ones.

Reproductive biology: Sex ratio $0.2(n=9)$. All examined females $(n=7)$ carry shelled embryos in their brood pouch.
Brood pouch contains 2-11 embryos, their size can reach $7.8 \mathrm{~mm}$ (Table 3 ).

Embryonic shells (Fig. 16c-e): Ovate, with strong straight axial ribs emerging on the second whorl. Fine, narrow-spaced spiral striae emerge (a)

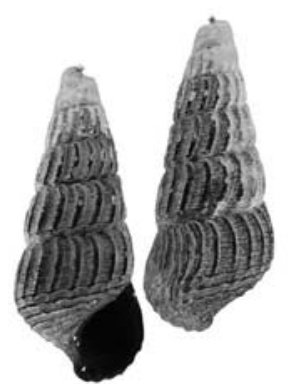

(b)

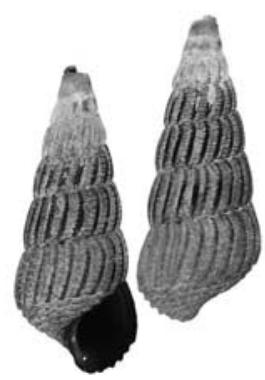

(c)

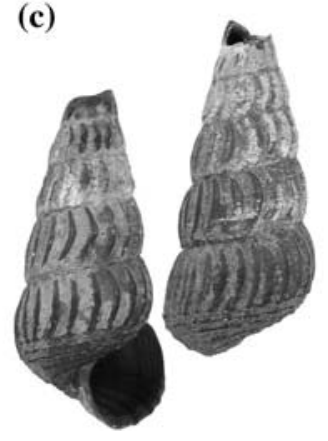

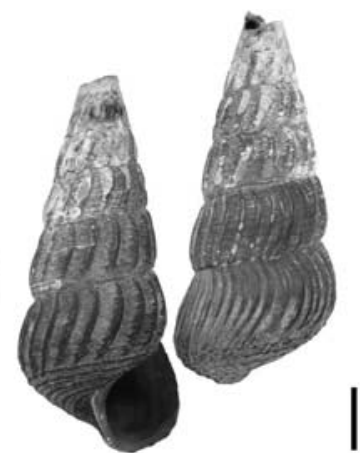

Fig. 11 T. amphiderita, shells. a, holotype, MNHN (loc. 49); b, c, paratypes. b, ZMB 191153 (loc. 49); c, MNHN (TW 1). Scale bar $=1 \mathrm{~cm}$
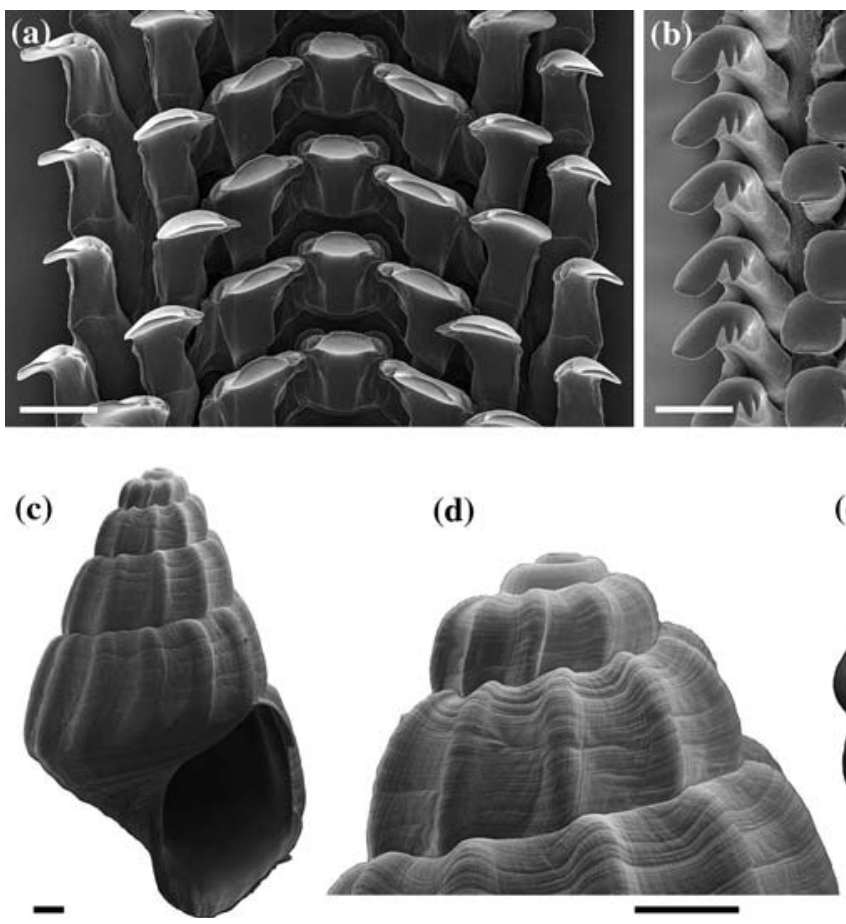

Fig. $12 T$. amphiderita, radula and embryonic shells. Paratypes., ZMB 191153 (loc. 49). a, b, radula. a, segment, frontal; b, segment, apical $\left(45^{\circ}\right)$. Scale bar $=0.1 \mathrm{~mm}$. $\mathbf{c}-\mathbf{e}$,
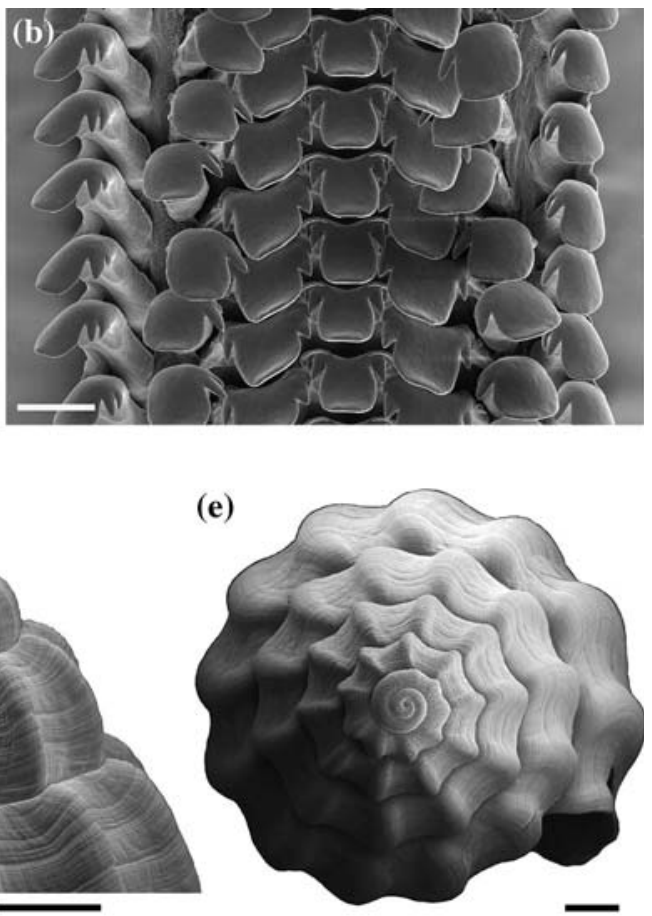

embryonic shells. c, lateral view; d, apical whorls, lateral; e, apical view. Scale bar $=0.5 \mathrm{~mm}$ 

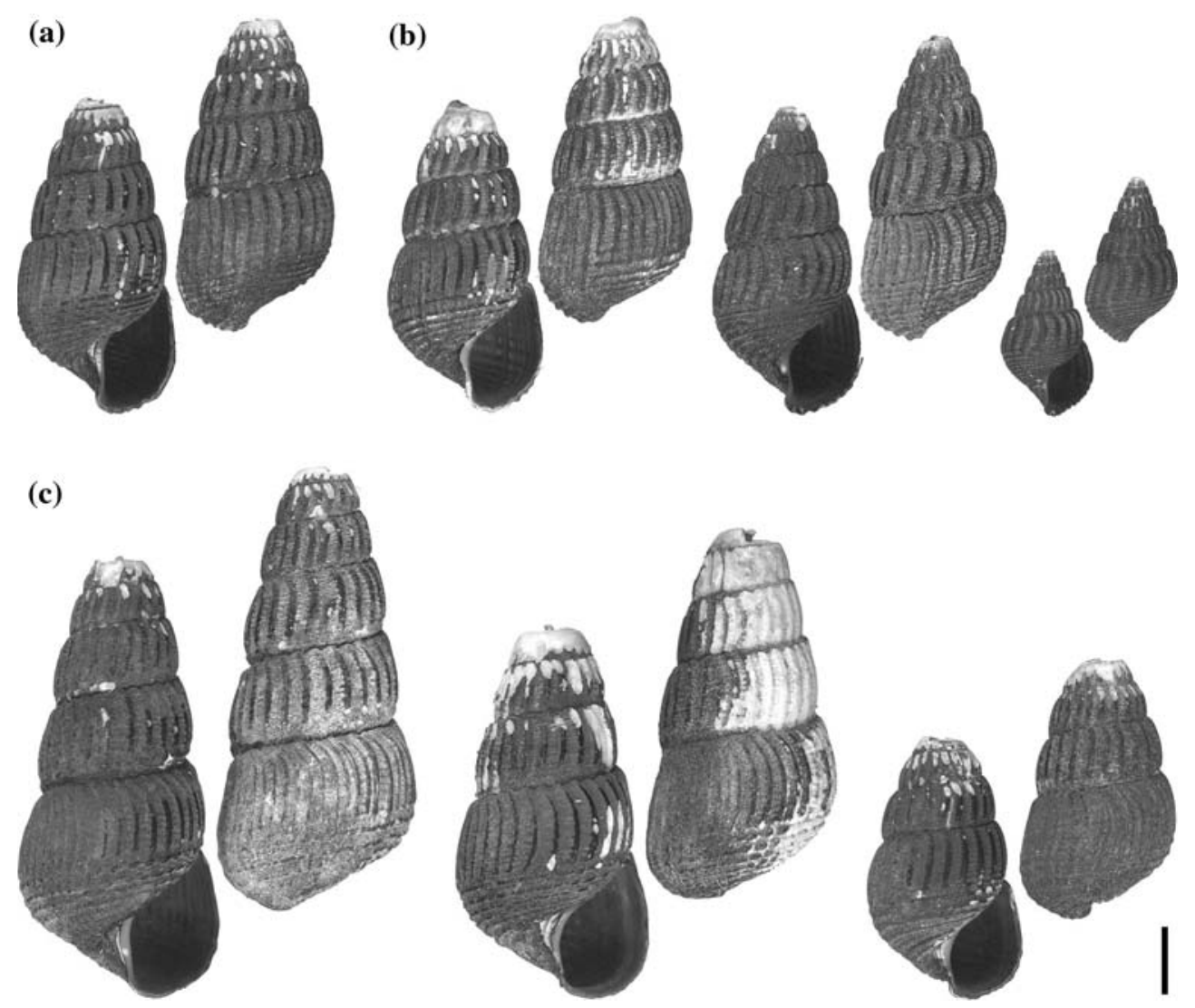

Fig. 13 T. bakara, shells. a, holotype, MZB Gst. 11.956 (loc. 34); b, ZMB 190131 (loc. 34); c, ZMB 190184 (loc. 53 ). Scale bar $=1 \mathrm{~cm}$

on 2nd to 3rd whorl. Diameter of first whorl between 257 and $304 \mu \mathrm{m}$ (Table 3).

\section{Distribution}

South Sulawesi, Lake Mahalona (Fig. 9).

\section{Ecology and habitat}

Hard substrate dweller, on rocks and wood. Occurs syntopic with $T$. kruimeli, which is predominantly found on wood, though.

\section{Taxonomic remarks}

This species had already been collected by Abendanon, and Kruimel (1913: 221) described a taxon Melania mahalonica whose type series apparently contains specimens of two different species, one being $T$. confusa as described here and the second T. mahalonensis (see also taxonomic remarks there). The specimen figured in the description of $T$. mahalonica by Kruimel (1913: pl. 4 Fig. 11; Fig. 31c in this study) is most likely a somewhat untypical T. mahalonensis as described below, though, and several other specimens in the mahalonica types series also belong to T. mahalonensis. As the text of the original description also fails to clearly differentiate the taxon from T. mahalonensis, it has been deemed more sensible to regard $T$. mahalonica altogether as a synoynm of $T$. mahalonensis, irrespective of the fact that some of the paralectotypes of $T$. mahalonica belong to a different taxon described here as $T$. confusa in order to minimize taxonomic confusion.

Tylomelania confusa is a characteristic hard substrate dweller in Lake Mahalona. It can easily 

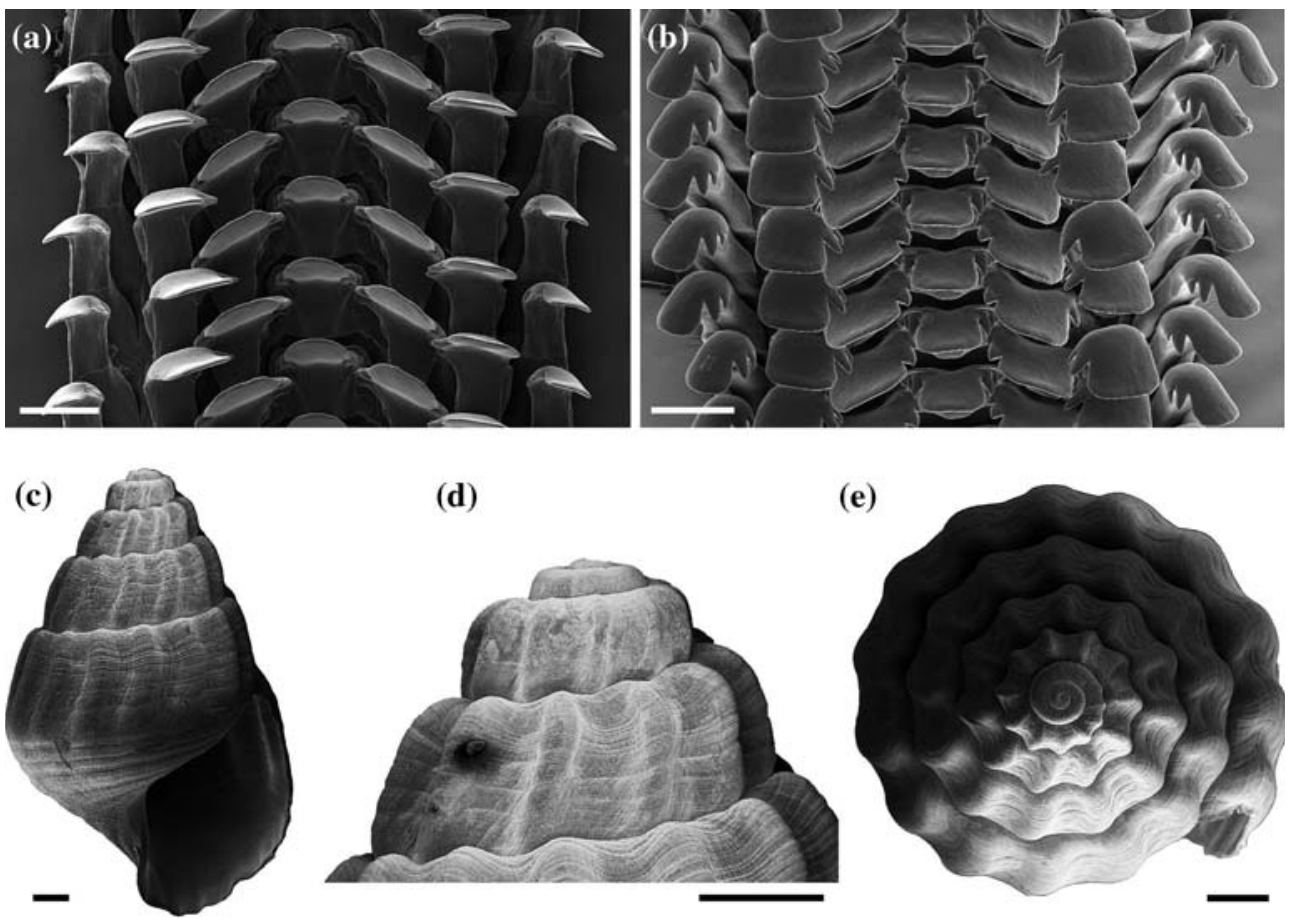

Fig. 14 T. bakara, radula and embryonic shells. ZMB 190131 (loc. 34). a, b, radula. a, segment, frontal; b, segment, apical $\left(45^{\circ}\right)$. Scale bar $=0.1 \mathrm{~mm}$. c-e, embryonic shells. c, lateral view; d, apical whorls, lateral; e, apical view. Scale bar $=0.5 \mathrm{~mm}$

\section{Description}

Shell (Fig. 17): Medium sized to large, brown or black, usually highly turreted, spire angle 13$20^{\circ}$, top whorls in adult specimens always corroded to a varying degree, 5-13 remaining whorls, can reach up to $80.1 \mathrm{~mm}$ (Table 2). Comparatively few strong, straight or mildly curved axial ribs per whorl, almost always inclined, 9-23 on body whorl. Spiral ribs weak. Aperture oval, pointed at top. Outer lip slightly siphonated at base.

External morphology: Headfoot with yellow dots or blotches, tentacles with yellow stripes, snout yellow, mantle edge serrated to a varying degree. Body coiled in 2.5-3.5 whorls.

Operculum (Fig. 7e): Almost round and multispiral, with 6-7 whorls.

Radula (Fig. 18): Typically highly modified, appears thiarid-like, $102-159$ rows, $3.8-8.1 \mathrm{~mm}$ long, on average 22.9 teeth $/ \mathrm{mm}(n=11)$. Central Fig. 22. 

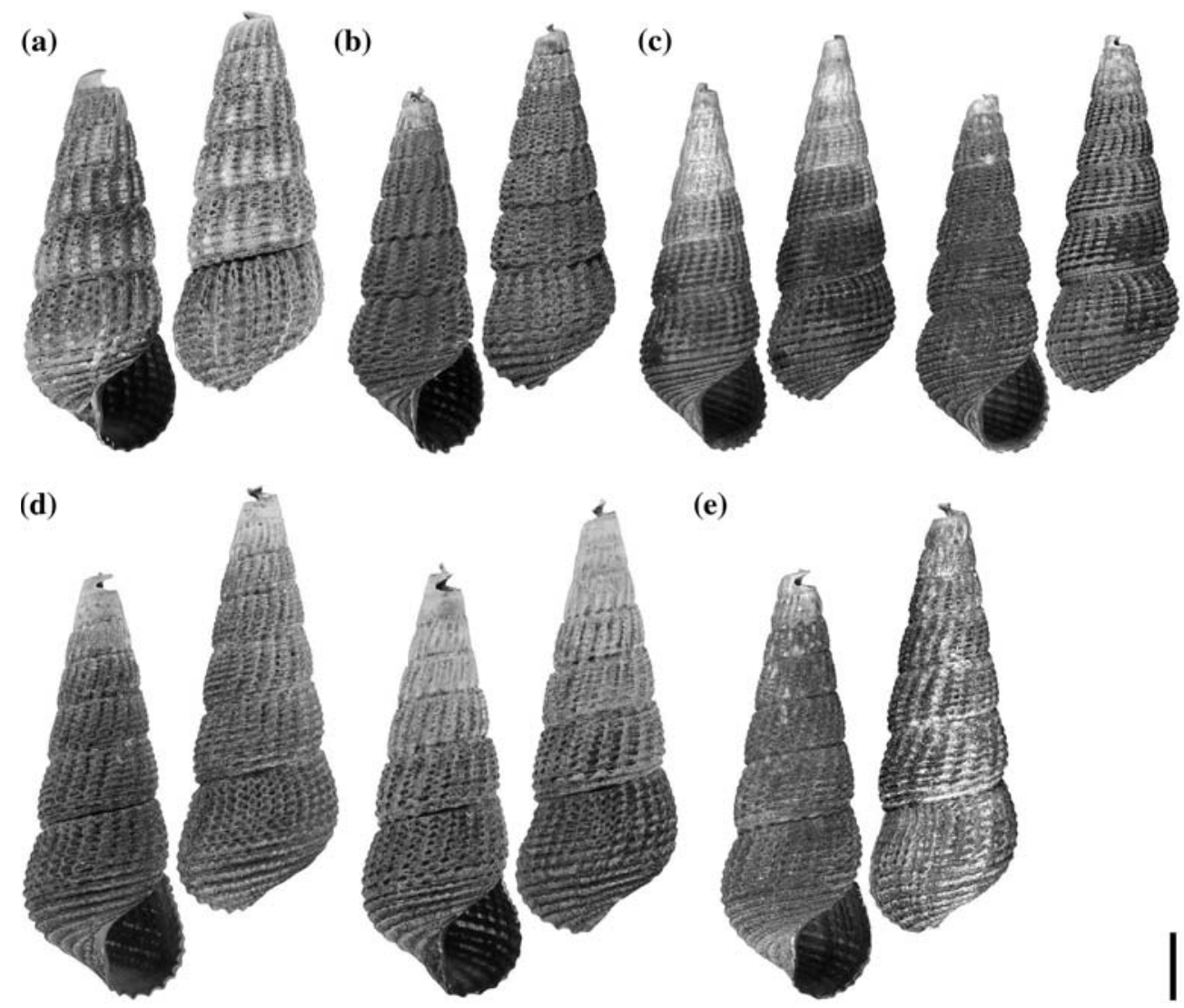

Fig. 15 T. confusa, shells. a, holotype, MNHN (loc. 42); b-d, paratypes. b, ZMB 190159 (loc. 42); c, ZMB 190161 (loc. 43); d, MNHN (MHL 2); e, paralectotypes of T. mahalonica, ZMA (Lake Mahalona). Scale bar $=1 \mathrm{~cm}$

tooth with larger, pointed major denticle, accompanied by two smaller denticles at each side of it. Glabella narrow. Lateral teeth with enlarged major denticles and two smaller denticles on each side as well. Marginal teeth straight at base, upper half widely curved, with 4-6, usually five, denticles, the outermost ones sometimes twice wider than the inner ones.

Two populations contained specimens with a different radula morph (loc. 10 \& 15, Fig. 18 e, f), 207-228 rows, $11.8-18.3 \mathrm{~mm}$ long, on average 14.9 teeth/mm $(n=4)$. Central tooth with very large, spoon-shaped major denticle, accompanied by two smaller denticles at each side of it. Lateral teeth with greatly enlarged major denticles and two smaller denticles on each side as well. Marginal teeth straight, tips strongly curved, with three denticles, the outermost one three times larger than the inner ones. See below under taxonomic remarks.
Reproductive biology: Sex ratio $0.55(n=52)$. Males do not differ significantly in size from females (ANOVA). About $79 \%$ of females $(n=34)$ carry shelled embryos in their brood pouch.

Brood pouch contains 1-8 embryos, their size can reach $9.25 \mathrm{~mm}$ (Table 3 ).

Embryonic shells (Fig. 19): Turreted, with usually strong axial ribs emerging on the third whorl. Shallow, widespaced spiral ribs emerge on 3rd whorl. Diameter of first whorl between 272 and $298 \mu \mathrm{m}$ (Table 3).

\section{Distribution}

South Sulawesi, Lake Matano (Fig. 9).

\section{Ecology and habitat}

Soft substrate dweller, on sand and mud. Occurs from a depth of c. $1 \mathrm{~m}$ to $20 \mathrm{~m}$, frequently 

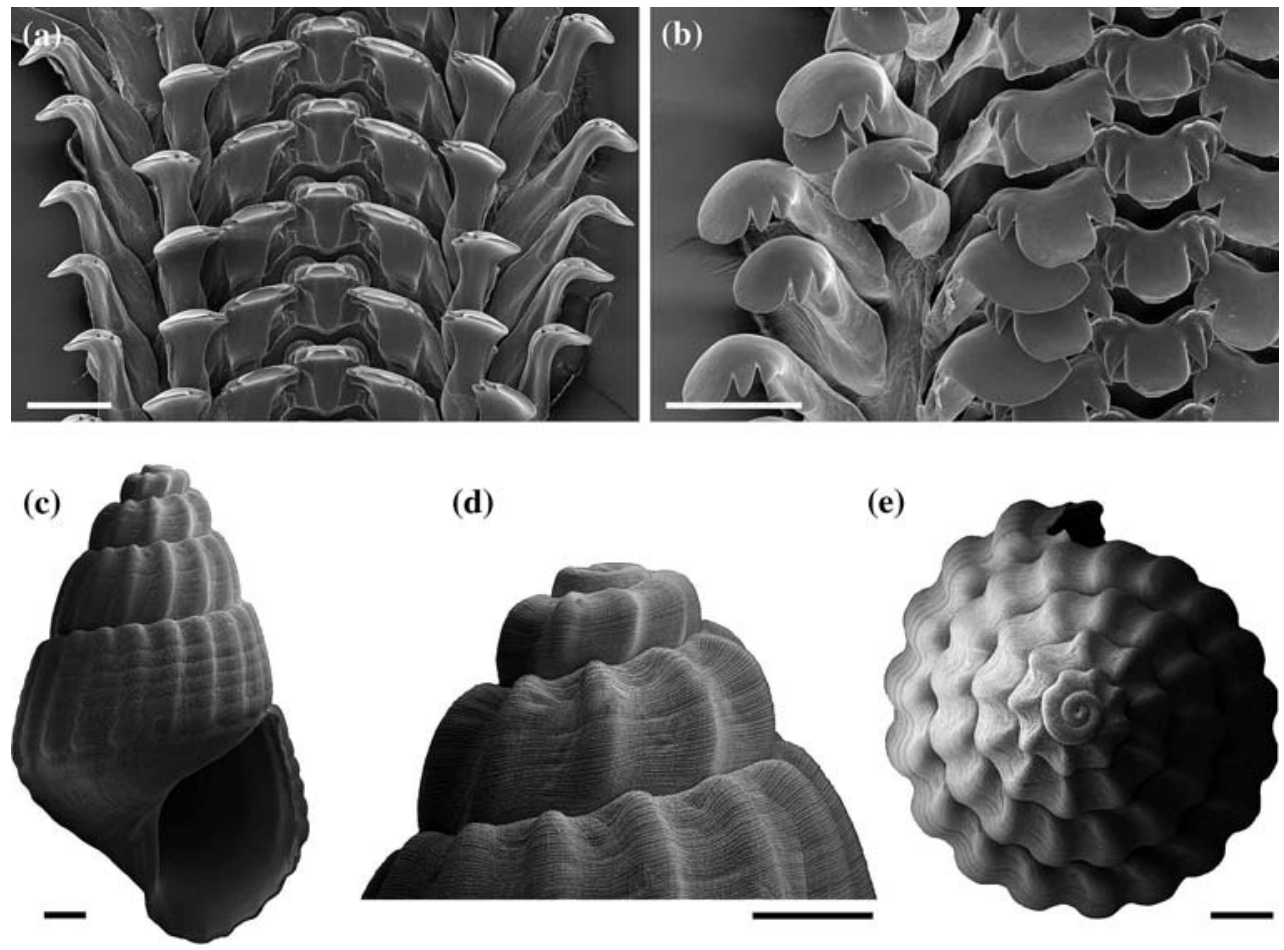

Fig. 16 T. confusa, radula and embryonic shells. a, b, radula, paratype, ZMB 190161 (loc. 43). a, segment, frontal; b, segment, apical $\left(45^{\circ}\right)$. Scale bar $=0.1 \mathrm{~mm}$. $\mathbf{c}-\mathbf{e}$,

syntopic with $T$. patriarchalis, but usually less abundant than that species.

\section{Taxonomic remarks}

Easily diagnosable by its highly turreted shell with strong wide-spaced axial ribs, its very unusual thiarid-like radula, and distinct embryonic shells. In two populations of $T$. gemmifera (loc. $10 \& 15$, see below, material examined), all specimens examined possess typical shells and embryos, but some have a very different radula (Fig. 18e, f). The radula of these animals is virtually identical to one radula form encountered in T. zeamais (Fig. 68a, b). At locality 15 the population contained both the deviant radula type $(n=2)$ and the typical gemmifera form $(n=2)$, while at loc. 10 only the zeamais type was found $(n=4)$. The cause of this radula polymorphism and a possible involvement of hybridization with $T$. zeamais remains to be investigated. embryonic shells, paratype, ZMB 190159 (loc. 42); c, lateral view; d, apical whorls, lateral; e, apical view. Scale bar $=0.5 \mathrm{~mm}$

T. gemmifera does not occur in Lakes Mahalona and Towuti, where it is ecologically replaced by species with an almost identical radula but distinct if somehow similar shells, T. wolterecki (Fig. 65, Mahalona) and T. kristinae (Fig. 25, Towuti). It might be speculated that the three species have a common origin and show a classical pattern of diversification in allopatry. Alternatively, an independent parallel evolution of the highly derived radula must be assumed. These hypotheses will have to be tested by use of a reliable (nuclear) species-level molecular phylogeny, which is currently in work.

\section{Material examined}

Lake Matano: SW-shore, Paku, 02²9.1' S, $121^{\circ} 15.5^{\prime} \mathrm{E}$, loc. MT1 (MNHN, $n=9 ; n=9$, in alc.); S-shore, bay with islands, $02^{\circ} 34^{\prime} \mathrm{S}$, $121^{\circ} 26.8^{\prime} \mathrm{E}$, loc. MT5 (MNHN, $n=10 ; n=76$, in alc.); E-shore, easternmost bay, $02^{\circ} 32.4^{\prime} \mathrm{S}$, $121^{\circ} 28.1^{\prime} \mathrm{E}$, loc. MT6 (MNHN, $\left.n=2\right)$; Soroako, 


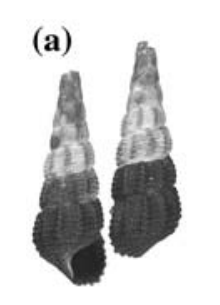

(b)
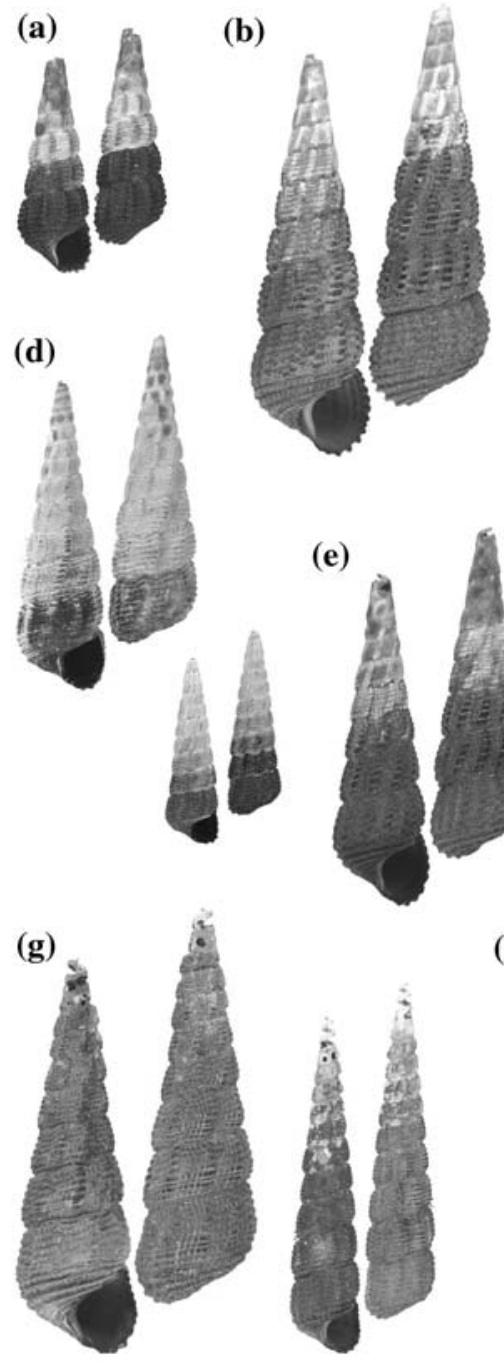

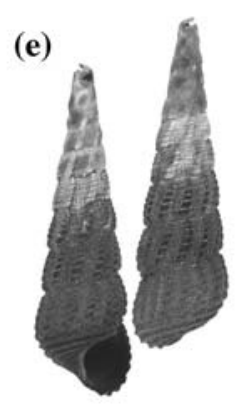

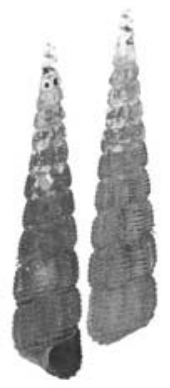
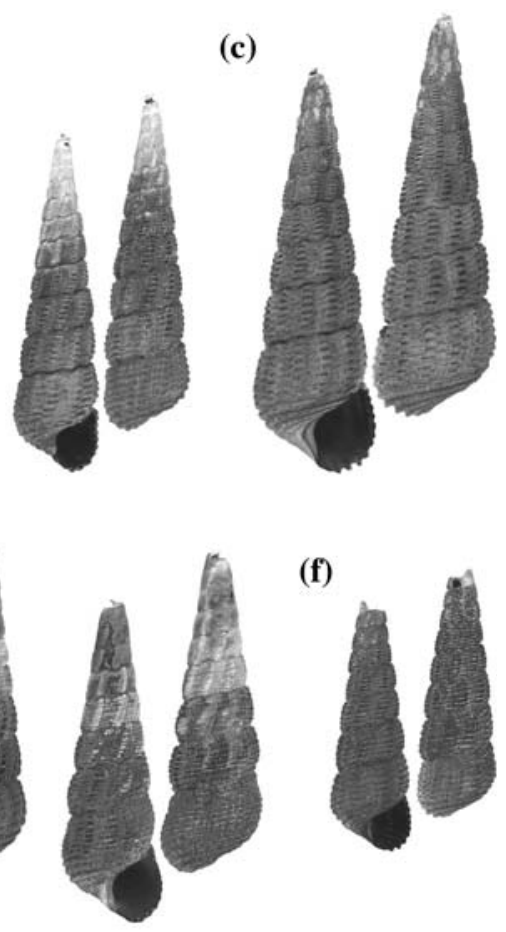

(f)

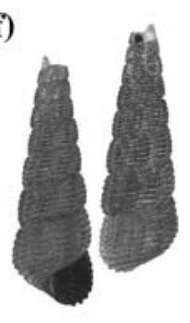

(h)
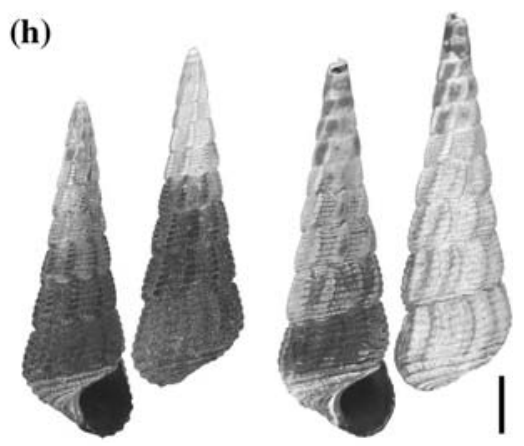

Fig. 17 T. gemmifera, shells. a, lectotype, NMB 1344a; b, ZMB 190051 (loc. 1); c, ZMB 190089 (loc. 17); d, ZMB 190070 (loc. 13); e, ZMB 190058 (loc. 6); f, ZMB 190060

Salonsa, $02^{\circ} 30.49^{\prime} \mathrm{S}, 121^{\circ} 19.96^{\prime} \mathrm{E}$, loc.1 \& 2 (loc. 1 : MZB Gst. 12.257, $n=10$; ZMB 190051, $n=45$; loc. 2, $-20 \mathrm{~m}$ : ZMB 190088, $n=8$ in alc.); Soroako, Salonsa, loc.3, ca. $300 \mathrm{~m}$ E of loc. 1 (MZB Gst. 12.259, $n=22$; ZMB 190054, $n=21$; all in alc.); $\mathrm{S}$ shore, $02^{\circ} 28.44^{\prime} \mathrm{S}, 121^{\circ} 15.78^{\prime} \mathrm{E}$, loc. 6 (MZB Gst. 12.260, $n=42$; ZMB 190058, $n=42$; all in alc.); $\mathrm{S}$ shore, small bay, $02^{\circ} 28.04^{\prime} \mathrm{S}, 121^{\circ} 14.04^{\prime} \mathrm{E}$, loc. 7 (ZMB 190060, $n=2$ in alc.); E-Bay, at outlet of Petea River, $02^{\circ} 32.06^{\prime} \mathrm{S}, 121^{\circ} 28.50^{\prime} \mathrm{E}$, loc. 10 (MZB Gst. 12.280, $n=21$; ZMB 190066, $n=40$; all in alc.); Mouth of E-bay, Cape Una, 02 ${ }^{\circ} 31.40^{\prime} \mathrm{S}$, $121^{\circ} 26.99^{\prime} \mathrm{E}$, loc. 13 (ZMB 190070, $n=28$ in alc.); (loc. 7); g, ZMB 190107 (loc. 54); h, ZMB 190096 (loc. 20). Scale bar $=1 \mathrm{~cm}$

SE-bay, W-shore, $02^{\circ} 32.93^{\prime} \mathrm{S}, 1^{\circ} 1^{\circ} 25.22^{\prime} \mathrm{E}$, loc. 15 (ZMB 190075, $n=24$ in alc.); NW-shore, $02^{\circ} 25.87^{\prime} \mathrm{S}, 121^{\circ} 13.41^{\prime} \mathrm{E}$, loc. 17 (ZMB 190089, $n=2$ in alc.); N-shore, $02^{\circ} 26.28^{\prime} \mathrm{S}, 121^{\circ} 18.73^{\prime} \mathrm{E}$, loc. 20 (ZMB 190096, $n=20$ in alc.); N-shore, $02^{\circ} 26.71^{\prime} \mathrm{S}, 121^{\circ} 20.02^{\prime} \mathrm{E}$, loc. 22 (ZMB 190102, $n=3$ in alc.); N-shore, $02^{\circ} 27.29^{\prime} \mathrm{S}, 121^{\circ} 21.18^{\prime} \mathrm{E}$, loc. 23 (MZB Gst. 12.267, $n=15$; ZMB 190104, $n=23$; all in alc.); S-shore, 02 $29.99^{\prime} \mathrm{S}$, $121^{\circ} 19.04^{\prime} \mathrm{E}$, loc. 54 (MZB Gst. 12.268, $n=14$; ZMB 190107, $n=50$; all in alc.); N-shore, $-20 \mathrm{~m}$, $02^{\circ} 29.64^{\prime} \mathrm{S}, 121^{\circ} 25.65^{\prime} \mathrm{E}$, loc. 56 (ZMB 190338, $n=3$ in alc.). 

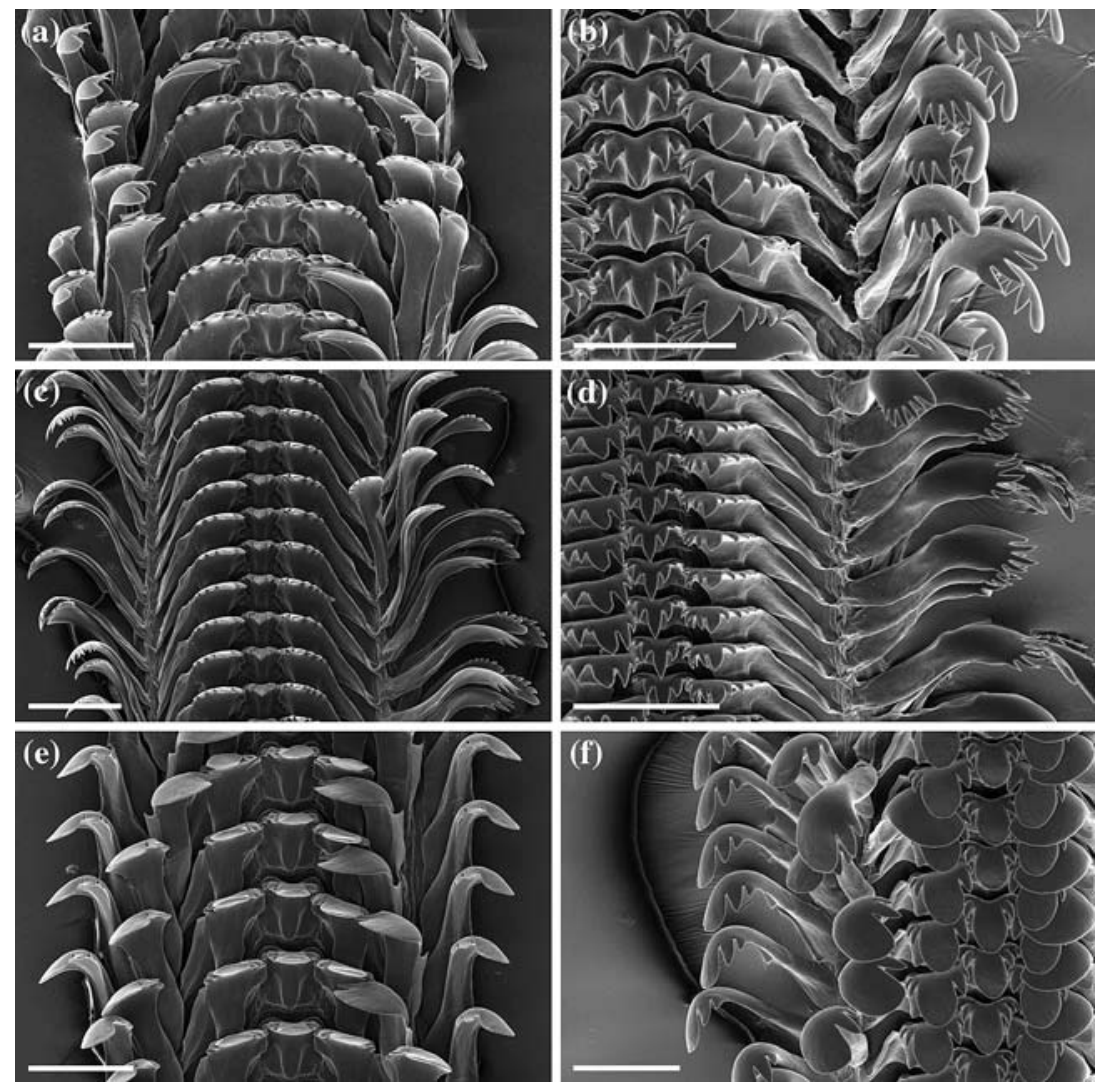

Fig. 18 T. gemmifera, radula. a, b, ZMB 190051 (loc. 1). a, segment, frontal; b, segment, apical $\left(45^{\circ}\right)$. c-f, ZMB 190095 (loc. 15). c, segment, frontal; d, segment, apical

$\left(45^{\circ}\right)$; e, segment, frontal; f, segment, apical $\left(45^{\circ}\right)$. Scale bar $=0.1 \mathrm{~mm}$

Tylomelania cf. gemmifera: S-shore, bay with islands, $02^{\circ} 34^{\prime} \mathrm{S}, 121^{\circ} 26.8^{\prime} \mathrm{E}$, loc. MT5 (MNHN, $n=67 ; n=17$, in alc.);

\section{Tylomelania inconspicua new species}

Type material: Lake Mahalona: E-shore, Timbalo, inlet of Petea River, loc. MHL4. Holotype (Fig. 20 a; $20.4 \mathrm{~mm} \times 8.3 \mathrm{~mm}$; MNHN 9972). Paratypes (Fig. 20b; MNHN, $n=51 ; n=9$, in alc.; MZB Gst. 12.107, $n=10$; ZMB 190633, $n=10$ ).

Etymology: The name inconspicua refers to the "inconspicuous nature" of this small and easily overlooked species.

\section{Description}

Shell (Fig. 20): Small, brown, ovate to turreted, spire angle $14-28^{\circ}$, top whorls in adult specimens always corroded to a varying degree, 4-7

remaining whorls, can reach up to $22.0 \mathrm{~mm}$ (Table 2). Smooth shell. Aperture oval, pointed at top and in larger specimens slightly siphonated at base.

External morphology: Headfoot black, mantle edge smooth or slightly serrated. Body coiled in 3.5 whorls.

Operculum (Fig. 7f): almost round, last whorl inflated, multispiral, with 8 whorls.

Radula (Fig. 21a, b): 165-250 rows, 9.8$13.2 \mathrm{~mm}$ long, on average 17.1 teeth $/ \mathrm{mm}(n=3)$. Central tooth with large elongated, blunt major denticle, accompanied by two smaller denticles at each side of it. Lateral teeth with very large major denticles and two smaller denticles on each side as well. Marginal teeth shovel-like, with three denticles each, the outermost ones are about four times wider than the inner ones.

Reproductive biology: Brood pouch contains 34 embryos, their size can reach $4.5 \mathrm{~mm}$ (Table 3 ). 

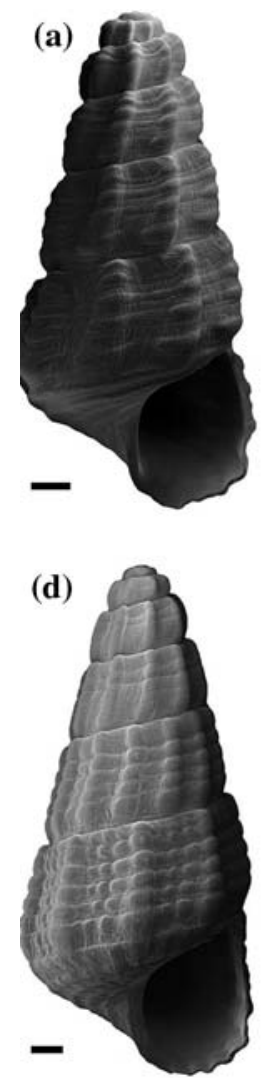

(b)

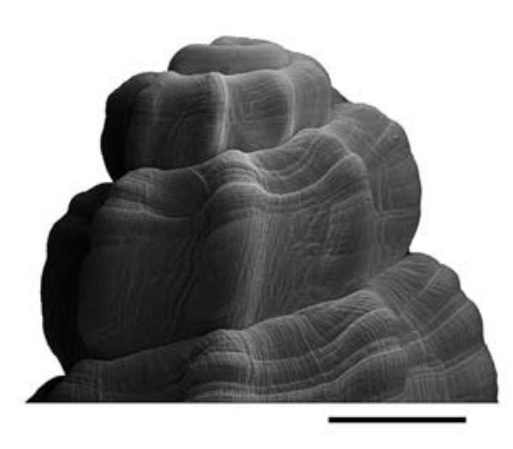

(e)

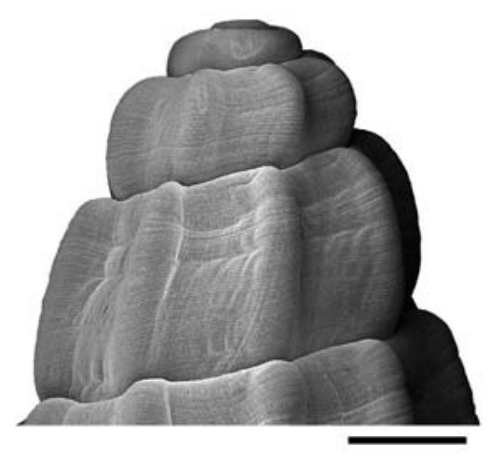

(c)

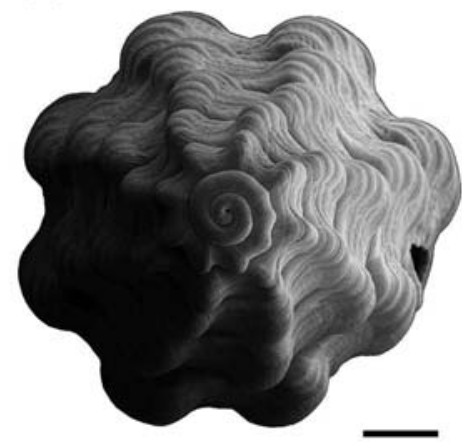

(f)

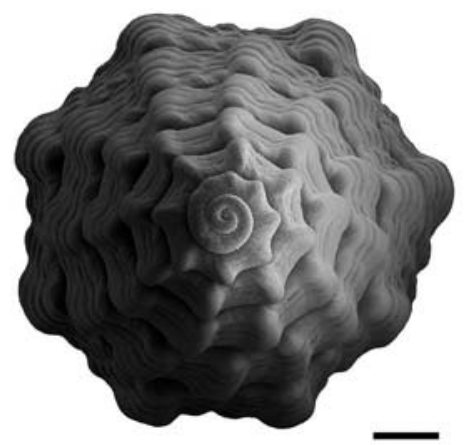

Fig. 19 T. gemmifera, embryonic shells. a-c, ZMB 190104 (loc. 23). a, lateral view; b, apical whorls, lateral; c, apical view. d-f, ZMB 190051 (loc. 1). d, lateral view; e, apical whorls, lateral; f, apical view. Scale bar $=0.5 \mathrm{~mm}$
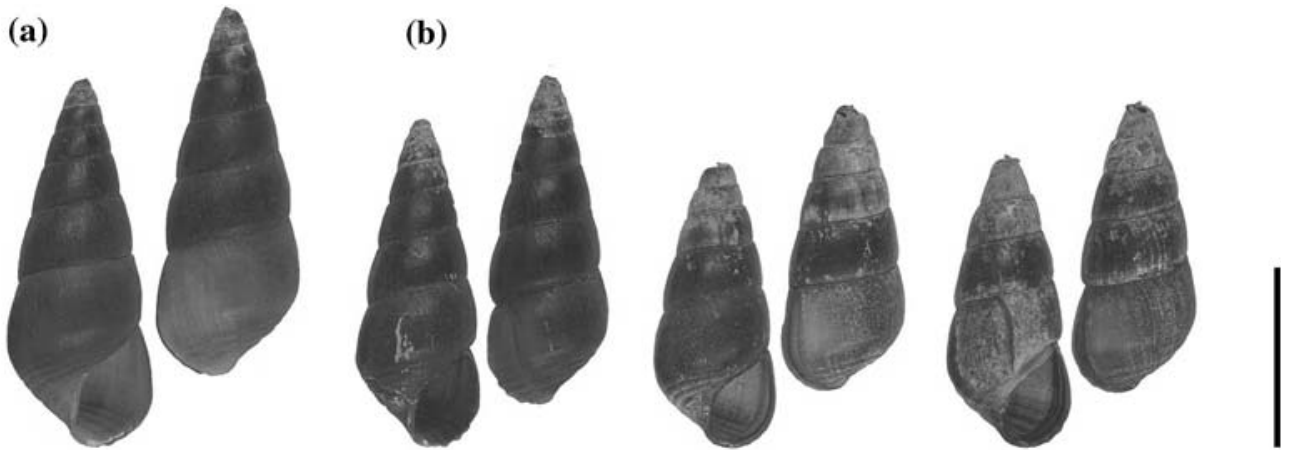

Fig. 20 T. inconspicua, shells. Types, MNHN (loc. MHL4). a, holotype; b, paratypes. Scale bar $=1 \mathrm{~cm}$

Embryonic shells (Fig. 21c-e): Conic, with few very weak axial ribs on the third whorl, and very fine spiral striae emerging on third whorl. Diameter of first whorl between 233 and $264 \mu \mathrm{m}$ (Table 3).

\section{Distribution}

South Sulawesi, Lake Mahalona, E-shore (Fig. 10). 

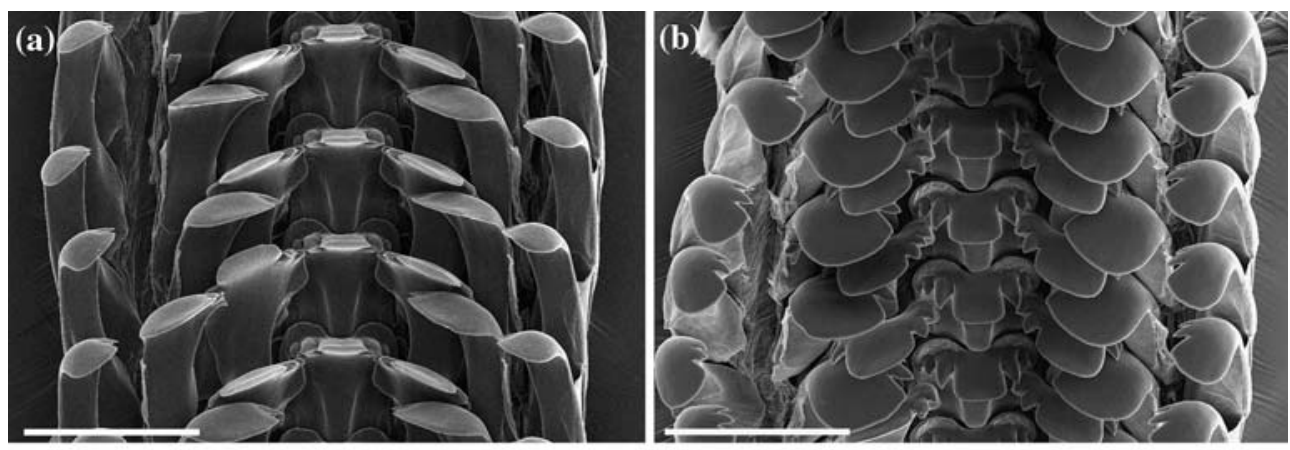

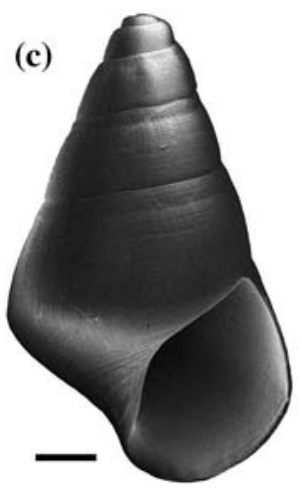

(d)

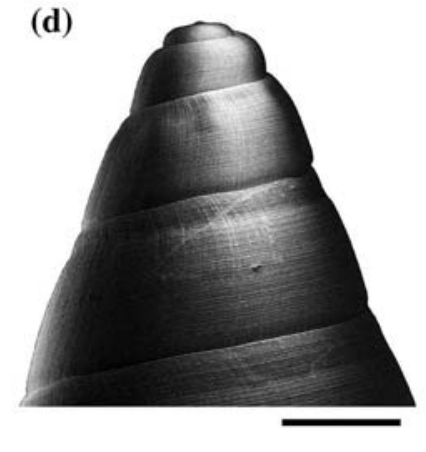

(e)

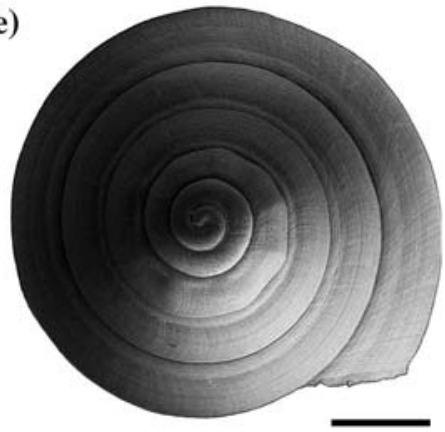

Fig. $21 T$. inconspicua, radula and embryonic shells. Paratypes, MNHN (loc. MHL4). a, b, radula. a, segment, frontal; b, segment, apical $\left(45^{\circ}\right)$. Scale bar $=0.1 \mathrm{~mm}$. $\mathbf{c}-\mathbf{e}$,

\section{Ecology and habitat}

Deep ooze and plants.

\section{Taxonomic remarks}

Tylomelania inconspicua is the smallest species in the Malili system and cannot be confused with any other taxon in the lakes, while its radula and embryonic shells are unparalleled among Sulawesi pachychilids in general.

Tylomelania insulaesacrae (Sarasin \& Sarasin, 1897)

Melania insulae sacrae Sarasin \& Sarasin, 1897: 315. (Lake Towuti, Loeha Island; lectotype, NMB 1342a, present designation, 4 paralectotypes, NMB 1342a', 2 broken). - Sarasin \& Sarasin, 1898: 32, pl. 2 Figs. 20, 21; pl. 5 Fig. 72 (op.); pl. 7 Figs. 98, 98a, 99 (rad.); pl. 9 Fig. 118. —Kruimel, 1913: 225. embryonic shells. c, lateral view; d, apical whorls, lateral; e, apical view. Scale bar $=0.5 \mathrm{~mm}$

\section{Description}

Shell (Fig. 22): Very small to small, yellowishbrown or brown, ovate to conic, last whorl angular to a varying degree, spire angle $19-43^{\circ}$, top whorls in adult specimens always corroded to a varying degree, 2-6 remaining whorls, can reach up to $20.6 \mathrm{~mm}$ (Table 2). If present, sculpture consists of spiral ribs only, 3-6 on body whorl. Aperture oval, pointed at top, slightly siphonated at base.

External morphology: Headfoot black, the tentacles are c. twice as long in relation to body size as in other species, mantle edge serrated to a varying degree. Body coiled in 2-3.5 whorls.

Operculum (Fig. 7g): Almost round and multispiral, with 5-6 whorls.

Radula (Fig. 23): 164-253 rows, 9.5-15.0 mm long, on average 17.4 teeth $/ \mathrm{mm}(n=13)$. Central tooth distinctly longer than wide, with large protruding, spoon-shaped major denticle, accompanied by two smaller denticles at each side of it. 


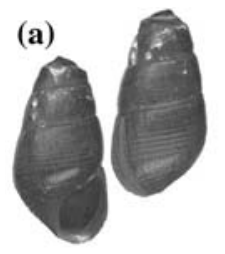

(b)

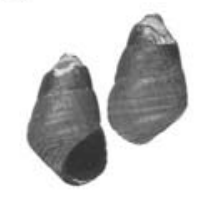

(d)
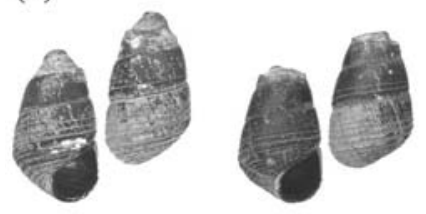

(f)
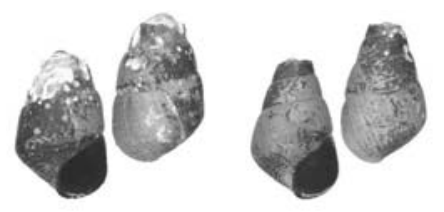

(h)
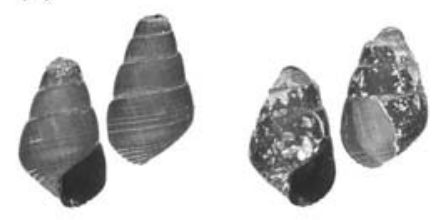

(k)
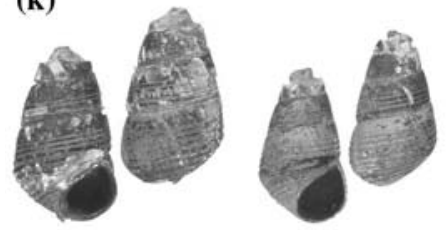

(c)

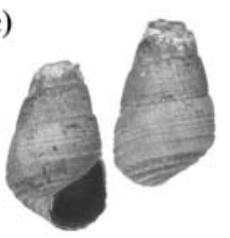

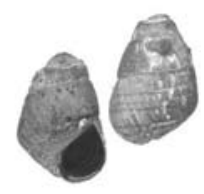

(e)
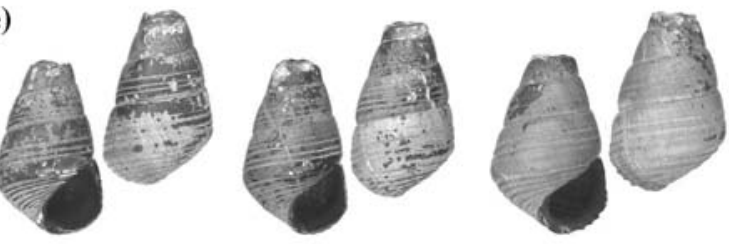

(g)
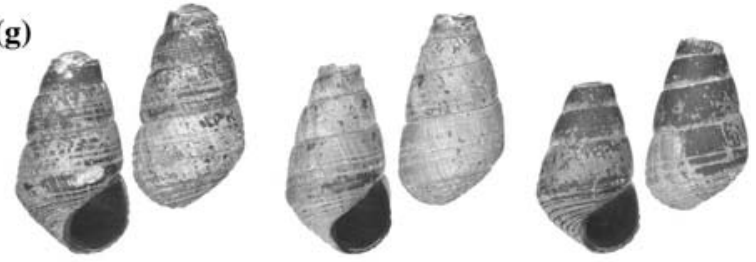

(i)
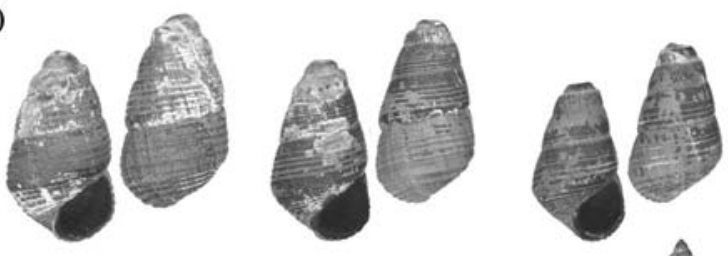

(I)
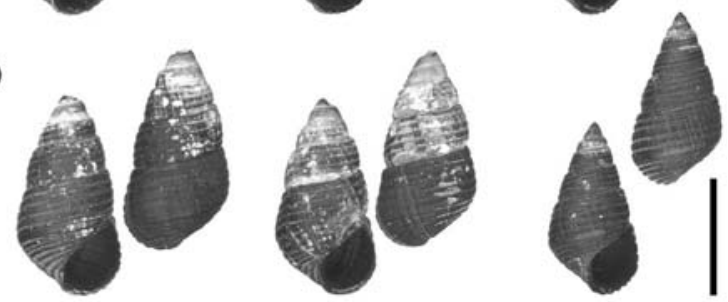

Fig. 22 T. insulaesacrae, shells. a, b, types (Lake Towuti, Loeha Island). a, lectotype, NMB 1342a; b, paralectotype, NMB 1342a'. c, ZMB 190117 (loc. 27); d, ZMB 190122 (loc. 29); e, ZMB 190130 (loc. 33); f, ZMB 190133 (loc. 34); g, ZMB 190142 (loc. 37); h, ZMB 190173 (loc. 49); i. ZMB 190180 (loc. 51); k, ZMB 190183 (loc. 52); l, ZMB 190160 (loc. 42). Scale bar $=1 \mathrm{~cm}$
Glabella narrow. Lateral teeth with very large, blunt major denticles and two smaller denticles on each side as well. Marginal teeth slightly concave, tips curved and narrow, with three denticles each, the outermost cusps c. three times larger than the inner ones. One population (loc. 37) contained a specimen with a different radula morph (Fig. 23c,d), 188 rows, $12.5 \mathrm{~mm}$ long, 15.0 teeth $/ \mathrm{mm}$. See below under taxonomic remarks.
Reproductive biology: Sex ratio $0.39(n=52)$. About $92 \%$ of females $(n=31)$ carry shelled embryos in their brood pouch.

Brood pouch contains 2-15 embryos, their size can reach $4.5 \mathrm{~mm}$ (Table 3 ).

Embryonic shells (Fig. 24): Oval, with medium sized axial ribs emerging on the 2 nd to 3rd whorl. In some specimens very shallow spiral ribs emerge on third whorl. Diameter of first whorl between 245 and $306 \mu \mathrm{m}$ (Table 3). 

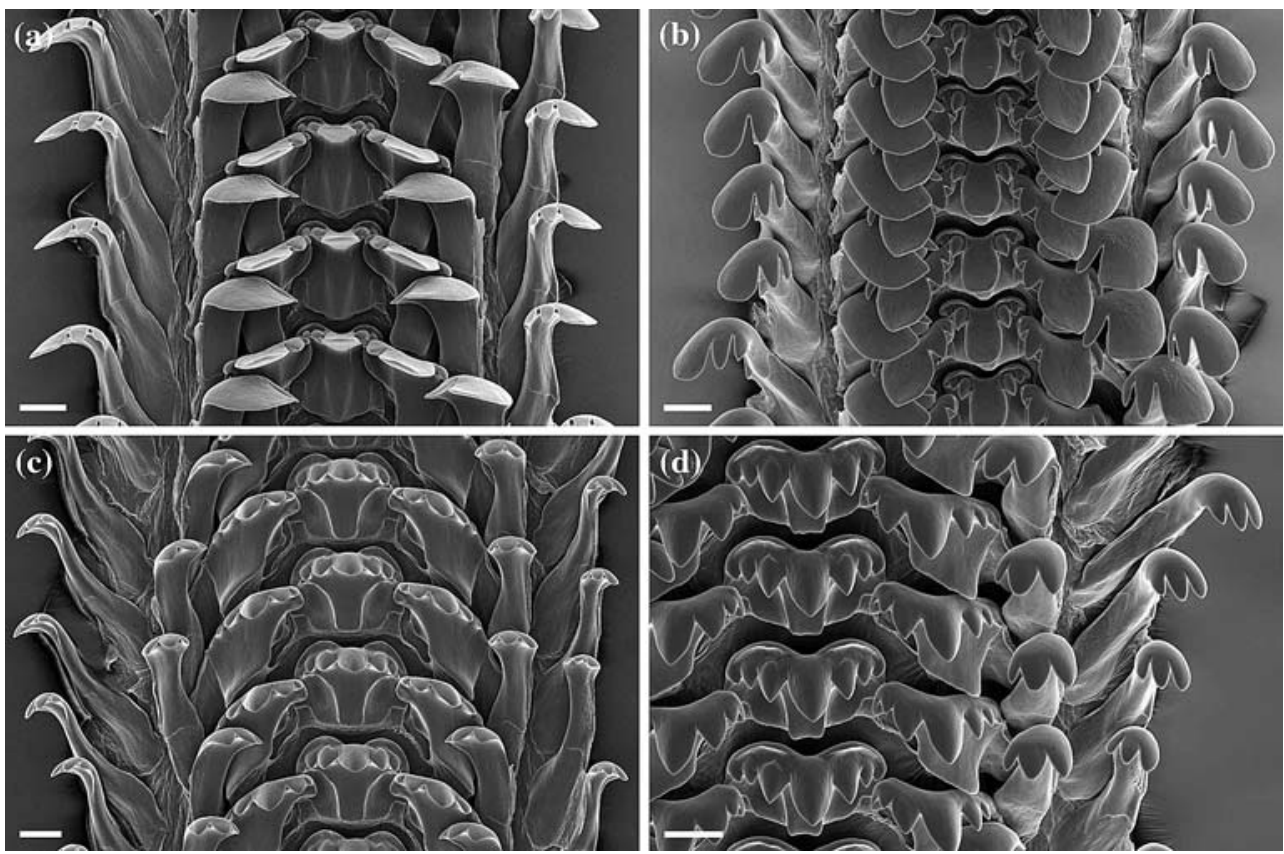

Fig. 23 T. insulaesacrae, radula. a, b, ZMB 190180 (loc. 51). a, segment, frontal; b, segment, apical (45). c, d, ZMB 190142 (loc. 37). c, segment, frontal; d, Segment, apical $\left(45^{\circ}\right)$. Scale bar $=30 \mu \mathrm{m}$
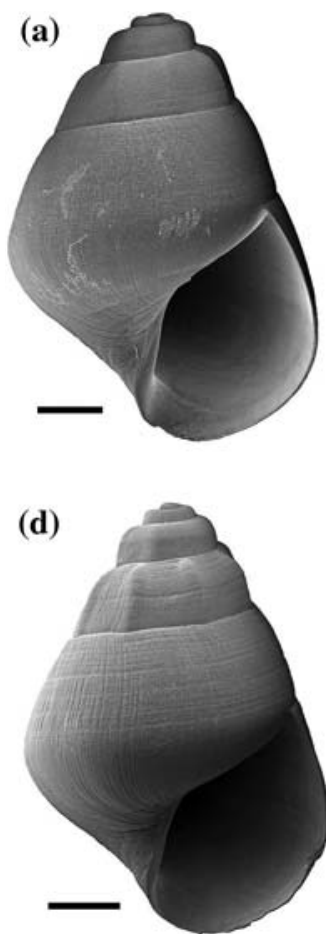

(b)

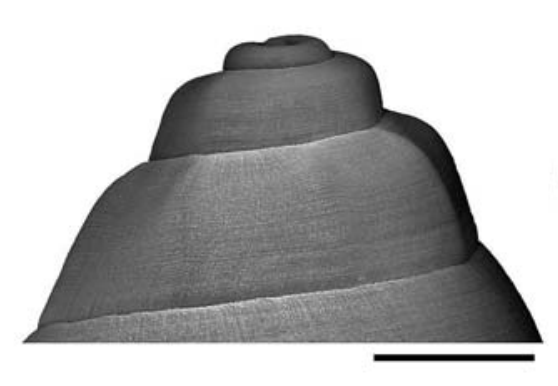

(e)

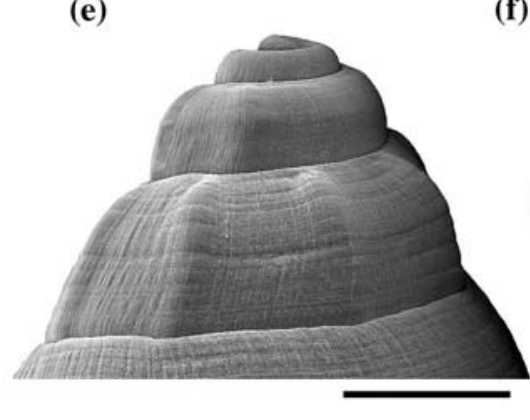

(c)

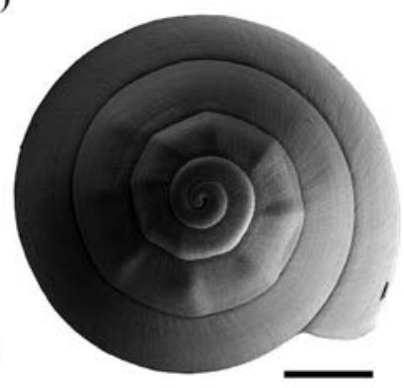

(f)

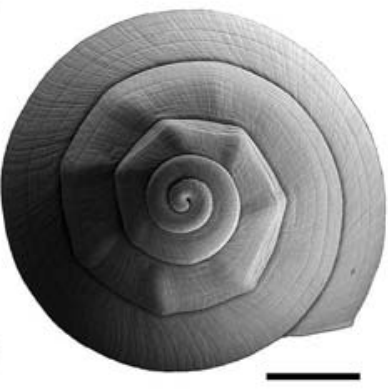

Fig. 24 T. insulaesacrae, embryonic shells. a-c, ZMB 190117 (loc. 27). a, lateral view; b, apical whorls, lateral; c, apical view. d-f, ZMB 190180 (loc. 51). d, lateral view; e, apical whorls, lateral; f, apical view. Scale bar $=0.5 \mathrm{~mm}$ 
(a)

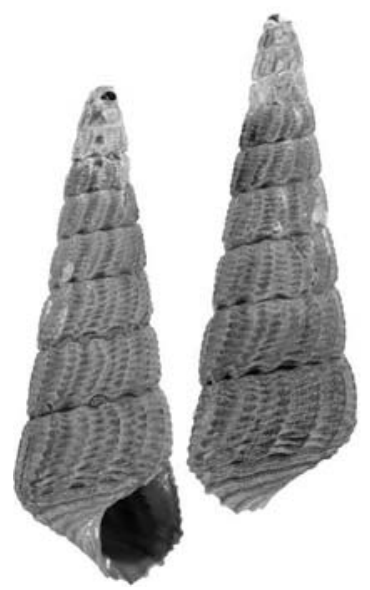

(b)

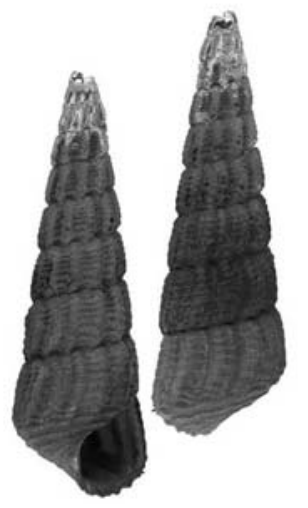

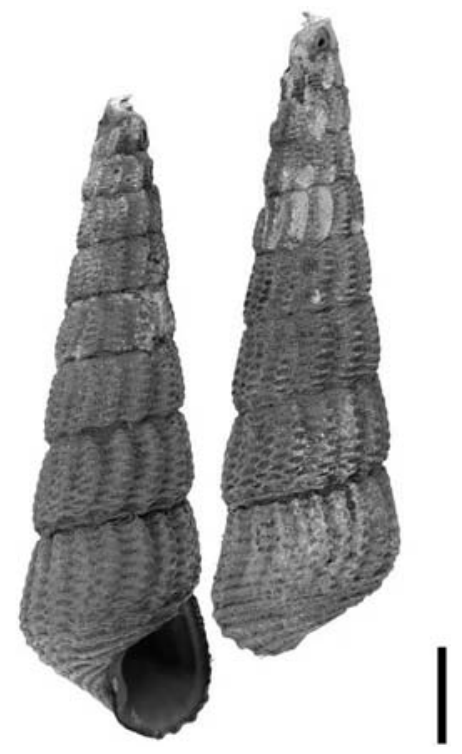

Fig. 25 T. kristinae, shells, loc. 27. a, holotype, MZB Gst. 12.105; b, paratypes, ZMB 190114. Scale bar $=1 \mathrm{~cm}$
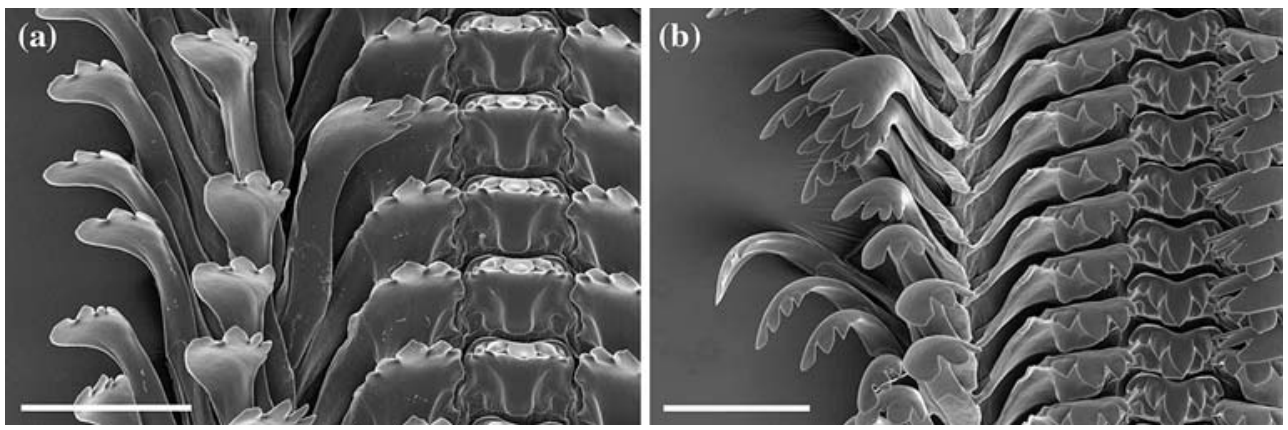

Fig. 26 T. kristinae, radula. Paratypes, ZMB 190114 (loc. 27). a, b, radula. a, segment, frontal; b, segment, apical (45). Scale bar $=0.1 \mathrm{~mm}$

\section{Distribution}

South Sulawesi, Lake Mahalona and Lake Towuti (Fig. 10).

\section{Ecology and habitat}

Hard substrate dweller, on rocks and boulders in shallow water $(0-0.5 \mathrm{~m})$.

\section{Taxonomic remarks}

Tylomelania insulaesacrae is next to T. inconspicua the smallest species in the Malili system and very distinct. Apart from its size, the almost smooth shell, the peculiar radula and the embryonic shells distinguish it from all other taxa. Variation both among and within populations is comparatively low for all examined characters. A different radula morph was found in one population only (loc. 37). Notwithstanding the possibility that studies of larger radula samples might reveal a higher degree of polymorphism, the extraordinary substrate specificity- $T$. insulaesacrae has been almost exclusively collected from rocks, and is hardly present on wood as all other hard substrate dwellers in the Malili system - might explain the encountered uniformity. Both radula 

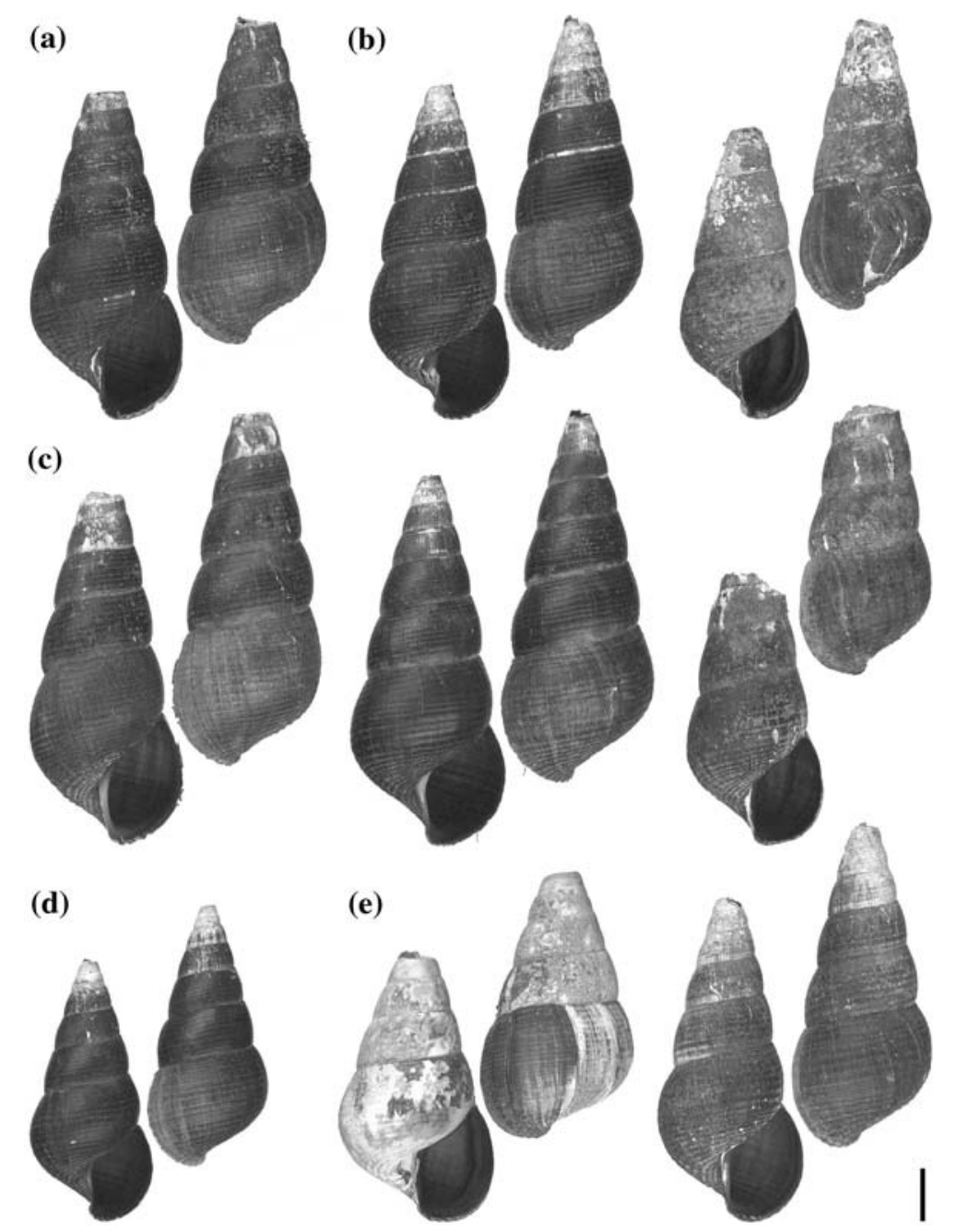

Fig. 27 T. kruimeli, shells. a, holotype, MZB Gst. 11.957 (loc. 41). b-e, paratypes. b, ZMB 190149 (loc. 39); c, ZMB 190155 (loc. 41); d, ZMB 190162 (loc. 43); e, ZMB 190158 (loc. 42). Scale bar = $1 \mathrm{~cm}$

form (compare Fig. 68) and depth preference are strongly reminiscent of the equally hard substrate dwelling T. zeamais in Lake Matano.

The only disjunct population from Lake Mahalona (loc. 42) differs only slightly from the Lake Towuti populations in having shells with a slightly more pronounced spiral sculpture. As all other characters are virtually identical, this population is considered to belong to T. insulaesacrae.

\section{Material examined}

Lake Mahalona: W-shore, Kaloa, 02³6.0' S, $121^{\circ} 29.6^{\prime} \mathrm{E}$, loc. MHL2 (MNHN, $\left.n=1\right)$; NW- shore, $02^{\circ} 34.86^{\prime} \mathrm{S}, 121^{\circ} 28.62^{\prime} \mathrm{E}$, Loc. 42 (ZMB $190160 n=13$; all in alc.).

Lake Towuti: N-shore, W of Tominanga River, 02'39.3' S, 121 $29.7^{\prime} \mathrm{E}$, loc. TW1 (MNHN, $n=1117 ; n=54$ in alc.); $\mathrm{N}$ shore, shallow bay W of mouth of Tominanga River, TW2 (MNHN, $n=13)$; N-shore, cape $\mathrm{E}$ of Tominanga River, 02³9.9' S, 121 $2^{\circ} 34.5^{\prime} \mathrm{E}$, loc. TW4 (MNHN, $n=116 ; n=6$ in alc.); N-shore, Topimanu Peninsula, $02^{\circ} 41.9^{\prime} \mathrm{S}, 121^{\circ} 38.5^{\prime} \mathrm{E}$, TW8 (MNHN, $n=38$ in alc.); Loeha Island, W-shore, 0245.49’ S, $121^{\circ} 30.93^{\prime} \mathrm{E}$, Loc. 27 (MZB Gst. $12.271 n=87$; ZMB $190117 n=105$; all in alc.); Loeha Island, N-shore, $02^{\circ} 45.60^{\prime} \mathrm{S}, 121^{\circ} 33.54^{\prime} \mathrm{E}$, 

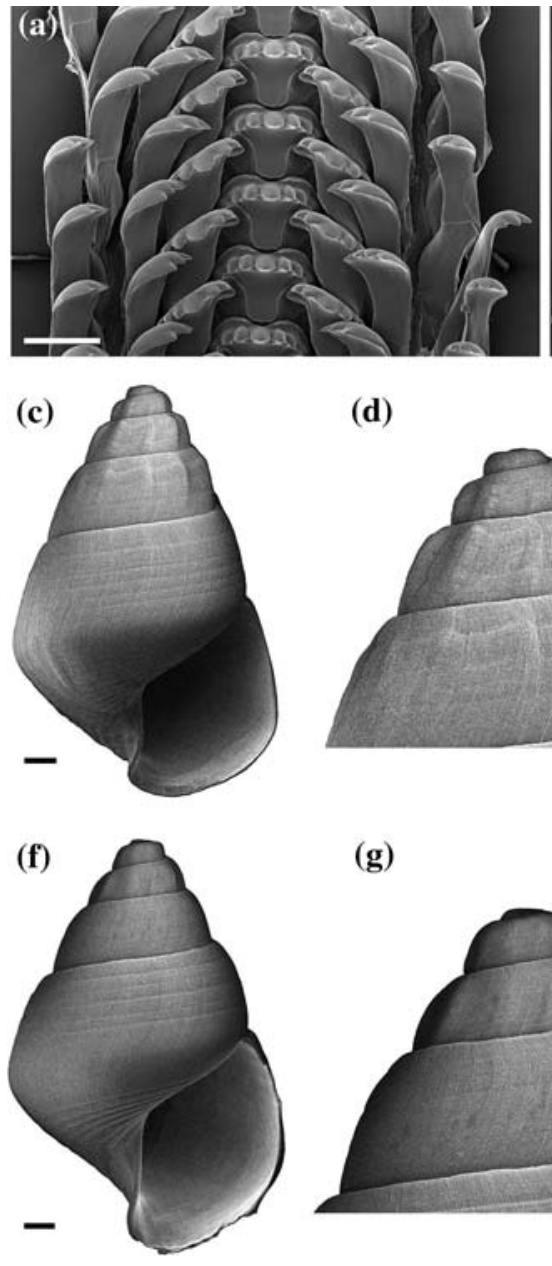

Fig. 28 T. kruimeli, radula and embryonic shells. a, b, radula, ZMB 190152 (loc. 40). a, segment, frontal; b, segment, apical $\left(45^{\circ}\right)$. Scale bar $=0.1 \mathrm{~mm}$. c-h, embryonic shells. c-e, ZMB 190152 (loc. 40). c, lateral view; d, apical

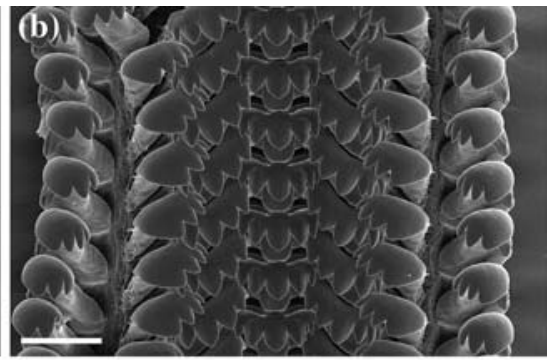

(e)

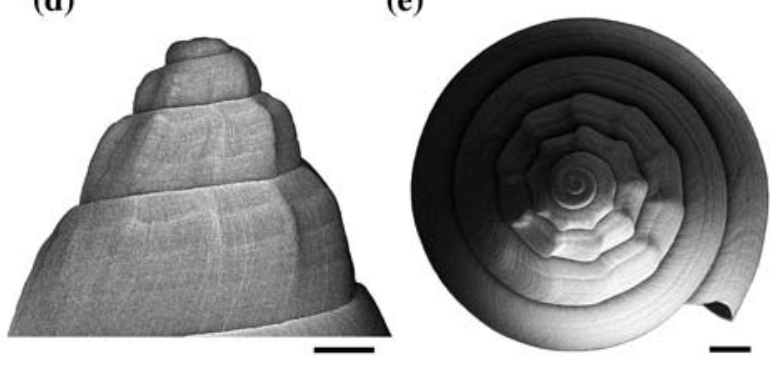

(g)

(h)
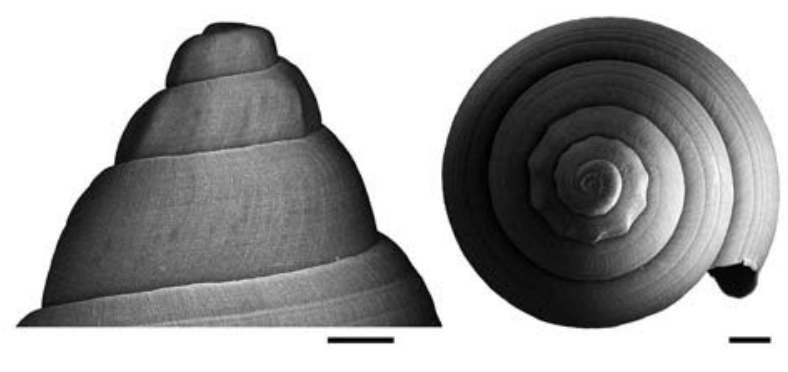

whorls, lateral; e, apical view. f-h, ZMB 190155 (loc. 41); f, lateral view; $\mathbf{g}$, apical whorls, lateral; h, apical view. Scale bar $=0.5 \mathrm{~mm}$
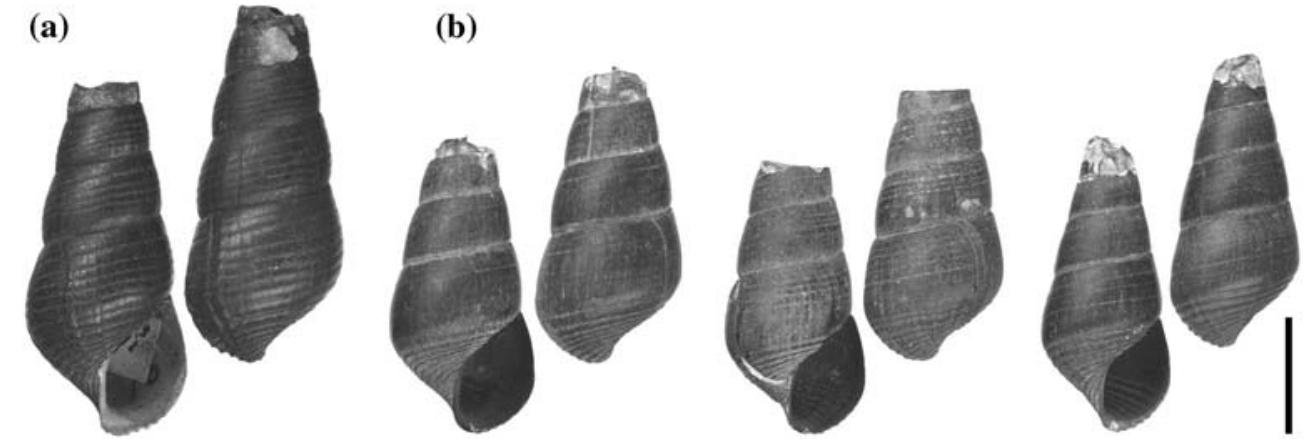

Fig. 29 T. lalemae, shells. Types, ZMA (Lake Towuti). a, lectotype; $\mathbf{b}$, paratypes. Scale bar $=1 \mathrm{~cm}$ 

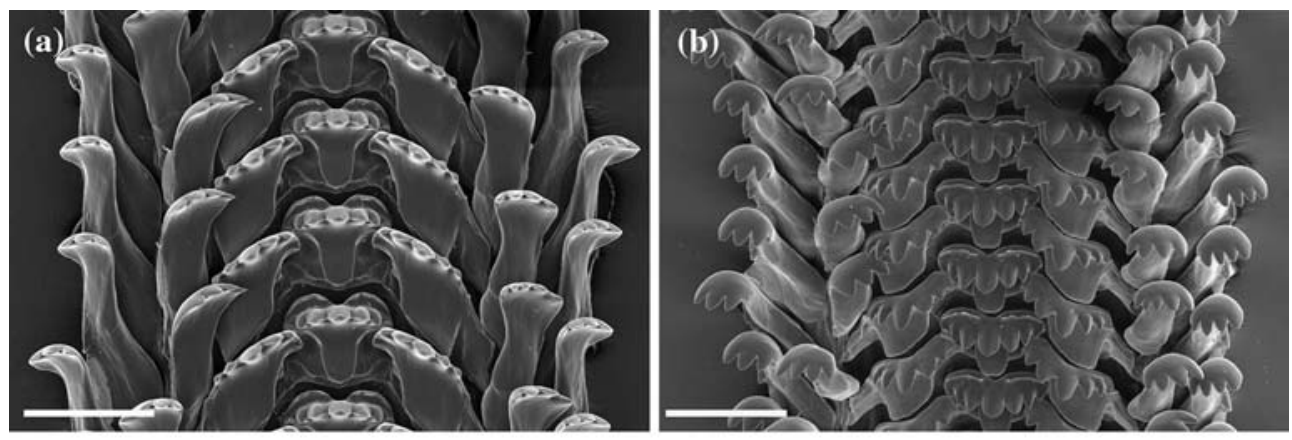
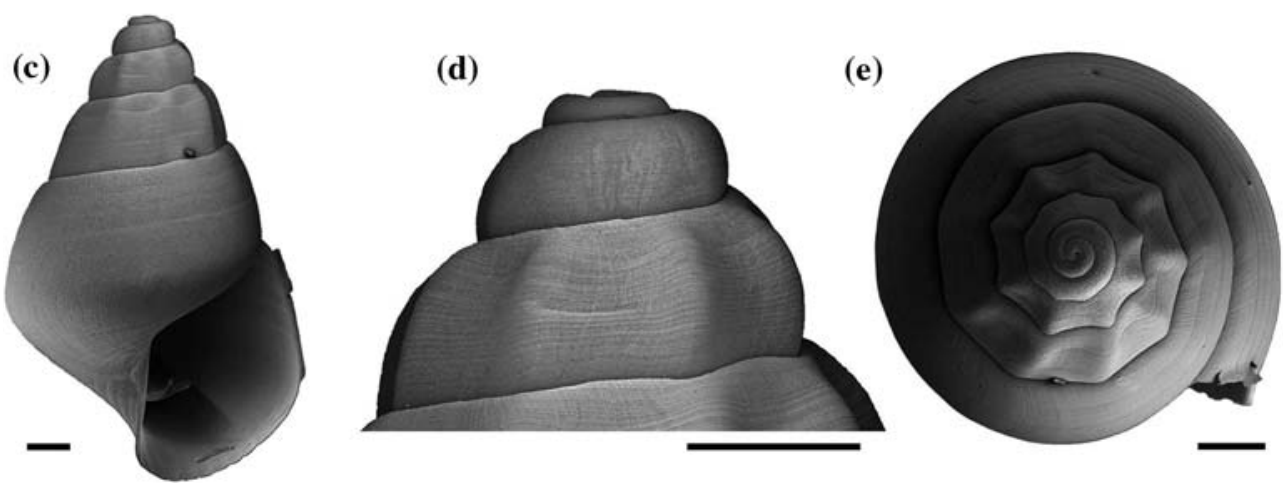

e)

embryonic shells. c, lteral view; d, apical whorls, lateral; e, apical view. Scale bar $=0.5 \mathrm{~mm}$ types, ZMA (Lake Towuti). a, b, radula. a, segment, frontal; b, segment, apical $\left(45^{\circ}\right)$. Scale bar $=0.1 \mathrm{~mm}$. $\mathbf{c}-\mathbf{e}$,

Loc. 33 (ZMB $190130 n=30$, in alc.); W-shore, $\mathrm{W}$ of Cape Sioloya, 02 ${ }^{\circ} 50.74^{\prime}$ S, 121 ${ }^{\circ} 26.09^{\prime}$ E, Loc. 29 (MZB Gst. $12.273 n=38$; ZMB $190122 n=54$; all in alc.); W-shore, Cape Bakara, 02 $40.76^{\prime} \mathrm{S}$, $121^{\circ} 26.09^{\prime}$ E, Loc. 34 (MZB Gst. $12.274 n=65$; ZMB $190133 n=114$; all in alc.); W-shore, cape S of Cape Bakara, 02 ${ }^{\circ} 41.32^{\prime} \mathrm{S}, 121^{\circ} 25.99^{\prime} \mathrm{E}$, Loc. 35 (ZMB $190359 n=4$, in alc.); W-shore, Cape Rumbia, 02 $43.36^{\prime} \mathrm{S}, 121^{\circ} 27.85^{\prime} \mathrm{E}$, Loc. 37 (MZB Gst. $12.276 n=127$; ZMB $190142 n=129$; all in alc.); N-shore, $02^{\circ} 39.36^{\prime} \mathrm{S}, 121^{\circ} 29.80^{\prime} \mathrm{E}$, Loc. 49 (MZB Gst. $12.277 n=48$; ZMB $190173 n=87$; all in alc.); N-shore, $02^{\circ} 41.67^{\prime} \mathrm{S}, 121^{\circ} 36.83^{\prime} \mathrm{E}$, Loc. 51 (ZMB $190180 n=38$, in alc.); Anue Island, $02^{\circ} 47.20^{\prime} \mathrm{S}, 121^{\circ} 30.59^{\prime} \mathrm{E}$, Loc. 52 (MZB Gst. $12.279 n=91$; ZMB $190183 n=91$; all in alc.).

\section{Tylomelania kristinae new species}

Type material: Lake Towuti: Loeha Island, Wshore, $02^{\circ} 45.49^{\prime} \mathrm{S}, 121^{\circ} 30.93^{\prime} \mathrm{E}$, loc. 27 . Holotype (Fig. 25a; $50.6 \mathrm{~mm} \times 17.2 \mathrm{~mm}$; MZB Gst.
12.105). Paratypes (Fig. 25b); MZB Gst. 12.106, $n=2$; ZMB 190114, $n=6$; all in alc.).

Etymology: T. kristinae has been named after Kristina von Rintelen (Berlin), who greatly contributed to the success of several field trips 20022005 to Sulawesi and the Malili lakes in particular.

\section{Description}

Shell (Fig. 25): Medium sized, yellowish to light brown, usually highly turreted, spire angle $17-17^{\circ}$, top whorls in adult specimens always corroded to a varying degree, $8-9$ remaining whorls, can reach up to $50.6 \mathrm{~mm}$ (Table 2). Comparatively few strong, straight or mildly curved axial ribs per whorl, almost always inclined, 12-14 on body whorl. Spiral ribs weak. Aperture with light brown interior and white outer margin.

External morphology: Headfoot black with few fine white dots, tentacles striped, mantle edge smooth or slightly serrated. Body coiled in 2.5-3 whorls. 

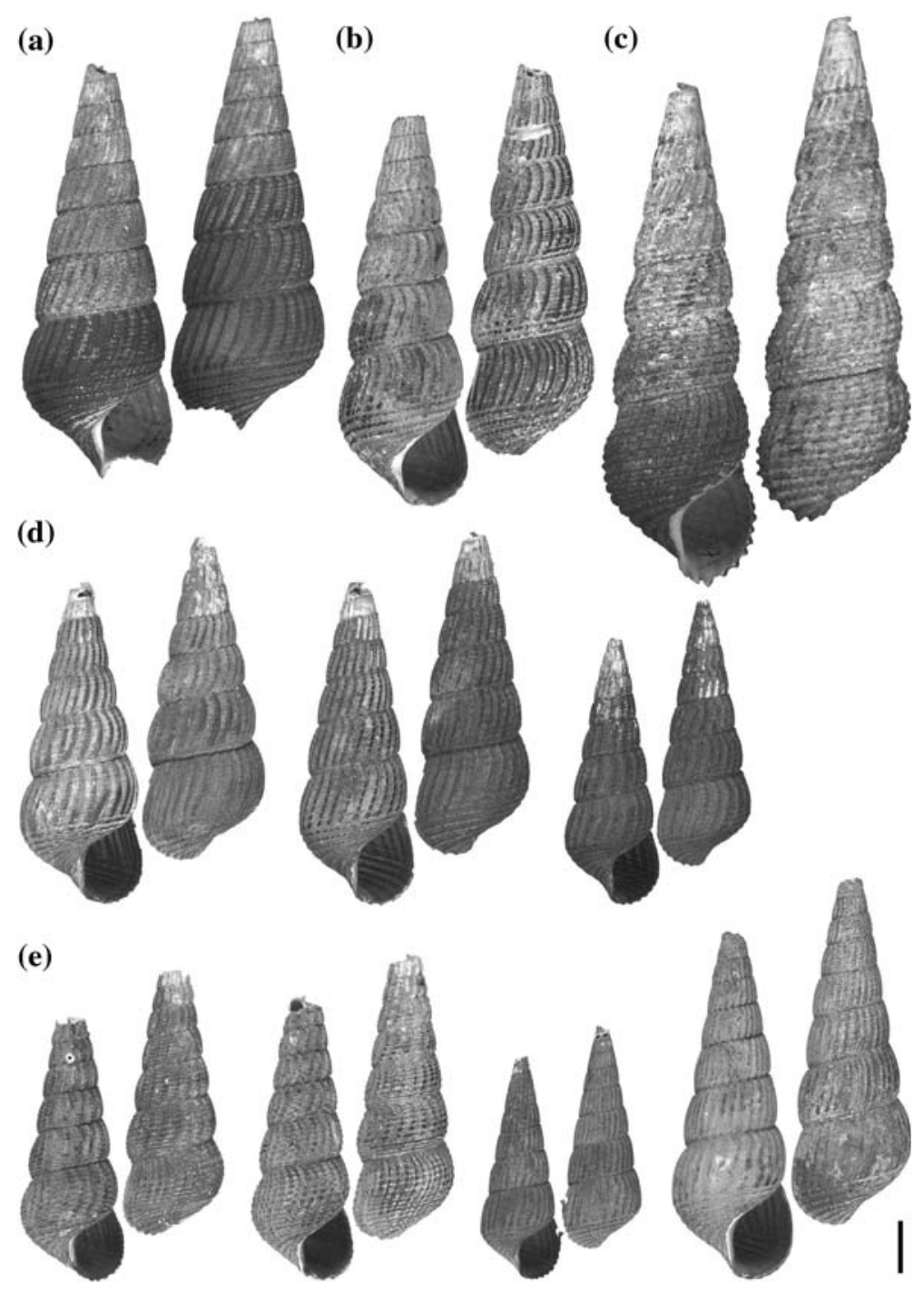

Fig. 31 T. mahalonensis, shells. a, b, types, ZMA (Lake Mahalona). a, lectotype; b, paralectotypes. c, lectotype of T. mahalonica. d, ZMB 190146 (loc. 38); e, ZMB 190167 (loc. 39). Scale bar $=1 \mathrm{~cm}$

Operculum (Fig. 7h): almost round, last whorl inflated, multispiral, with 5 whorls.

Radula (Fig. 26a, b): Typically highly modified, appears thiarid-like, 148-158 rows, $8.0-8.7 \mathrm{~mm}$ long, on average 18.1 teeth $/ \mathrm{mm}$ $(n=3)$. Central tooth with larger, pointed major denticle, accompanied by two smaller denticles at each side of it. Glabella narrow; Lateral teeth with enlarged major denticles and two smaller denticles on each side as well. Marginal teeth straight at base, upper half widely curved, with $3-4$, usually three, denticles, the outermost ones sometimes twice wider than the inner ones.

Reproductive biology and embryonic shells: No data available, only males present among dissected animals.

\section{Distribution}

South Sulawesi, Lake Towuti, Loeha Island (Fig. 9). 


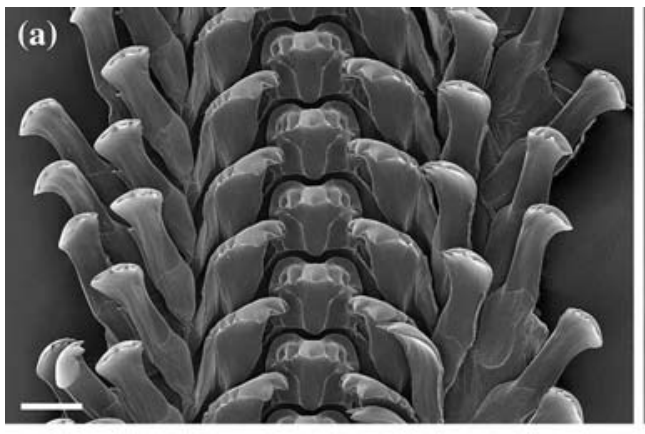

(c)

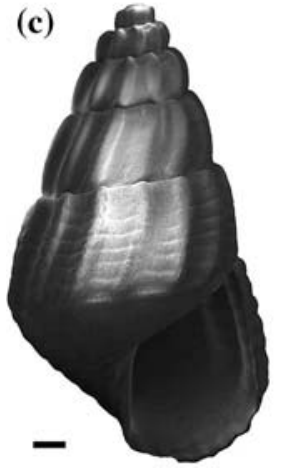

Fig. 32 T. mahalonensis, radula and embryonic shells. a, b, radula, ZMB 190167 (loc. 39); a, segment, frontal; b, Segment, apical $\left(45^{\circ}\right)$. Scale bar $=0.1 \mathrm{~mm}$. $\mathbf{c}-\mathbf{e}$, embryonic

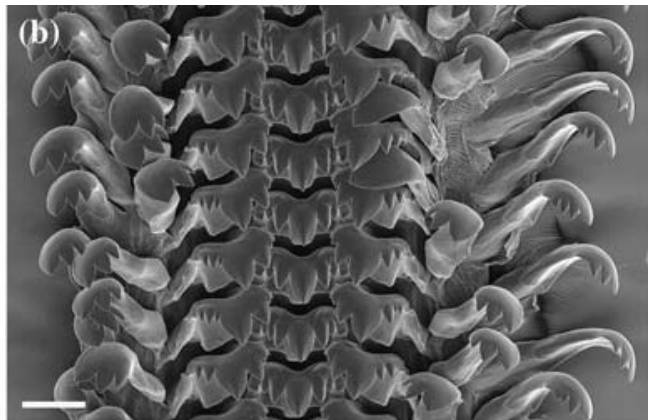

(e) (a)

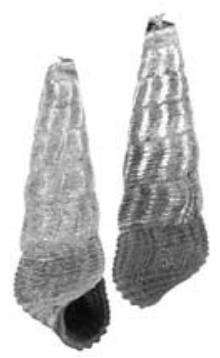

(b)

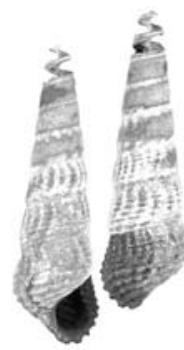

(d)

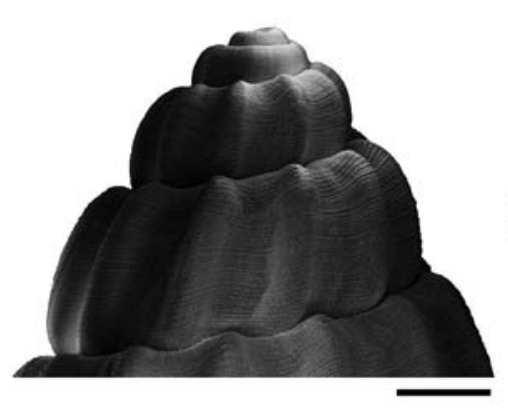

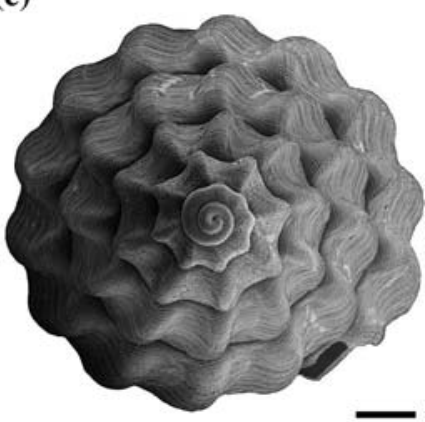

shells, ZMB 190154 (loc. 41). c, lateral view; d, apical whorls, lateral; e, apical view. Scale bar $=0.5 \mathrm{~mm}$

Fig. 33 T. marwotoae, shells. a, holotype, MZB Gst. 12.319; b, c, paratypes. b, ZMB 190163 (loc. 44); c, MNHN (MHL 2). Scale bar $=1 \mathrm{~cm}$

\section{Ecology and habitat}

On soft substrate, syntop with T. towutensis, less abundant.

\section{Taxonomic remarks}

The shell of Tylomelania kristinae is very characteristic due to its slender form in combination with the prominent wide-spaced axial ribs, colour and pattern of the aperture. This distinctiveness and the syntopic occurence with $T$. towutensis prompted the description of this new species despite the rather small sample size. The shells of Tylomelania kristinae vaguely resemble those of T. gemmifera in Lake Matano and T. wolterecki in Lake Mahalona by possessing strong axial ribs and being highly turreted. The most striking 

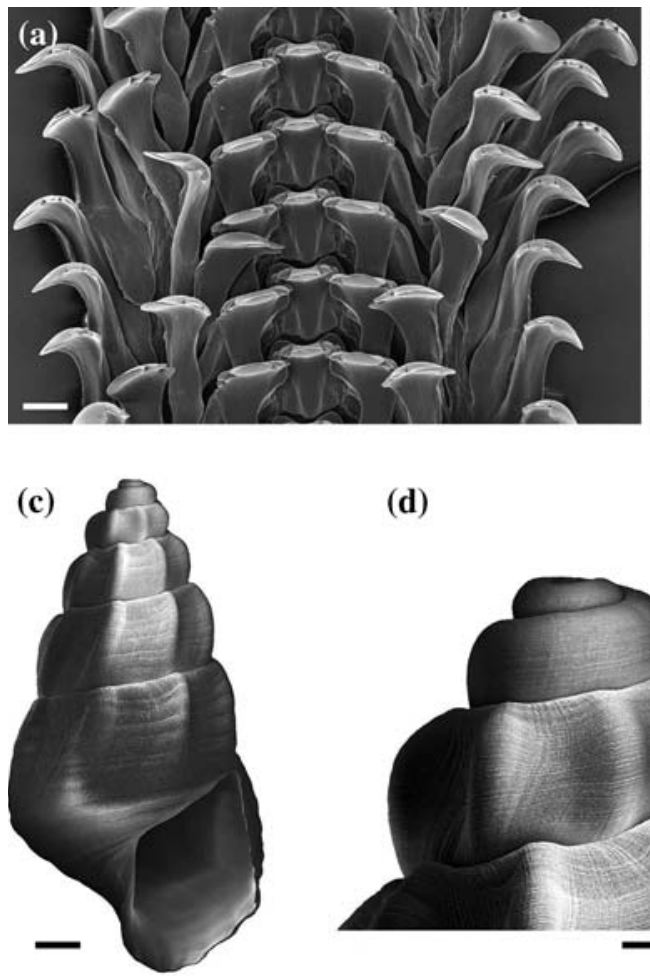

(d)

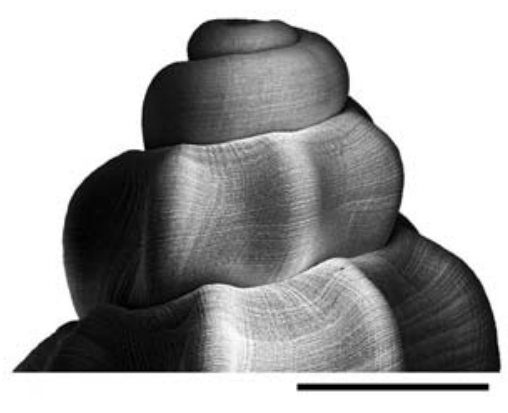

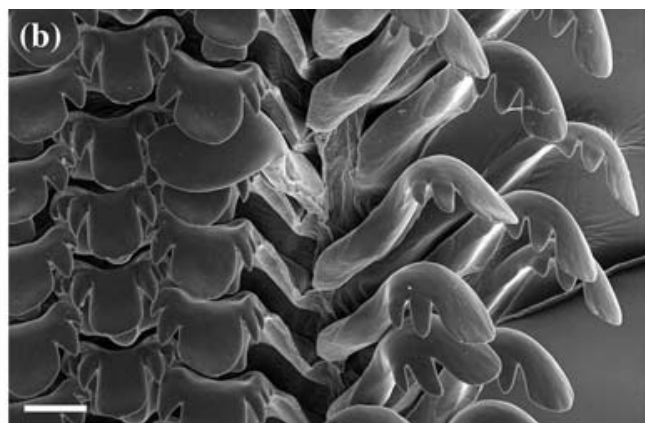

(e)

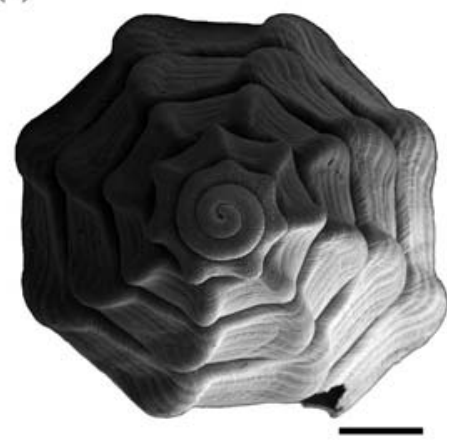

Fig. $34 T$. marwotoae, radula and embryonic shells. Paratypes, ZMB 190163 (loc. 44). a, b, radula. a, segment, frontal; b, segment, apical $\left(45^{\circ}\right)$. Scale bar $=30 \mu \mathrm{m}$. $\mathbf{c}-\mathbf{e}$,

resemblance is found in the almost thiarid-like radula shared by all three species, however (cf. Figs. 18, 66). The similarities in substrate preference, radula and shell morphology are suggestive of a common origin of the three taxa (see also remarks on the other two species).

\section{Tylomelania kruimeli Rintelen \& Glaubrecht, 2003}

Tylomelania kruimeli Rintelen \& Glaubrecht, 2003: 8, Figs. 10-12 (Lake Mahalona, NE corner, $02^{\circ} 33.87^{\prime} \mathrm{S}, 121^{\circ} 30.68^{\prime} \mathrm{E}$, loc. 41 ; holotype, MZB Gst. 11.959, in alc.; 25 paratypes, MZB 11.962; 53 paratypes, ZMB 190155; all in alc.; Lake Mahalona: E-shore, at promontory, $02^{\circ} 35.58^{\prime} \mathrm{S}$, $121^{\circ} 30.68^{\prime}$ E, loc. 39; 32 paratypes, MZB 11.960; 36 paratypes, ZMB 190149; all in alc.; E-shore, mouth of Petea River, $02^{\circ} 34.37^{\prime} \mathrm{S}, 121^{\circ} 30.53^{\prime} \mathrm{E}$, loc. 40; 2 paratypes, ZMB 190152; all in alc.; Nshore, $02^{\circ} 34.86^{\prime} \mathrm{S}, 121^{\circ} 28.62^{\prime} \mathrm{E}$, loc. $42 ; 10$ embryonic shells. c, lateral view; d, apical whorls, lateral; e, apical view. Scale bar $=0.5 \mathrm{~mm}$

paratypes, MZB 11.963; 17 paratypes, ZMB 190158; all in alc.; W-shore, 02³5.64' S, $121^{\circ} 28.52^{\prime} \mathrm{E}$, loc. 43; 3 paratypes, MZB 11.964; 8 paratypes, ZMB 190162; all in alc.; W-shore, Kaloa, 02 ${ }^{\circ} 36.0^{\prime}$ S, $121^{\circ} 29.6^{\prime}$ E, loc. MHL2; 44 and 29 (in alc.) paratypes, MNHN).

\section{Description}

Shell (Fig. 27): Medium sized, brown, conic, spire angle $18-39^{\circ}$, top whorls in adult specimens always corroded to a varying degree, 4-9 remaining whorls, can reach up to $69.3 \mathrm{~mm}$ (Table 2). Almost smooth, with spiral striae. Aperture oval, pointed at top and slightly siphonated at base.

External morphology: Headfoot black, mantle edge smooth or slightly serrated. Body coiled in 2-3.5 whorls

Operculum (Fig. 7i): roughly diamond shaped or ovate, multispiral, with 7-9 whorls. 


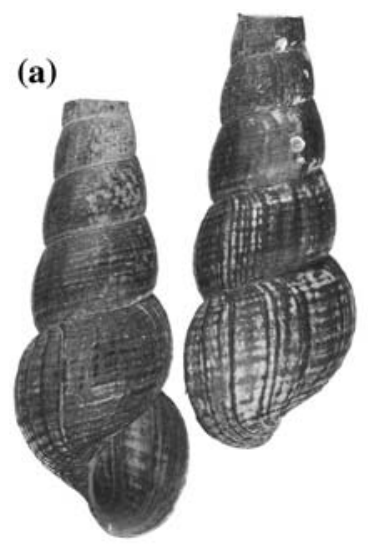

(b)

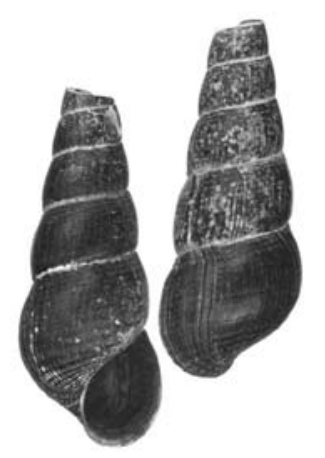

(c)

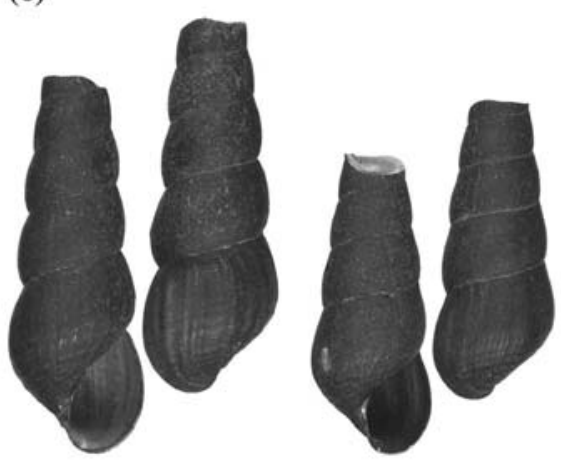

(d)

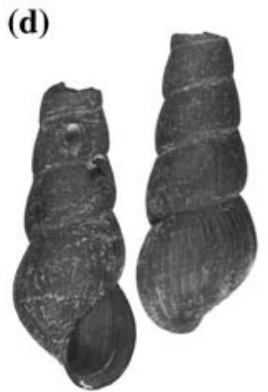

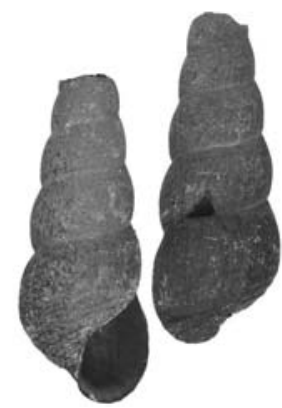
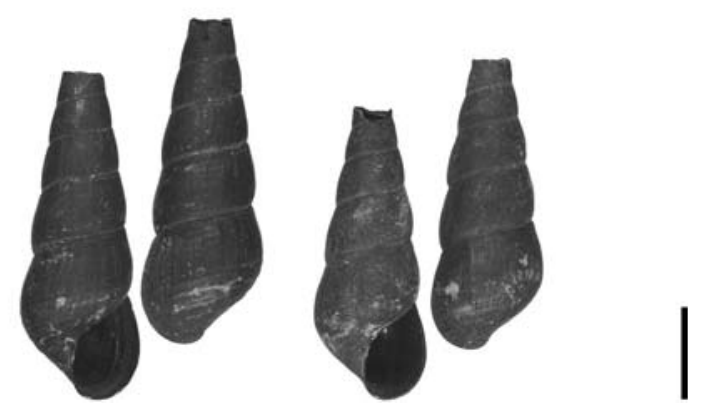

Fig. 35 T. masapensis, shells. Lake Masapi. a, b, types, ZMA. a, lectotype; b, paralectotype. c, MNHN; d, ZMB 190208 (loc. 0026). Scale bar $=1 \mathrm{~cm}$

Radula (Fig. 28a, b): 214-257 rows, 18.5$22.3 \mathrm{~mm}$ long, on average 11.3 teeth $/ \mathrm{mm}(n=4)$. Central tooth with larger, pointed major denticle, accompanied by two smaller denticles at each side of it. Lateral teeth with enlarged major denticles and two smaller denticles on each side as well. Marginal teeth shovel-like, inner marginals with 4-5 denticles, the outermost one double as wide as the inner ones. Outer marginals with 3-4 denticles, the outermost one is slightly enlarged.

Reproductive biology: Sex ratio $0.49(n=51)$. Males are highly significantly smaller than females (ANOVA, last three whorls: $F=8.89, P=0.002$, $n=60)$. About $90 \%$ of females $(n=24)$ carry shelled embryos in their brood pouch.

Brood pouch contains 2-14 embryos, their size can reach $11 \mathrm{~mm}$ (Table 3 ).

Embryonic shells (Fig. 28c-e): Ovate to conic, with strong axial ribs emerging on the third whorl and fading on the fourth whorl. Shallow, widespaced spiral ribs emerging on 2nd to 3rd whorl. Diameter of first whorl between 237 and $367 \mu \mathrm{m}$ (Table 3).

\section{Distribution}

Lake Mahalona (Fig. 10).

\section{Ecology and habitat}

Hard substrate dweller, on rocks, sunken wood and Pandanus roots. Occurs from the surface down to a depth of several meters. Occasionally syntopic with $T$. confusa. Interestingly, $T$. sarasinorum is lacking in Lake Mahalona and T. kruimeli occupies the same habitat as the former in Lake Towuti.

\section{Taxonomic remarks}

Very distinct and homogenous species, vaguely resembles $T$. sarasinorum, but has a much thinner and more fragile shell. In contrast to $T$. sarasinorum the shell structure consists of fine spiral striae instead of spiral ribs. The embryonic shells are similar to those of $T$. sarasinorum, but more 

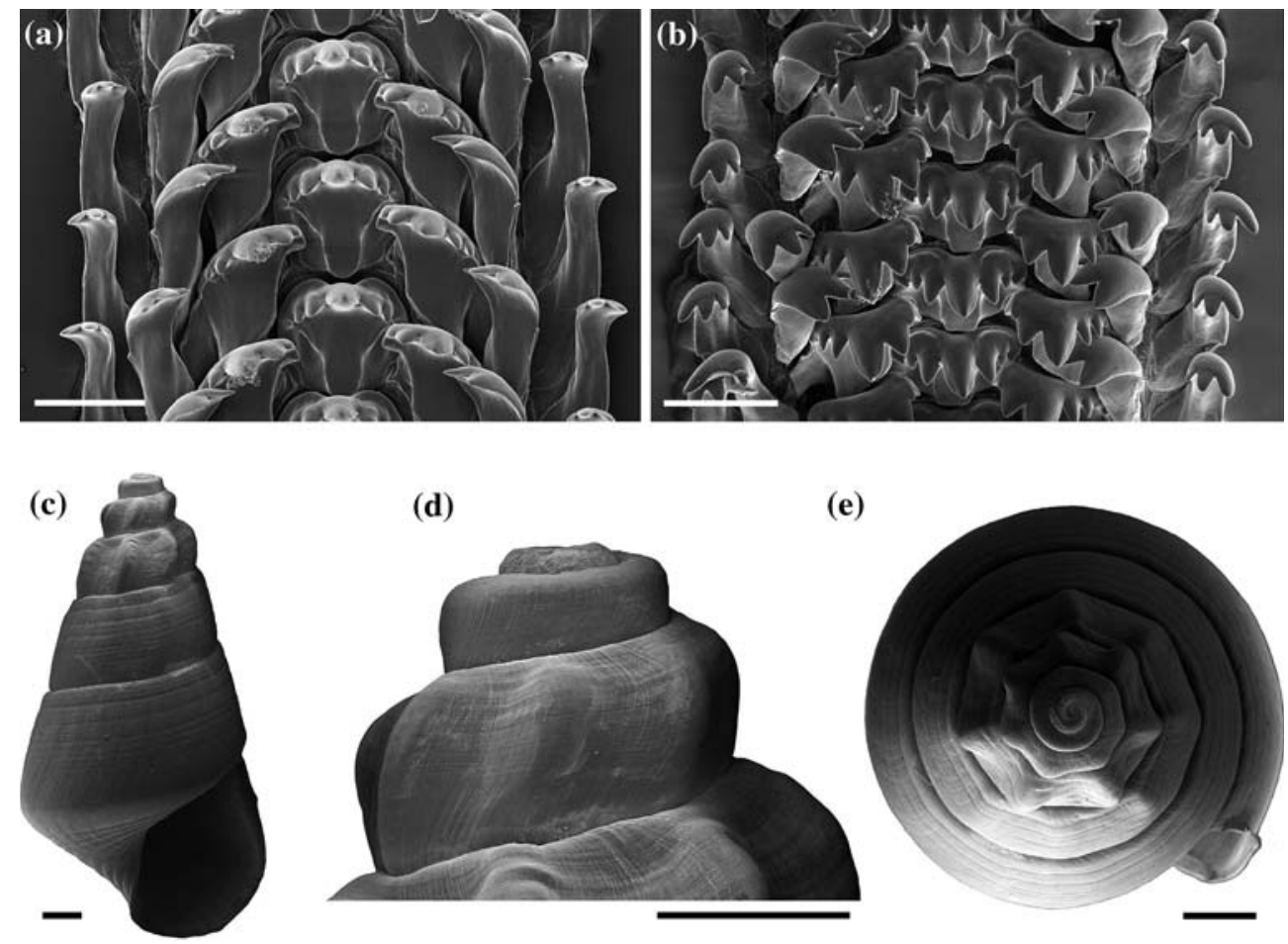

(d)

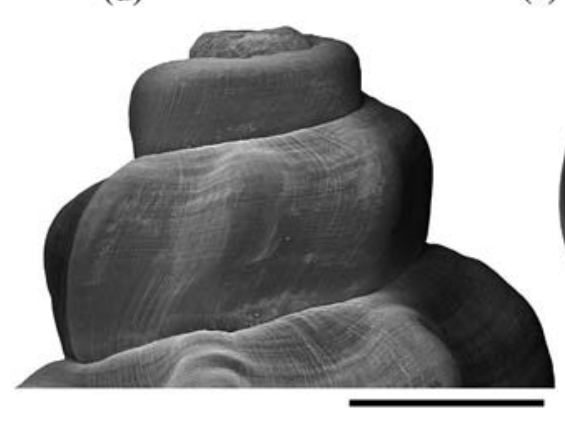

(e)

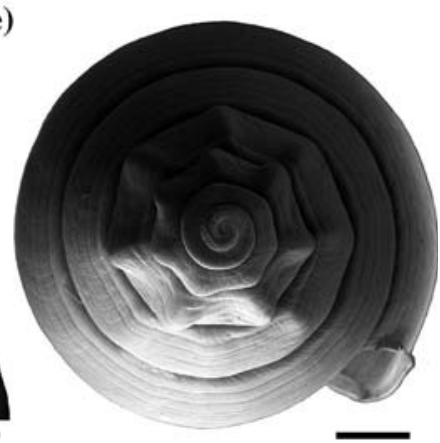

Fig. 36 T. masapensis, radula and embryonic shells, ZMB 190208 (loc. 0026). a, b, radula. a, segment, frontal; b, segment, apical $\left(45^{\circ}\right)$. Scale bar $=0.1 \mathrm{~mm}$. c-e, embryonic shells. c, lateral view; d, apical whorls, lateral; e, apical view. Scale bar $=0.5 \mathrm{~mm}$

External morphology: Headfoot black with sparse white blotches, mantle edge slightly serrated. Body coiled in three whorls.

Operculum (Fig. 7k): ovate, multispiral, with 7-8 whorls.

Radula (Fig. 30a, b): 182 rows, $11.8 \mathrm{~mm}$ long, 15.4 teeth $/ \mathrm{mm}$. Central tooth with larger, pointed major denticle, accompanied by two smaller denticles at each side of it. Lateral teeth with enlarged major denticles and two smaller denticles on each side as well. Marginal teeth shovel-like, the outermost one twice as long as the inner ones.

Reproductive biology: Brood pouch contains 26 embryos, max. size $7.5 \mathrm{~mm}$ (Table 3).

Embryonic shells (Fig. 30c-e): Conic, with strong axial ribs emerging on the second whorl and fading on the fifth whorl. Shallow, widespaced spiral ribs emerge on third whorl. Protoconch height $52 \mu \mathrm{m}$, width $90 \mu \mathrm{m}$, diameter of first whorl $267 \mu \mathrm{m}$. 

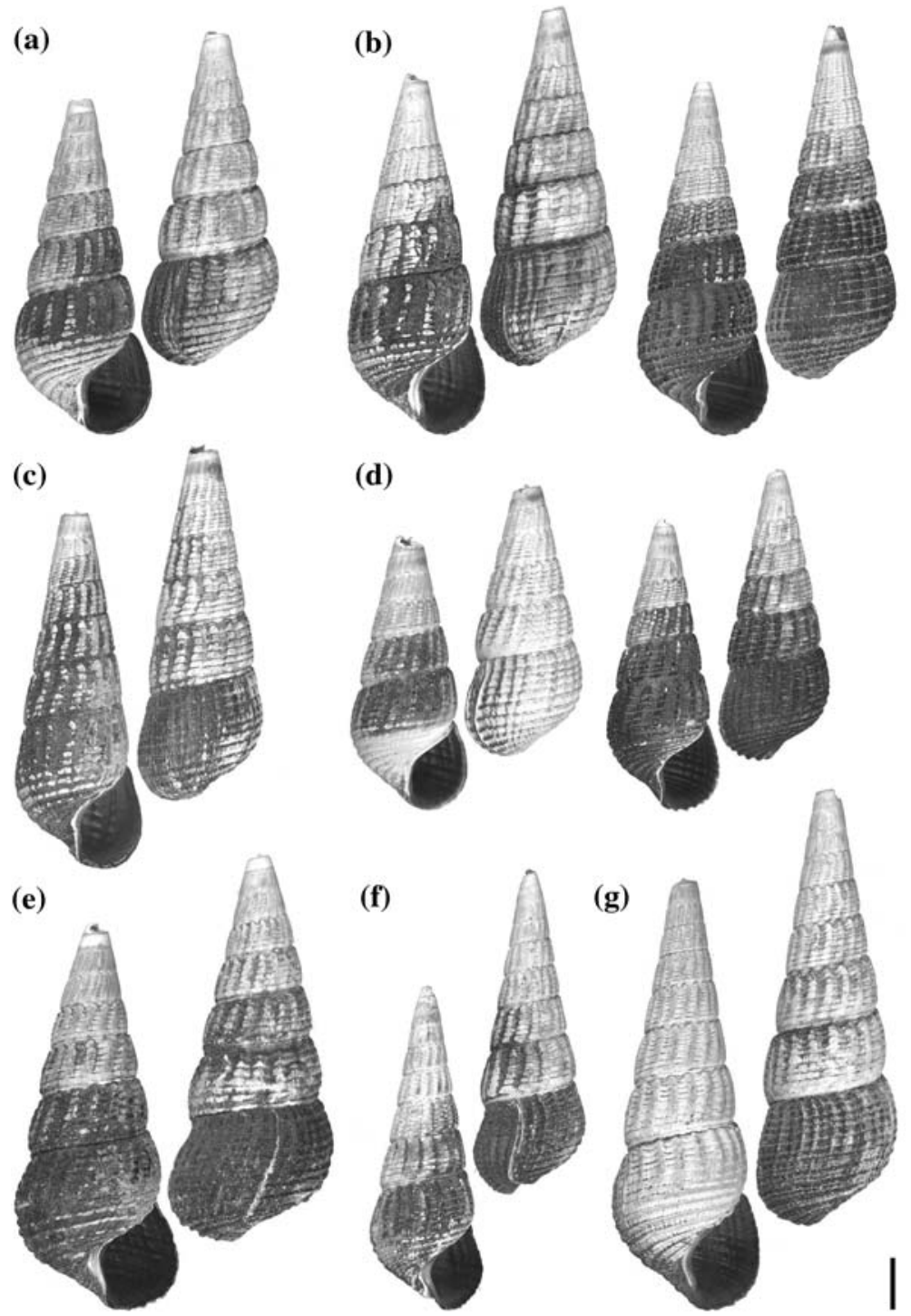

Fig. 37 T. matannensis, shells. a, holotype, MZB Gst. 12.309 (loc. 22). b-g, paratypes. b, ZMB 190109 (loc. 55); c, ZMB 190094 (loc. 19); d, ZMB 190097 (loc. 20); e, ZMB

190071 (loc. 13); f, ZMB 190100 (loc. 21); g, ZMB 190105 (loc. 23). Scale bar $=1 \mathrm{~cm}$

\section{Systematic remarks}

South Sulawesi, Lake Towuti.

This species is only known from the type series. Ecology and habitat

$T$. lalemae has a rather distinct shell and has been tentatively regarded as a valid species.

No information available. New material is needed to verify this status, though. 

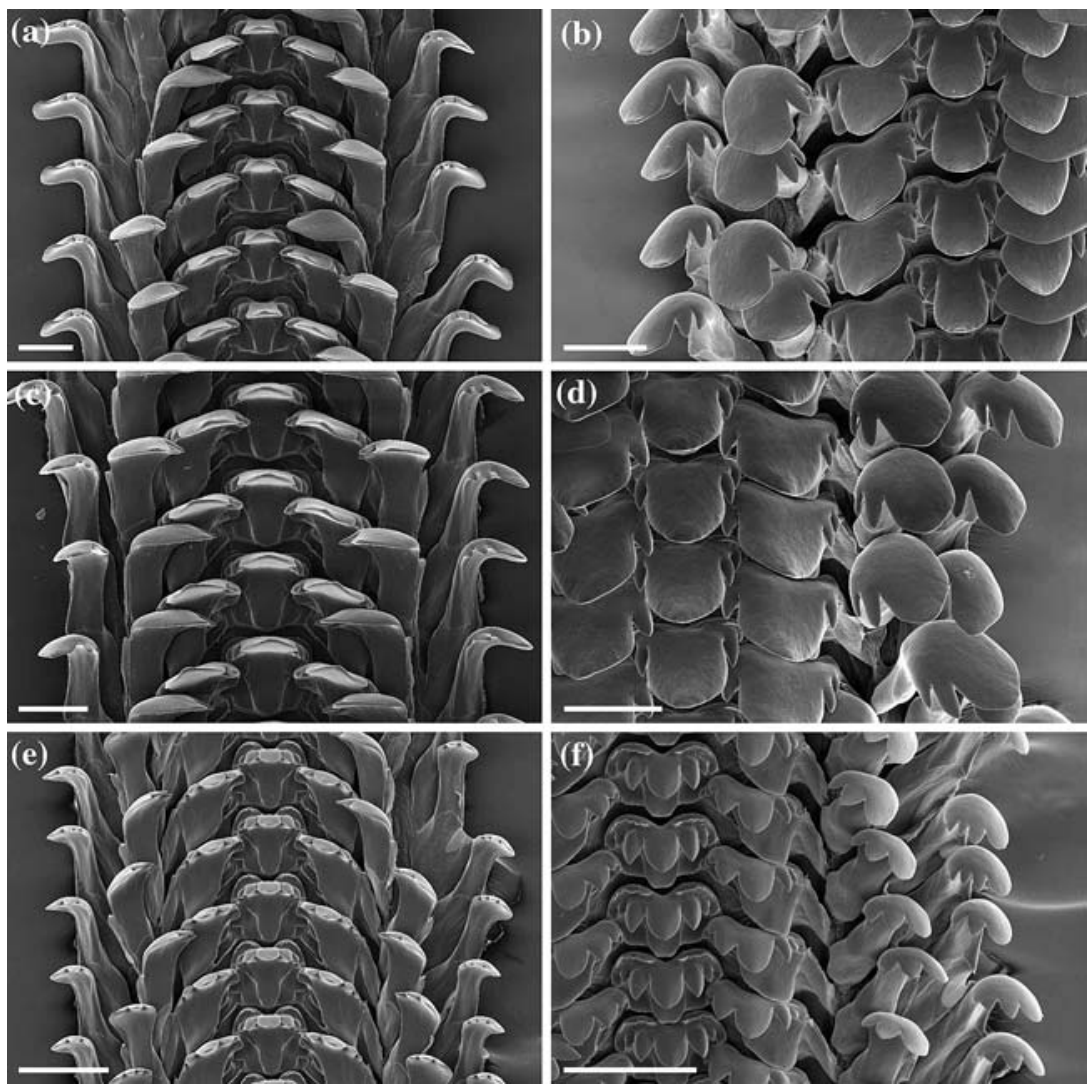

Fig. 38 T. matannensis, radula. Paratypes. a, b, ZMB 190103 (loc. 22). a, segment, frontal; b, segment, apical (45). c, d, ZMB 190094 (loc. 19). c, segment, frontal; d,

\section{Tylomelania mahalonensis (Kruimel, 1913)}

Melania mahalonensis Kruimel, 1913: 222, pl. 4 Fig. 12. (Lake Mahalona; lectotype, present designation, ZMA; 17 and 13 (in alc.) paralectotypes, ZMA; 2 paralectotypes, MCZ 65143).

Melania mahalonica Kruimel, 1913: 221, pl. 4 Fig. 11. (Lake Mahalona; lectotype ZMA, 9 and 10 (in alc.) paralectotypes ZMA; 3 paralectotypes, MCZ 53569).

\section{Description}

Shell (Fig. 31): Medium sized to large, light brown to black, highly turreted, spire angle 14 $26^{\circ}$, top whorls in adult specimens always corroded to a varying degree, 4-10 remaining whorls, can reach up to $80.7 \mathrm{~mm}$ (Table 2). Axial ribs fine to medium sized, always curved to a varying

segment, apical $\left(45^{\circ}\right)$. e, f, ZMB 190100 (loc. 21). e, segment, frontal; f, segment, apical $\left(45^{\circ}\right)$. Scale bar $=0.1$ $\mathrm{mm}$

degree, on older whorls often just inclined, usually narrow-spaced, 19-42 on body whorl. Spiral ribs weak. Aperture oval, pointed at top and slightly siphonated at base.

External morphology: Headfoot with yellowish-orange dots or blotches, tentacles with orange stripes, mantle edge slightly serrated. Body coiled in 2.5-3 whorls.

Operculum (Fig. 71): Almost round and multispiral, with 8-9 whorls.

Radula (Fig. 32a, b): 176-217 rows, 14.2$19.5 \mathrm{~mm}$ long, on average 11.5 teeth $/ \mathrm{mm}$ $(n=5)$. Central tooth with larger, pointed major denticle, accompanied by two smaller denticles at each side of it. Lateral teeth with enlarged major denticles and two smaller denticles on each side as well. Marginal teeth shovel-like, inner marginals with three denticles each, outer marginals mostly with three denticles, occasionally four, 
even in the same animal (see Fig. 32b). The outermost denticles of both marginals are wider than the inner ones.

Reproductive biology: Sex ratio $0.48(n=85)$. Males are significantly smaller than females (ANOVA, last three whorls: $F=7.954$, $P=0.007)$. About $88 \%$ of females $(n=44)$ carry shelled embryos in their brood pouch.

Brood pouch contains 1-11 embryos, their size can reach $10.2 \mathrm{~mm}$ (Table 3 ).

Embryonic shells (Fig. 32c-e): Conic to turreted, with strong inclined axial ribs emerging on the third whorl. Fine narrow-spaced spiral striae emerge on the 2nd whorl. Diameter of first whorl between 282 and $299 \mu \mathrm{m}$ (Table 3).

\section{Distribution}

South Sulawesi, Lake Mahalona (Fig. 9).

\section{Ecology and habitat}

Soft substrate dweller, on sand and mud. Often syntopic with $T$. wolterecki or T. marwotoae.

\section{Taxonomic remarks}

T. mahalonensis is one of two species in Lake Mahalona described by Kruimel (1913). While the type series of $T$. mahalonensis is rather homogenous, that of the second species, $T$. mahalonica, clearly contains two species. The specimen figured in the description of T. mahalonica by Kruimel (1913: pl. 4 Fig. 11; Fig. 31c in this study) is most likely a somewhat untypical $T$. mahalonensis as described above, and several other specimens in the series are here regarded to belong to that species as well. The description text of Kruimel (1913: 221) also fits to T. mahalonensis and the radulae depicted by Kruimel for the two species are virtually identical. As First Revisers, under Art. 24.2, we give precedence to the name Melania mahalonensis over M. mahalonica. In order to minimize taxonomic confusion T. mahalonica has been synonymized with $T$. mahalonensis. The specimens in the type series of $T$. mahalonica that are not $T$. mahalonensis are considered to belong to $T$. confusa new sp., which is described here based on new samples collected in 1991 and 1999 (see also taxonomic remarks for that species).

Tylomelania mahalonensis is a characteristic soft-bottom dweller in Lake Mahalona. The species resembles $T$. patriarchalis from Lake Matano and T. towutensis from Lake Towuti and the Tominanga River. It can be distinguished from the two latter taxa by its usually smaller and considerably thinner shell with its characteristic narrow-spaced, curved and comparatively fine axial ribs. The radula of $T$. mahalonensis is virtually identical to the typical radula morphs of the two other species, though. Its embryonic shells are rather similar to those of T. towutensis, with which it also shares the orange-yellow pigmentation of its headfoot. In stark contrast to the other two species the examined populations were very homogenous in all examined characters, which might be due to the fact that Lake Mahalona is much smaller than the other two lakes, thus offering less opportunity for the geographic isolation of populations.

\section{Material examined}

Lake Mahalona: W-shore, Kaloa, 02 $36^{\prime} \mathrm{S}$, $121^{\circ} 29.6^{\prime} \mathrm{E}$, loc. MHL2 (MNHN, $n=24 ; n=12$, in alc.); Timbalo, inlet of Petea River, $02^{\circ} 34.6^{\prime} \mathrm{S}$, $121^{\circ} 9^{\prime} \mathrm{E}$, loc. MHL4 (MNHN, $n=64 ; n=13$, in alc.); S-shore, c. $1 \mathrm{~km} \mathrm{~W}$ of Tominanga River

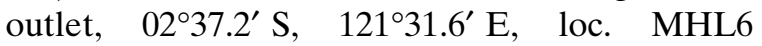
(MNHN, $n=1 ; n=9$, in alc.); SE corner, at mouth of outlet, $02^{\circ} 36.88^{\prime} \mathrm{S}, 121^{\circ} 30.98^{\prime} \mathrm{E}$, loc. 38 (MZB Gst. 12.376, $n=30$; ZMB 190146, $n=54$; all in alc.); E-shore, at promontory, 02 $35.58^{\prime} \mathrm{S}$, $121^{\circ} 30.68^{\prime} \mathrm{E}$, loc. 39 (ZMB 190167, $n=4$, in alc.); E-shore, mouth of Petea River, $02^{\circ} 34.37^{\prime} \mathrm{S}$, 121 ${ }^{\circ} 30.53^{\prime} \mathrm{E}$, loc. 40 (MZB 12.380, $n=40$; ZMB $190151, n=110$; all in alc.); $\mathrm{NE}$ corner, $02^{\circ} 33.87^{\prime} \mathrm{S}, 121^{\circ} 30.68^{\prime} \mathrm{E}$, loc. 41 (MZB 12.381, $n=20$; ZMB 190154, $n=75$; all in alc.); S-shore, $02^{\circ} 36.98^{\prime} \mathrm{S}, 121^{\circ} 30.02^{\prime} \mathrm{E}$, loc. 44 (MZB 12.382, $n=40$; ZMB 190164, $n=84$; all in alc.).

\section{Tylomelania marwotoae new species}

Type material: Holotype (Fig. 33a; $46.2 \mathrm{~mm} \times$ $14.4 \mathrm{~mm}$ ): Lake Mahalona, S-shore, 02 $36.98^{\prime} \mathrm{S}$, $121^{\circ} 30.02^{\prime} \mathrm{E}$, loc. 44 (MZB Gst. 12.319, in alc.). 
Paratypes (Fig. 33b,c): Lake Mahalona: W-shore, Kaloa, 02 $36^{\prime}$ S, $121^{\circ} 29.6^{\prime}$ E, loc. MHL 2 (MNHN 9975, $n=193$; MNHN 9976, $n=39$, in alc.); Eshore, Timbalo, inlet of Petea River, $02^{\circ} 34.6^{\prime} \mathrm{S}$, $121^{\circ} 9^{\prime} \mathrm{E}$, loc. MHL4 (MNHN 9977, $n=40$; MNHN 9978, $n=12$, in alc.); S shore, c. $1 \mathrm{~km} \mathrm{~W}$ of Tominanga River outlet, $02^{\circ} 37.2^{\prime} \mathrm{S}$, 121 31.6' E, loc. MHL6 (MNHN 9979, $n=3$; MNHN 9980, $n=18$, in alc.); W-shore, at cape, $02^{\circ} 35.64^{\prime} \mathrm{S}, 121^{\circ} 28.52^{\prime} \mathrm{E}$, loc. 43 (ZMB 190538, $n=1$ in alc.); S-shore, $02^{\circ} 36.98^{\prime} \mathrm{S}, 121^{\circ} 30.02^{\prime} \mathrm{E}$, loc. 44 (MZB Gst. 12.321, $n=30$; ZMB 190163, $n=76$; all in alc.).

Etymology: The name marwotoae is given in reference to the Indonesian malacologist Ristiyanti Marwoto, who strives towards increasing interest in and knowledge of the Indonesian freshwater malacofauna, especially on Sulawesi.

\section{Description}

Shell (Fig. 33): Medium sized, yellowish-green, highly turreted, top whorls in adult specimens always corroded to a varying degree, 6-11 remaining whorls, can reach up to $56.3 \mathrm{~mm}$ (Table 2). Widely spaced and mildly curved axial ribs, occasionally inclined, 13-21 on body whorl. Spiral ribs weak. Aperture ovate, pointed at top. Outer lip drawn out at base.

External morphology: Headfoot with yellow stripey blotches, mantle edge slightly serrated. Body coiled in 3-3.5 whorls.

Operculum (Fig. $7 \mathrm{~m}$ ): almost round and multispiral, with 5-6 whorls.

Radula (Fig. 34a, b): 175-211 rows, 11.3$4.6 \mathrm{~mm}$ long, on average 14.7 teeth $/ \mathrm{mm}(n=3)$. Central tooth with larger, blunt spade-shaped major denticle, accompanied by two smaller denticles at each side of it. Lateral teeth with greatly enlarged spade-shaped major denticles and two smaller denticles on each side as well. Marginal teeth straight, tips curved, with three denticles each, the outermost ones are vastly enlarged.

Reproductive biology: Sex ratio $0.29(n=15)$. About $90 \%$ of females $(n=10)$ carry shelled embryos in their brood pouch.

Brood pouch contains four embryos, their size can reach $6.3 \mathrm{~mm}$ (Table 3 ).
Embryonic shells (Fig. 34c-e): Elongately conic, sutures deep, with strong axial ribs emerging on the second whorl. Shallow, widespaced spiral ribs emerge on third whorl. Diameter of first whorl between 265 and $306 \mu$ m (Table 3).

\section{Distribution}

South Sulawesi, Lake Mahalona (Fig. 9).

\section{Ecology and habitat}

Soft substrate dweller, in shallow water on sand and mud. Syntopic with T. mahalonensis, about equally abundant.

\section{Taxonomic remarks}

T. marwotoae is easily diagnosable by its unusually coloured and highly turreted shell with almost straight, wide-spaced axial ribs, its characteristic radula, and distinct embryonic shells. While vaguely resembling $T$. gemmifera from Lake Matano, T. marwotoae has smaller shells with comparatively straight axial ribs (see above), and the radula lacks the thiarid appearance of the former species and rather resembles that of $T$. zeamais (compare Fig. 68). The same characters distinguish $T$. marwotoae from the parapatric $T$. wolterecki, in addition the axial ribs of that species appear to consist of dots due to the overlap of axial and spiral ribs.

\section{Tylomelania masapensis (Kruimel, 1913)}

Melania masapensis Kruimel, 1913: 218, pl. 4 Fig. 13. (Lake Masapi; lectotype, present designation, ZMA; 56 paralectotypes, ZMA; all in alc.; 3 paralectotypes, MCZ 65150).

\section{Description}

Shell (Fig. 35): Medium sized, brown to almost black, almost turreted, spire angle $12-25^{\circ}$, top whorls in adult specimens always corroded to a varying degree, 3-6 remaining whorls, can reach up to $48.0 \mathrm{~mm}$ (Table 2). Shell smooth. Aperture oval, pointed at top, slightly siphonated at base. 
External morphology: Headfoot black, mantle edge smooth. Body coiled in 3.5 whorls.

Operculum (Fig. 7n): Almost round, last whorl inflated, multispiral, with 9-10 whorls.

Radula (Fig. 36a, b): 135-156 rows, 13.2$18.1 \mathrm{~mm}$ long, on average $9.4 \mathrm{teeth} / \mathrm{mm}(n=2)$. Central tooth with larger, pointed major denticle, accompanied by two smaller denticles at each side of it. Lateral teeth with enlarged major denticles and two smaller denticles on each side as well. Marginal teeth straight, tips curved and narrow, with three denticles each, the outermost ones are only slightly larger than the inner ones.

Reproductive biology: Sex ratio $0.25(n=121)$. Males are highly significantly smaller than females (ANOVA, last three whorls: $F=8.137, P<0.001$, $n=116)$. About $90 \%$ of females $(n=88)$ carry shelled embryos in their brood pouch.

Brood pouch contains 1-5 embryos, their size can reach $10 \mathrm{~mm}$ (Table 3 ).

Embryonic shells (Fig. 36c-e): Elongately conic, almost turreted, with strong axial ribs emerging on the 2nd to 3rd whorl and fading on the fifth whorl. Shallow, widespaced spiral ribs emerge on third whorl. Diameter of first whorl between 269 and $299 \mu \mathrm{m}$ (Table 3).

\section{Distribution}

South Sulawesi, Lake Masapi (Fig. 10).

\section{Ecology and habitat}

On mixed substrates, sand and gravel, on dead leaves.

\section{Taxonomic remarks}

Tylomelania masapensis has a smooth and highly turreted shell which resembles that of $T$. palicolarum (Fig. 42), but is nevertheless quite distinct. The radula and embryonic shells are not very characteristic of the species, the former is virtually identical to the typical form encountered in almost all riverine taxa as well as $T$. palicolarum. However, assuming that these characters simply reflect the plesiomorphic condition found in unspecialized soft-substrate dwellers and may consequently be shared by unrelated taxa, and given its isolated occurence, T. masapensis is here regarded as a valid species.

\section{Material examined}

Lake Masapi: $\mathrm{S}$ and E-shore (MNHN, $n=247$; $n=42$, in alc.); S-shore, $02^{\circ} 50.84^{\prime} \mathrm{S}, 121^{\circ} 21.09^{\prime} \mathrm{E}$, loc. 0026 (MZB 12.424, $n=97$, ZMB 190208, $n=337$; all in alc.).

\section{Tylomelania matannensis new species}

Type material: Holotype (Fig. 37a; $62.7 \mathrm{~mm} \times$ $26.3 \mathrm{~mm}$ ): Lake Matano, N-shore, 02 ${ }^{\circ} 26.71^{\prime} \mathrm{S}$, $121^{\circ} 20.02^{\prime}$ E, loc. 22 (MZB Gst. 12.309). Paratypes (Fig. 37b-g): Lake Matano: Mouth of Ebay, Cape Una, 02³1.40’ S, 121 ${ }^{\circ} 26.99^{\prime} \mathrm{E}$, loc. 13 (MZB Gst. 12.311, $n=9$; ZMB 190071, $n=21$; all in alc.); N-shore, $02^{\circ} 25.64^{\prime} \mathrm{S}, 121^{\circ} 16.48^{\prime} \mathrm{E}$, loc. 19 (MZB Gst. 12.313, $n=18$; ZMB 190094, $n=36$; all in alc.); N-shore, $02^{\circ} 26.28^{\prime} \mathrm{S}, 121^{\circ} 18.73^{\prime} \mathrm{E}$, loc. 20 (MZB Gst. 12.314, $n=5$; ZMB 190097, $n=12$; all in alc.); N-shore, $02^{\circ} 26.27^{\prime} \mathrm{S}, 121^{\circ} 18.91^{\prime} \mathrm{E}$, loc. 21 (MZB Gst. 12.315, $n=10$; ZMB 190100, $n=24 ; \quad$ all in alc.); N-shore, $02^{\circ} 26.71^{\prime} \mathrm{S}$, $121^{\circ} 20.02^{\prime} \mathrm{E}$, loc. 22 (ZMB 190103, $n=6$; all in alc.); N-shore, $02^{\circ} 27.29^{\prime} \mathrm{S}, 121^{\circ} 21.18^{\prime} \mathrm{E}$, loc. 23 (MZB Gst. 12.317, $n=18$; ZMB 190105, $n=27$; all in alc.); N-shore, $02^{\circ} 27.82^{\prime} \mathrm{S}, 121^{\circ} 23.07^{\prime} \mathrm{E}$, loc. 55 (MZB Gst. 12.318, $n=16$; ZMB 190109, $n=30 ; \quad$ all in alc.); S-shore, $02^{\circ} 29.84^{\prime} \mathrm{S}$, $121^{\circ} 18.71^{\prime} \mathrm{E}$, loc. 4 (MZB Gst. $12.323 n=36$; ZMB 190056, $n=127$; all in alc.); S-shore, $02^{\circ} 28.95^{\prime} \mathrm{S}, 121^{\circ} 17.24^{\prime} \mathrm{E}$, loc. 5 (MZB Gst. $12.324 n=17$; ZMB 190057, $n=30$; all in alc.).

Etymology: The new species is named matannensis as it is an endemic and rather characteristic form of rock and boulder habitats in Lake Matano.

\section{Description}

Shell (Fig. 37): Medium sized to large, yellowish brown to brown, turreted, top whorls in adult specimens always corroded to a varying degree, 5-10 remaining whorls, can reach up to $82.0 \mathrm{~mm}$ (Table 2). Strong, widely spaced straight or slightly inclined axial ribs, seldom weakly curved, 15-29 on body whorl. Spiral ribs shallow. 
Aperture ovate, pointed at top. Outer lip slightly siphonated at base.

External morphology: Headfoot with white or yellowish-white dots or blotches, tentacles striped, mantle edge slightly serrated. Body coiled in 2.5-3.5 whorls.

Operculum (Fig. 7o): almost round and multispiral, with 6-7 whorls.

Radula (Fig. 38): 184-255 rows, 16.0-32.0 mm long, on average 8.8 teeth $/ \mathrm{mm}(n=9)$. Central tooth with very large, spoon- or spade-shaped major denticle (Fig. 38b, d, respectively), accompanied by two smaller denticles at each side of it. Glabella width variable (Fig. 38a, c). Lateral teeth with greatly enlarged major denticles and two smaller denticles on each side as well. Marginal teeth straight or mildly concave, tips curved, shovel-like, with three denticles each, the outermost ones vastly enlarged and 3-4 times wider than the inner ones.

In one population (loc. 21) a completely different radula morph was found (Fig. 38e, f): 215 rows, $15.4 \mathrm{~mm}$ long, 14.0 teeth $/ \mathrm{mm}$. Central tooth with slightly larger, pointed major denticle, accompanied by two smaller denticles at each side of it. Glabella with rather narrow lateral extensions. Lateral teeth with just slightly enlarged major denticles and two smaller denticles on each side as well. Marginal teeth straight, tips curved, shovel-like, three denticles on inner marginals, outer marginals with 3-4 denticles. The outermost denticles only slightly wider than the inner ones.

Reproductive biology: Sex ratio $0.46(n=118)$. Males do not differ significantly in size from females. About $85 \%$ of females $(n=62)$ carry shelled embryos in their brood pouch.

Brood pouch contains 1-7 embryos, their size can reach $13.8 \mathrm{~mm}$ (Table 3).

Embryonic shells (Fig. 39): Ovate to slender conic, with medium sized to strong and slightly inclined axial ribs emerging on the second whorl. Fine, narrow-spaced spiral striae or more widely spaced ribs emerge on 2 nd to 3rd whorl. Diameter of first whorl between 242 and $338 \mu \mathrm{m}$ (Table 3).

\section{Distribution}

South Sulawesi, Lake Matano, North, East and South shore (Fig. 9).

\section{Ecology and habitat}

Hard substrate dweller on rocks and boulders, from a depth of about $1 \mathrm{~m}$. The only species in the lake on steep rocky drop-offs. In shallow water occasionally syntopic with $T$. zeamais where the depth ranges of both species overlap.

\section{Taxonomic remarks}

Tylomelania matannensis is a very distinct species of rocky habitats in Lake Matano. It cannot be confused with the only syntopic species, $T$. zeamais, as it is much larger and differs considerably in shell morphology and radula characters as well (compare Figs. 67, 68). T. matannensis can be easily distinguished from the soft substrate dwelling $T$. patriarchalis by the different shell sculpture with its stronger and fewer axial ribs on the last whorl, and by the radula with its immensely enlarged major denticles (but see below). Differences in the embryonic shells between the two species are less conspicuous. Within T. matannensis there is generally little variation in shell or embryonic shell morphology. The radula of $T$. matannensis is polymorphic, the population from locality 21 has a radula resembling the 'typical' form of the soft substrate dwelling $T$. patriarchalis.

\section{Material examined}

See also above, type material

Tylomelania cf. matannensis: Lake Matano, Nshore, $02^{\circ} 25.76^{\prime} \mathrm{S}, 121^{\circ} 15.17^{\prime} \mathrm{E}$, loc. 18 (ZMB 190093, $n=100$, in alc.).

\section{Tylomelania molesta (Sarasin \& Sarasin, 1897)}

Melania molesta Sarasin \& Sarasin, 1897: 316 (Lake Matano; lectotype, present designation, NMB 1340a; 2 paralectotypes, NMB 1340a', 1 broken). - Sarasin \& Sarasin, 1898: 23, pl. 2 Figs. 11, 12; pl. 5 Fig. 64 (op.).

\section{Description}

Shell (Fig. 40): Small, brown, elongately conic, almost barrel-like, spire angle $12-15^{\circ}$, top whorls 


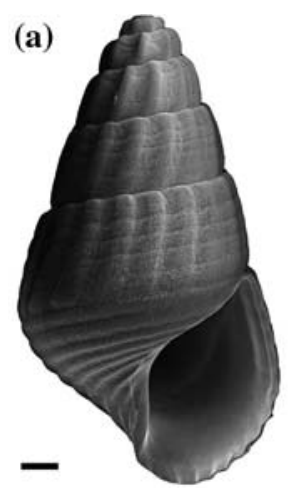

(b)

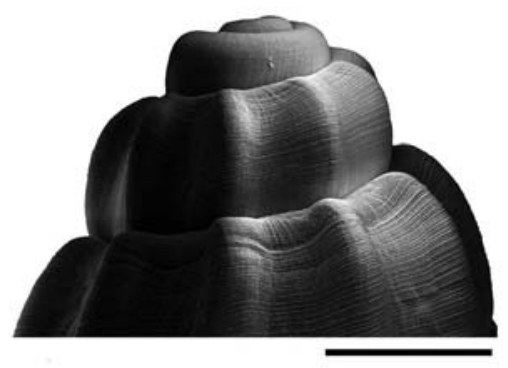

(c)

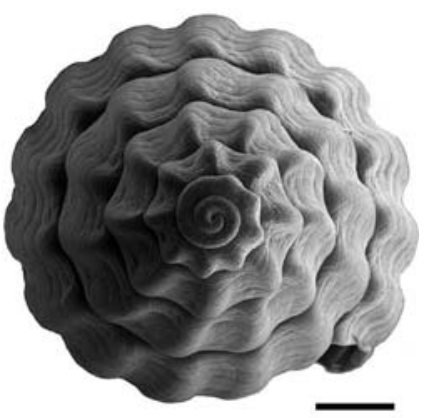

Fig. 39 T. matannensis, embryonic shells. ZMB 190100 (loc. 21). a, lateral view; b, apical whorls, lateral; c, apical view. Scale bar $=0.5 \mathrm{~mm}$

corroded, five remaining whorls, can reach up to $34.8 \mathrm{~mm}$ (Table 2). Smooth. Aperture oval, pointed at top, almost round at base.

\section{Distribution}

South Sulawesi, Lake Matano.

\section{Taxonomic remarks}

T. molesta is only known from the three specimens of the type series. Neither radula nor embryonic shells are known. This species faintly resembles the Lake Matano form of $T$. palicolarum as both are smooth and tend to have a very low spire angle. However, T. molesta is much smaller than $T$. palicolarum, and in contrast to that species the lower rim of its aperture is
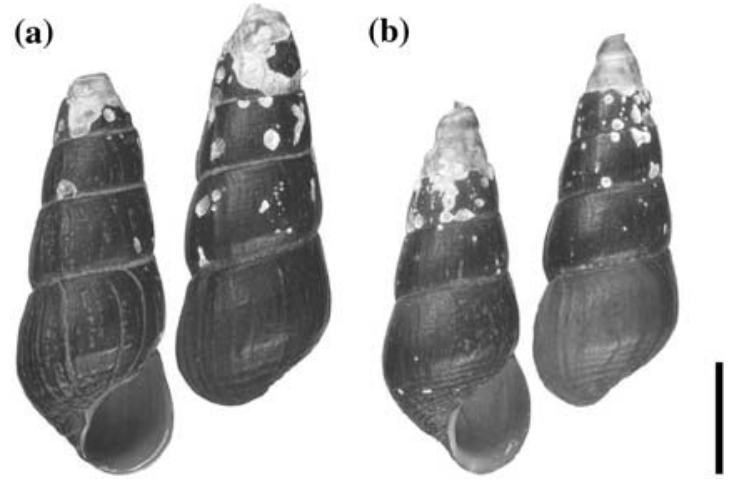

Fig. 40 T. molesta, shells. Types (Lake Matano, N shore). a, lectotype, NMB 1340a; b, paralectotype, NMB 1340a'. Scale bar $=1 \mathrm{~cm}$ rounded. T. molesta is therefore tentatively regarded as a valid species here.

Tylomelania palicolarum (Sarasin \& Sarasin, 1897)

Melania palicolarum Sarasin \& Sarasin, 1897: 312. (Lake Towuti; lectotype, present designation, NMB 1331a; 3 and 2 (in alc.) paralectotypes, NMB 1331a; paralectotype, BMNH, paralectotype, ZMB 50785). - Sarasin \& Sarasin, 1898: 16, pl. 1 Figs. 3, 4; pl. 5 Fig. 59 (op.); pl. 6 Fig. 85,86 (rad.). -Kruimel, 1913: 218.

\section{Description}

Shell (Fig. 41): Medium sized to large, (dark) brown, elongately conic, in Lake Matano almost barrel-shaped, spire angle $12-26^{\circ}$. Top whorls in adult specimens always corroded to a varying degree, 5-11 remaining whorls, can reach up to $81.0 \mathrm{~mm}$ (Table 2). Smooth. Aperture oval, pointed at top, drawn out at base.

External morphology: Headfoot black with small white dots, mantle edge almost smooth. Body coiled in 3.5-5 whorls.

Operculum (Fig. 7p): roughly diamond shaped and multispiral, with 9-10 whorls.

Radula (Fig. 42a-d): 150-183 rows, 18.3$25.1 \mathrm{~mm}$ long, on average 7.9 teeth/mm $(n=5)$. Central tooth with larger, very pointed major denticle, accompanied by two (occasionally three on the outer side) smaller pointed denticles at each side of it. Lateral teeth with enlarged 
pointed major denticles and two smaller denticles on each side as well. Marginal teeth shovel-like, inner and outer marginals with three almost equal sized denticles each. The radula from on population of Lake Mahalona (loc. MHL 6) is qualitatively virtually identical, but is more condensed, i.e. has more teeth rows but is shorter than the typical T. palicolarum radulae (235 rows, $15.4 \mathrm{~mm}$ long, 15.3 teeth $/ \mathrm{mm}$ ).

Lake Matano specimens have slightly wider and less pointed major denticles (155-179 rows, $16.5-18.6 \mathrm{~mm}$ long, on average 9.5 teeth $/ \mathrm{mm}$ $(n=2))$.

Reproductive biology: Sex ratio $0.25(n=12)$. Brood pouch contains $2-8$ embryos, their size can reach $15.5 \mathrm{~mm}$ (Table 3 ).

Embryonic shells (Fig. 42e-k): Elongately conic, the typical form with strong axial ribs emerging on the third whorl and vanishing again on the 6th or 7 th whorl. In animals from Lake Matano the axial ribs vanish on the fifth whorl. Shallow spiral ribs emerge on 2nd to 3rd whorl. Diameter of first whorl 257-322 $\mu \mathrm{m}$ (Table 3).

\section{Distribution}

South Sulawesi, Lake Matano, Lake Mahalona and Lake Towuti (Fig. 10).

\section{Ecology and habitat}

On soft substrate, mud.

\section{Taxonomic remarks}

T. palicolarum is the only large and almost turreted smooth-shelled species in the Malili lake system and very distinct (but see T. masapensis, taxonomic remarks). Within the species there is considerable variation in shell size, embryonic shell sculpture and radula morphology (see above). T. palicolarum as described here might indeed represent a species complex rather than a single species. The typical large form described by Sarasin \& Sarasin $(1897,1898)$ could easily be identified in Lake Mahalona and Lake Towuti (Fig. 41a-f). Lake Matano might harbour a different species based on differences in shell form, the embryonic shells, and, to a lesser degree, the radula. However, only very few badly preserved specimens $(n=5)$ of the Lake Matano populations were available for study, and the description of a new species was consequently considered premature. Single populations in Lake Mahalona (loc. MHL 6) and Towuti (loc. TW 2) can also be distinguished from the typical form by smaller shells and in the former case also by a slightly different radula. While a considerable number of specimens of these populations could be studied, information on habitat and substrate preferences is completely lacking. These smaller forms are therefore here tentatively regarded as belonging to $T$. palicolarum.

\section{Material examined}

Lake Matano: SW-shore, Paku, 02²9.1' S, $121^{\circ} 15.5^{\prime} \mathrm{E}$, loc. MT1 (MNHN, $n=2$ in alc.); NE-shore, small bay near river inlet, $02^{\circ} 31.3^{\prime} \mathrm{S}$, $121^{\circ} 28.7^{\prime} \mathrm{E}$, loc. MT8 (MNHN, $n=3$ in alc.).

Lake Mahalona: no detail locality (ZMA, $n=99$ in alc.); E-shore, Timbalo, inlet of Petea River, $02^{\circ} 34.6^{\prime} \mathrm{S}, 121^{\circ} 9^{\prime} \mathrm{E}$, loc. MHL4 (MNHN, $n=4$; $n=3$, in alc.); $\mathrm{S}$ shore, c. $1 \mathrm{~km} \mathrm{~W}$ of Tominanga River outlet, MHL6 (MNHN, $n=662, n=57$ in alc.); SE corner, at mouth of outlet, $02^{\circ} 36.88^{\prime} \mathrm{S}$, 121³0.98' E, loc. 38 (ZMB 190628, $n=2$ ); E-shore, mouth of Petea River, $02^{\circ} 34.37^{\prime}$ S, $121^{\circ} 30.53^{\prime}$ E, loc. 40 (ZMB 190153, $n=1$ in alc.);

Tominanga River: at midway between Lakes Mahalona and Towuti, $02^{\circ} 38.5^{\prime} \mathrm{S}, 121^{\circ} 45.1^{\prime} \mathrm{E}$, loc. MHL1 (MNHN, $n=1)$;

Lake Towuti: No detail locality (ZMA, $n=51$ in alc.); Loeha Island (ZMA, $n=26$ in alc.); $\mathrm{N}$ shore, shallow bay W of mouth of Tominanga River, TW2 (MNHN, $n=105, n=22$ in alc); Wshore, bay at outlet of Larona River, $02^{\circ} 46.09^{\prime} \mathrm{S}$, $121^{\circ} 21.57^{\prime} \mathrm{E}$, loc. 26 (ZMB 190145, $n=4$, in alc.).

Tylomelania patriarchalis (Sarasin \& Sarasin, 1897)

Melania patriarchalis Sarasin \& Sarasin, 1897: 310, text fig. 4. (Lake Matano; lectotype, present designation, NMB 1330a, 4 paralectotypes (1 broken), NMB 1330b; 2 paralectotypes - one is T. zeamais; ZMB 50783; paralectotype, BMNH). —Sarasin \& Sarasin, 1898: 17, pl. 1 Figs. 5, 6; pl. 5 
Fig. 60 (op.); pl. 7 Fig. 89,89a (rad. Kruimel, 1913: 219. -Marwoto, 1997: 110.

\section{Description}

Shell (Figs. 43, 44): Large or very large, light to dark brown, turreted, spire angle $12-26^{\circ}$, top whorls in adult specimens always corroded to a varying degree, 4-13 remaining whorls, can reach up to $117.0 \mathrm{~mm}$ (Table 2). Axial ribs of varying strength, straight to mildly curved, usually slightly inclined, 10-42 on body whorl. Spiral ribs weak. Aperture oval, pointed at top and drawn out at base.

External morphology: Headfoot with white dots or blotches, tentacles with white stripes, mantle edge serrated to a varying degree. Body coiled in 2.5-3.5 whorls.

Operculum (Fig. 7q): Roughly diamond shaped, last whorl strongly expanded, multispiral, with 8-9 whorls.

Radula (Fig. 45): Three forms present: A, (Fig. 45a, b). 176-224 rows, 15.6-20.6 mm long, on average 11.3 teeth $/ \mathrm{mm}(n=6)$. Central tooth with slightly larger, pointed major denticle, accompanied by two smaller denticles at each side of it. Glabella wide. Lateral teeth with enlarged pointed major denticle and two smaller denticles on each side as well. Marginal teeth weakly concave, tips curved, inner marginals with three denticles, outer marginals with 3-4 denticles. The outermost denticles on both marginals are only slightly larger than the inner ones. Found in specimens at loc. 1,3,7,17,54 (Fig. 46).

B, (Fig. 45c, d). 209-244 rows, 22.0-24.5 mm long, on average 9.6 teeth $/ \mathrm{mm}(n=3)$. Very similar to form A, but major denticles on both central and lateral teeth significantly longer. Marginal teeth with three denticles each. Found in specimens at loc. 10,11 (Fig. 46).

C, (Fig. 45e, f). 175-221 rows, 20.8-27.6 mm long, on average 8.4 teeth $/ \mathrm{mm}(n=3)$. Central tooth with significantly enlarged, to a varying degree blunt major denticle, accompanied by two smaller denticles at each side of it. Glabella more narrow than in form A and B. Lateral teeth with larger and almost blunt major denticles and two smaller denticles on each side as well. Marginal teeth with three denticles each, the outermost ones c. three times wider than inner ones. Found in specimens at loc. 6,9,14,18,56 (Fig. 46).

Reproductive biology: Sex ratio $0.50(n=139)$. Males do not differ significantly in size from females (ANOVA). About $93 \%$ of females $(n=69)$ carry shelled embryos in their brood pouch.

Brood pouch contains 2-29 embryos, their size can reach $17.5 \mathrm{~mm}$ (Table 3 ).

Embryonic shells (Fig. 47): Conic to elongately conic, with strong axial ribs and shallow, widespaced spiral emerging on the 2nd to 3rd whorl. Height and shape of the first 3-4 whorls variable, the axial ribs might become less prominent on later whorls. Diameter of first whorl between 261 and $351 \mu \mathrm{m}$ (Table 3).

\section{Distribution}

South Sulawesi, Lake Matano (Fig. 9).

\section{Ecology and habitat}

Soft substrate dweller, on sand and mud. Occurs from a depth of $0.5-1 \mathrm{~m}$ to $20-40 \mathrm{~m}$. In Lake Matano usually syntopic with $T$. gemmifera, more abundant than that species.

\section{Taxonomic remarks}

Tylomelania patriarchalis is a widespread and, together with $T$. gemmifera, very characteristic soft bottom dweller in Lake Matano. While $T$. patriarchalis is hard to confuse with other species in this lake, it has a rather variable shell (Figs. 43, 44) and embryonic shell morphology (Fig. 47). The radula is polymorphic (Fig. 45). The distribution of the different radula morphs follows no apparent geographic pattern (Fig. 46; with the exception of form $\mathrm{B})$, and is not linked to shell morphology variation. While it is possible that $T$. patriarchalis as conceived of here may include more than one species, the incongruent and confusing patterns displayed by the different characters and the lack of information on possible ecological differences have precluded the description of new taxa at this point. 

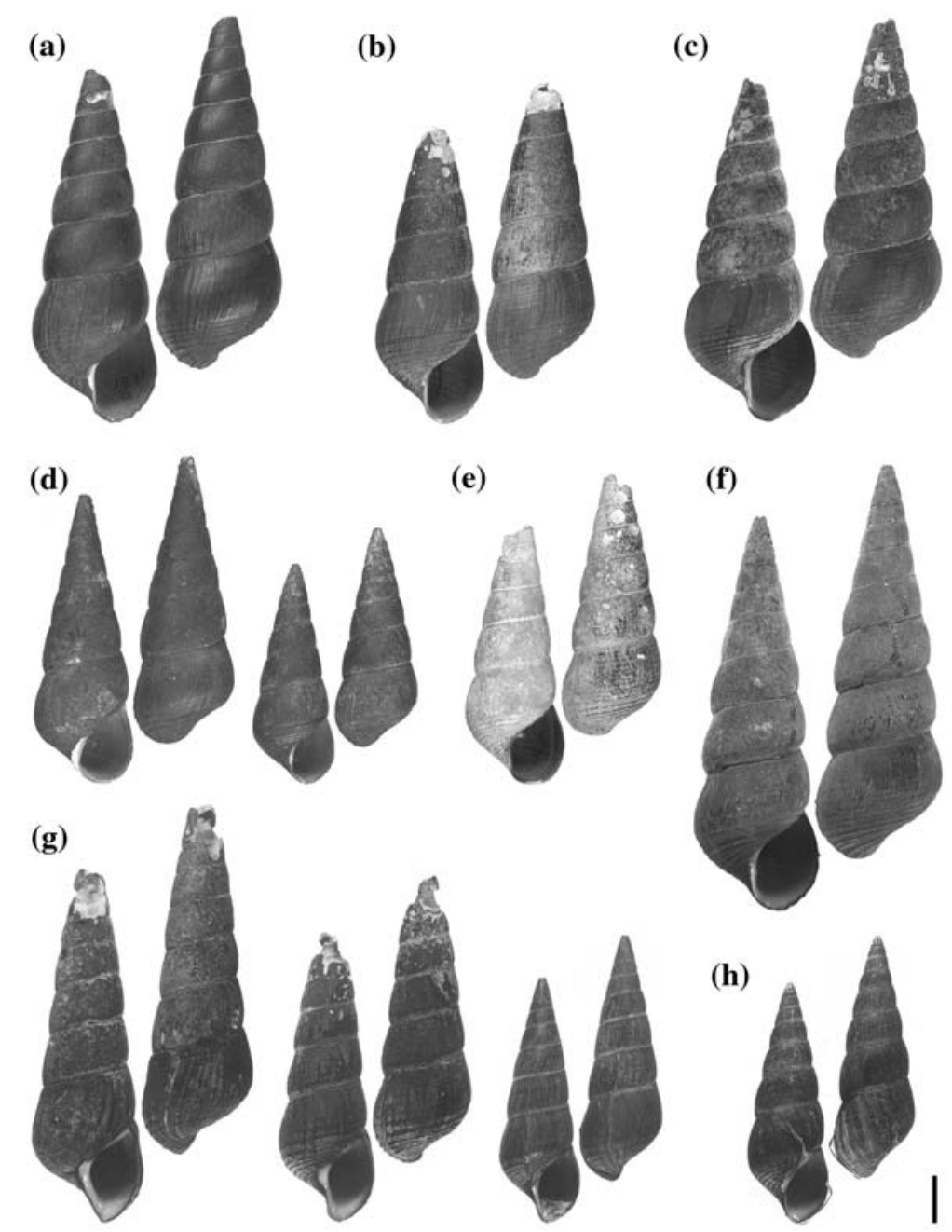

Fig. $41 T$. palicolarum, shells. a, b, types, NMB (Lake Towuti). a, lectotype, NMB 1331a; b, paralectotype, NMB 1331a'. c, ZMB 190145 (loc. 26); d, MNHN (MHL4); e,

ZMA (Loeha Island); f, ZMB 190153 (loc. 40); g, MNHN (loc. MT8), h, MNHN (loc. MT1). Scale bar $=1 \mathrm{~cm}$

\section{Material examined}

Lake Matano: SW-shore, Paku, 02²9.1' S, $121^{\circ} 15.5^{\prime} \mathrm{E}$, loc. MT1 (MNHN, $n=48 ; n=30$, in alc.); NW-shore, inlet of Lawa River, $02^{\circ} 27^{\prime} \mathrm{S}$, $121^{\circ} 13.8^{\prime} \mathrm{E}$; loc. MT3 (MNHN, $n=11$, in alc.); Sshore, bay with islands, $02^{\circ} 34^{\prime} \mathrm{S}, 121^{\circ} 26.8^{\prime} \mathrm{E}$, loc. MT5 (MNHN, $n=29 ; n=17$, in alc.); E-shore, easternmost bay, $02^{\circ} 32.4^{\prime} \mathrm{S}, 121^{\circ} 28.1^{\prime} \mathrm{E}$, loc. MT6 (MNHN, $n=11 ; n=7$, in alc.); Soroako, Salonsa, $02^{\circ} 30.49^{\prime} \mathrm{S}, 121^{\circ} 19.96^{\prime} \mathrm{E}$, loc. 1 \& 2 (loc. 1: MZB Gst. 12.289, $n=20$; ZMB 190050, $n=160$; loc. 2, -20m: MZB Gst. 12.290, $n=50$;
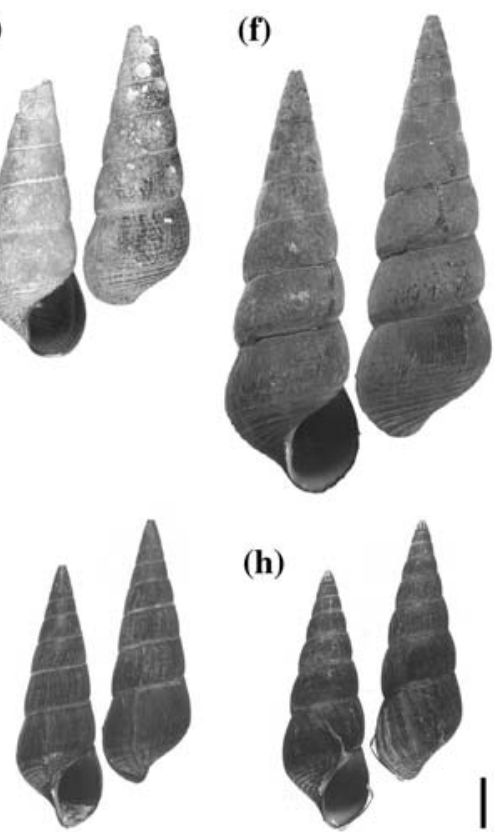

(h)

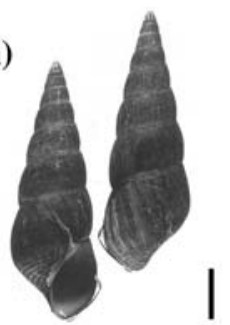

ZMB 190087, $n=190$; all in alc.); Soroako, Salonsa, loc.3, ca. 300m E of loc. 1 (MZB Gst. 12.291, $n=22$; ZMB 190055, $n=22$; all in alc.); Sshore, $02^{\circ} 28.44^{\prime} \mathrm{S}, 121^{\circ} 15.78^{\prime} \mathrm{E}$, loc. 6 (ZMB 190078, $n=4$, in alc.); S-shore, small bay, 0228.04' S, 121⒕04' E, loc. 7 (MZB Gst. 12.293, $n=15$; ZMB 190061, $n=29$; all in alc.); W-shore, $02^{\circ} 26.97^{\prime} \mathrm{E}, 121^{\circ} 13.00^{\prime} \mathrm{E}$, loc. 9 (ZMB $190063, n=35$, in alc.); E-Bay, at outlet of Petea River, $02^{\circ} 32.06^{\prime} \mathrm{S}, 121^{\circ} 28.50^{\prime} \mathrm{E}$, loc. 10 (ZMB $190067, n=5$, in alc.); E-bay, S-shore, 02³2.09’ S, $121^{\circ} 27.88^{\prime} \mathrm{E}$, loc. 11 (ZMB 190068, $n=14$, in alc.); SE-bay, W-shore, $02^{\circ} 33.28^{\prime} \mathrm{S}, 121^{\circ} 24.97^{\prime} \mathrm{E}$, 

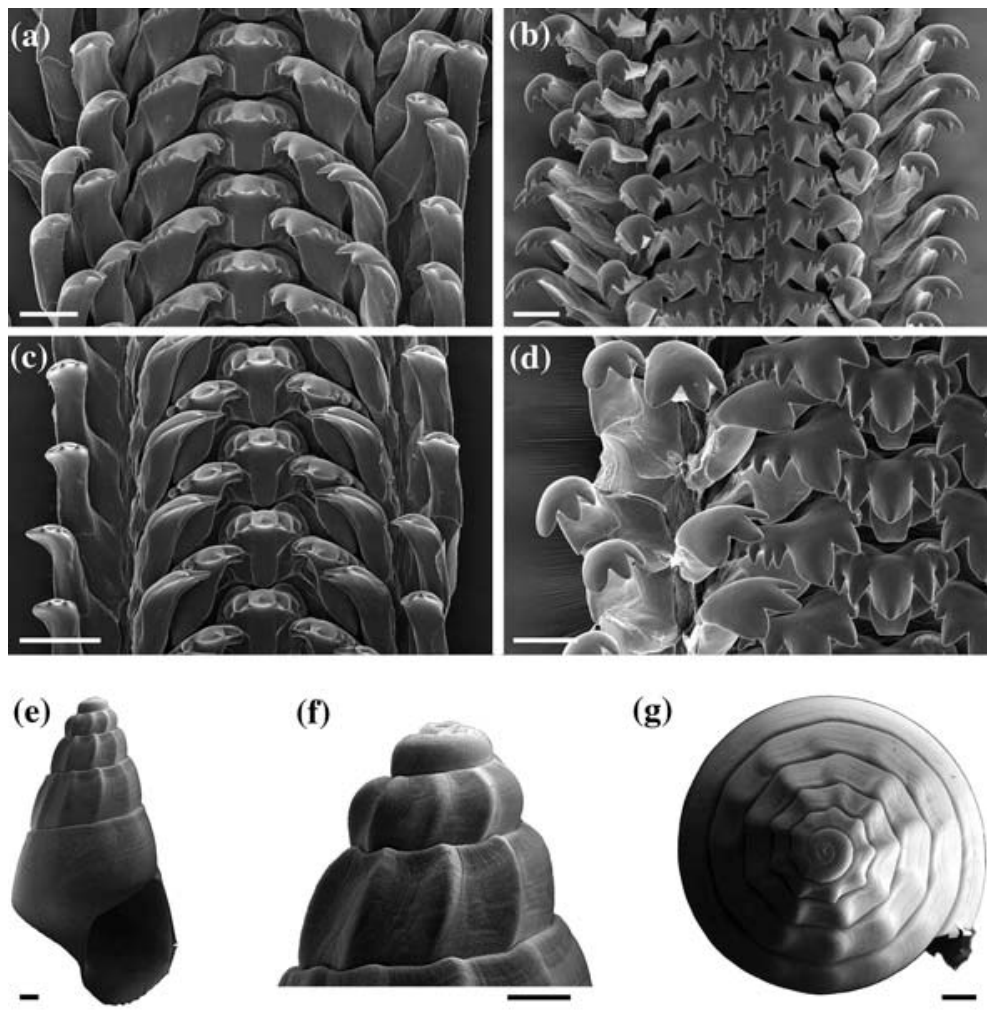

(g)
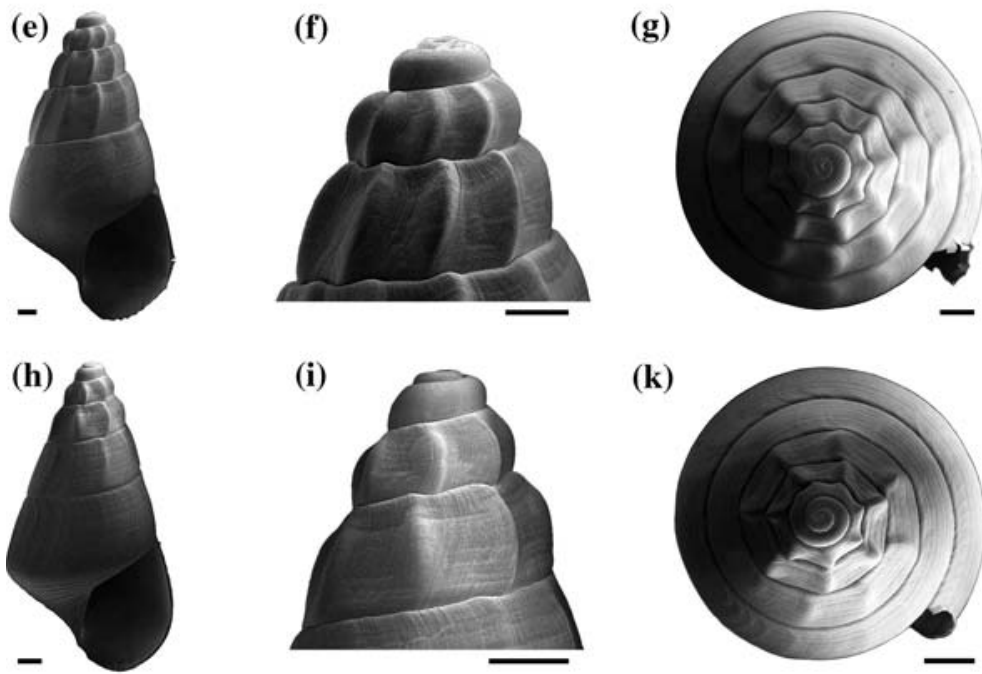

(k)

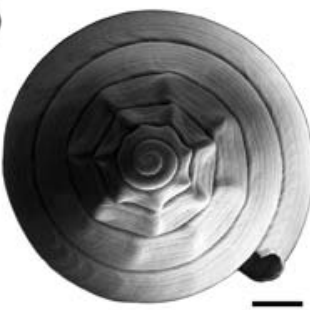

Fig. $42 T$. palicolarum, radula and embryonic shells. a-d, radula. a, b, ZMB 190145 (loc. 26). a, segment, frontal; b, segment, apical $\left(45^{\circ}\right)$. c, d, MNHN (loc. MT1). c, segment, frontal; d, segment, apical $\left(45^{\circ}\right)$. Scale bar $=0.1 \mathrm{~mm}$. e-k, embryonic shells. e-g, MNHN (loc. MHL4). e, lateral view; f, apical whorls, lateral; $\mathbf{g}$, apical view. h-k, MNHN (loc. MT8). h, lateral view; i, apical whorls, lateral; k, apical view. Scale bar $=0.5 \mathrm{~mm}$

Tylomelania sarasinorum (Kruimel, 1913)

loc. 14 (MZB Gst. 12.296, $n=5$; ZMB 190074, $n=20$; all in alc.); NW-shore, $02^{\circ} .26 .01^{\prime} \mathrm{S}$, $121^{\circ} 13.03^{\prime} \mathrm{E}$, loc. 16 (ZMB 190053, $n=7$, in alc.); N NW-shore, $02^{\circ} 25.87^{\prime} \mathrm{S}, 121^{\circ} 13.41^{\prime} \mathrm{E}$, loc. 17 (ZMB 190090, $n=16$, in alc.); N-shore, 02 $25.76^{\prime} \mathrm{S}, 121^{\circ} 15.17^{\prime} \mathrm{E}$, loc. 18 (ZMB 190092, $n=14$, in alc.); S-shore, $02^{\circ} 29.99^{\prime} \mathrm{S}, 121^{\circ} 19.04^{\prime} \mathrm{E}$, loc. 54 (ZMB 190108, $n=3$, in alc.); N-shore, $-20 \mathrm{~m}, 02^{\circ} 29.64^{\prime} \mathrm{S}, 121^{\circ} 25.65^{\prime} \mathrm{E}$, loc. 56 (MZB Gst. 12.307, $n=10$; ZMB 190111, $n=23$; all in alc.).
Melania sarasinorum Kruimel, 1913: 223, pl. 4 Fig. 7. (Lake Towuti, Loeha Island; lectotype, present designation, ZMA; 12 and 19 (in alc.) paralectotypes, ZMA).

\section{Description}

Shell (Fig. 48): Medium sized, reddish-brown or brown, conic or elongated conic, spire angle $8-41^{\circ}$, 

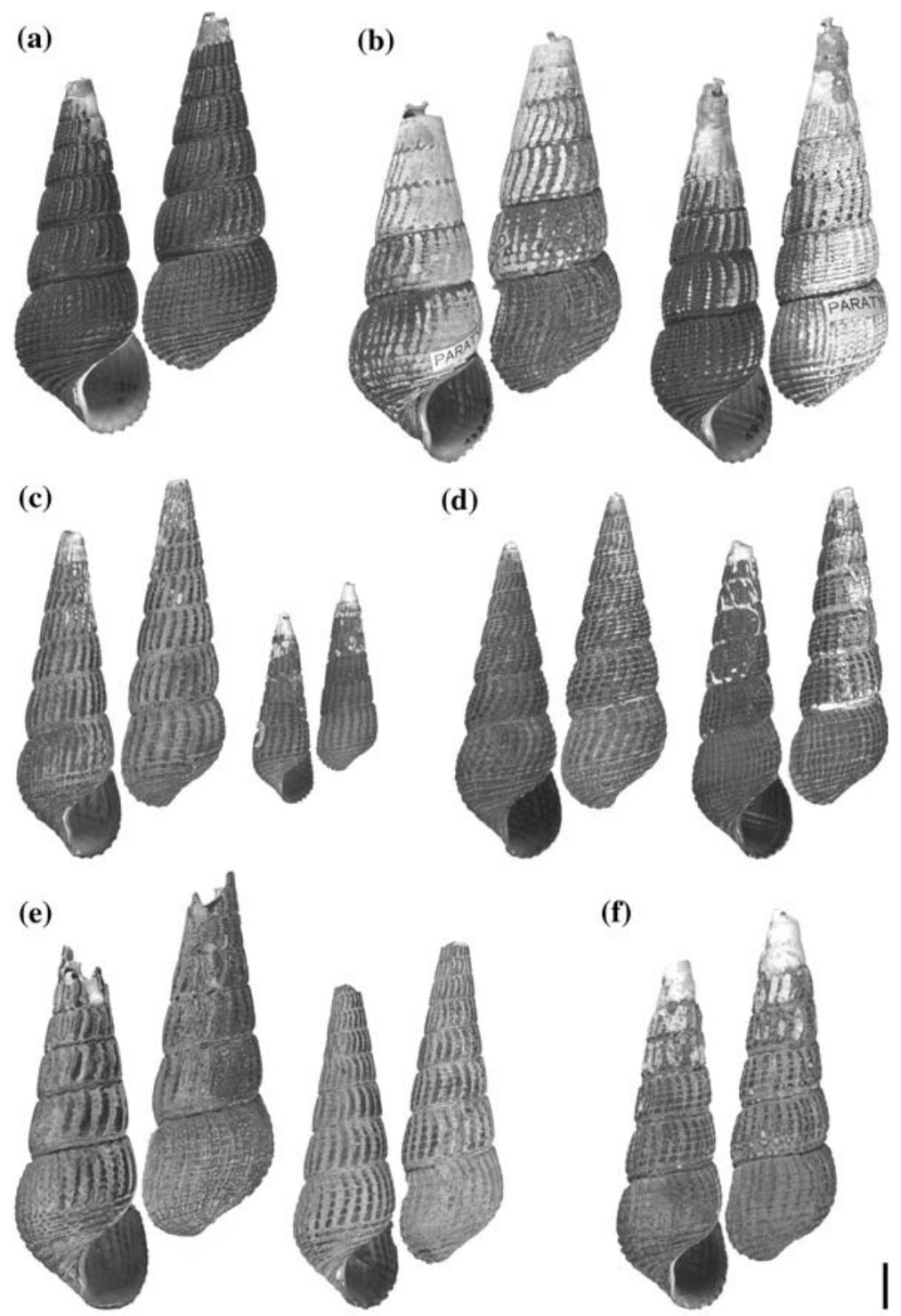

Fig. 43 T. patriarchalis, shells. a, b, types (Lake Matano). a, lectotype, NMB 1330a; b, paralectotypes, NMB 1330b. c, ZMB 190050 (loc. 1); d, ZMB 190061 (loc. 7); e, ZMB 190090 (loc. 17); f, ZMB 190053 (loc. 16). Scale bar = $1 \mathrm{~cm}$

top whorls in adult specimens always corroded to a varying degree, 2-7 remaining whorls, can reach up to $58.9 \mathrm{~mm}$ (Table 2). Sculpture consists of spiral ribs only, 5-11 on body whorl. Aperture oval, pointed at top, slightly siphonated at base.

External morphology: Headfoot black with no or usually only few white dots of varying size, mantle edge serrated. Body coiled in 2.5-3.5 whorls.

Operculum (Fig. 7r): Almost round and multispiral, with 6-7 whorls.
Radula (Fig. 49): Three distinct forms:

A (Fig. 49a, b). 176-296 rows, 15.3-24.7 mm long, on average 12.4 teeth $/ \mathrm{mm}(n=32)$. Central tooth with five pointed denticles of almost equal size, the major denticle being only slightly enlarged. Glabella very wide, rounded at base. Lateral teeth with slightly enlarged major denticles and two denticles on each side as well. Marginal teeth with 4-6, usually five, denticles of almost equal size. Found in specimens at loc. 27,28,29,33,37,49,51 (Fig. 50). 


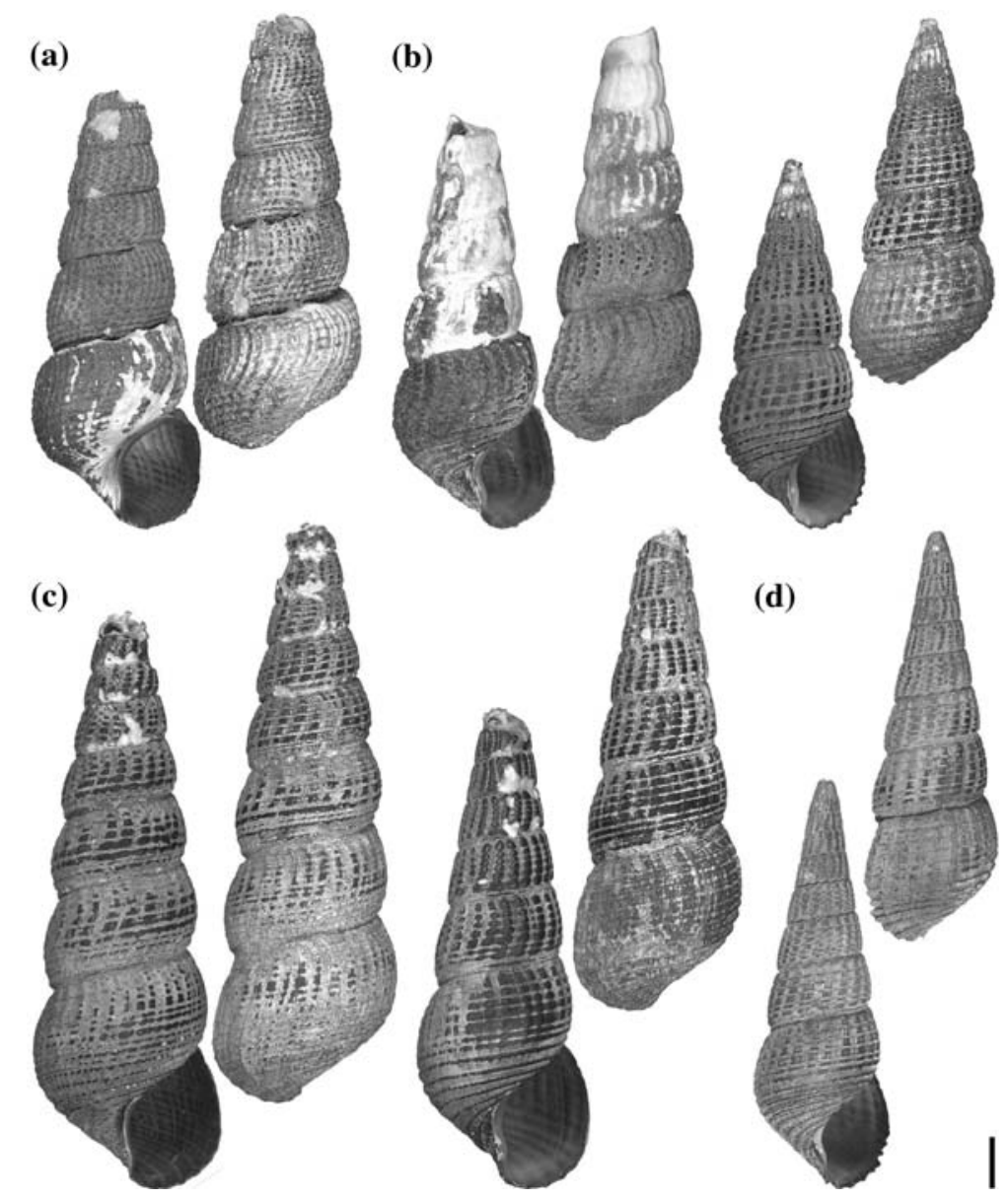

Fig. 44 T. patriarchalis?, shells. a, ZMB 190063 (loc. 9); b, ZMB 190068 (loc. 11); c, ZMB 190074 (loc. 14 ); d, ZMB 190111 (loc. 56). Scale bar $=1 \mathrm{~cm}$

B (Fig. 49c, d). 177-320 rows, 18.0-28.7 mm long, on average 10.5 teeth $/ \mathrm{mm}(n=20)$. Central tooth with very large and almost perfect squarish major denticle, accompanied by two basal, small denticles at each side of it. Glabella more narrow at base. Lateral teeth with very large and squarish major denticle and two smaller denticles at each side as well. Marginal teeth with three (seldom four) denticles each. Outermost denticles large and shovel-like, in the inner marginals squarish, each c. three times larger than innermost denticles, these small and pointed in both marginals. Found in specimens at loc. 29,33,34,36, TW6 (Fig. 50).

C (Fig. 49e, f). 229 rows, $23.0 \mathrm{~mm}$ long, 10.0 teeth $/ \mathrm{mm}$. Central tooth with larger, weakly pointed major denticle, accompanied by two smaller denticles at each side of it. Glabella intermediate between form A and B. Lateral teeth with larger and almost blunt major denticles and two smaller denticles on each side as well. Marginal teeth with three (inner) and 3-4 (outer) denticles, the outermost ones c. three times wider than inner ones. Found in specimens at loc. 34,35 (Fig. 50).

Reproductive biology: Sex ratio $0.49(n=184)$. Males were found to be significantly smaller than females in three populations with sufficiently large sample sizes (ANOVA, shell height): ZMB 190123 (loc. 29), $F=10.956, \quad P<0.001$, $n=48 ; \quad$ ZMB 190134 (loc. 34), $F=16.895$, $P<0.001, \quad n=32$. About $86 \%$ of females $(n=87)$ carry shelled embryos in their brood pouch. 

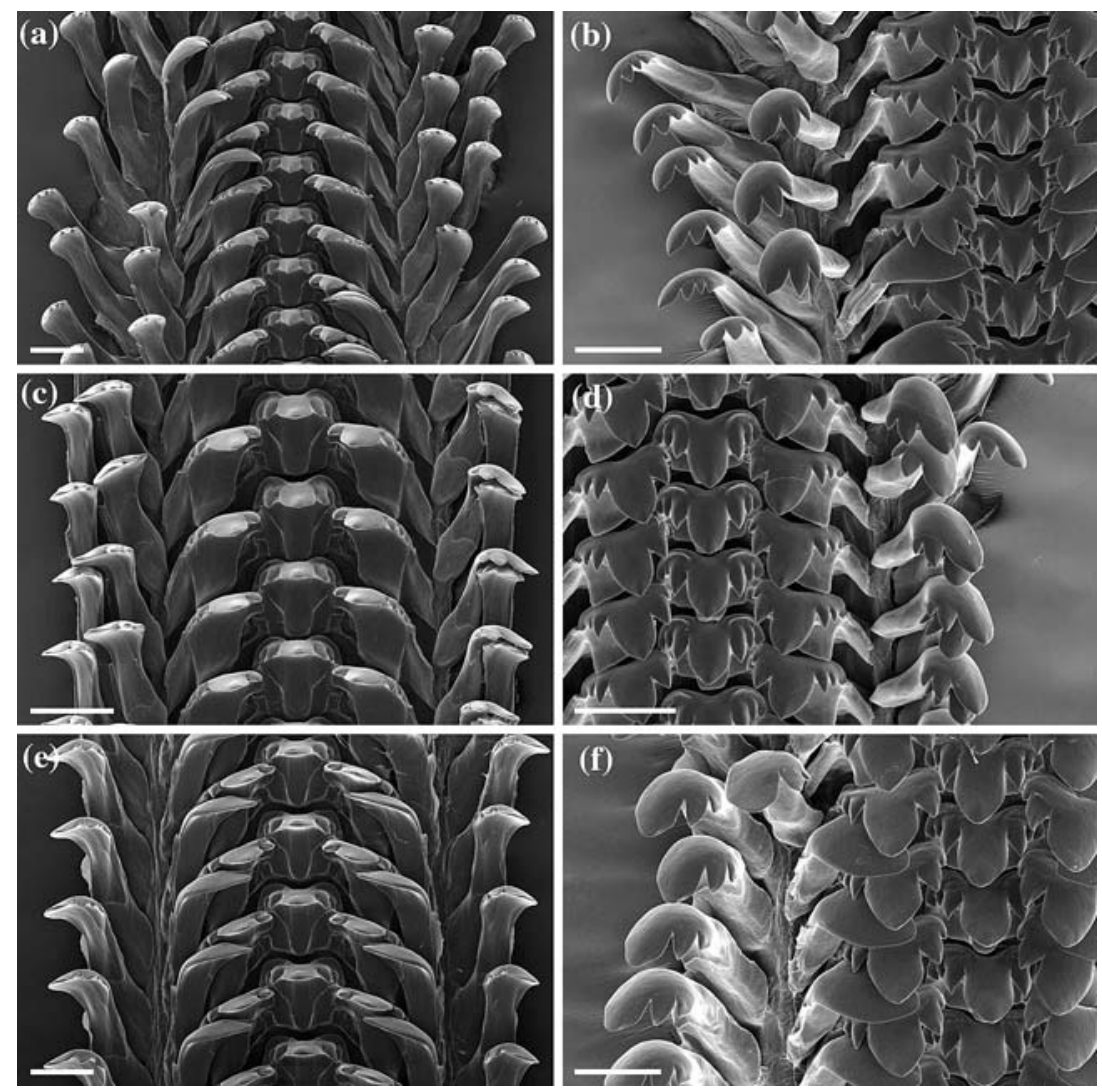

Fig. 45 T. patriarchalis, radula. a, b, ZMB 190050 (loc. 1). a, segment, frontal; b, segment, apical $\left(45^{\circ}\right)$. c, d, ZMB 190061 (loc. 7). c, segment, frontal; d, segment, apical

$\left(45^{\circ}\right)$. e, f, ZMB 190074 (loc. 14). e, segment, frontal; f, segment, apical $\left(45^{\circ}\right)$. Scale bar $=0.1 \mathrm{~mm}$

Brood pouch contains 1-14 embryos, their size can reach $8.0 \mathrm{~mm}$ (Table 3 ).

Embryonic shells (Fig. 51): Conic, with medium to strong axial ribs emerging on the 2nd to 3rd whorl and fading on the 4th to 5th whorl. Shallow, widespaced spiral ribs emerge on the 2nd whorl. Diameter of first whorl between 236 and $332 \mu \mathrm{m}$ (Table 3).

\section{Distribution}

South Sulawesi, Lake Towuti (Fig. 10).

\section{Ecology and habitat}

On hard substrate, rocks and wood.

\section{Taxonomic remarks}

T. sarasinorum has a very distinct shell morphology which generally shows little variation across populations (Fig. 48, Table 2), and the same is true for the embryonic shells (Fig. 51). In contrast, three very different morphs can be distinguished in the radula (forms A-C, see above and Fig. 49). At least three populations (loc. 29, 33, 34, see above) contain both forms $\mathrm{A}$ and $\mathrm{B}$, in addition form $\mathrm{C}$ is found at locality 34 and the geographically close loc. 35 (Fig. 50). This radula polymorphism is quite remarkable, since all other species possessing more than one radula form, as e.g. T. patriarchalis (Figs. 43-45), have in contrast to $T$. sarasinorum a shell which can be highly variable between populations. 


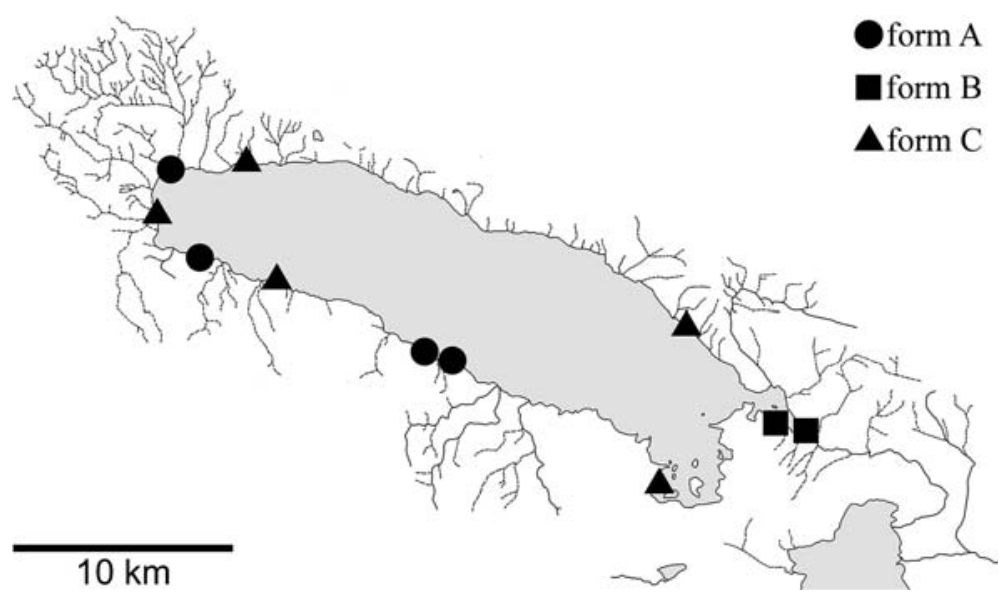

Fig. 46 T. patriarchalis, distribution of radula morphs

\section{Material examined}

Lake Towuti: N-shore, W of Tominanga River, 02 39.3' S, $121^{\circ} 29.7^{\prime} \mathrm{E}$, loc. TW1 (MNHN, $n=9$; $n=31$ in alc.); Loeha Island, E-shore, $02^{\circ} 47.4^{\prime} \mathrm{S}$, $121^{\circ} 35.7^{\prime} \mathrm{E}$, loc. TW6 (MNHN, $\left.n=26\right)$; N-shore, Topimanu Peninsula, $02^{\circ} 41.9^{\prime} \mathrm{S}, 121^{\circ} 38.5^{\prime} \mathrm{E}$, TW8 (MNHN, $n=1 ; n=26$ in alc.); Loeha Island, Wshore, $02^{\circ} 45.49^{\prime} \mathrm{S}, 121^{\circ} 30.93^{\prime} \mathrm{E}$, Loc. 27 (ZMB $190212 n=3$, in alc.); $02^{\circ} 45.91^{\prime} \mathrm{S}, 121^{\circ} 31.38^{\prime} \mathrm{E}$, Loc. 28 (ZMB $190119 n=22$, in alc.); Loeha Island, N-shore, 02 $45.60^{\prime} \mathrm{S}, 121^{\circ} 33.54^{\prime} \mathrm{E}$, Loc. 33 (MZB Gst. $12.360 n=40$; ZMB $190129 n=89$; all in alc.); W-shore, SW of Cape Sioloya, 02 $50.74^{\prime} \mathrm{S}$, 12126.09’ E, Loc. 29 (MZB Gst. $12.361 n=50$; ZMB $190123 n=117$; all in alc.); W-shore, Cape Bakara, 02 40.76' S, 121 $26.09^{\prime}$ E, loc. 34 \& 53 (loc. 34: MZB Gst. $12.362 n=35$; ZMB $190134 n=94$; loc. 53, dive: ZMB $190185 n=9$; all in alc.); W-shore, cape $\mathrm{S}$ of Cape Bakara, 02 ${ }^{\circ} 41.32^{\prime} \mathrm{S}, 121^{\circ} 25.99^{\prime} \mathrm{E}$, Loc. 35 (ZMB $190136 n=9$; all in alc.); W-shore, Cape Rumbia, 02 ${ }^{\circ} 43.36^{\prime} \mathrm{S}, 121^{\circ} 27.85^{\prime} \mathrm{E}$, Loc. 37 (MZB Gst. $12.364 n=25$; ZMB $190143 n=39$; all in alc.); N-shore, $02^{\circ} 39.36^{\prime} \mathrm{S}, 121^{\circ} 29.80^{\prime} \mathrm{E}$, Loc. 49 (ZMB $190171 n=16$, in alc.); N-shore, 02 ${ }^{\circ} 41.67^{\prime} \mathrm{S}$, $121^{\circ} 36.83^{\prime}$ E, Loc. 51 (MZB Gst. $12.366 n=20$; ZMB $190178 n=33$; all in alc.).

\section{Tylomelania tominangensis (Kruimel, 1913)}

Melania tominangensis Kruimel, 1913: 225, pl. 4 Fig. 14. (Tominanga River near Lake Towuti; lectotype, present designation, and 14 paralectotypes, ZMA).

\section{Description}

Shell (Fig. 52): Medium sized, brown, elongately conic, spire angle $15-28^{\circ}$. Top whorls in adult specimens always corroded, 4-8 remaining whorls, can reach up to $39.1 \mathrm{~mm}$ (Table 2). Shell smooth or with spiral striae. Aperture oval, pointed posteriorly and slightly siphonated anteriorly.

External morphology: Headfoot with yellowish-white dots, tentacles striped, mantle edge smooth or slightly serrated. Body coiled in 3-4 whorls.

Operculum (Fig. 7s): almost round and multispiral with 6-7 whorls, last whorl only slightly inflated.

Radula (Fig. 53a, b): Typically pachychilid, 183-244 rows, $11.0-17.8 \mathrm{~mm}$ long, on average 15.5 teeth $/ \mathrm{mm}(n=4)$. Central tooth with slightly enlarged pointed major denticle, accompanied by two smaller denticles at each side of it. Glabella rounded at base. Lateral teeth with enlarged major denticles and two smaller denticles on each side as well. Marginal teeth straight, tips curved and narrow, with three denticles each, the outermost one c. twice as wide as the inner ones.

Reproductive biology: Sex ratio $0.35(n=20)$. About $60 \%$ of females $(n=13)$ carry shelled embryos in their brood pouch, which contains 1-4 embryos, their size can reach $8.5 \mathrm{~mm}$ (Table 3 ). 

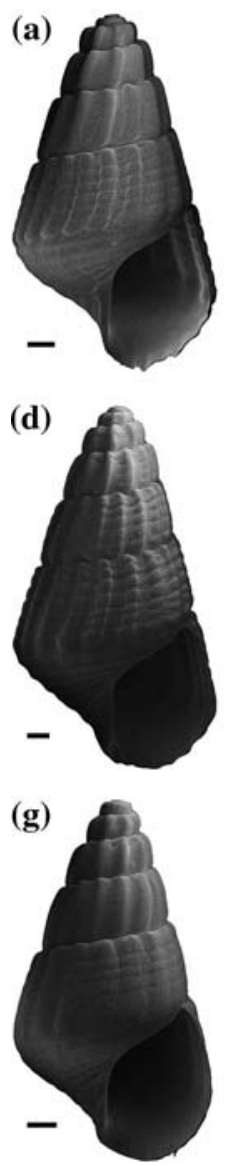

Fig. $47 T$. patriarchalis, embryonic shells. a-c, ZMB 190108 (loc. 54). a, lateral view; b, apical whorls, lateral; c, apical view. d-f, ZMB 190063 (loc. 9). d, lateral view; e, (b)

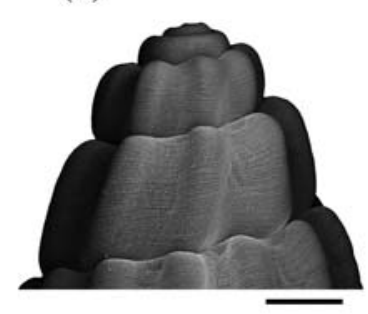

(e)

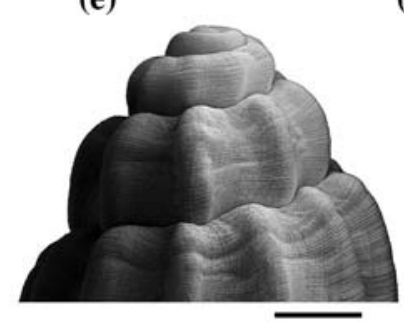

(h)

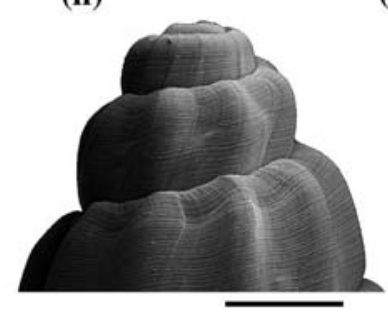

(c)

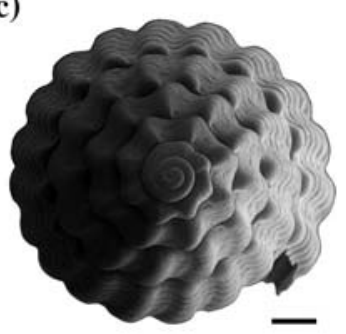

(f)

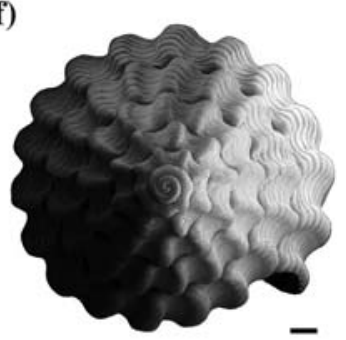

(i)

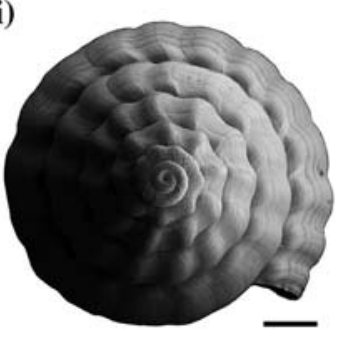

apical whorls, lateral; f, apical view. g-i, ZMB 190061 (loc. 7). g, lateral view; $\mathbf{h}$, apical whorls, lateral; $\mathbf{i}$,. apical view. Scale bar $=0.5 \mathrm{~mm}$
Embryonic shells (Fig. 53c-e): Elongately conic, with strong axial ribs starting with the third whorl and fading on the fifth whorl. Shallow spiral ribs emerge on 3rd to 4th whorl. Diameter of first whorl 263-344 $\mu \mathrm{m}$ (Table 3).

\section{Distribution}

South Sulawesi, Tominanga River and Lake Lontoa (Fig. 10).

\section{Ecology and habitat}

On soft substrate and submerged wood.

\section{Systematic remarks}

T. tominangensis has been described from specimens collected in the Tominanga River. From this locality it is only known from the type series, all attempts to find it during three recent field trips (1999-2002) have been in vain. The specimens from the type locality are distinct from all other species found in the Tominanga River, but barely distinguishable from a smooth form in Lake Lontoa (Figs. 52, 54). The morphological similarity and the connection between the Tominanga River and Lake Lontoa suggest a conspecific status of the smooth Lake 


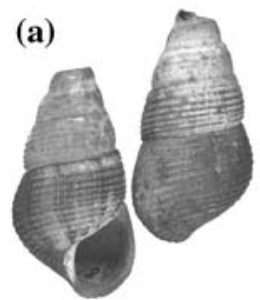

(d)

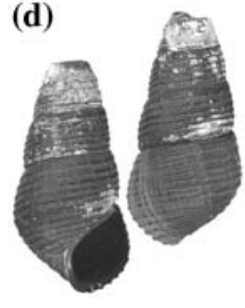

(f)

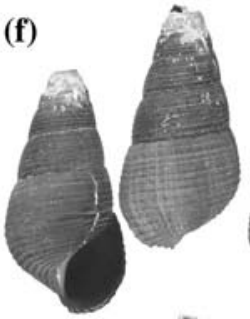

(h)

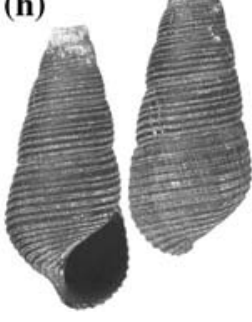

(b)
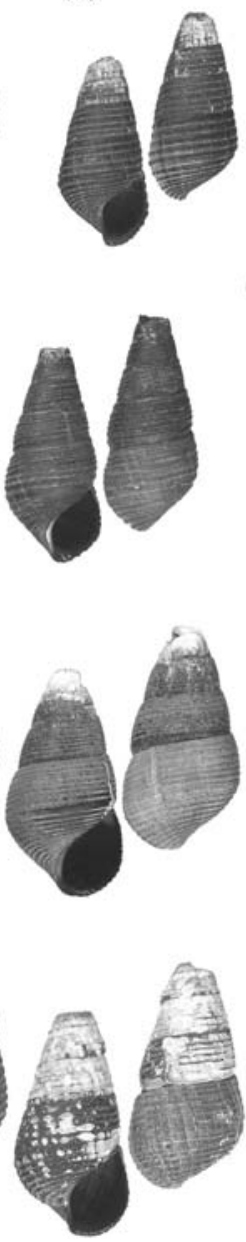

Fig. 48 T. sarasinorum, shells. a, b, types, ZMA (Lake Towuti, Loeha Island). a, lectotype; b, paralectotypes. c, ZMB 190212 (loc. 27); d, ZMB 190119 (loc. 28); e, ZMB

Lontoa species with $T$. tominangensis as proposed above in the description. However, new material from the type locality and samples from the connecting river system (Lampesue River) are needed to test this hypothesis.

\section{Material examined}

Lake Lontoa: SW-shore, loc. WWT1 (MNHN $n=83$ dry, $n=18$ in alc.); W-shore, loc. WWT2 (MNHN $n=70, n=57$ in alc.); W-shore, loc. WWT3 (MNHN $n=28$ in alc.); W-shore,

(c)
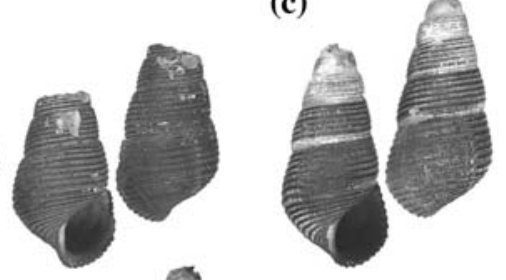

(e)
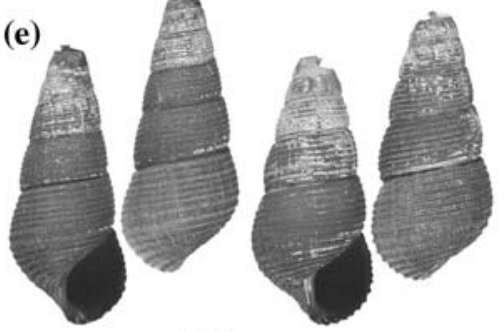

(g)

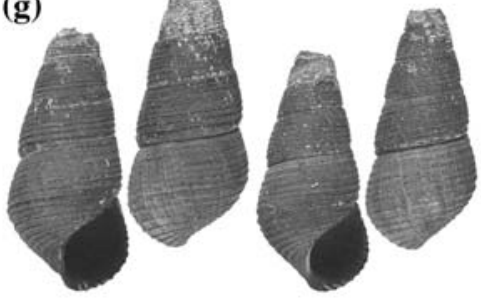

(i)

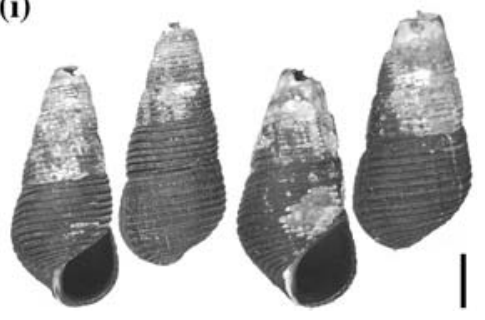

190123 (loc. 29); f, ZMB 190134 (loc. 34); g, ZMB 190143 (loc. 37); h, ZMB 190171 (loc. 49); i, ZMB 190178 (loc. 51). Scale bar $=1 \mathrm{~cm}$

02³9.90’ S, 12143.46’ E, loc. 0028 (MZB Gst. $12.258 n=20$; ZMB 190210b $n=71$ );

Tylomelania towutensis (Sarasin \& Sarasin, 1897)

Melania patriarchalis towutensis Sarasin \& Sarasin, 1897: 311. (Lake Towuti; lectotype NMB 4790a, present designation; 2 (shells -1 of these is not towutensis) and 3 (in alc.) paralectotypes NMB 4790b; paralectotype ZMB 50784). - Sarasin \& Sarasin, 1898: 19, pl. 1 Figs. 7, 8; pl. 5 Fig. 61 (op.); 

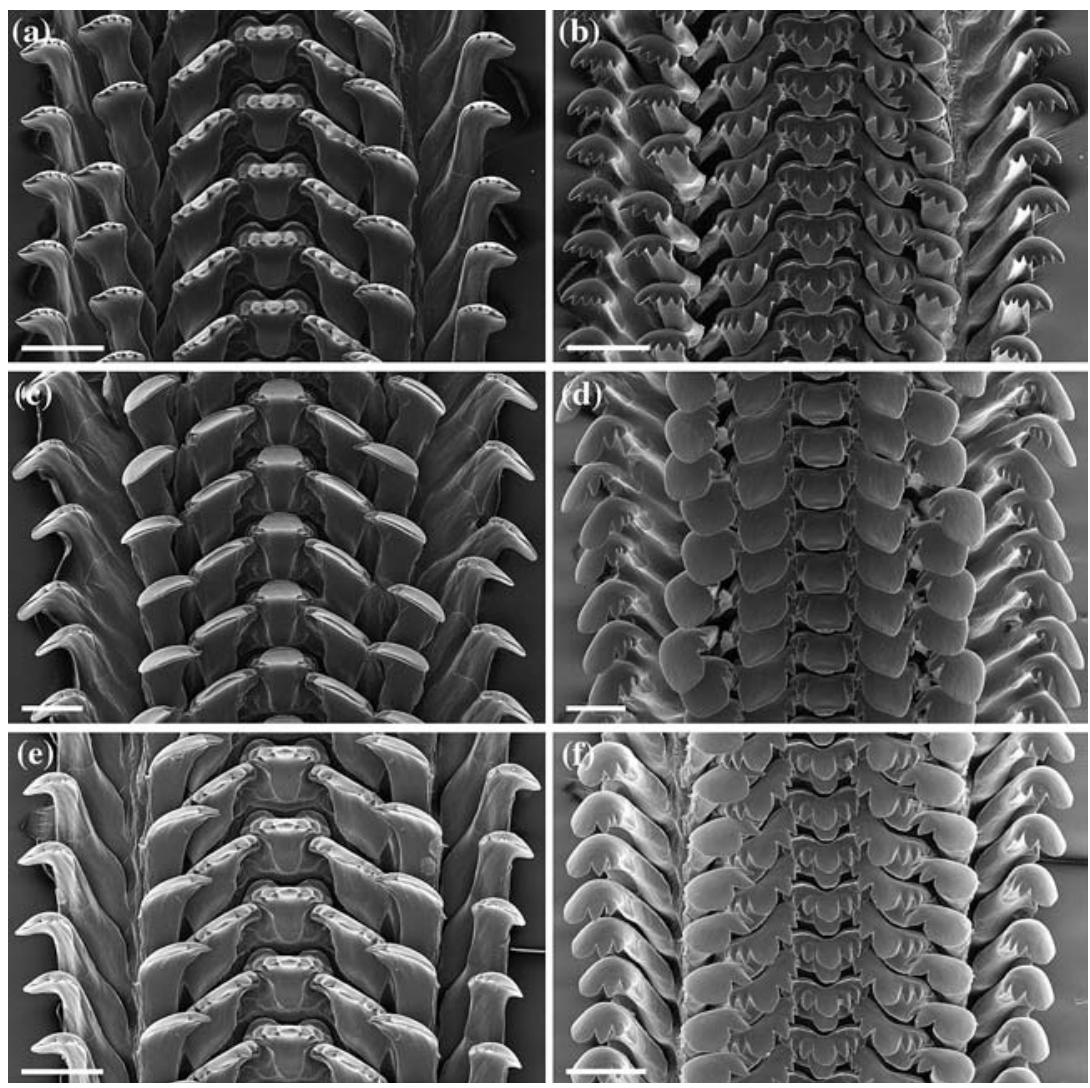

Fig. 49 T. sarasinorum, radula. a-d, ZMB 190123 (loc. 29). a, segment, frontal; b, segment, apical $\left(45^{\circ}\right)$; c, segment, frontal; d, segment, apical $\left(45^{\circ}\right)$. e-f, ZMB

190134 (loc. 34). e, segment, frontal; f, segment, apical $\left(45^{\circ}\right)$. Scale bar $=0.1 \mathrm{~mm}$

pl. 7 Fig. 87,88 (rad.). -Kruimel, 1913: 221, pl. 4 Fig. 6.

\section{Description}

Shell (Fig. 55): Large to very large, brown, occasionally almost red due to encrustations, elongately conic or turreted, spire angle $10-24^{\circ}$. Top whorls in adult specimens always corroded to a varying degree, 4-10 remaining whorls, can reach up to $86.2 \mathrm{~mm}$ (Table 2 ). With to a varying degree inclined or occasionally curved strong axial ribs and weaker spiral ribs. Aperture oval, pointed at top and slightly siphonated at base. Columella and interior white or cream coloured.

External morphology: Headfoot with usually many small white dots, tentacles with white stripes, mantle edge serrated to a varying degree. Body coiled in 3-4.5 whorls.
Operculum (Fig. 7t): ovate, last whorl strongly inflated, multispiral with 9-10 whorls.

Radula (Fig. 56): 172-251 rows, 12.0-20.2 mm long, on average 12.6 teeth per $\mathrm{mm}(n=20)$. Central tooth with to a varying degree larger, pointed major denticle, accompanied by two (rarely three) smaller denticles at each side of it. Lateral teeth with enlarged major denticles and two smaller denticles on each side as well (four denticles on outer side in population at loc. 26). Marginal teeth shovel-like, inner and outer marginals with three denticles each, the outermost ones are more than double as wide as the inner ones.

Reproductive biology: Sex ratio $0.47(n=221)$. Males do not differ significantly in size from females (ANOVA). About $87 \%$ of females $(n=115)$ carry shelled embryos in their brood pouch. 


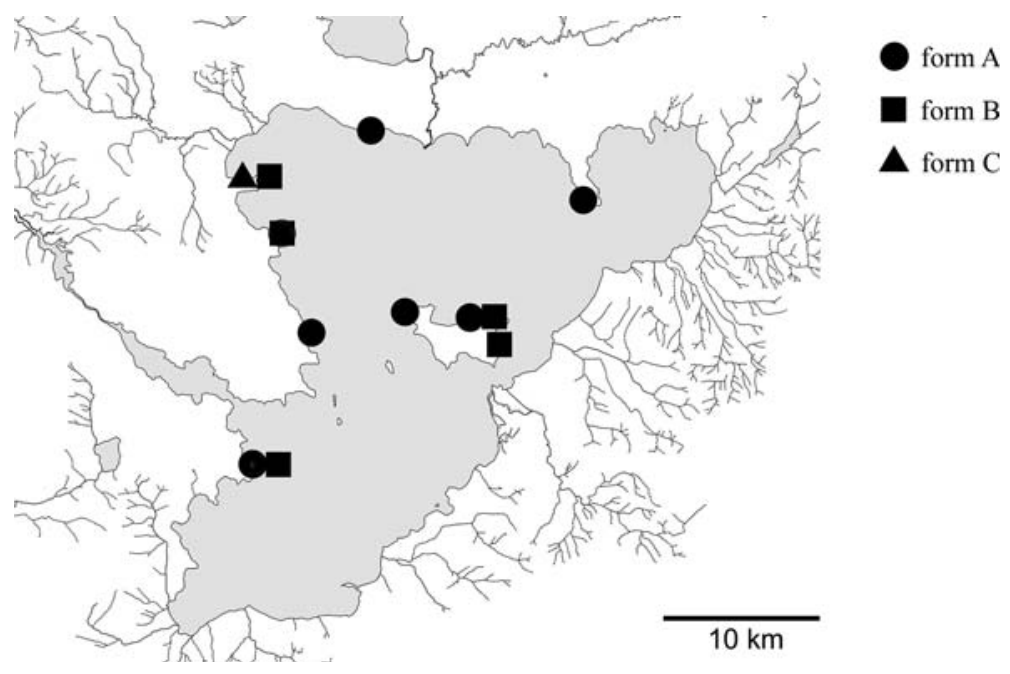

Fig. 50 T. sarasinorum, distribution of radula morphs

Brood pouch contains 1-8 embryos, their size can reach $16.0 \mathrm{~mm}$ (Table 3).

Embryonic shells (Fig. 57): Conic, with strong axial ribs emerging on the 2nd to 3rd whorl. Shallow, widespaced spiral ribs emerge on $3^{\text {rd }}$ to $4^{\text {th }}$ whorl. Diameter of first whorl between 257 and $334 \mu \mathrm{m}$ (Table 3).

\section{Ecology and habitat}

Soft substrate dweller, sand and mud. Occurs from the surface down to a depth of several meters.

\section{Remarks}

Tylomelania towutensis is only slightly less variable than its ecological equivalent in Lake Matano, T. patriarchalis. In contrast to the latter, the shell (Fig. 55) accounts for most of the variability, the radula (Fig. 56) is polymorphic to a much lesser degree. Nevertheless this species might potentially represent a species complex as well. However, similar to the situation in $T$. patriarchalis, more samples with detailed information on substrates are deemed necessary to address this question with some certainity.

\section{Distribution}

South Sulawesi, Lake Towuti and Tominanga River (Fig. 9).

\section{Material examined}

Lake Towuti: N-shore, $\mathrm{W}$ of Tominanga River, $02^{\circ} 39.3^{\prime} \mathrm{S}, 1^{\circ} 1^{\circ} 29.7^{\prime} \mathrm{E}$, loc. TW1 (MNHN, $n=13 ; n=2$, in alc.); $\mathrm{N}$ shore, shallow bay $\mathrm{W}$ of mouth of Tominanga River, TW2 (MNHN, $n=449 ; n=81$, in alc); Loeha Island, E shore, 02 47.4' S, $121^{\circ} 35.7^{\prime} \mathrm{E}$, loc. TW6 (MNHN, $n=61)$ N-shore, Topimanu Peninsula, $02^{\circ} 41.9^{\prime} \mathrm{S}, 121^{\circ} 38.5^{\prime} \mathrm{E}$, TW8 (MNHN, $n=3$, in alc.); NE-shore, Naote Bay, 02 $39.1^{\prime} \mathrm{S}$, $121^{\circ} 42.2^{\prime} \mathrm{E}$, loc. TW9 (MNHN, $n=26$, in alc.); Larona Bay, N-shore, $02^{\circ} 48.7^{\prime} \mathrm{S}, 121^{\circ} 26.5^{\prime} \mathrm{E}$, loc. TW12 (MNHN, $n=11$ in alc.); W-shore, bay at outlet of Larona River, $02^{\circ} 46.09^{\prime} \mathrm{S}, 121^{\circ} 21.57^{\prime} \mathrm{E}$, loc. 26 (MZB Gst. $12.339 n=37$; ZMB 190113 $n=216$; all in alc.); Loeha Island, W-shore, 0245.49’ S, 121 ${ }^{\circ} 30.93^{\prime}$ E, Loc. 27 (MZB Gst. $12.340 n=12$; ZMB $190115 n=31$; all in alc.); W-shore, W of Cape Sioloya, 02 $50.74^{\prime} \mathrm{S}$, $121^{\circ} 26.09^{\prime} \mathrm{E}$, Loc. 29 (ZMB $190120 n=44$, in alc.); W-shore, Cape Tetetu, 02 $54.14^{\prime} \mathrm{S}$, $121^{\circ} 23.75^{\prime}$ E, Loc. 30 (ZMB $190124 n=29$, in 

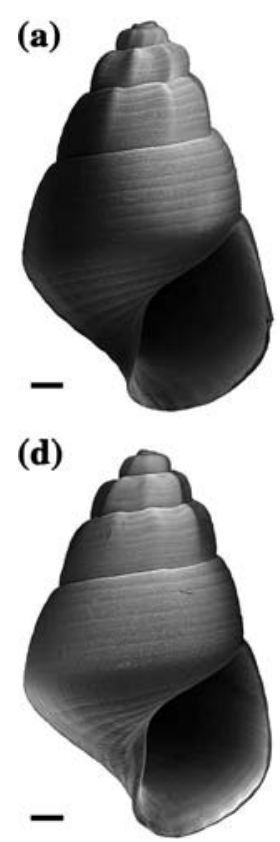

(b)

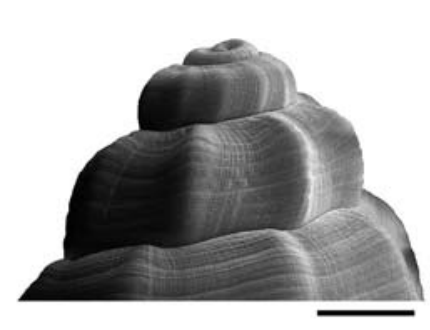

(e)

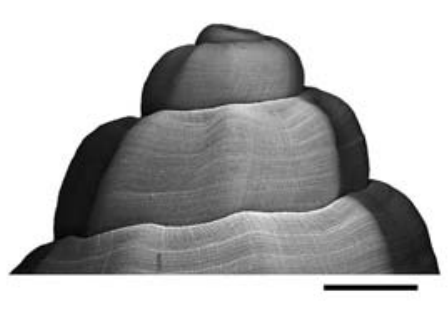

(c)

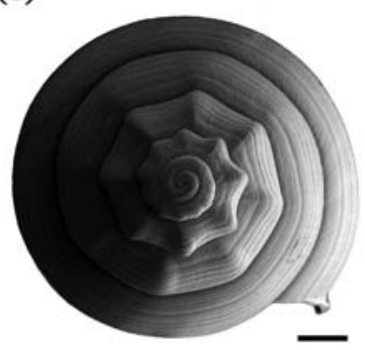

(f)

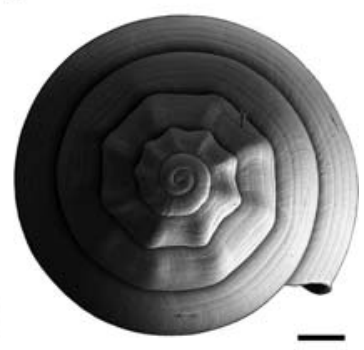

Fig. 51 T. sarasinorum, embryonic shells. a-c, ZMB 190129 (loc. 33). a, lateral view; b, apical whorls, lateral; c, apical view. d-f, ZMB 190143 (loc. 37). d, lateral view; e, apical whorls, lateral; f, apical view. Scale bar $=0.5 \mathrm{~mm}$

alc.); Loeha Island, S-shore, $02^{\circ} 47.17^{\prime} \mathrm{S}$, 121 32.68' E, Loc. 31 (ZMB $190126 n=39$, in alc.); Loeha Island, S-shore, $02^{\circ} 47.21^{\prime} \mathrm{S}$, 121 33.93' E, Loc. 32 (MZB Gst. $12.344 n=20$; ZMB $190127 n=73$; all in alc.); Loeha Island, Nshore, $02^{\circ} 45.60^{\prime} \mathrm{S}, 121^{\circ} 33.54^{\prime} \mathrm{E}$, Loc. 33 (ZMB $190128 n=21$, in alc.); W-shore, cape $\mathrm{S}$ of Cape Bakara, 0241.32' S, 12125.99’ E, Loc. 35 (ZMB $190138 n=61$, in alc.); W-shore, Cape Timbalo, 02 ${ }^{\circ} 42.73^{\prime} \mathrm{S}, 121^{\circ} 26.93^{\prime} \mathrm{E}$, Loc. 36 (ZMB 190139 $n=14$, in alc.); N-shore, Cape Bintu, 02 $39.88^{\prime} \mathrm{S}$, 121 33.01' E, Loc. 50 (ZMB $190174 n=14$, in alc.); N-shore, $02^{\circ} 41.67^{\prime} \mathrm{S}, 121^{\circ} 36.83^{\prime} \mathrm{E}$, Loc. 51 (MZB Gst. $12.350 n=20$; ZMB $190177 n=36$; all in alc.); Anue Island, $02^{\circ} 47.20^{\prime} \mathrm{S}, 121^{\circ} 30.59^{\prime} \mathrm{E}$, Loc. 52 (MZB Gst. $12.351 n=20$; ZMB 190181 $n=40$; all in alc.).

Tominanga River: Bend or outlet of Lake Mahalona, $02^{\circ} 36.52^{\prime} \mathrm{S}, 121^{\circ} 31.58^{\prime} \mathrm{E}$, loc. 45 (ZMB $190166 n=49$, in alc.).

\section{Tylomelania towutica (Kruimel, 1913)}

Melania towutica Kruimel, 1913: 220, pl. 4 Fig. 8. (Lake Towuti, Loeha Island; lectotype, present designation, ZMA; 22 and 63 (in alc.) paralectotypes ZMA; 3 paralectotypes MCZ 65146).

\section{Description}

Shell (Fig. 58): Medium sized, brown, turreted, spire angle $13-25^{\circ}$. Top whorls in adult specimens always corroded to a varying degree, 4-9 remaining whorls, can reach up to $64.9 \mathrm{~mm}$ (Table 2). Straight or slightly inclined, seldomly mildly curved strong axial and weaker spiral ribs. Aperture oval, pointed at top and slightly siphonated at base. Columella and interior dark grey, sometimes almost brownish.

External morphology: Headfoot with white dots or blotches, mantle edge at least partly serrated. Body coiled in 2.5-3.5 whorls.

Operculum (Fig. $7 \mathrm{u}$ ): almost round and multispiral, with 8-9 whorls.

Radula (Fig. 59): 154-274 rows, 11.7-18.8 mm long, on average 13.3 teeth per mm $(n=18)$. Central tooth with considerably larger, pointed major denticle, accompanied by two smaller denticles at each side of it. Glabella with short extensions. Lateral teeth with enlarged major 

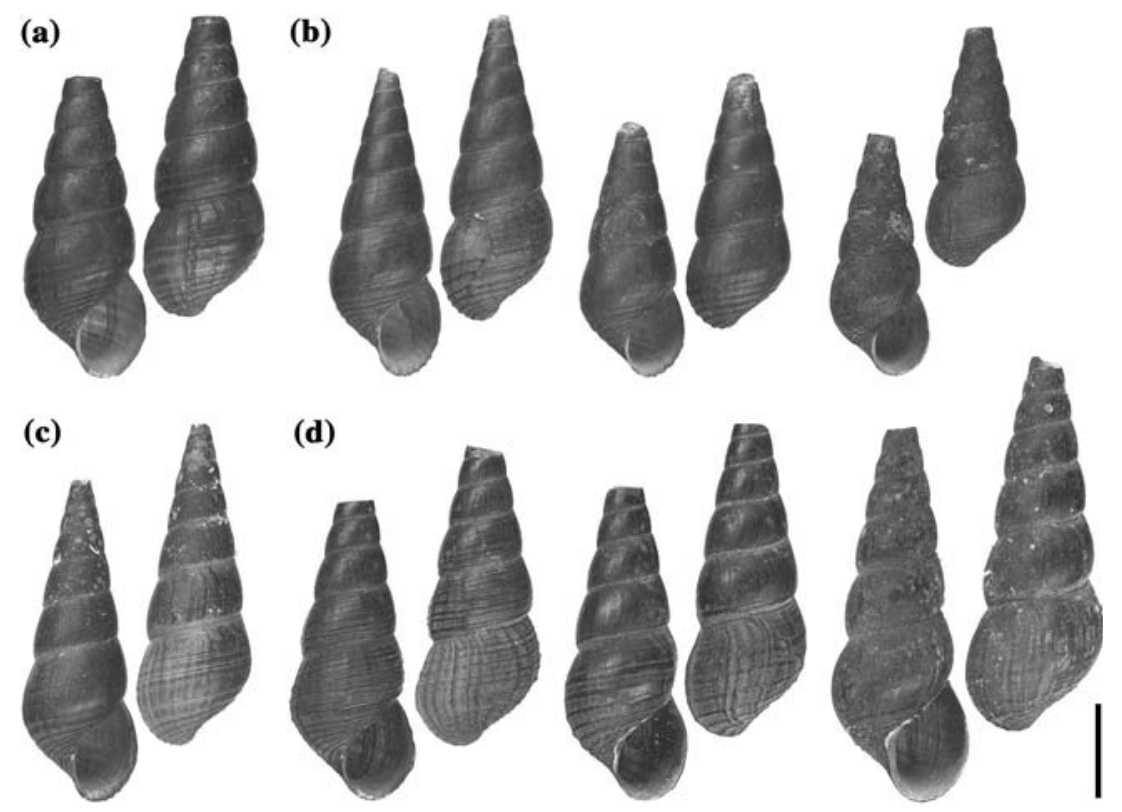

Fig. 52 T. tominangensis, shells. a, b, Types, ZMA (Tominanga River). a, lectotype; b, paralectotypes. c, ZMB 190210 (loc. 0028). Scale bar $=1 \mathrm{~cm}$

denticles and two smaller denticles on each side as well. Marginal teeth shovel-like, inner and outer marginals with three denticles each, the outermost ones are more than double as wide as the inner ones.

Reproductive biology: Sex ratio $0.36(n=103)$. About $92 \%$ of females $(n=65)$ carry shelled embryos in their brood pouch. Brood pouch contains 1-7 embryos, their size can reach $9.3 \mathrm{~mm}$ (Table 3).

Embryonic shells (Fig. 60): Ovate to conic, with strong axial ribs emerging on the second whorl. Shallow, widespaced spiral ribs emerge on the third whorl. Diameter of first whorl between 241 and $333 \mu \mathrm{m}$ (Table 3).

\section{Ecology and habitat}

Hard substrate dweller, on rocks and sunken wood. Occurs from a depth of ca. $0.5-1 \mathrm{~m}$ to several meters. Often syntopic with $T$. sarasinorum.

\section{Taxonomic remarks}

Tylomelania towutica has probably the most homogenous morphology of any widespread species in the Malili lake system. It can easily be distinguished from all other axially ribbed species by its highly turreted shell with the more or less straight axial ribs in combination with its relatively small size.

\section{Distribution}

South Sulawesi, Lake Towuti and Tominanga River (Fig. 9).

\section{Material examined}

Lake Towuti: N-shore, $\mathrm{W}$ of Tominanga River, 02³9.3' S, 121 $29.7^{\prime} \mathrm{E}$, loc. TW1 (MNHN, $n=536 ; n=32$, in alc.); N-shore, cape $\mathrm{E}$ of Tominanga River, $02^{\circ} 39.9^{\prime} \mathrm{S}, 121^{\circ} 34.5^{\prime} \mathrm{E}$, loc. TW4 (MNHN, $n=66 ; n=13$, in alc.); Loeha Island, E shore, $02^{\circ} 47.4^{\prime} \mathrm{S}, 121^{\circ} 35.7^{\prime} \mathrm{E}$, loc. TW6 (MNHN, $n=86$ ); N-shore, Topimanu Peninsula, $02^{\circ} 41.9^{\prime} \mathrm{S}, 121^{\circ} 38.5^{\prime} \mathrm{E}$, TW8 (MNHN, $n=178$; $n=35$, in alc.); Loeha Island, W-shore, 0245.49’ S, 12130.93’ E, Loc. 27 (MZB Gst. $12.326 n=50$; ZMB $190116 n=168$; all in alc.); Loeha Island, W-shore, $02^{\circ} 45.91^{\prime} \mathrm{S}, 121^{\circ} 31.38^{\prime} \mathrm{E}$, Loc. 28 (MZB Gst. $12.327 n=30$; ZMB 190118 $n=149$; all in alc.); W-shore, W of Cape Sioloya, 


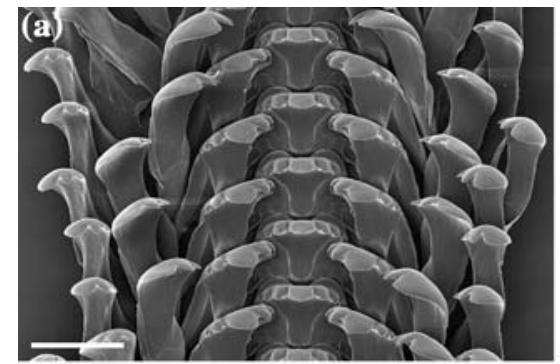

(c)

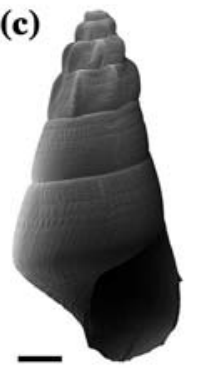

(d)

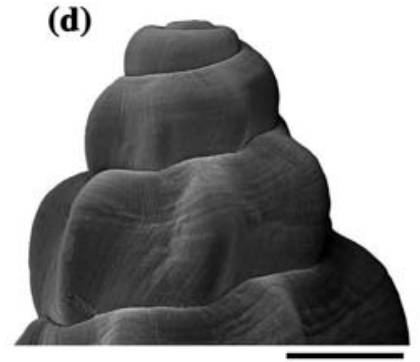

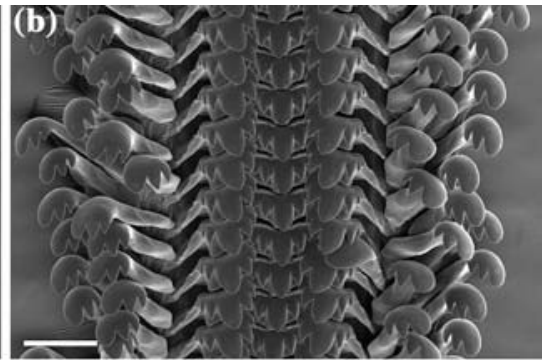

(e)

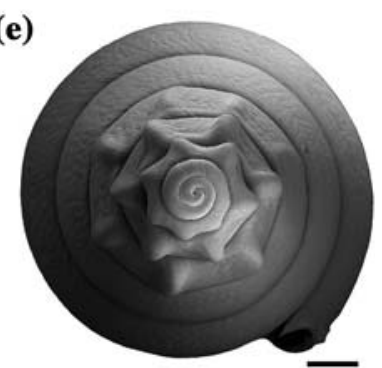

Fig. 53 T. tominangensis, radula and embryonic shells, ZMB 190210 (loc. 0028). a, b, radula. a, segment, frontal; b, segment, apical $\left(45^{\circ}\right)$. Scale $=0.1 \mathrm{~mm}$. $\mathbf{c}-\mathbf{e}$, embryonic shells. c, lateral view; d, apical whorls, lateral; e, apical view. Scale bar $=0.5 \mathrm{~mm}$
02 $50.74^{\prime} \mathrm{S}, 1^{\circ} 1^{\circ} 26.09^{\prime} \mathrm{E}$, Loc. 29 (ZMB 190121 $n=3$, in alc.); W-shore, Cape Tetetu, 02 $54.14^{\prime} \mathrm{S}$, 121 $23.75^{\prime}$ E, Loc. 30 (ZMB $190125 n=134$, in alc.); W-shore, cape $\mathrm{S}$ of Cape Bakara, 0241.32' S, 121 ${ }^{\circ} 25.99^{\prime}$ E, Loc. 35 (ZMB 190135 $n=67$, in alc.); W-shore, Cape Timbalo, 02 ${ }^{\circ} 42.73^{\prime} \mathrm{S}, 1^{\circ} 1^{\circ} 26.93^{\prime} \mathrm{E}$, Loc. 36 (MZB Gst. $12.331 n=45$; ZMB $190141 n=106$; all in alc.); W-shore, Cape Rumbia, 02 43.36 S, $121^{\circ} 27.85^{\prime}$ E, Loc. 37 (MZB Gst. $12.332 n=20$; ZMB $190144 n=75$; all in alc.); N-shore, $02^{\circ} 39.36^{\prime} \mathrm{S}, 121^{\circ} 29.80^{\prime} \mathrm{E}$, Loc. 49 (MZB Gst. $12.333 n=45$; ZMB $190172 n=88$; all in alc.);

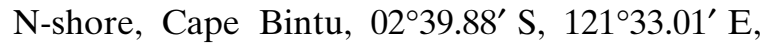
Loc. 50 (MZB Gst. $12.334 n=35$; ZMB 190176 $n=85$; all in alc.); N-shore, $02^{\circ} 41.67^{\prime} \mathrm{S}$, 12136.83' E, Loc. 51 (ZMB $190179 n=22$; all in alc.); Anue Island, $02^{\circ} 47.20^{\prime} \mathrm{S}, 121^{\circ} 30.59^{\prime} \mathrm{E}$, Loc. 52 (ZMB $190182 n=4$, in alc.).

Tominanga River: at midway between Lakes Mahalona and Towuti, 02³8.5' S, 121 ${ }^{\circ} 45.1^{\prime} \mathrm{E}$, loc. MHL1 (MNHN, $n=79 ; n=16$, in alc.); in lower course below rapids, $02^{\circ} 39^{\prime} \mathrm{S}, 121^{\circ} 33.3^{\prime} \mathrm{E}$, loc. MHL7 (MNHN, $n=74 ; n=17$, in alc.); terminal part, $02^{\circ} 39.8^{\prime} \mathrm{S}, 121^{\circ} 33.1^{\prime} \mathrm{E}$, loc. TW3 (MNHN, $n=1$ ); above rapids, $02^{\circ} 37.26^{\prime} \mathrm{S}$,
12131.85' E, loc. 46 (ZMB $190166 n=36$, in alc.); beneath mouth of Lampesue River, 0237.56’ S, 121 $31.94^{\prime} \mathrm{E}$, loc. 47 (MZB Gst. $12.338 n=25$; ZMB $190169 n=48$; all in alc.).

Tylomelania turriformis new species

Type material: Holotype (Fig. 61a; $94.5 \mathrm{~mm} \times$ $28.3 \mathrm{~mm}$; Lake Matano: N-shore, 02²5.76’ S, $121^{\circ} 15.27^{\prime}$ E, loc. 18 (MZB Gst. 12.103). Paratypes (Fig. 61b,c): Lake Matano: N-shore, $02^{\circ} 25.76^{\prime} \mathrm{S}, 121^{\circ} 15.27^{\prime} \mathrm{E}$, loc. 18 (MZB Gst. 12.288, $n=8$; ZMB 190091, $n=26$; all in alc.); SE-bay, W-shore, $02^{\circ} 33.28^{\prime} \mathrm{S}, 121^{\circ} 24.97^{\prime} \mathrm{E}$, loc. 14 (ZMB 190073, $n=5$; all in alc.).

Etymology: The new species has been named T. turriformis because of its highly turreted shell.

\section{Description}

Shell (Fig. 61): Large, yellowish to light brown, highly turreted, spire angle $9-20^{\circ}$, top whorls in adult specimens always corroded to a varying degree, 7-10 remaining whorls, can reach up to $94.6 \mathrm{~mm}$ (Table 2). Comparatively few strong, straight or mildly curved axial ribs per whorl, 
Type series, Tominanga River, ZMA ( $\mathrm{n}=11)$

$\bigcirc$ Lake Lontoa specimens, MNHN \& ZMB ( $n=149)$

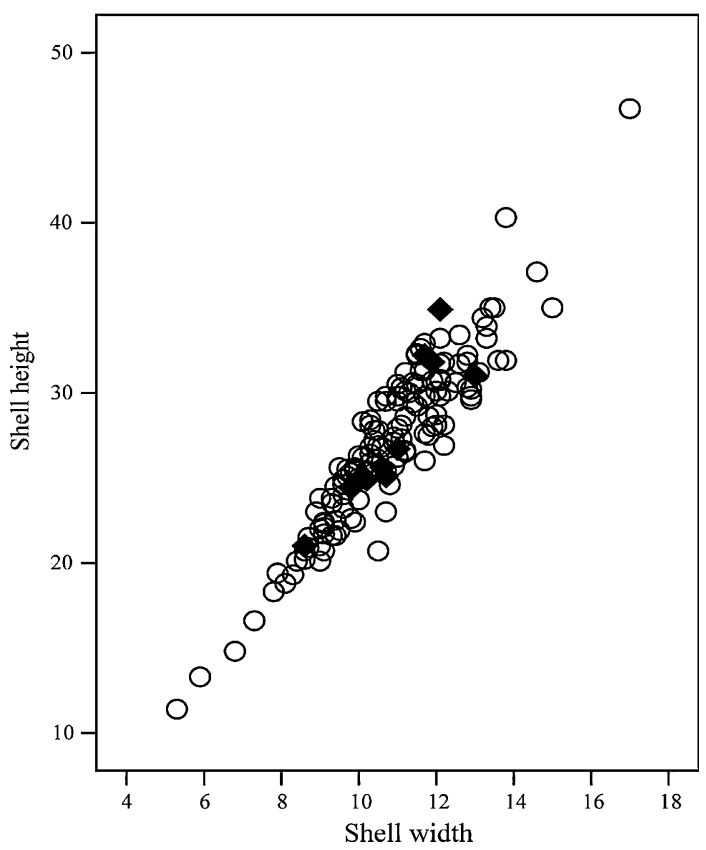

Fig. 54 T. tominangensis, scatter plots of selected shell parameters

almost always inclined, 14-22 on body whorl. Spiral ribs weak. Aperture almost round to oval, interior brown to whitish.

External morphology: Headfoot with fine white dots or stripes, tentacles with white stripes, mantle edge smooth or slightly serrated. Body coiled in 3.5 whorls.

Operculum (Fig. 7w): almost round, multispiral, with 8 whorls.

Radula (Fig. 62a, b): 168-247 rows, 14.7$17.5 \mathrm{~mm}$ long, on average 13.3 teeth per mm $(n=4)$. Central tooth with large, spoon-shaped major denticle, accompanied by two very much smaller denticles at each side of it. Glabella more narrow at base. Lateral teeth with enlarged, wide spoon-shaped major denticle and two smaller denticles on each side as well. Marginal teeth weakly concave, tips curved and comparatively long, with three denticles each, the outermost ones are c. four times larger than the inner ones.

Reproductive biology: Sex ratio $0.1(n=10)$. All examined females $(n=4)$ carried shelled embryos in their brood pouch. Brood pouch contains 2-24 embryos, their size can reach $8.1 \mathrm{~mm}$ (Table 3).

Embryonic shells (Fig. 62c-e): Elongated conic, with strong axial ribs emerging on the 2nd to 3rd whorl. Shallow, widespaced spiral ribs emerge on the third whorl. Diameter of first whorl between 268 and $318 \mu \mathrm{m}$ (Table 3).

\section{Distribution}

South Sulawesi, Lake Matano (Fig. 9).

\section{Ecology and habitat}

On soft substrate, syntopic with $T$. patriarchalis, less abundant.

\section{Taxonomic remarks}

The shell of Tylomelania turriformis is very characteristic due to its size, highly turreted form and the prominent wide-spaced axial ribs. In some specimens the whorls have a tendency to become detached. This distinctiveness and the syntopic occurence with $T$. patriarchalis prompted the description of this new species despite the rather small sample sizes. The shells of Tylomelania turriformis rather vaguely resemble those of $T$. gemmifera by possessing strong axial ribs and being turreted, but the radula lacks the thiarid-like appearance found in the latter species and is similar to that found in T. zeamais (cf. Fig. 68).

\section{Tylomelania wesseli new species}

Type material: Holotype (Fig. 63a; $30.2 \mathrm{~mm} \times$ $14.4 \mathrm{~mm}$ ): Tominanga River, $\mathrm{S}$ of Lampesue inlet, $02^{\circ} 37.56^{\prime} \mathrm{S}, 121^{\circ} 31.94^{\prime} \mathrm{E}$, loc. 47 (MZB Gst. 12.104, in alc.). Paratypes (Fig. 63b-d): Tominanga River: in lower course below rapids, 0239’ S, 121 33.3' E, loc. MHL7 (MNHN 9981, $n=31$; MNHN 9982, $n=17$ in alc.); terminal part, $02^{\circ} 39.8^{\prime} \mathrm{S}, 121^{\circ} 33.1^{\prime} \mathrm{E}$, loc. TW3 (MNHN 9983, $n=61$ in alc.); $\mathrm{S}$ of Lampesue inlet, 02 $37.56^{\prime} \mathrm{S}, 121^{\circ} 31.94^{\prime} \mathrm{E}$, loc. 47 (MZB Gst. 12.368, $n=50$; ZMB $190168 n=122$; all in alc.). 

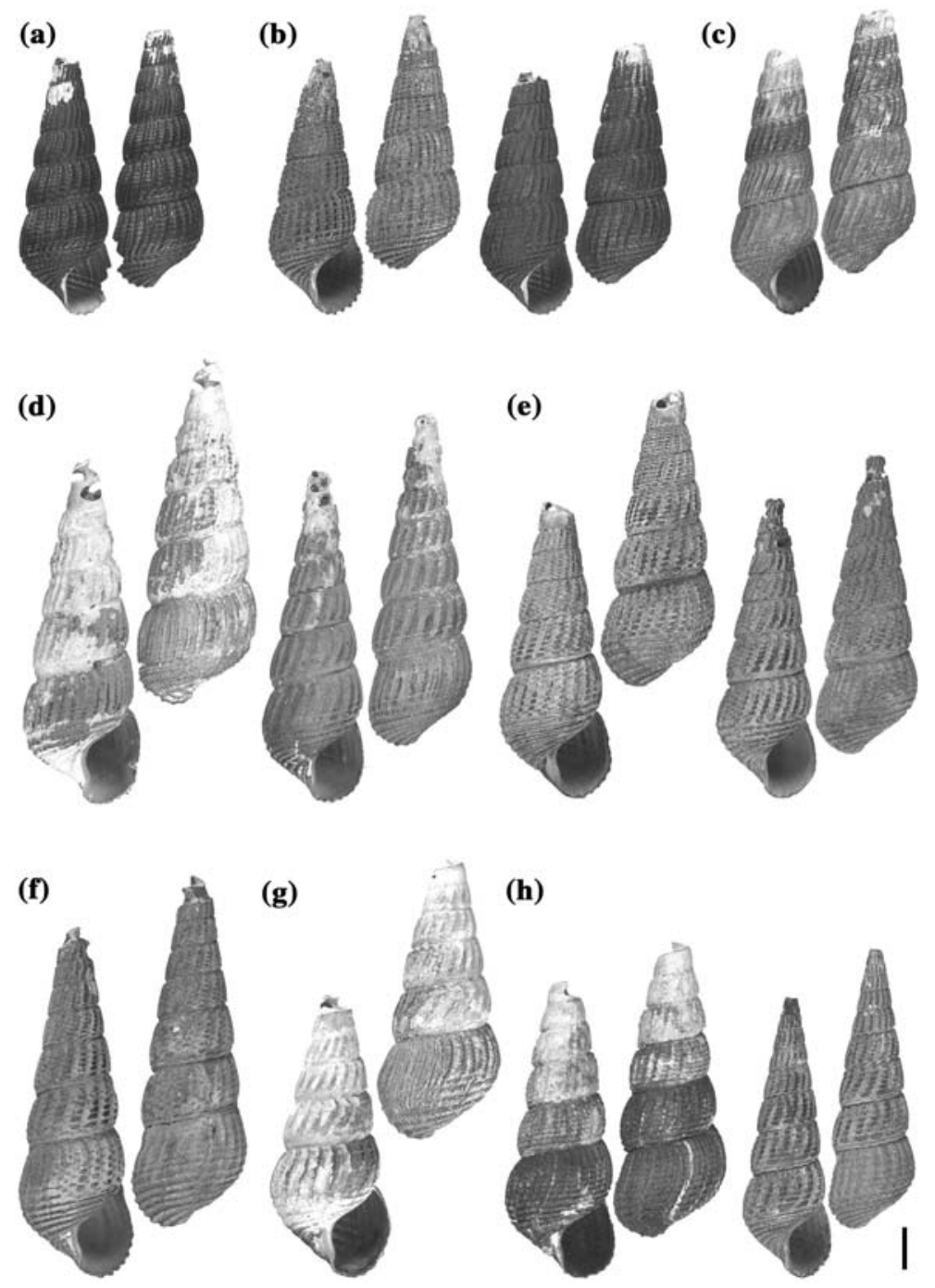

Fig. 55 T. towutensis, shells. a,b, types (Lake Towuti). a, lectotype, NMB 4790a; b, paralectotypes, NMB 4790b. c, ZMB 190113 (loc. 26); d, ZMB 190115 (loc. 27); e, ZMB
190126 (loc. 31); f, ZMB 190181 (loc. 52); g, ZMB 190139 (loc. 36); h, ZMB 190165 (loc. 45). Scale bar $=1 \mathrm{~cm}$
Etymology: The new species is named wesseli for the remembrance of a delightful yet involuntary swim by Andreas Wessel (ZMB) and the first author at the type locality at the rapids of Tominanga River owing to the navigation skills of the local boatdriver.

\section{Description}

Shell (Fig. 63): Small sized, reddish-brown or brown, elongated conic, spire angle $13-42^{\circ}$, top whorls in adult specimens always corroded to a varying degree, 3-7 remaining whorls, can reach up to $30.2 \mathrm{~mm}$ (Table 2). Sculpture consists of spiral ribs only, 5-9 on body whorl. Aperture oval, pointed at top, slightly siphonated at base.

External morphology: Headfoot black with no or usually only few white dots of varying size, mantle edge serrated. Body coiled in 2.5-3.5 whorls.

Operculum (Fig. 7x): almost round, last whorl inflated, multispiral, with 6 whorls. 

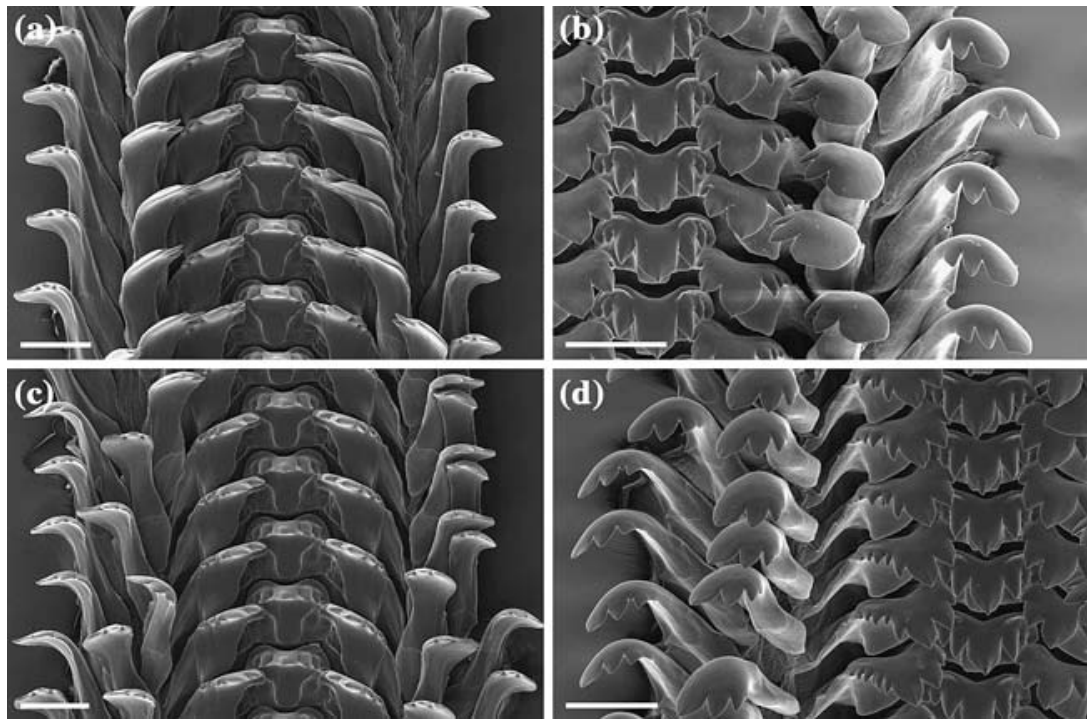

Fig. 56 T. towutensis, radula. a, b, ZMB 190115 (loc. 27). a, segment, frontal; b, segment, apical $\left(45^{\circ}\right)$. c, d, ZMB 190113 (loc. 26). c, segment, frontal; d, segment, apical

(45). e, f, ZMB 190139 (loc. 36). e, segment, frontal; f, segment, apical $\left(45^{\circ}\right)$. Scale bar $=0.1 \mathrm{~mm}$

Radula (Fig. 64a, b): 143-167 rows, 10.5$13.2 \mathrm{~mm}$ long, on average 13.1 teeth/mm $(n=2)$. Central tooth with very large and almost perfect squarish major denticle, accompanied by two basal, small denticles at each side of it. Glabella more narrow at base. Lateral teeth with very large and squarish major denticle and two smaller denticles at each side as well. Marginal teeth with three (seldom four) denticles each. Outermost denticles large and shovel-like, in the inner marginals squarish, each c. three times larger than innermost denticles, these small and pointed in both marginals.

Reproductive biology: Sex ratio $0.28(n=18)$. About $33 \%$ of females $(n=3)$ carry shelled embryos in their brood pouch. Brood pouch contains seven embryos, their size can reach $4.0 \mathrm{~mm}$ (Table 3).

Embryonic shells (Fig. 64c-e): Conic, with medium sized axial ribs emerging on the second whorl and fading on the 4th to 5th whorl. Shallow, widespaced spiral ribs emerge on the 3rd whorl. Diameter of first whorl between 260 and $274 \mu \mathrm{m}$ (Table 3).

\section{Distribution}

South Sulawesi, Tominanga River (Fig. 10).

\section{Ecology and habitat}

On hard substrate, rocks and wood.

\section{Taxonomic remarks}

T. wesseli resembles a smaller and slender version of $T$. sarasinorum, and it has a radula very similar to one radula morph of the latter species (Fig. 49 c, d). Despite this superficial similarity, however, $T$. wesseli is a rather distinct species with a very localized distribution.

\section{Tylomelania wolterecki new species}

Type material: Holotype (Fig. 65a; $41.8 \mathrm{~mm} \times$ $13.5 \mathrm{~mm}$ ): Lake Mahalona, SE shore, outflow into Tominanga River, $02^{\circ} 36.88^{\prime} \mathrm{S}, 121^{\circ} 30.98^{\prime} \mathrm{E}$, loc. 38 (MZB Gst. 12.281). Paratypes (Fig. 65b-d): Lake Mahalona: E-shore, Timbalo, inlet of Petea River, 02³4.6' S, $121^{\circ} 9^{\prime}$ E, loc. MHL4 (MNHN 9997, $n=83$; MNHN 9998, $n=14$, in alc.); S shore, c. $1 \mathrm{~km} \mathrm{~W}$ of Tominanga River outlet, $02^{\circ} 37.2^{\prime} \mathrm{S}$, 12131.6' E, loc. MHL6 (MNHN 9984, $n=6$; MNHN 9985, $n=1$, in alc.); SE shore, outflow into Tominanga River, $02^{\circ} 36.88^{\prime} \mathrm{S}, 121^{\circ} 30.98^{\prime} \mathrm{E}$, loc. 38 (MZB Gst. 12.282, $n=40$; ZMB 190147, $n=78$; all in alc.); E shore, cape, $02^{\circ} 35.58^{\prime} \mathrm{S}, 121^{\circ} 30.68^{\prime} \mathrm{E}$, 

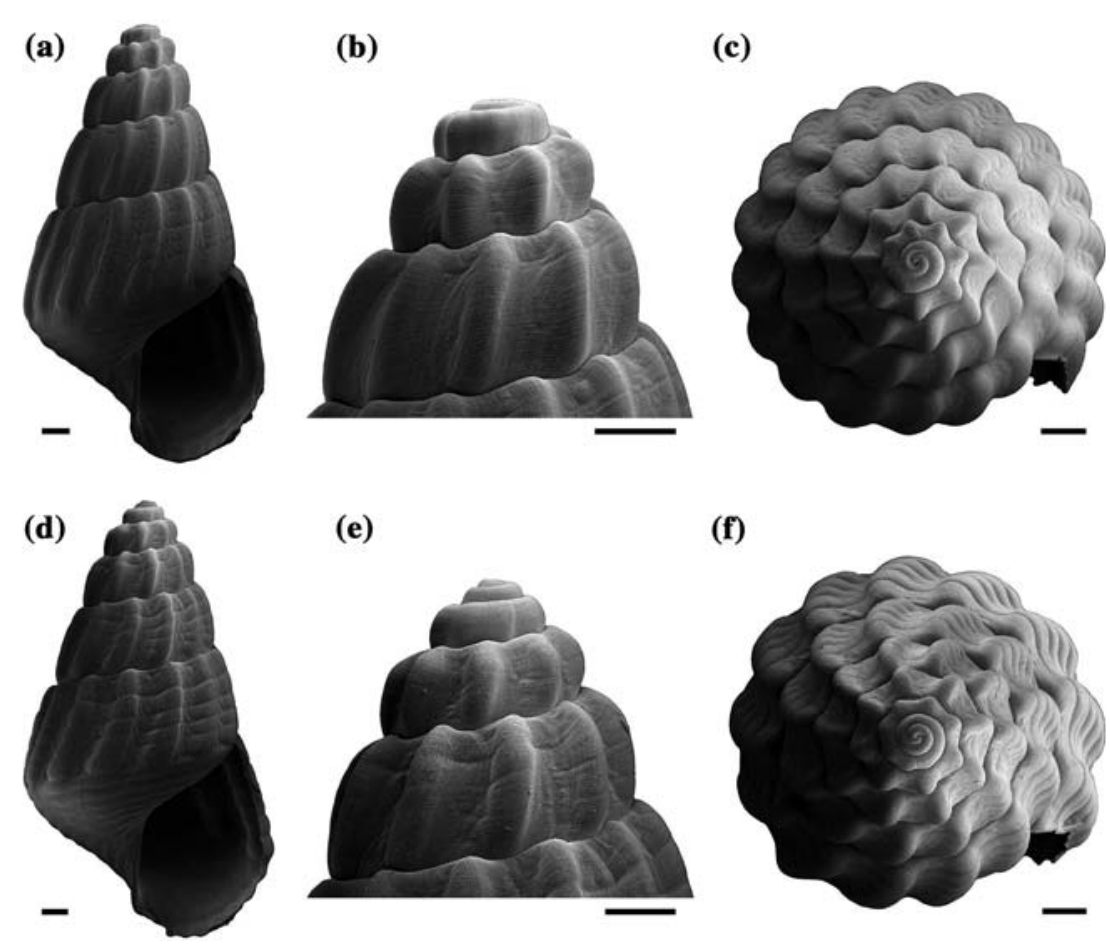

Fig. 57 T. towutensis, embryonic shells. a-c, ZMB 190113 (loc. 26). a, lateral view; b, apical whorls, lateral; c, apical view. df, ZMB 190138 (loc. 35). d, lateral view; e, apical whorls, lateral; f, apical view. Scale bar $=0.5 \mathrm{~mm}$

Loc. 39 (MZB Gst. 12.283, $n=39$; ZMB 190148, $n=69$; all in alc.). Lake Towuti: $\mathrm{N}$ shore, shallow bay $\mathrm{W}$ of mouth of Tominanga River, TW2 (MNHN 9986, $n=83$; MNHN 9987, $n=6$, in alc);

Etymology: The name wolterecki is given in reference to the German limnologist Richard Woltereck, who early recognized the potential of the Malili lakes as a model system for speciation research (Woltereck 1931, 1941).

\section{Description}

Shell (Fig. 65): Medium sized, almost black, turreted to highly turreted, top whorls in adult specimens always corroded to a varying degree, 3-8 remaining whorls, can reach up to $49.2 \mathrm{~mm}$ (Table 2). Usually widely spaced and mildly curved axial ribs, occasionally inclined, 12-36 on body whorl. Spiral ribs weaker. Aperture roundish, pointed at top. Outer lip slightly siphonated at base.

External morphology: Headfoot with yellow dots, tentacles with yellow stripes, mantle edge slightly serrated. Body coiled in 3-3.5 whorls.
Operculum (Fig. 7y): almost round and multispiral, with 5 whorls.

Radula (Fig. 66a, b): Highly modified, appears thiarid-like, 101-144 rows, 3.2-6.4 mm long, on average 28.4 teeth $/ \mathrm{mm}(n=3)$. Central tooth with larger, pointed major denticle, accompanied by two smaller denticles at each side of it. Lateral teeth with enlarged major denticles and two smaller denticles on each side as well. Marginal teeth straight in basal half, widely curved above, tips narrow, with 5-6 denticles of almost equal size.

Reproductive biology: Sex ratio $0.36(n=15)$. About $86 \%$ of females $(n=7)$ carry shelled embryos in their brood pouch.

Brood pouch contains 1-3 embryos, their size can reach $7.8 \mathrm{~mm}$ (Table 3 ).

Embryonic shells (Fig. 66c-e): Elongately conic, almost turreted, with strong axial ribs emerging on the second whorl. Shallow, widespaced spiral ribs emerge on 2nd to 3rd whorl. Diameter of first whorl between 289 and $375 \mu \mathrm{m}$ $(n=2$, Table 3$)$. 

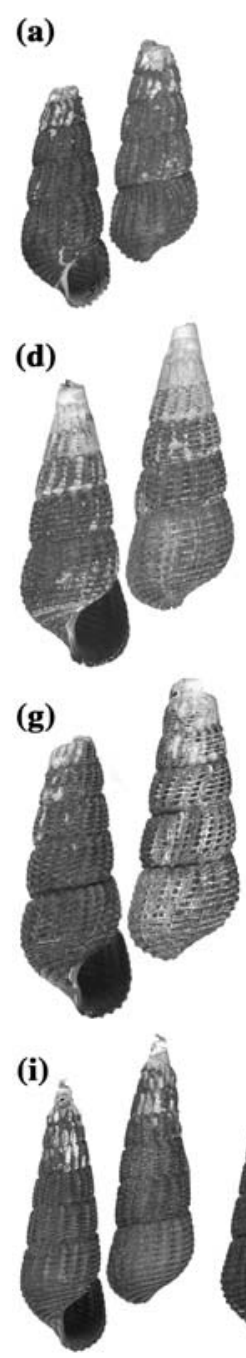

(b)

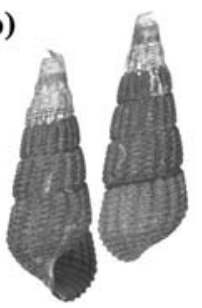

(e)
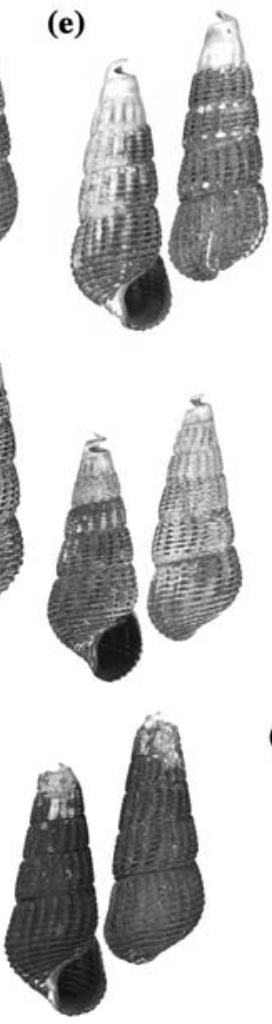

Fig. 58 T. towutica, shells. a, lectotype, ZMA (Lake Towuti); b, ZMB 190116 (loc. 27); c, ZMB 190118 (loc. 28); d, ZMB 190135 (loc. 35); e, ZMB 190141 (loc. 36); f,

\section{Distribution}

South Sulawesi, Lake Mahalona and Lake Towuti (Fig. 9).

\section{Ecology and habitat}

Soft substrate dweller, in shallow water on sand and mud. Syntopic with T. mahalonensis, about equally abundant.

(c)
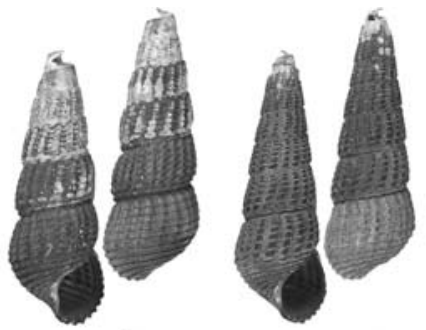

(f)
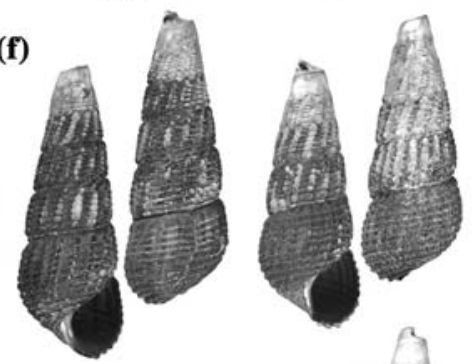

(h)

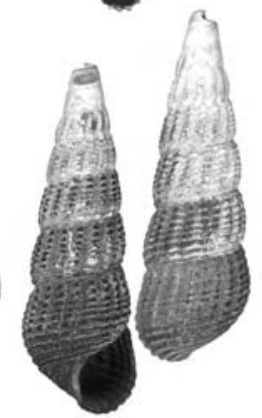

(k)
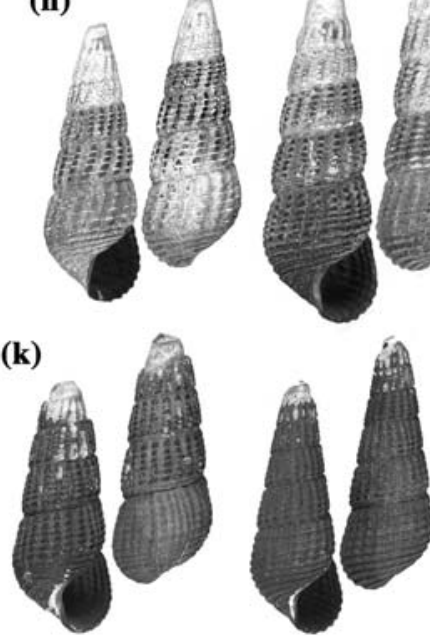

ZMB 190144 (loc. 37); g, ZMB 190172 (loc. 49); h, ZMB 190179 (loc. 51); i, ZMB 190166 (loc. 46); k, ZMB 190169 (loc. 47). Scale bar $=1 \mathrm{~cm}$

\section{Taxonomic remarks}

Tylomelania wolterecki is one of the most distinct species in the Malili lake system. While vaguely resembling $T$. gemmifera from Lake Matano, T. wolterecki has smaller shells, the axial ribs are much finer, and the radula has even more teeth rows per $\mathrm{mm}$. Nevertheless the similarity in substrate preference, shell and particularly the highly derived radula to $T$. gemmifera and 

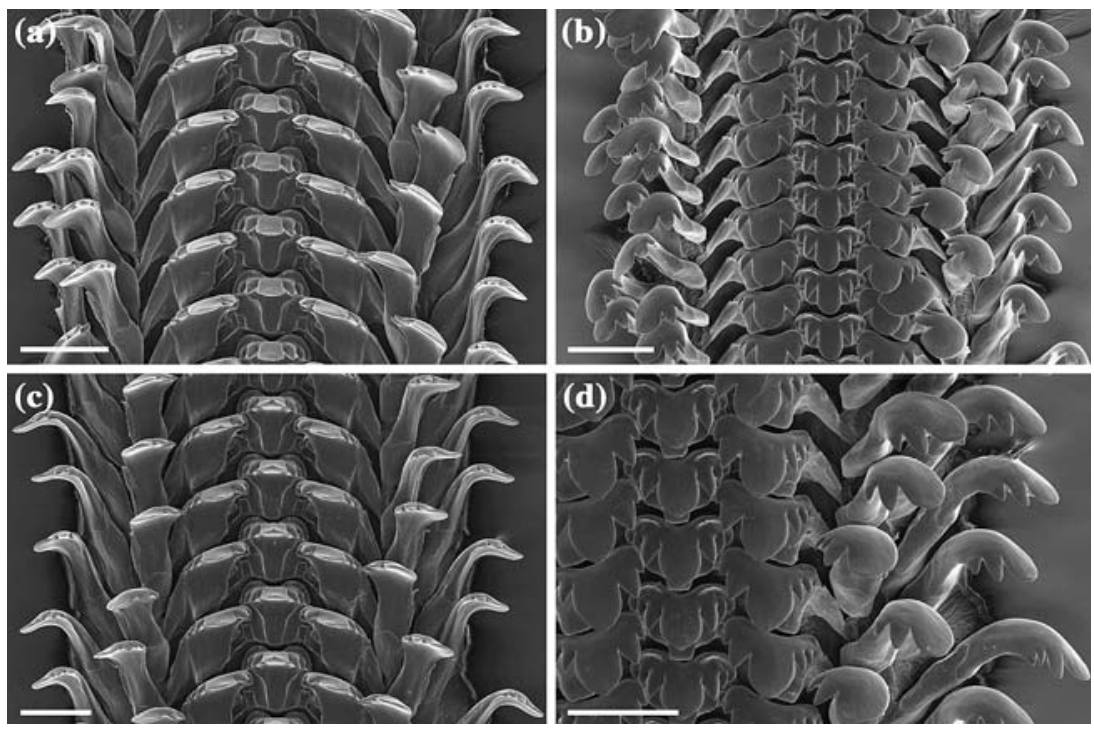

Fig. 59 T. towutica, radula. a, b, ZMB 190176 (loc. 50). a, segment, frontal; b, segment, apical (45). c, d, ZMB 190135 (loc. 35). c, segment, frontal; d, segment, apical $\left(45^{\circ}\right)$. Scale bar $=0.1 \mathrm{~mm}$

T. kristinae (from Lake Towuti) suggest. T. wolterecki as described here comprises two shell morphs, viz. the typical one with characteristically wide-spaced axial ribs (Fig. 65a, c) and a form with rather more axial ribs per whorl and a less conical shell shape (Fig. 65b). Both share an identical radula, though, and occur on the same substrate within a population, suggesting a shell polymorphism rather than pointing towards the existence of cryptic species.

\section{Tylomelania zeamais (Sarasin \& Sarasin,} 1897)

Melania zea mais Sarasin \& Sarasin, 1897: 314, text Fig. 5. (Lake Matano; lectotype, present designation, NMB 1337a, 4 paralectotypes (1 broken). NMB 1337a'). - Sarasin \& Sarasin, 1898: 30, pl. 3 Fig. 35, 36; pl. 5 Fig. 71 (op.); pl. 7 Fig. 97 (rad.).-Marwoto (1997): 110.

Melania monacha Sarasin \& Sarasin, 1898: 21, pl. 3 Figs. 37, 38; pl. 5 Fig. 62 (op.); pl. 6 Fig. 90 (rad.). (Lake Matano, northern shore near ,Sokoijo" (=Nuha); lectotype NMB 1348a, 15 paralectotypes (and fragments of additional one). NMB 1348a'). —Kruimel, 1913: 223.

\section{Description}

Shell (Fig. 67): Small to medium sized, yellowishbrown to black, shape varies from almost globose to elongately conic, usually ovate, spire angle 15$34^{\circ}$, top whorls in adult specimens always corroded to a varying degree, 4-9 remaining whorls, can reach up to $45.3 \mathrm{~mm}$ (Table 2). With strong axial ribs, 11-26 on body whorl, and weaker spiral ribs. Aperture oval, pointed at top and slightly siphonated at base.

External morphology: Headfoot with usually few white dots, mantle edge serrated to a varying dgree. Body coiled in 2.5-3.5 whorls.

Operculum (Fig. 7z): ovate, last whorl strongly expanded, multispiral, with 5-6 whorls.

Radula (Fig. 68): Four forms present: A (Fig. 68a, b). 176-224 rows, 15.6-20.6 mm long, on average 11.3 teeth $/ \mathrm{mm}(n=6)$. Central tooth with large, spoon-shaped major denticle, accompanied by two very much smaller denticles at each side of it. Glabella more narrow at base. Lateral teeth with enlarged spoon-shaped major denticle and two smaller denticles on each side as well. Marginal teeth weakly concave, tips curved and comparatively long, with three denticles each, the 


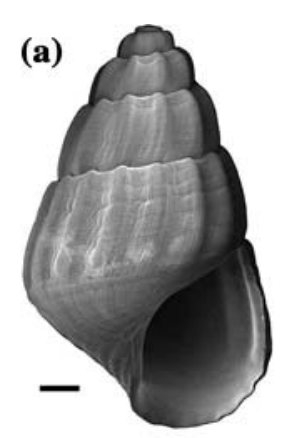

(b)

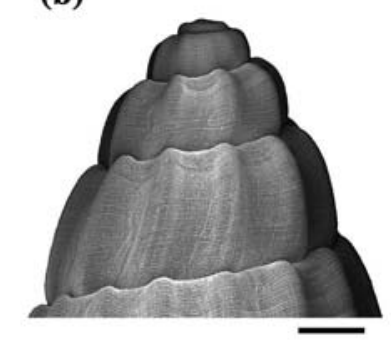

(d)
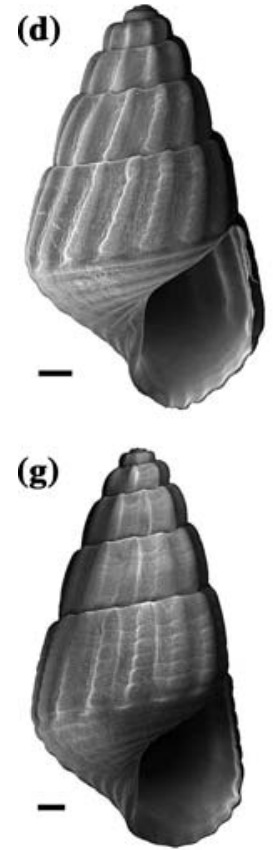

Fig. 60 T. towutica, embryonic shells. a-c, ZMB 190166 (loc. 46). a, lateral view; b, apical whorls, lateral; c, apical view. d-f, ZMB 190176 (loc. 50). d, lateral view. e, apical

outermost ones are c. three times larger than the inner ones. Found in specimens at loc. 1,12,1820,55 (Fig. 69).

B (Fig. 68c, d). 209-244 rows, 22.0-24.5 mm long, on average 9.6 teeth $/ \mathrm{mm}(n=3)$. Central tooth with larger, pointed major denticle, accompanied by two smaller denticles at each side of it. Glabella similar to form A. Lateral teeth with enlarged pointed major denticle and two smaller denticles on each side as well. Marginal teeth straight, tips curved, with three denticles each, the outermost ones are c. twice wider than the inner ones. Found in specimens at loc. 15,21,23 (Fig. 69).

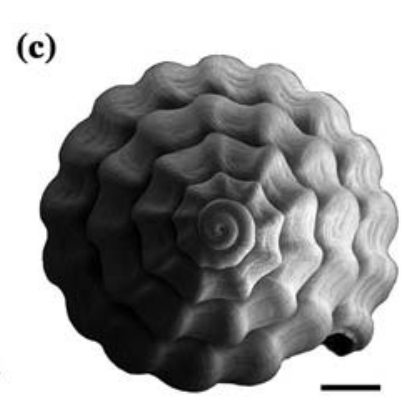

(f)

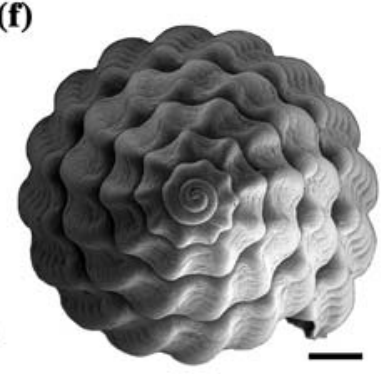

(i)

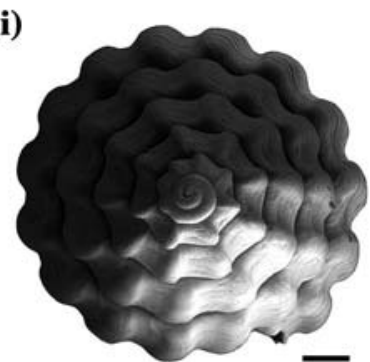

whorls, lateral. f, apical view. g-i. ZMB 190116 (loc. 27). g, lateral view. h, apical whorls, lateral. i, apical view. Scale bar $=0.5 \mathrm{~mm}$

C (Fig. 68e, f). 175-221 rows, 20.8-27.6 mm long, on average 8.4 teeth $/ \mathrm{mm}(n=3)$. Central tooth with three almost equal sized denticles at the centre, accompanied by one slightly smaller denticle at each side of those. Glabella wider than in form $\mathrm{A}$ and $\mathrm{B}$, rounded at base. Lateral teeth with two almost equal sized major denticles, and one or two, respectively, smaller denticles on the inner and outer side of those. Marginal teeth weakly concave, tips curved, inner marginals with four denticles, outer marginals with 3-4 denticles. The outermost denticles are not significantly larger than 

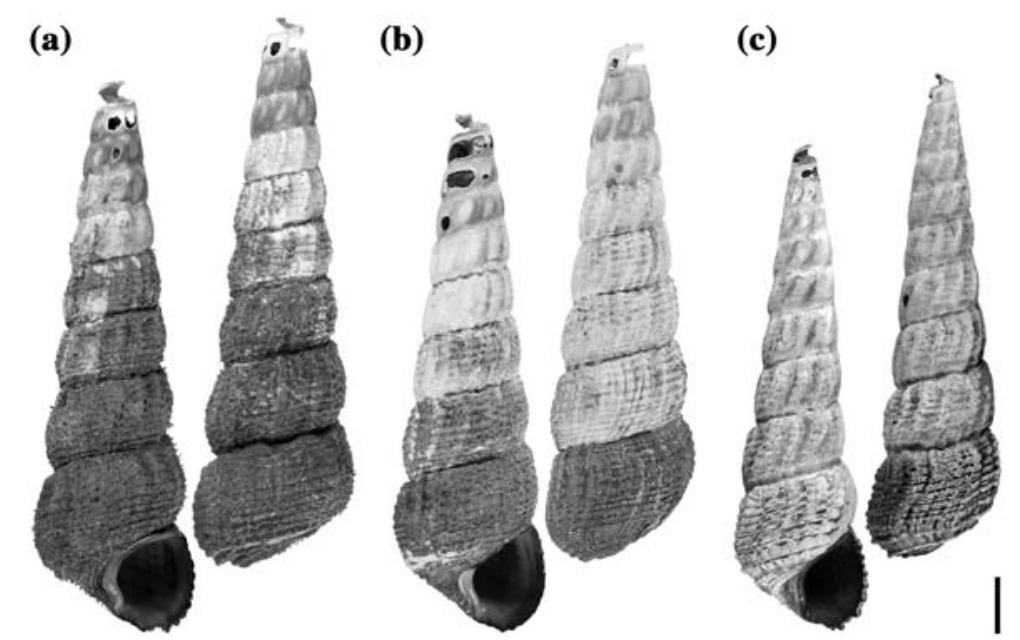

Fig. 61 T. turriformis, shells. a, holotype, MZB Gst. 12.103 (loc. 18); b,c, paratypes. b, ZMB 190091 (loc. 18); c, ZMB 190073 (loc. 14). Scale bar $=1 \mathrm{~cm}$

the inner ones. Found in specimens at loc. 10,23 (Fig. 69).

D (Fig. 68g, h). 227 rows, $32.0 \mathrm{~mm}$ long, 8.0 teeth $/ \mathrm{mm}$. Central tooth with very large, spadeshaped pointed major denticle, accompanied by two much smaller denticles at each side of it. Glabella comparatively long. Lateral teeth with greatly enlarged pointed major denticles and two smaller denticles on each side as well. Marginal teeth mildly concave, tips curved, with three denticles each, the outermost ones are vastly enlarged. Found in specimens at loc. 6,9 (Fig. 69).

Reproductive biology: Sex ratio $0.46(n=157)$. Males do not differ significantly in size from females (ANOVA). About $92 \%$ of females $(n=85)$ carry shelled embryos in their brood pouch, which contains 1-10 embryos, their size can reach $7.6 \mathrm{~mm}$ (Table 3 ).

Embryonic shells (Fig. 70): Ovate, with strong axial ribs emerging on the second whorl. Shallow, widespaced spiral ribs emerge on 2 nd to $3 \mathrm{rd}$ whorl, occasionally accompanied by fine spiral striae. Diameter of first whorl between 240 and $340 \mu \mathrm{m}$ (Table 3).

\section{Ecology and habitat}

Hard substrate dweller, rocks, sunken wood, and pseudomangrove roots. Occurs from the surface to a depth of 1-2 m.

\section{Systematic remarks}

T. monacha was described by Sarasin \& Sarasin (1898) based on radula differences to $T$. zeamais, though they did not fail to notice the almost identical shells. In their figures the radulae of the two species have been depicted at a slightly different angle, which might account for the described differences. It has not been possible to unambiguously distinguish two morphs resembling T. zeamais and T. monacha among the material studied. Thus, $T$. monacha is regarded as junior synonym of $T$. zeamais.

While $T$. zeamais is easily distinguishable from all other Malili system species, not least by its size, it is a highly variable species, both in shell (Fig. 67) and radula morphology (Fig. 68). The latter is polymorphic. While it is possible that $T$. zeamais as described here comprises two or more taxa, splitting it has been considered rather arbitrary based on the material available. Neither could the pattern of shell morphology variation be aligned with the different radula morphs, nor is there any apparent geographic pattern (Fig. 70).

\section{Distribution}

South Sulawesi, Lake Matano (Fig. 9). 

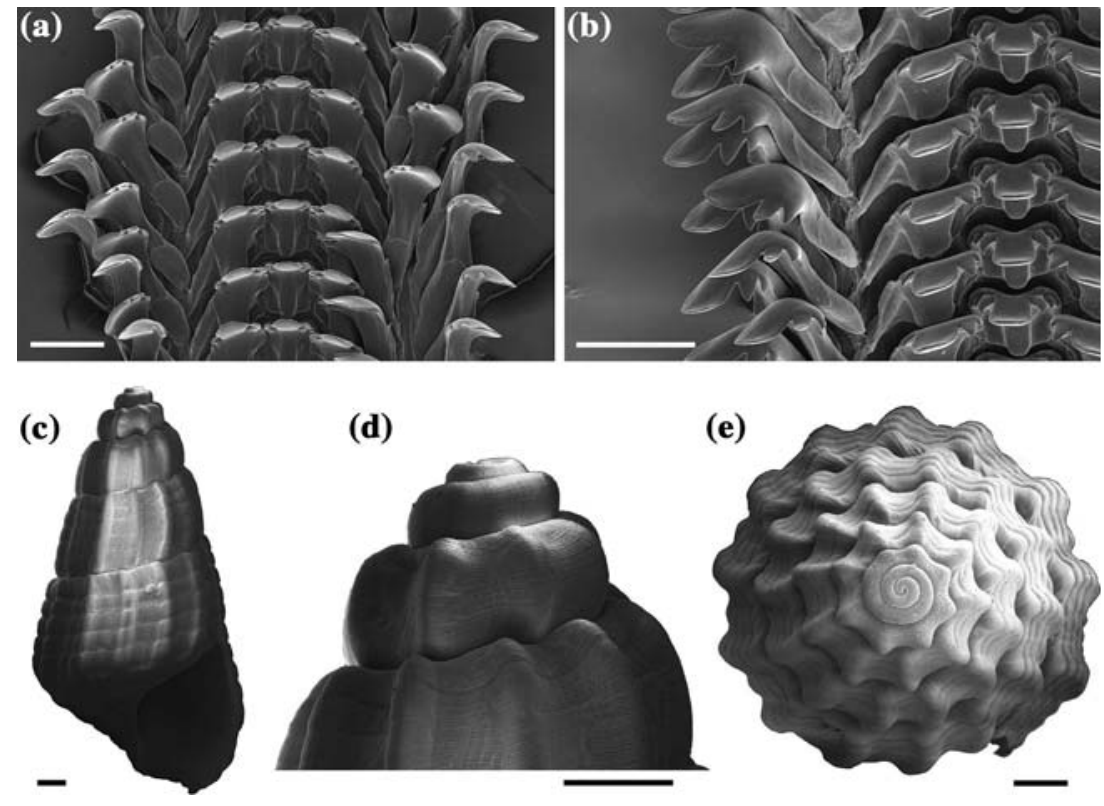

Fig. 62 T. turriformis, radula and embryonic shells, paratypes. a, b, radula, ZMB 190073 (loc. 14). a, segment, frontal; b, segment, apical $\left(45^{\circ}\right)$. Scale bar $=0.1 \mathrm{~mm}$. $\mathbf{c}-\mathbf{e}$,

\section{Material examined}

Lake Matano: SW-shore, Paku, 02²9.1' S, $121^{\circ} 15.5^{\prime} \mathrm{E}$, loc. MT1 (MNHN, $\left.n=38\right)$; NWshore, inlet of Lawa River, $02^{\circ} 27^{\prime} \mathrm{S}, 121^{\circ} 13.8^{\prime} \mathrm{E}$, loc. MT3 (MNHN, $n=1$, in alc.); E-shore, easternmost bay, $02^{\circ} 32.4^{\prime} \mathrm{S}, 121^{\circ} 28.1^{\prime} \mathrm{E}$, loc. MT6 $(\mathrm{MNHN}, n=20)$; outlet of Petea River, 02 $32.4^{\prime} \mathrm{S}$, $121^{\circ} 29.5^{\prime} \mathrm{E}$, loc. MT7 (MNHN, $n=63 ; n=11$ in alc.); N-shore, c. $1 \mathrm{~km} \mathrm{~W}$ of Nuha, $02^{\circ} 27.2^{\prime} \mathrm{S}$, $121^{\circ} 20.5^{\prime} \mathrm{E}$, loc. MT10 (MNHN, $n=98$ in alc.); Soroako, Salonsa, $02^{\circ} 30,49^{\prime} \mathrm{S}, 121^{\circ} 19,96^{\prime} \mathrm{E}$, loc. 1 (MZB Gst. 12.353, $n=117$; ZMB 190052, $n=442$; all in alc.); Soroako, Salonsa, loc.3, ca. 300m E of loc. 1 (ZMB 190213, $n=3$, in alc.); S-shore, $02^{\circ} 28,44^{\prime} \mathrm{S}, 121^{\circ} 15,78^{\prime} \mathrm{E}$, loc. 6 (MZB Gst. 12.355, $n=56$; ZMB 190059, $n=56$; all in alc.); W-shore, $02^{\circ} 26.97^{\prime} \mathrm{S}, 121^{\circ} 13.00^{\prime} \mathrm{E}$, loc. 9 (MZB Gst. 12.356, $n=26$; ZMB 190064, $n=78$; all in alc.); E-bay, outlet of Petea River, 02 $32.06^{\prime} \mathrm{S}$, $121^{\circ} 28.50^{\prime} \mathrm{E}$, loc. 10 (MZB Gst. 12.357, $n=35$; ZMB 190065, $n=166)$; E-bay, Alabona Island, $02^{\circ} 31.60^{\prime} \mathrm{S}, 121^{\circ} 27.78^{\prime} \mathrm{E}$, loc. 12 (ZMB 190069, $n=33$, in alc.). Mouth of E-bay, Cape Una, $02^{\circ} 31,40^{\prime} \mathrm{S}, 121^{\circ} 26,99^{\prime} \mathrm{E}$, Loc. 13 (ZMB 190072, $n=33$, in alc.); SE-bay, $\mathrm{W}$-shore, $02^{\circ} 32,93^{\prime} \mathrm{S}$, embryonic shells, ZMB 190091 (loc. 18). c, lateral view; d, apical whorls, lateral; e, apical view. Scale bar $=0.5 \mathrm{~mm}$

12125,22’ E, loc. 15 (MZB Gst. 12.370, $n=30$; ZMB 190076, $n=61$; all in alc.); N-shore, $02^{\circ} 25.76^{\prime} \mathrm{S}, 121^{\circ} 15.27^{\prime} \mathrm{E}$, loc. 18 (ZMB 190093, $n=100, \quad$ in alc.); N-shore, $02^{\circ} 25.64^{\prime} \mathrm{S}$, $121^{\circ} 16.48^{\prime} \mathrm{E}$, loc. 19 (MZB Gst. 12.372, $n=25$; ZMB 190095a, $n=15$; ZMB 190095b, $n=46$; all in alc.); N-shore, $02^{\circ} 26,28^{\prime} \mathrm{S}, 121^{\circ} 18,73^{\prime} \mathrm{E}$, loc. 20 (MZB Gst. 12.373, $n=50$; ZMB 190098, $n=63$; all in alc.); N-shore, $02^{\circ} 26.27^{\prime} \mathrm{S}, 121^{\circ} 18.91^{\prime} \mathrm{E}$, loc. 21 (MZB Gst. 12.374, $n=27$; ZMB 190101, $n=30$; all in alc.); N-shore, $02^{\circ} 26,71^{\prime} \mathrm{S}, 121^{\circ} 20,02^{\prime} \mathrm{E}$, loc. 22 (MZB Gst. 12.375, $n=41$; ZMB 190112, $n=41$; all in alc.); N-shore, $02^{\circ} 27,29^{\prime} \mathrm{S}, 121^{\circ} 21,18^{\prime} \mathrm{E}$, loc. 23 (ZMB 190106, $n=40$, in alc.); N-shore, -20m, $02^{\circ} 29,64^{\prime} \mathrm{S}, 121^{\circ} 25,65^{\prime} \mathrm{E}$, loc. 55 (MZB Gst. 12.377, $n=32$; ZMB 190110, $n=31$; all in alc.).

\section{Discussion}

The biological species concept and species recognition in Tylomelania

This study aims at providing basic taxonomic and systematic data on the endemic gastropods of the Sulawesi lakes, which are deemed indispensable 


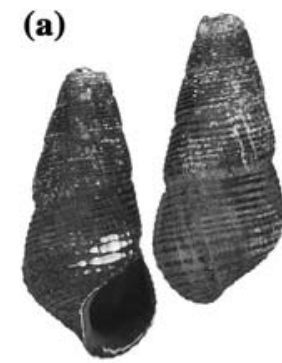

(c)

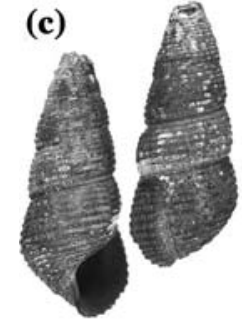

(b)

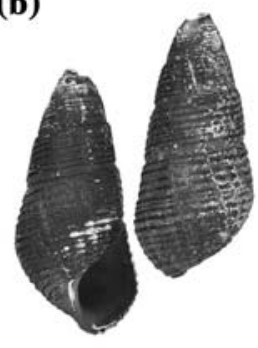

(d)
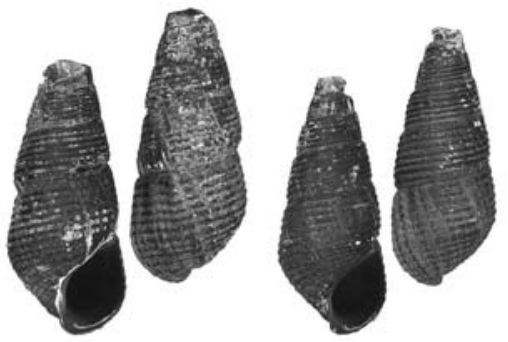
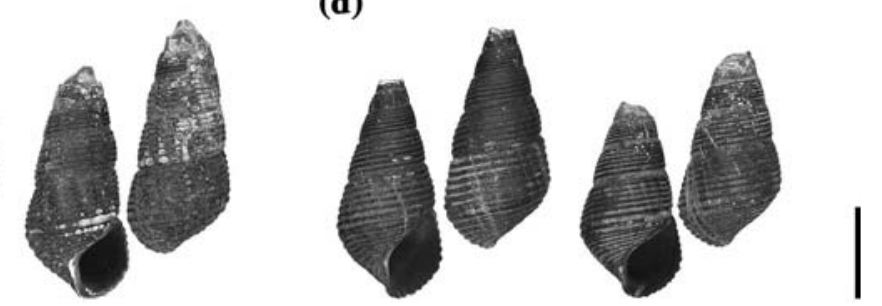

Fig. 63 T. wesseli shells, loc. 47. a, holotype, MZB Gst. 12.104; b-d, paratypes. b, ZMB 190168 (loc. 47); c, MNHN (TW 3); d, MNHN (MHL 7). Scale bar $=1 \mathrm{~cm}$

to discuss evolutionary processes (Rintelen \& Glaubrecht, 2005). It has been attempted to achieve this goal by applying the biological species concept (BSC, Mayr, 1942, 1963, 2000). The BSC defines species as reproductively isolated populations or groups of populations, and reproductive isolation is here regarded as a pattern, following Harrison (1998). In recent decades a major debate on species concepts has been arising (see e.g. discussion papers in Wheeler \& Meier, 2000), which stems from the wish to overcome the uncertainty inherent in the 'species problem' (Hey et al., 2003; Hey, 2006). However, the BSC is still the most widely used species concepts by evolutionary biologists, as outlined e.g. by Coyne \& Orr (2004) and Glaubrecht (2004), and we largely adhere to their reasoning. Even though the BSC is not character based, in general taxonomic practise e.g. morphological or molecular characters may be used to infer reproductive isolation between populations, i.e. biological species status (Mayr, 2000).

It should be noted that all species concepts use operational criteria for species delimitation, and none of these criteria can be considered entirely objective (Sites \& Marshall, 2004). Ecophenotypic variation, i.e. phenotypic variation dependent on ecological variables, can be discrete and thus create the impression of two coexisting and morphologically quite distinct species (review and examples e.g. in Schlichting \& Pigliucci, 1998); see also discussion of radula variability below). Purely arbitrary decisions on species status can only be avoided by an extensive survey of intra- and interpopulation character variability in the study group. Consequently, the following discussion focuses on an evaluation of species level character variability in Tylomelania. Obviously, an assessment of character variability is not just useful for assessing the species status of different forms. Unless only (presumably neutral) genetic markers are considered, most (morphological) characters are at the organism-environment interface, and their comparison across geographic and taxon boundaries can help to discover common factors in evolution (Harvey \& Pagel, 1991).

Gastropod taxonomy has traditionally been based on shell, operculum, and radula characters, especially at the species level (for early discussions of molluscan species discrimination see e.g. Martens, 1883; Westerlund, 1892; Sarasin \& Sarasin, 1898). Only comparatively recently has it become common practise to include anatomical descriptions, provided that suitable material is present. In this study, ethanol preserved specimens were available from almost every species and population. In addition, basic ecological data 

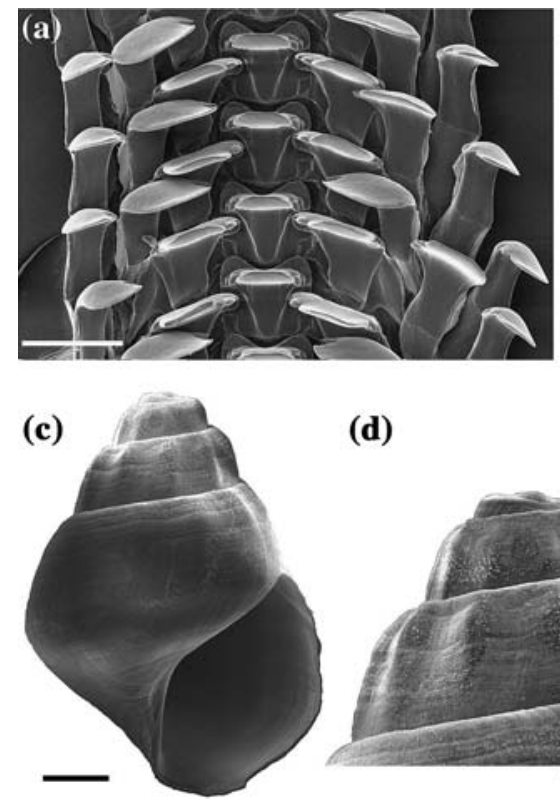

(d)

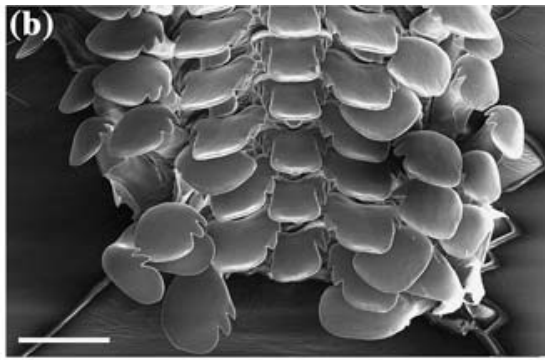

(e)

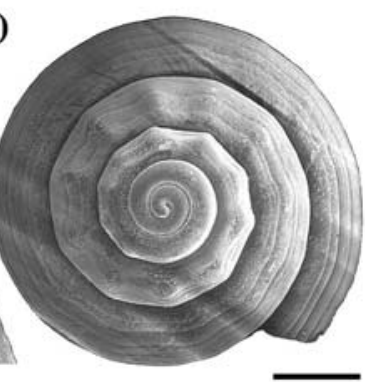

Fig. $64 T$. wesseli, radula and embryonic shells. Paratypes, ZMB 190168 (loc. 47). a, b, radula. a, segment, frontal; b, segment, apical $\left(45^{\circ}\right)$. Scale bar $=0.1 \mathrm{~mm}$. c-e, embryonic shells. c, lateral view; d, apical whorls, lateral; e, apical view. Scale bar $=0.5 \mathrm{~mm}$

documented in marine gastropods (Palmer, 1990), while there is no comparative data on the influence of substrate. The influence of wave exposure on shell shape and robustness has been studied in several limnic taxa (see citations in Gorthner, 1992), no evidence for this phenomenon could be found in lacustrine Tylomelania species, though.

In contrast to the prominent role of the adult shell in species recognition, the variation of embryonic (juvenile) shells in Tylomelania can be high even among specimens from the same brood pouch. Using embryonic shell characters may fail to distinguish between presumably closely related species, thus, as e.g. T. patriarchalis (Fig. 47), and T. matannensis (Fig. 39). Frequently embryonic shells rather allow to distinguish between species groups.

The radula has been established by Troschel (1857) as a pivotal systematic character in malacology. He was critical on its use at the species level, though, a view followed by several other authors (Ihering, 1885; Westerlund, 1892; Sarasin \& Sarasin, 1898; Benthem Jutting, 1934; but see Martens, 1883). The monograph of Sarasin \& Sarasin (1898) on Sulawesi freshwater molluscs is 

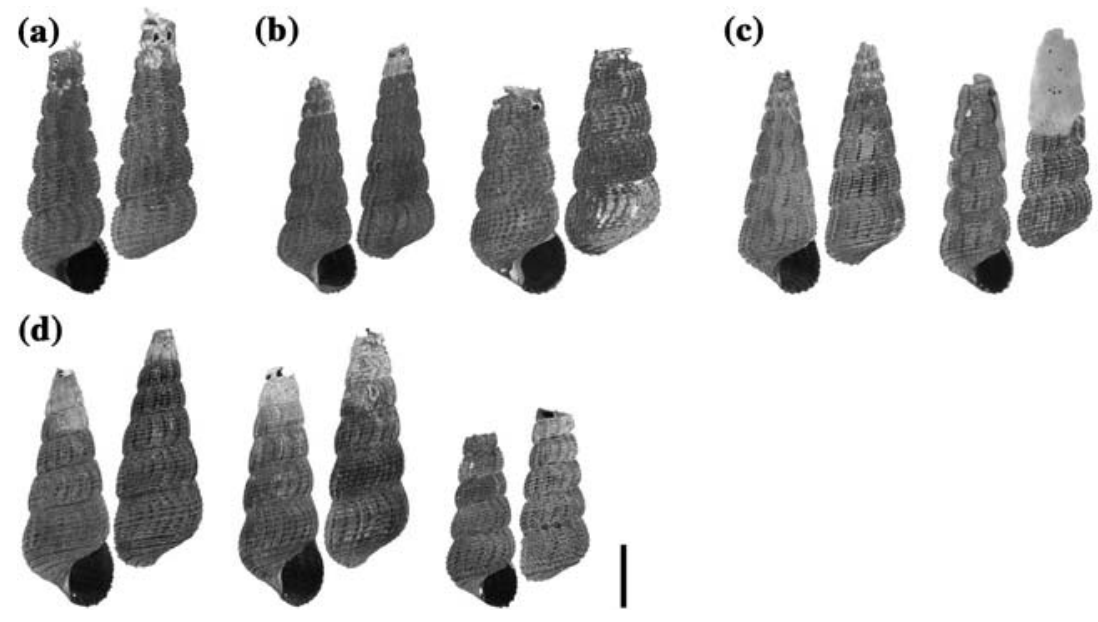

Fig. 65 T. wolterecki, shells. a, holotype, MZB Gst. 12.281; b-d, paratypes. b, ZMB 190147 (loc. 38 ); c, ZMB 190148 (loc. 39); d, MNHN (TW 2). Scale bar = $1 \mathrm{~cm}$

an early example of the consequent inclusion of the radula (and the operculum) in species descriptions. However, the authors explicitly warned against uncritical use of the radula as a character for species discrimination, because they regarded it as too invariable at that level. In stark contrast to the observations by Sarasin \& Sarasin (1898), an extremely high amount of inter- and intraspecific radula variability has been encountered in Tylomelania. This variability is almost entirely confined to the lacustrine species, though, while riverine taxa nearly always have more or less identical radulae (Rintelen et al., 2004).

In every Malili lake species with several populations examined two or more different radula morphs were found. In some species this polymorphism was only observed between populations (e.g. T. patriarchalis, Fig. 45; T. zeamais, Fig. 68), in others both in between and within populations (e.g. T. gemmifera, Fig. 18; T. sarasinorum, Fig. 49). Sample sizes differ strongly between species and populations, though, and it is likely that upon study of larger series radula polymorphism will also be found within populations in species where polymorphism has so far only been observed between populations. Several explanations for these findings are possible: (1) If the radula is regarded as a species-specific character, the different radula morphs would imply the existence of several cryptic species. In a similar marine case the existence of cryptic species has indeed been suggested (McLean, 1971), but was later refuted by molecular data (Simison \& Lindberg, 1999). Based on other morphological characters, no evidence is found in Tylomelania to suspect the existence of a large number of cryptic species. (2) Within some populations genetic polymorphisms exist, and individuals move to the substrate most suitable for them. This hypothesis is hard to distinguish without experimental data from alternative (3), viz. ecophenotypic plasticity. Recently, studies on ecophenotypic variation of the radula have suggested that apparently fundamentally different radula morphs can be induced environmentally (Padilla, 1998; Reid \& Mak, 1999; Reid, 2000). The findings of Reid \& Mak are of special relevance in the context of this study. They contrast two radula forms each of eight Littoraria species from rocks and mangrove roots (Reid \& Mak, 1999: Figs. 3, 4), which closely resemble some forms frequently encountered in polymorphic species or populations of Tylomelania (e.g. Fig. 49a, b and c, d). Thus, a similar ecophenotypism might be suspected in Tylomelania as well, especially since fine scale substrate differences (for example wood versus rock among hard substrates) cannot be ruled out due to the unspecific sampling method. While in none of the cited examples a congruent polymorphism of the shell has been found, though, the best examined Tylomelania species in respect to 


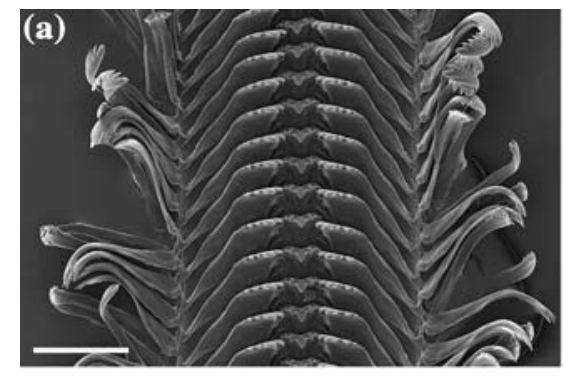

(c)

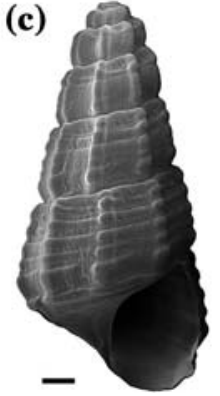

(d)

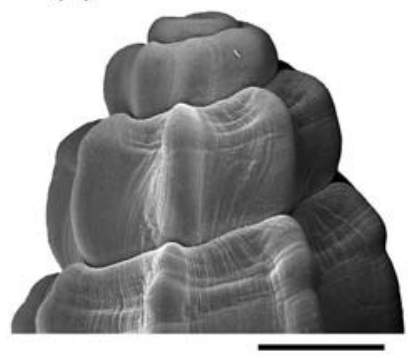

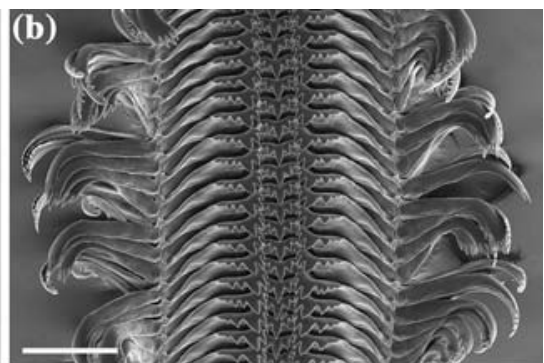

(e)

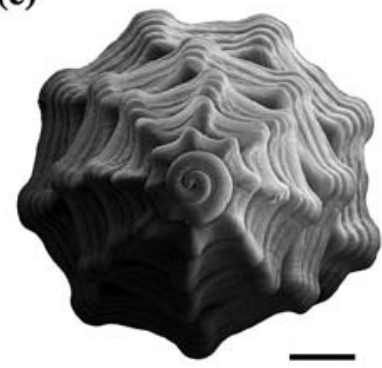

Fig. 66 T. wolterecki, radula and embryonic shells. Paratypes. a, b, radula, ZMB 190147 (loc. 38). a, segment, frontal; b, segment, apical $\left(45^{\circ}\right)$. Scale bar $=0.1 \mathrm{~mm}$. $\mathbf{c}-\mathbf{e}$, embryonic shells, ZMB 190148 (loc. 39). c, lateral view; d, apical whorls, lateral; e, apical view. Scale bar $=0.5 \mathrm{~mm}$ radula variation so far, $T$. sarasinorum, shows a match of shell and radula polymorphism in one population (Rintelen et al., unpubl. data). For this population it could also be shown that each morph is restricted to one substrate, i.e. wood versus rock. The finding of congruent polymorphism in two presumably unlinked characters does not necessarily falsify the hypothesis of ecophenotypic plasticity, but it at least requires the concerted modification of those two characters by environmental influences. In addition, the clear link between radula form and substrate is lacking for the minor shell polymorphism encountered. However, even though this finding is confined to one population so far, it indicates that a monocausal explanation might be too simplistic in the Tylomelania species flock.

In summary, the cautious approach of Sarasin \& Sarasin (1898) regarding the use of the radula in species recognition is fully supported by the data gained in this study, even though the reasoning is very different. Thus, from a morphological point of view in the sense outlined above, the most consistent, still highly applicable and useful character in delimiting species in Tylomelania is the shell.

Any species revision should attempt to critically assess the match between ambition and reality, i.e. the species concept in mind and the degree to which it could be applied in the study case. A brief glimpse through the revision will show that in almost every widespread species there is a varying amount of uncertainity concerning the species status of one or more allopatric populations. Single 'aberrant' populations were not merited specific status if they showed a discrete difference to the 'typical' populations in just one character. This approach will likely lead to an underestimation of species diversity, particularly if contrasted with a 'phylogenetic species concept' approach (Glaubrecht, 2004). Nevertheless, we maintain that more heuristic value is to be gained from accepting the inherent uncertainty when dealing with species (Hey et al., 2003) than from a possibly mere pretence of objectivity. More detailed studies of the suspected species complexes using population genetic techniques will likely lead to a further increase in our 

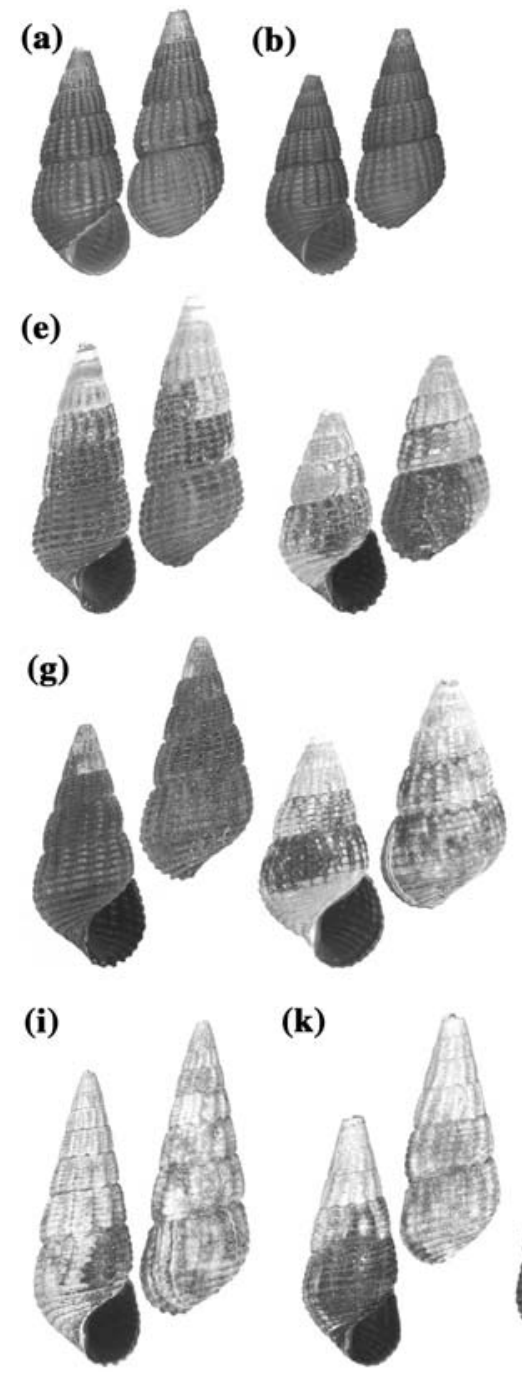

(c)
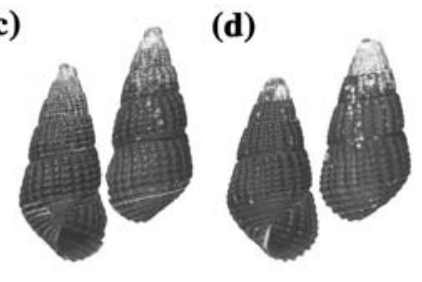

(f)
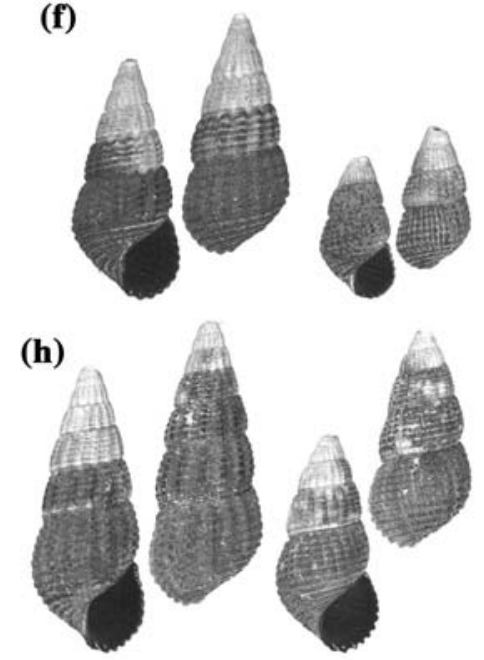

(l)
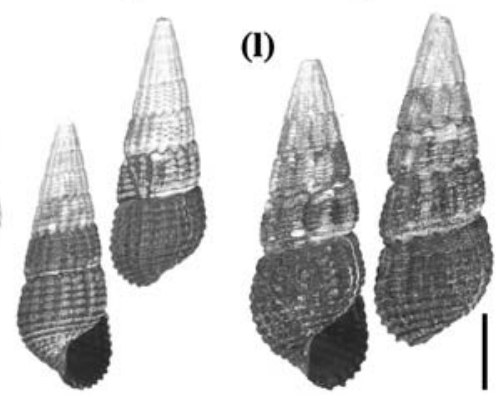

Fig. 67 T. zeamais, shells. a, b, types (Lake Matano). a, lectotype, NMB 1337a; b, paralectotypes, NMB 1337a'. c, d, T. monacha, types (Lake Matano); c, lectotype, NMB $1348^{\circ}$; d, paralectotype, NMB 1348a'. e, ZMB 190052 (loc.

1); f, ZMB 190059 (loc. 6); g, ZMB 190065 (loc. 10); h, ZMB 190095 (loc. 19); i, ZMB 190112 (loc. 22); k, ZMB 190101 (loc. 21); l, ZMB 190110 (loc. 55). Scale bar $=1 \mathrm{~cm}$

knowledge of species diversity within the ancient lakes of Sulawesi.

Species diversity, distribution and ecology of Tylomelania in the Malili lakes

Here 25 species are recognized in the Malili system, all of which are endemic to the lakes. Endemism is not restricted to the lake system as a

whole, however, but 20 species $(80 \%)$ are single lake endemics, i.e. occur in only one lake or Tominanga River (Table 4). Among the major lakes, Lake Towuti is most species-rich with 10 species, six of which are endemic, while Lake Mahalona harbours eight species (five endemics) and Lake Matano seven (six endemics). Tominanga River between Lake Mahalona and Towuti hosts four species, only one of which is endemic, 

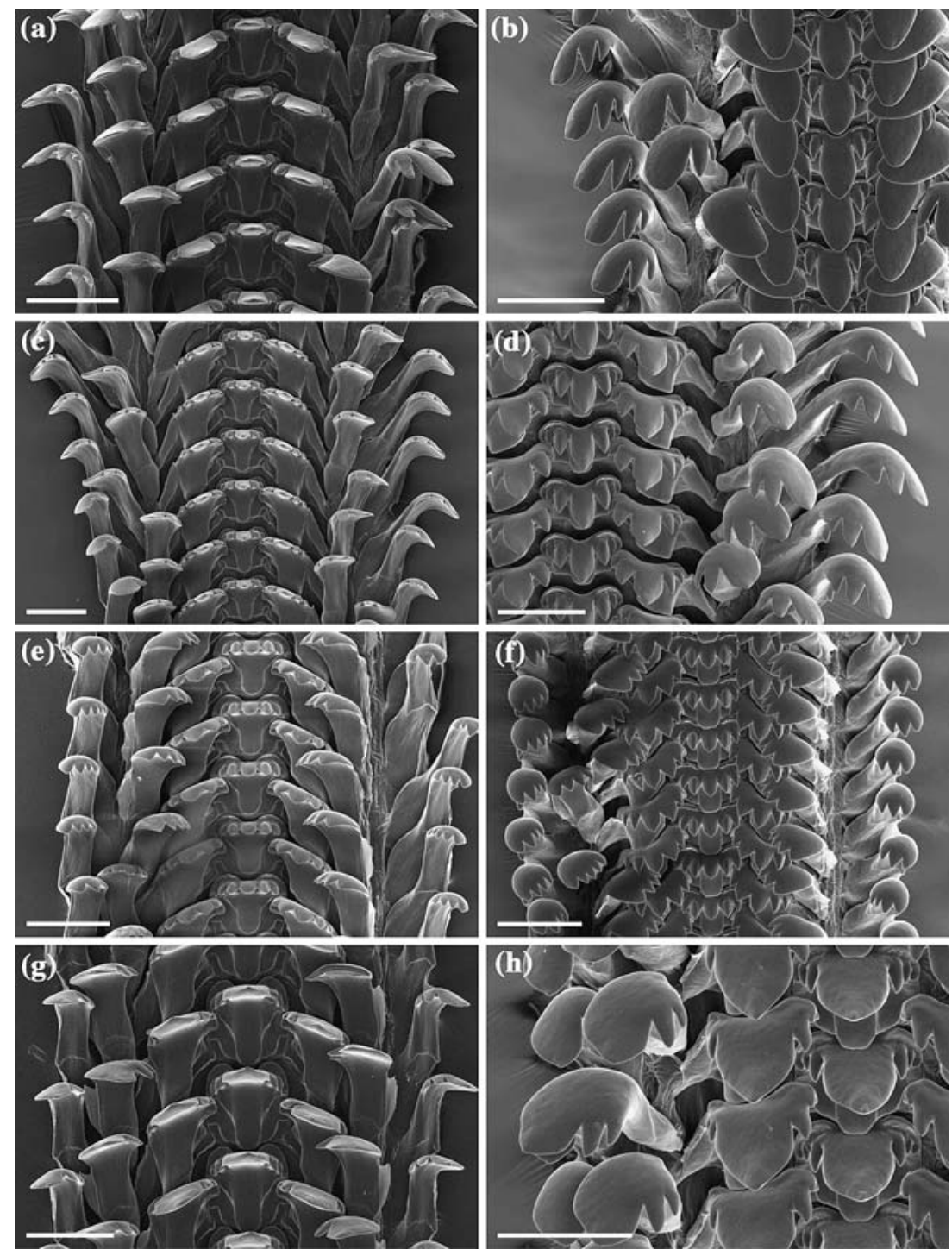

Fig. 68 T. zeamais, radula. a, b, ZMB 190072 (loc. 13). a, segment, frontal; b, segment, apical $\left(45^{\circ}\right)$. c, d, ZMB 190076 (loc. 15). c, segment, frontal; d, segment, apical $\left(45^{\circ}\right)$. e, f, ZMB 190065 (loc. 10). e, segment, frontal, f,

segment, apical $\left(45^{\circ}\right) . \mathbf{g}, \mathbf{h}$, ZMB 190064 (loc. 9). g, segment, frontal; $\mathbf{h}$, segment, apical $\left(45^{\circ}\right)$. Scale bar $=0.1$ $\mathrm{mm}$

though. The smaller satellite lakes only harbour one (Lake Masapi) or two (Lake Lontoa) endemic species, respectively.

The high amount of endemism in each lake or river is a striking finding, which suggests a strong influence of geographic factors in species divergence, i.e. allopatric speciation, which is perhaps not entirely unexpected given the spatial structure of the system (cf Fig. 1b). A few taxa also show a highly localized occurrence within single lakes, such

as e.g. in Lake Towuti T. bakara, which is apparently confined to one cape, or T. kristinae at Loeha Island (Fig. 9). The available data do not offer an easy explanation for these restricted distribution ranges, since these taxa are by no means specialized to substrates that only occur locally nor are there any obvious obstacles to dispersal.

All species in the major lakes of the Malili system for which data on substrate preferences are available are specialized on either soft (mud, 


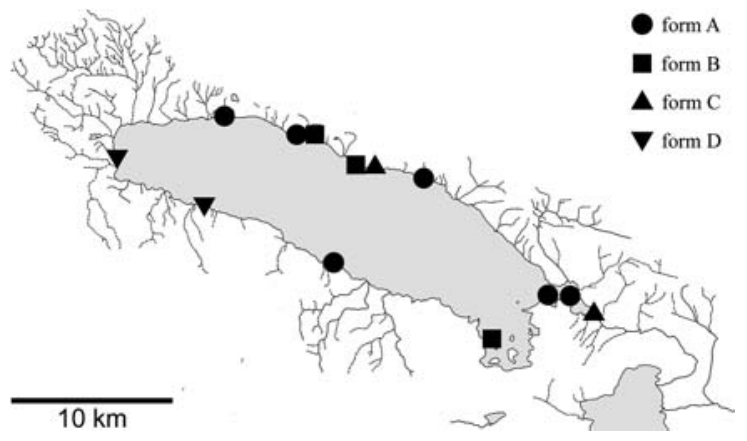

Fig. 69 T. zeamais, distribution of radula morphs

sand) or hard (rock, sunken wood) substrates, with about $50 \%$ of species occurring on either substrate category (Table 4). The distribution of substrate preferences among the different lacustrine clades of Tylomelania is not homogenous (Fig. 71): Malili clade 2 e.g. comprises predominantly hard substrate dwellers, while Malili clade 3 has rather more soft substrate dwelling species. The distribution of hard substrate dwellers in the molecular phylogeny also reveals that this is apparently a derived and exclusively lacustrine condition in Tylomelania (Fig. 71). This holds not just true for the Malili lakes' species, but also for the Lake Poso taxa.

The lake species are also characterized by a multitude of radula forms, which are in contrast to the uniformity encountered in riverine species (Rintelen et al., 2004). Radula differences among the lacustrine taxa roughly correlate to substrate categories, a finding interpreted as indicative of a pivotal role for trophic specialization in the adaptive radiation of Tylomelania in the lakes (Rintelen et al., 2004). The major idea is still supported by the more detailed description of radula forms presented in the revision part of this paper. Generally, hard substrate dwellers overwhelmingly possess radulae with conspicuously enlarged central denticles (Fig. 71), while soft substrate dwellers often retain the presumably less specialized radula form encountered in a wide range of riverine pachychilids, not just Tylomelania (see e.g. Köhler \& Glaubrecht, 2006 for Southeast Asian Brotia). The pattern is rather more complex, though, as evident from the radula polymorphism in many species (e.g. $T$. matannensis and $T$. sarasinorum among hard substrate dwellers or $T$. patriarchalis on soft substrate). Deviances from a strict correlation of hard substrate and derived radulae are also apparent when these characters are compared on a molecular phylogeny (Fig. 71; see e.g. $T$. kruimeli, Malili clade 1, or T. sarasinorum, Malili clade 2). A number of explanations for this phenomenon have already been discussed above in the section on species recognition, as well as the need for fine-scaled substrate specific sampling to distinguish between the different hypotheses. Irrespective of this problem, the importance of radula (i.e. trophic) diversification in the ecological diversification of the lake species stressed by Rintelen et al. (2004) is fully supported by the results of this study: (i) Radula differences are most conspicuous where two or more species occur syntopic on the same substrate, as for example on soft substrates $T$. gemmifera and $T$. patriarchalis in Lake Matano (comp. Figs. 18, 45), or T. mahalonensis, $T$. marwotoae and $T$. wolterecki in Lake Mahalona (comp. Figs. 32, 34, 66). (ii) The same radula form is found repeatedly in different species on the same substrate in different lakes. The rock dwelling $T$. insulaesacrae (Lake Towuti) and $T$. zeamais (Lake Matano) (comp. Figs. 22, 68), which are not even closely related, or the mud dwelling T. gemmifera (Lake Matano), T. wolterecki (Lake Mahalona) and $T$. kristinae (Lake Towuti) (comp. Figs. 18, 26, 66) provide good examples in this respect.

Further evidence for a crucial role of radula differentiation in radiations of pachychilids in general is provided by the analogous example of a Brotia species flock in Thailand's Kaek River (Glaubrecht \& Köhler, 2004), where hard and soft substrate dwelling taxa show a very similar pattern of radula differentiation to that described here for the lacustrine Tylomelania.

While species-specific substrate preferences and radula differentiation appear to be most crucial in enabling species coexistence, depth preferences are also found, albeit to a lesser degree. On soft substrates no marked depth preferences were observed, only on rock one species each in Lake Matano (T. zeamais) and L. Towuti ( $T$. insulaesacrae) are confined to the 

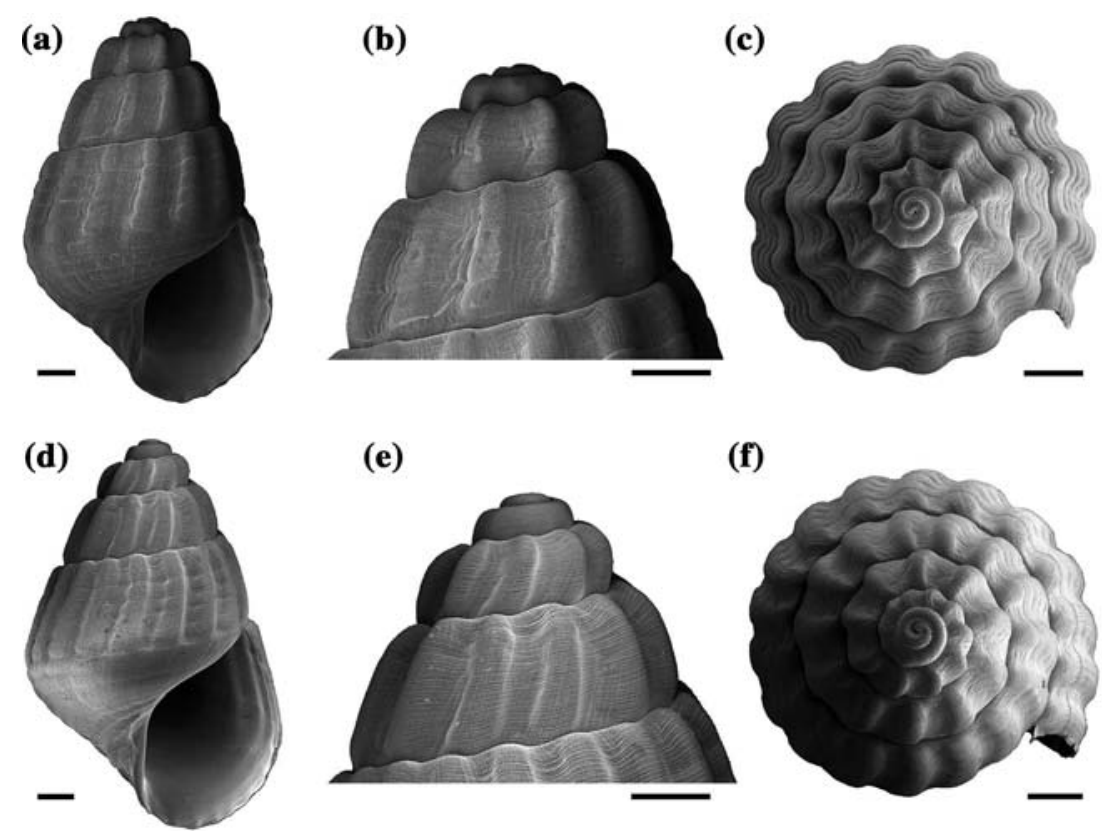

Fig. 70 T. zeamais, embryonic shells. a-c, ZMB 190110 (loc. 55). a, lateral view; b, apical whorls, lateral; c, apical view. d-f, ZMB 190065 (loc. 10). d, lateral view; e, apical whorls, lateral; f, apical view. Scale bar $=0.5 \mathrm{~mm}$

Table 4 Distribution and substrate preferences of Malili lake system Tylomelania

\begin{tabular}{|c|c|c|c|c|c|c|}
\hline & L. Matano & L. Mahalona & L. Towuti & L. Lontoa & L. Masapi & Tominanga $\mathrm{R}$. \\
\hline T. gemmifera & Soft & & & & & \\
\hline T. matannensis & Hard & & & & & \\
\hline T. molesta & $?$ & & & & & \\
\hline T. palicolarum & Mixed & Soft & Soft & & & $?$ \\
\hline T. patriarchalis & Soft & & & & & \\
\hline T. turriformis & Soft & & & & & \\
\hline T. zeamais & Hard & & & & & \\
\hline T. confusa & & Hard & & & & \\
\hline T. inconspicua & & Soft, plants & & & & \\
\hline T. insulaesacrae & & Hard & Hard & & & \\
\hline T. kruimeli & & Hard & & & & \\
\hline T. mahalonensis & & Soft & & & & \\
\hline T. marwotoae & & Soft & & & & \\
\hline T. wolterecki & & Soft & Soft & & & \\
\hline T. amphiderita & & & Hard & & & \\
\hline T. bakara & & & Hard? & & & \\
\hline T. kristinae & & & Soft & & & \\
\hline T. lalemae & & & $?$ & & & \\
\hline T. sarasinorum & & & Hard & & & \\
\hline T. towutensis & & & Soft & & & \\
\hline T. towutica & & & Hard & & & Hard \\
\hline T. abendanoni & & & & Mixed & & \\
\hline T. tominangensis & & & & Mixed & & $?$ \\
\hline T. masapensis & & & & & Mixed & \\
\hline T. wesseli & & & & & & Hard \\
\hline
\end{tabular}

Species are arranged according to their distribution, names in bold type indicate single lake or river endemics. Substrate preferences: soft—mud and sand; hard—rock and sunken wood; mixed—both on soft and hard substrates; ?—no data 


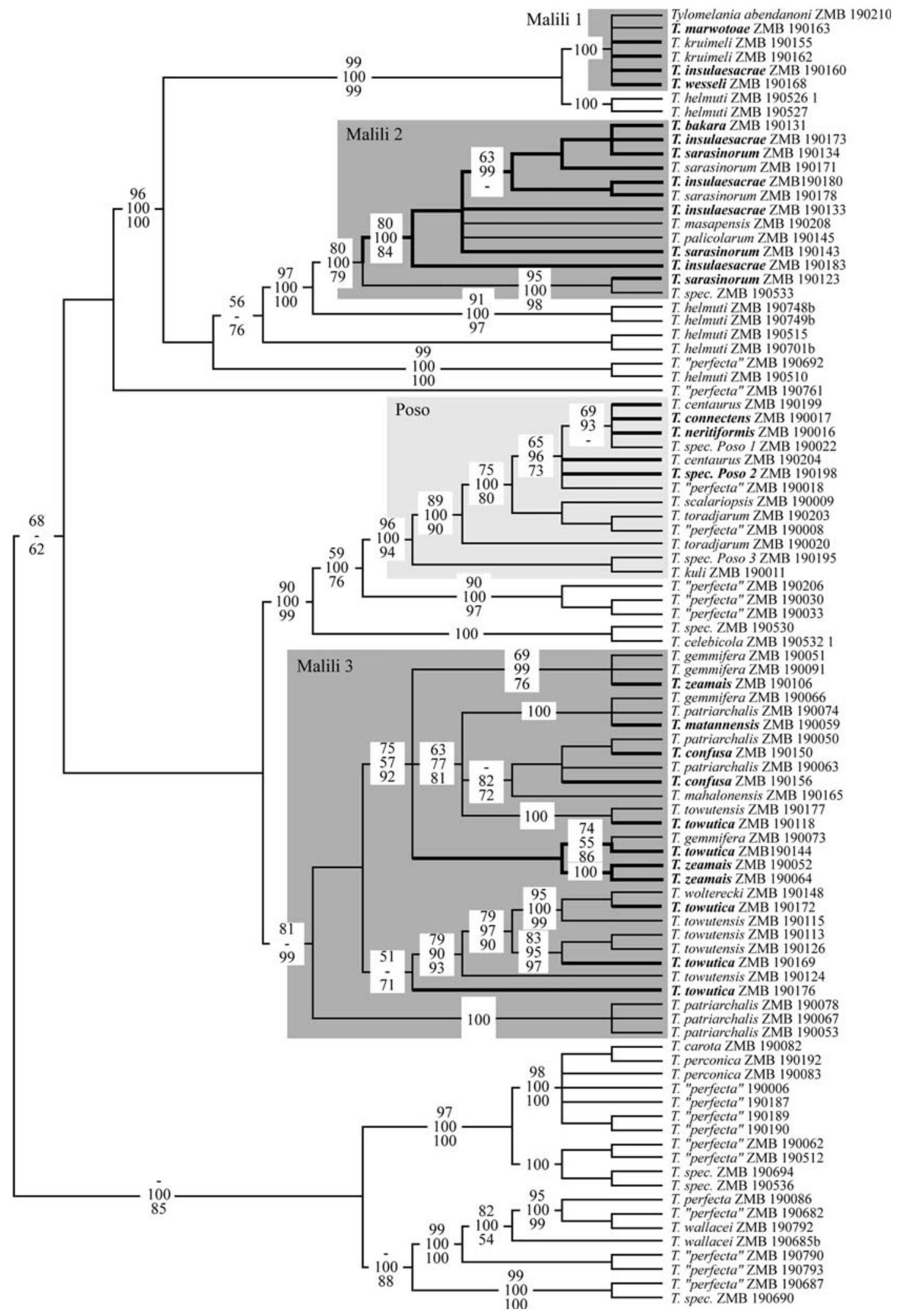


Fig. 71 Molecular phylogeny of Tylomelania and the correlation between substrate preferences and radula form. Maximum parsimony strict consensus tree based on 1498 bp of mitochondrial DNA. Tree topology from Fig. 2 in Rintelen et al. (2004), see there for technical details. Lacustrine species are marked by grey boxes (dark grey-Malili lakes, light grey-Lake Poso), bold branches indicate hard substrate dwellers. Species names in bold highlight taxa with an enlarged radula denticulation. Numbers on branches are, from top, MP bootstrap values, Bayesian posterior probabilities, and NJ bootstrap values

shallow water zone $(0-$ c. $0.5 \mathrm{~m})$, with little or no overlap with other hard substrate dwellers.

The high overall degree of habitat specialization (substrate and depth preferences) and radula differentiation in Malili system Tylomelania enables a maximum of five species to coexist at localities with sufficiently structured habitats. This level of single-site diversity was only observed in Lake Mahalona and Lake Towuti, in Lake Matano a maximum of four species were found together. Differences also exist in the contribution of hard and soft substrate dwellers to single-site diversity; in Lake Matano two species co-occur on each substrate, while in Lake Mahalona three species co-occur on soft substrates and two on hard substrates, and this proportion is reversed in Lake Towuti. While the absolute numbers of co-occuring species at a single site in the lakes are not particularly impressive for themselves, they become more striking if contrasted with the situation in rivers, where only a single species is found in almost all cases.

In a broader perspective, the results from Tylomelania and pachychilid gastropods in general suggest a wider applicability of a radiation model proposed for vertebrates by Streelman \& Danley (2003), which assumes that trophic specialization and habitat specialization drive the initial stages of adaptive radiation.

The Malili lake gastropod species flock in the context of radiations in ancient lakes

Gastropod species flocks in ancient lakes (Table 5) have been known for a long time, and discussions on their origin arose almost immediately after their discovery (review e.g. in Brooks, 1950; Boss, 1978; Michel, 1994; Glaubrecht, 1996). Unfortunately, almost all these gastropod radiations are rather poorly known, and modern treatments including molecular data are only available for two cases, the Sulawesi lake radiations (Rintelen et al., 2004; Rintelen \& Glaubrecht, 2005) and the Lake Tanganyika one (West \& Michel, 2000; West et al., 2003; Michel, 2004; Wilson et al., 2004). Consequently, comparative treatments are largely confined to discussions of diversity patterns and taxonomic range of the groups involved, with all the pitfalls arising from the widespread lack of a well-studied taxonomic basis (see Rintelen \& Glaubrecht, 2005). However, if the Malili lake species flock of Tylomelania is considered against this background, using the data provided by various authors as indicated in Table 4, it stands out as second largest radiation within a single genus in an ancient lake (system) after Lavigeria from Lake Tanganyika. The composition of the gastropod fauna of the Sulawesi lakes in general is remarkable as they are the only ancient lakes known with large cerithioidean (Tylomelania) and hydrobioid radiations co-occuring (Haase \& Bouchet, 2006). The latter authors expect 30-40 hydrobiid species in the Malili lakes, a diversity which, if confirmed, would considerably exceed that of Tylomelania. In Lake Poso 16 (15 endemic) hydrobiid species have been described so far, compared against four described species of Tylomelania, a number bound to increase considerably, however (Marwoto, pers. comm.).

Considering all endemic species including also hydrobioids (employing the lower estimate of Haase \& Bouchet, 2006) and pulmonates (Glaubrecht \& Rintelen, unpubl. data), the Malili lakes contain to present knowledge the second largest tropical ancient lake radiation surpassed only by that in Lake Tanganyika, and the third-largest ancient lake radiation overall (Table 4). Both Lake Tanganyika and Lake Baikal are roughly 40 times larger than the Malili lakes, but in terms of species richness they harbour just a few more (Lake Tanganyika) or barely twice as many endemic taxa (Lake Baikal). If the number of endemic species is set in relation to the total area of the lakes compared, the Malili lakes rank 
second after Lake Ohrid. The pattern of species occurrence derived from this revision suggests that the specific setting of the Malili system with five geographically separated lakes (see Introduction, Fig. 1b) increases the opportunity for allopatric speciation, which might help to explain the comparatively large species diversity in this overall small system. This hypothesis fails to explain the twice as high (Lake Ohrid) or equal density (Lake Poso) of endemic species in these single basin lakes, though. Past changes in hydrological conditions (such as lake level fluctuations and drainage modifications), which are not known at all in the case of Lake Poso at least, certainly play a role here as well.

A striking difference to the other great ancient lake radiations is the comparative morphological homogeneity of the Sulawesi radiations, reflected by the lack of diversification on the generic level within a family both in the Malili system and less pronounced in Lake Poso (Table 4). In the Sulawesi lakes, Protancylus Sarasin \& Sarasin, 1898, a shell-dweller on Tylomelania (cf. Albrecht \& Glaubrecht, 2006), is endemic with a single species each in the Malili lakes and Lake Poso. In addition there are in the latter two endemic genera, viz. Miratesta Sarasin \& Sarasin, 1898 (Planorbidae) and Keindahan Haase \& Bouchet, 2006 (a hydrobioid). In contrast, Lake Tanganyika e.g. hosts a range of anatomically very distinct endemic paludomid genera (Glaubrecht 1996; Glaubrecht \& Strong, 2004; Strong \& Glaubrecht, 2002, 2003; West et al., 2003; Michel, 2004), and several genera have also been described from Lake Baikal (Benedictiidae and particularly Baicaliidae, Sitnikova, 1994) and Lake Ohrid (Orientalinidae, (Radoman, 1985). This finding might be explained by the fact that the Sulawesi lakes, which are much younger than Lake Tanganyika, Lake Baikal and also Lake Ohrid (Haffner et al., 2001), are characterized by speciose radiations of single genera. The Tylomelania species flocks, and apparently also the hydrobioids in Lake Poso (Haase \& Bouchet, 2006) represent more recent, and consequently in some respects less diversified, radiations. Moreover, it has been shown for Lake Tanganyika that the origin of the paludomid gastropod assemblage predates lake formation, suggesting the lake rather to be an evolutionary

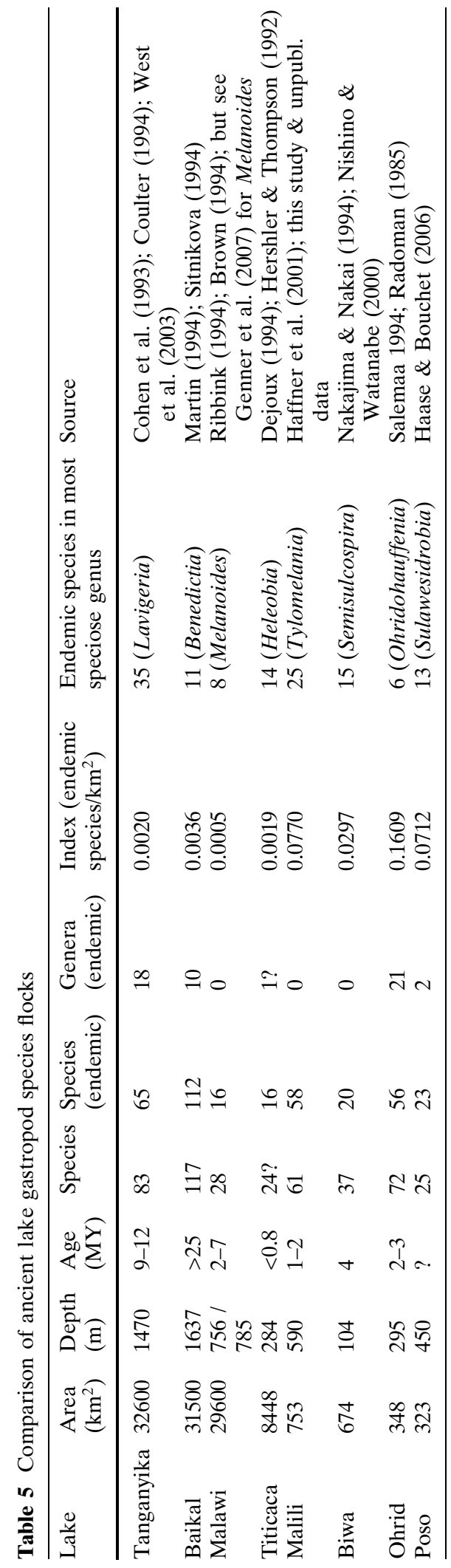


reservoir than a cradle of diversity (Wilson et al., 2004). Only one genus, Lavigeria, has apparently radiated in situ (West et al., 2003; Michel, 2004; Wilson et al., 2004; Glaubrecht \& Strong, 2007, in press). The pattern of diversity found in Lavigeria, which is also an ovoviviparous uterine brooder, closely resembles that of Tylomelania on Sulawesi, but Lavigeria and its less speciose, oviparous sister group Vinundu are confined to rocks for substrate, though (see Michel, 2004).

All gastropod groups taken into consideration (for bivalves see Rintelen \& Glaubrecht, 2006), the Malili lakes certainly represent one of the most diverse endemic assemblages of freshwater mollusc species known. This is also true for other groups, as e.g. crustaceans with a major shrimp radiation (Woltereck, 1937a, b; Zitzler \& Cai, pers. comm.), and telmatherinid fishes (Kottelat, 1990, 1991; Kottelat et al., 1993; Herder et al., 2006a, b), each with c. 16 species. Consequently, the Malili lake system is a hotspot of freshwater diversity, among the largest in generally speciesrich Southeast Asia. This region is among those hit hardest by the 'biodiversity crisis', and habitats are lost at a brisk pace (Sodhi et al., 2004). The ancient lakes of Sulawesi have so far apparently been spared major extinctions since their discovery, at least it was possible to re-find all mollusc and crustacean taxa described before 1950. Ongoing human migration from other regions of Indonesia and heavy exploitation of the adjacent environment (e.g. through nickel mining and illegal logging) are already under way to take their toll, though. Thus, it is about time to recognize the uniqueness of the lakes, which can be likened to a 'submerged Galapagos', and take immediate measures for their protection.

Acknowledgements We are very grateful to Ristiyanti Marwoto (MZB) for the immense support in arranging the field trip of 1999, which yielded a considerable part of the material studied. We also thank LIPI (Indonesian Institute of Sciences) for the permit to conduct research in Indonesia. Invaluable support was experienced from INCO at Soroako, Lake Matano. Without their help in providing accommodation, transport and general logistics this study would not have yielded the same amount of results. Thanks are also due to Ambros Hänggi, Urs Wüest (NMB) and Robert Moolenbeck (ZMA) for their courtesy and generous help with the loan of material. Many thanks go to M. Drescher, V. Heinrich, I. Kilias, (ZMB) and
A. Munandar (MZB) for technical assistence, and to $\mathrm{N}$. Brinkmann (ZMB) for her help with radula preparation. This study was made possible through continuous funding from the Deutsche Forschungsgemeinschaft (DFG) through grants GL 297/1-1 and 1-2.

\section{References}

Albrecht, C. \& M. Glaubrecht, 2006. Brood care among basommatophorans: a unique reproductive strategy in the freshwater limpet snail Protancylus (Heterobranchia: Protancylidae), endemic to ancient lakes on Sulawesi, Indonesia. Acta Zoologica 87: 49-58.

Benthem Jutting, W. S. S. v., 1934. Über den Bau der Radula und ihre Bedeutung für die Nahrungsaufnahme bei einigen Javanischen Süßwassergastropoden. Verhandlungen der Internationalen Vereinigung für theoretische und angewandte Limnologie 6: 325-330.

Boss, K. J., 1978. On the evolution of gastropods in ancient lakes. In Fretter V. \& J. F. Peake (eds), Systematics, Evolution and Ecology, 2A. Academic Press, London: 385-428.

Bouchet, P., 1995. A major new mollusc radiation discovered in the ancient lakes of Sulawesi. In Guerra A., E. Rolán \& F. Rocha (eds), Abstracts 12th International Malacological Congress, Vigo 1995. UNITAS, Vigo: 14-15.

Brooks, J. L., 1950. Speciation in ancient lakes. Quarterly Review of Biology 25: 30-60, 131-176.

Brown, D. S., 1994. Freshwater snails of Africa and their medical importance. Taylor and Francis, London.

Cohen, A. S., M. J. Soreghan \& C. A. Scholz, 1993. Estimating the age of formation of lakes: an example from Lake Tanganyika, East African Rift system. Geology 21: 511-514.

Coulter, G. W., 1994. Lake Tanganyika. In Martens K., B. Goddeeris \& G. Coulter (eds), Speciation in ancient lakes. E.Schweizerbart'sche Verlagsbuchhandlung, Stuttgart: $13-18$.

Coyne, J. A. \& H. A. Orr, 2004. Speciation. Sinauer, Sunderland, Mass.

Davis, G. M., 1982. Historical and ecological factors in the evolution, adaptive radiation, and biogeography of freshwater mollusks. American Zoologist 22: 375-395.

Dejoux, C., 1994. Lake Titicaca. In Martens K., B. Goddeeris \& G. Coulter (eds), Speciation in ancient lakes. E. Schweizerbart'sche Verlagsbuchhandlung, Stuttgart: $35-42$.

Dillon, R. T., 1984. What shall I measure on my snails? Allozyme data and multivariate analysis used to reduce the non-genetic component of morphological variance in Goniobasis proxima. Malacologia 25: 503 511.

Funk, D. J. \& K. E. Omland, 2003. Species-level paraphyly and polyphyly: frequency, causes, and consequences, with Insights from animal mitochondrial DNA. Annual Review of Ecology and Systematics 34: $397-423$. 
Genner, M. J., J. A. Todd, E. Michel, D. Erpenbeck, A. Jimoh, D. A. Joyce, A. Poechocki \& J.-P. Pointier, 2007. Amassing diversity in an ancient lake: evolution of a morphologically diverse parthenogenetic gastropod assemblage in Lake Malawi. Molecular Ecology 16: 517-530.

Giesen, W., 1994. Indonesia's major freshwater lakes: a review of current knowledge, development processes and threats. Mitteilungen der Internationalen Vereinigung für Theoretische und Angewandte Limnologie 24: 115-128.

Giesen, W., M. Baltzer \& R. Baruadi, 1991. Integrating conservation with land-use development in wetlands of South Sulawesi. Directorate General of Forest Protection and Nature Conservation, Bogor.

Glaubrecht, M., 1996. Evolutionsökologie und Systematik am Beispiel von Süß- und Brackwasserschnecken (Mollusca: Caenogastropoda: Cerithioidea): Ontogenese-Strategien, paläontologische Befunde und historische Zoogeographie. Backhuys, Leiden, 499 pp.

Glaubrecht, M., 2004. Leopold von Buch's legacy: treating species as dynamic natural entities, or why geography matters. American Malacological Bulletin 19: 111134.

Glaubrecht, M. \& F. Köhler, 2004. Radiating in a river: systematics, molecular genetics and morphological differentiation of viviparous freshwater gastropods endemic to the Kaek River, central Thailand (Cerithioidea, Pachychilidae). Biological Journal of the Linnean Society 82: 275-311.

Glaubrecht, M. \& E. E. Strong, 2004. Spermatophores of thalassoid gastropods (Paludomidae) in Lake Tanganyika, East Africa, with a survey of their occurrence in Cerithioidea: functional and phylogenetic implications. Invertebrate Biology 123: 218-236.

Glaubrecht, M. \& E. E. Strong, 2007. Ancestry to an endemic radiation in Lake Tanganyika? Evolution of the viviparous gastropod Potadomoides Leloup, 1953 in the Congo River system (Cerithioidea, Paludomidae). Biological Journal of the Linnean Society, in press.

Gorthner, A., 1992. Bau, Funktion und Evolution komplexer Gastropodenschalen in Langzeit-Seen Mit einem Beitrag zur Paläobiologie von Gyraulus "multiformis" im Steinheimer Becken. Stuttgarter Beiträge zur Naturkunde, Ser. B. 190, 1-173.

Haase, M. \& P. Bouchet, 2006. The species flock of hydrobioid gastropods (Caenogastropoda, Rissooidea) in ancient Lake Poso, Sulawesi. Hydrobiologia 556: 1746.

Haffner, G. D., P. E. Hehanussa \& D. Hartoto, 2001. The biology and physical processes of large lakes of Indonesia: Lakes Matano and Towuti. In Munawar, M. \& R. E. Hecky (eds), The Great Lakes of the World (GLOW): Food-web, Health and Integrity. Backhuys Publishers, Leiden: 183-192.

Harrison, R. G., 1998. Linking evolutionary pattern and process. The relevance of species concepts for the study of speciation. In Howard D. J. \& S. H. Berlocher (eds), Endless forms. Species and speciation. Oxford University press, New York: 19-31.
Harvey, P. H. \& M. D. Pagel, 1991. The Comparative Method in Evolutionary Biology. Oxford University Press, Oxford.

Herder, F., A. W. Nolte, J. Pfänder, J. Schwarzer, R. K. Hadiaty \& U. K. Schliewen, 2006. Adaptive radiation and hybridization in Wallace's dreamponds: evidence from sailfin silversides in the Malili lakes of Sulawesi. Proceedings of the Royal Society London B 273, 2209-2217.

Herder, F., J. Schwarzer, J. Pfänder, R. K. Hadiaty \& U. K. Schliewen, 2006. Preliminary checklist of sailfin silversides (Telostei: Telmatherinidae) in the Malili Lakes of Sulawesi (Indonesia), with a synopsis of systematics and threats. Verhandlungen der Gesellschaft für Ichthyologie 5: 139-163.

Hershler, R. \& F. G. Thompson, 1992. A review of the aquatic gastropod subfamily Cochliopinae (Prosobranchia: Hydrobiidae). Malacological Review Suppl. 5: 1-140.

Hey, J., 2006. On the failure of modern species concepts. Trends in Ecology and Evolution 21: 447-450.

Hey, J., R. S. Waples, M. L. Arnold, R. K. Butlin \& R. G. Harrison, 2003. Understanding and confronting species uncertainty in biology and conservation. Trends in Ecology and Evolution 18: 597-603.

Holznagel, W. E., 1998. A nondestructive method for cleaning gastropod radulae from frozen, alcohol-fixed, or dried material. American Malacological Bulletin 14: 181-183.

Hutchinson, G. E., 1957. A Treatise on Limnology. John Wiley \& Sons, New York.

Ihering, H. v., 1885. Zur Verständigung über Beschreibung und Abbildung von Radula-Zähnen. Nachrichtsblatt der Deutschen Malakozoologischen Gesellschaft 17: $1-7$.

International Commission on Zoological Nomenclature, 1999. International Code of Zoological Nomenclature, The International Trust for Zoological Nomenclature, London.

Köhler, F. \& M. Glaubrecht, 2003. Morphology, reproductive biology and molecular genetics of ovoviviparous freshwater gastropods (Cerithioidea, Pachychilidae) from the Philippines, with description of a new genus Jagora. Zoologica Scripta 32: 35-59.

Köhler, F. \& M. Glaubrecht, 2006. A systematic revision of the Southeast Asian freshwater gastropod Brotia (Cerithioidea: Pachychilidae). Malacologia 48: 159251.

Kottelat, M., 1990. Sailfin silversides (Pisces: Telmatherinidae) of Lakes Towuti, Mahalona and Wawontoa (Sulawesi, Indonesia) with descriptions of two new genera and two new species. Ichthyological Exploration of Freshwaters 1: 227-246.

Kottelat, M., 1991. Sailfin silversides (Pisces: Telmatherinidae) of Lake Matano, Sulawesi, Indonesia, with descriptions of six new species. Ichthyological Exploration of Freshwaters 1: 321-344.

Kottelat, M., A. J. Whitten, S. N. Kartikasari \& S. Wirjoatmodjo, 1993. Freshwater Fishes of Western Indonesia and Sulawesi. Periplus, Jakarta. 
Kruimel, J. H., 1913. Verzeichnis der von Herrn E. C. Abendanon in Celebes gesammelten SüsswasserMollusken. Bijdragen tot de Dierkunde 19: 217-235.

Martens, E. v., 1883. Die Weich- und Schaltiere gemeingefaßlich dargestellt. G. Freytag, Leipzig.

Martin, P., 1994. Lake Baikal. In Martens, K., B. Goddeeris \& G. Coulter (eds), Speciation in ancient lakes. E.Schweizerbart'sche Verlagsbuchhandlung, Stuttgart: 3-11.

Marwoto, R., 1997. A preliminary study of the biodiversity of the freshwater snail family Thiaridae from Indonesia (Mollusca: Prosobranchia). In Ulrich, H. (ed), Tropical Biodiversity and Systematics. Zoologisches Forschungsinstitut und Museum Alexander Koenig, Bonn: 109-112.

Mayr, E., 1942. Systematics and the Origin of Species. Columbia University Press, New York.

Mayr, E., 1963. Animal Species and Evolution. Belknap Press of Harvard University Press, Cambridge, Mass.

Mayr, E., 2000. The biological species concept. In Wheeler, Q. D. \& R. Meier (eds), Species Concepts and Phylogenetic Theory. A Debate. Columbia University Press, New York: 17-29.

McLean, J. H., 1971. Archaeogastropoda. In Keen, A. M. (ed), Seashells of Tropical West America. Stanford University Press, Stanford: 307-363.

Michel, E., 1994. Why snails radiate: a review of gastropod evolution in long-lived lakes, both recent and fossil. In Martens, K., B. Goddeeris \& G. Coulter (eds), Speciation in Ancient Lakes. E.Schweitzerbart'sche Verlagsbuchhandlung, Stuttgart: 285-317.

Michel, E., 2004. Vinundu, a new genus of gastropod (Cerithioidea: 'Thiaridae') with two species from Lake Tanganyika, East Africa, and its molecular pyhlogenetic relationships. Journal of Molluscan Studies 70: $1-19$.

Nakajima, T. \& K. Nakai, 1994. Lake Biwa. In Martens, K., B. Goddeeris \& G. Coulter (eds), Speciation in Ancient Lakes. E.Schweizerbart'sche Verlagsbuchhandlung, Stuttgart: 43-54.

Nishino, M. \& N. C. Watanabe, 2000. Evolution and endemism in Lake Biwa, with special reference to its gastropod mollusc fauna. In Rossiter, A. \& H. Kawanabe (eds), Ancient Lakes: Biodiversity, Ecology and Evolution. Academic Press, San Diego: 151-180.

Padilla, D. K., 1998. Inducible phenotypic plasticity of the radula in Lacuna (Gastropoda: Littorinidae). Veliger 4: 201-204.

Palmer, A. R., 1990. Effect of crab effluent and scent of damaged conspecifics on feeding, growth, and shell morphology of the Atlantic dogwhelk Nucella lapillus (L.). Hydrobiologia 193: 155-182.

Radoman, P., 1985. Hydrobioidea, a superfamily of Prosobranchia (Gastropoda). II. Origin, zoogeography, evolution in the Balkans and Asia Minor. Belgrade.

Reid, D. G., 2000. The use of the radula in the taxonomy and phylogeny of gastropods: cautionary cases of convergence, intraspecific variation and plasticity. Phuket Marine Biological Center Special Publication 21: 329-345.
Reid, D. G. \& Y. M. Mak, 1999. Indirect evidence for ecophenotypic plasticity in radular dentition of Littoraria species (Gastropoda: Littorinidae). Journal of Molluscan Studies 65: 355-370.

Ribbink, A. J., 1994. Lake Malawi. In Martens, K., B. Goddeeris \& G. Coulter (eds), Speciation in ancient lakes. E.Schweizerbart'sche Verlagsbuchhandlung, Stuttgart: $27-33$.

Rintelen, T. v. \& M. Glaubrecht, 2003. New discoveries in old lakes: three new species of Tylomelania Sarasin \& Sarasin, 1897 (Gastropoda: Cerithioidea: Pachychilidae) from the Malili lake system on Sulawesi, Indonesia. Journal of Molluscan Studies 69: 3-17.

Rintelen, T. v. \& M. Glaubrecht, 2005. Anatomy of an adaptive radiation: a unique reproductive strategy in the endemic freshwater gastropod Tylomelania (Cerithioidea: Pachychilidae) on Sulawesi, Indonesia, and its biogeographic implications. Biological Journal of the Linnean Society 85: 513-542.

Rintelen, T. v. \& M. Glaubrecht, 2006. Rapid evolution of sessility in an endemic species flock of the freshwater bivalve Corbicula from ancient lakes on Sulawesi, Indonesia. Biology Letters 2: 73-77.

Rintelen, T. v., A. B. Wilson, A. Meyer \& M. Glaubrecht, 2004. Escalation and trophic specialization drive adaptive radiation of viviparous freshwater gastropods in the ancient lakes on Sulawesi, Indonesia. Proceedings of the Royal Society London B 271: 2541-2549.

Salemaa, H., 1994. Lake Ohrid. In Martens, K., B. Goddeeris \& G. Coulter (eds), Speciation in ancient lakes. E.Schweizerbart'sche Verlagsbuchhandlung, Stuttgart: 55-64.

Sarasin, P. \& F. Sarasin, 1897. Über die Molluskenfauna der großen Süßwasser-Seen von Central-Celebes. Zoologischer Anzeiger 539/540: 308-320.

Sarasin, P. \& F. Sarasin, 1898. Die Süßwassermollusken von Celebes. Kreidel, Wiesbaden.

Sarasin, P. \& F. Sarasin, 1905. Reisen in Celebes ausgeführt in den Jahren 1893-1896 und 1902-1903. Kreidel, Wiesbaden.

Schlichting, C. D. \& M. Pigliucci, 1998. Phenotypic Evolution. A Reaction Norm Perspective. Sinauer Associates, Sunderland, MA.

Schluter, D., 2000. The Ecology of Adaptive Radiation. Oxford University Press, Oxford.

Simison, W. B. \& D. R. Lindberg, 1999. Morphological and molecular resolution of a putative cryptic species complex: a case study of Notoacmea fascicularis (Menke, 1851) (Gastropoda: Patellogastropoda). Journal of Molluscan Studies 65: 99-109.

Sites, J. W. \& J. C. Marshall, 2004. Operational criteria for delimiting species. Annual Review of Ecology and Systematics 35: 199-227.

Sitnikova, T., 1994. Recent views on the history and diversity of the Baikalian malacofauna. In Martens, K., B. Goddeeris \& G. Coulter (eds), Speciation in Ancient Lakes. E.Schweizerbart'sche Verlagsbuchhandlung, Stuttgart: 319-326.

Sodhi, N. S., L. P. Koh, B. W. Brook \& P. K. L. Ng, 2004. Southeast Asian biodiversity: an impending 
disaster. Trends in Ecology and Evolution 19: 654660.

Streelman, J. T. \& P. D. Danley, 2003. The stages of vertebrate evolutionary radiation. Trends in Ecology and Evolution, 18: 126-131.

Strong, E. E. \& M. Glaubrecht, 2002. Evidence for convergent evolution of brooding in a unique gastropod from Lake Tanganyika: anatomy and affinity of Tanganyicia rufofilosa (Caenogastropod, Cerithioidea, Paludomidae). Zoologica Scripta 31: 167-184.

Strong, E. E. \& M. Glaubrecht, 2003. Anatomy and systematic affinity of Stanleya neritinoides (Smith, 1880), an enigmatic member of the thalassoid gastropod species flock in Lake Tanganyika, East Africa (Cerithioidea, Paludomidae). Acta Zoologica 84: 249-265.

Troschel, F. H., 1857. Das Gebiss der Schnecken zur Begründung einer natürlichen Classification. Nicolaische Verlagsbuchhandlung, Berlin.

van Oosterzee, P., 1997. Where Worlds Collide. The Wallace Line. Cornell University Press, Ithaca.

Wesenberg-Lund, C., 1939. Biologie der Süsswassertiere. Wirbellose Tiere. Julius Springer, Wien.

West, K. \& E. Michel, 2000. The dynamics of endemic diversification: Molecular phylogeny suggests an explosive origin of the thiarid gastropods of Lake Tanganyika. In Rossiter, A. \& H. Kawanabe (eds), Ancient Lakes: Biodiversity, Ecology and Evolution. Academic Press, San Diego: 331-354.

West, K., E. Michel, J. Todd, D. Brown \& J. Clabaugh, 2003. The gastropods of Lake Tanganyika. International Association of Theoretical and Applied Limnology, Chapel Hill, NC.
Westerlund, C. A., 1892. Fundamenta Malacologia. Håkan Ohlsson, Lund.

Wheeler, Q. D. \& R. Meier, 2000. Species Concepts and Phylogenetic Theory. A Debate. Columbia University Press, New York.

Whitten, A. J., M. Mustafa \& G. S. Henderson, 2002. The Ecology of Sulawesi. Periplus, Singapore.

Wilson, A. B., M. Glaubrecht \& A. Meyer, 2004. Ancient lakes as evolutionary reservoirs: evidence from the thalassoid gastropods of Lake Tanganyika. Proceedings of the Royal Society London B 271: 529-536.

Wilson, M. E. J. \& S. J. Moss, 1999. Cenozoic palaeogeographic evolution of Sulawesi and Borneo. Palaeogeography, Palaeoclimatology, Palaeoecology 145: 303337.

Woltereck, E., 1937a. Systematisch-variationsanalytische Untersuchungen über die Rassen- und Artbildung bei Süßwassergarnelen aus der Gattung Caridina (Decapoda, Atyidae). Internationale Revue der gesamten Hydrobiologie und Hydrographie 34: 208-262.

Woltereck, E., 1937b. Zur Systematik und geographischen Verbreitung der Caridinen. Internationale Revue der gesamten Hydrobiologie und Hydrographie 34: 294330 .

Woltereck, R., 1931. Beobachtungen und Versuche zum Fragenkomplex der Artbildung. I. Wie entsteht eine endemische Rasse oder Art? Biologisches Zentralblatt 51: 231-253.

Woltereck, R., 1941. Die Seen und Inseln der "Wallacea"Zwischenregion und ihre endemische Tierwelt. Erster Teil: Vorgeschichte und Aufgabe der Forschungsreise. Internationale Revue der gesamten Hydrobiologie und Hydrographie 41: 1-36. 